OAK RIDGE

NATIONAL LABORATORY

MANAGED BY UT-BATTELLE FOR THE DEPARTMENT OF ENERGY

\title{
Metals Processing Laboratory Users (MPLUS) Facility Annual Report FY 2002 (October 1, 2001-September 30, 2002)
}

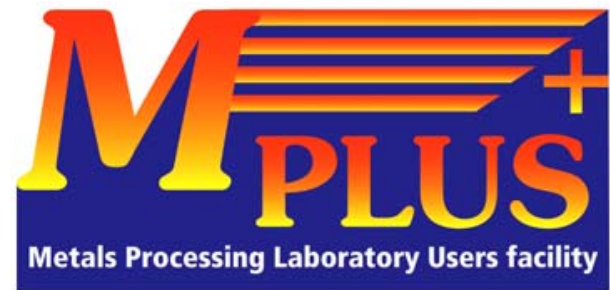




\section{DOCUMENT AVAILABILITY}

Reports produced after January 1, 1996, are generally available free via the U.S. Department of Energy (DOE) Information Bridge.

Web site http://www.osti.gov/bridge

Reports produced before January 1, 1996, may be purchased by members of the public from the following source:

National Technical Information Service

5285 Port Royal Road

Springfield, VA 22161

Telephone 703-605-6000 (1-800-553-6847)

TDD 703-487-4639

Fax 703-605-6900

E-mail info@ntis.fedworld.gov

Web site http://www.ntis.gov/support/ordernowabout.htm

Reports are available to DOE employees, DOE contractors, Energy Technology Data Exchange (ETDE) representatives, and International Nuclear Information System (INIS) representatives from the following source:

Office of Scientific and Technical Information

P.O. Box 62

Oak Ridge, TN 37831

Telephone 865-576-8401

Fax 865-576-5728

E-mail reports@adonis.osti.gov

Web site http://www.osti.gov/contact.html

This report was prepared as an account of work sponsored by an agency of the United States Government. Neither the United States Government nor any agency thereof, nor any of their employees, makes any warranty, express or implied, or assumes any legal liability or responsibility for the accuracy, completeness, or usefulness of any information, apparatus, product, or process disclosed, or represents that its use would not infringe privately owned rights. Reference herein to any specific commercial product, process, or service by trade name, trademark, manufacturer, or otherwise, does not necessarily constitute or imply its endorsement, recommendation, or favoring by the United States Government or any agency thereof. The views and opinions of authors expressed herein do not necessarily state or reflect those of the United States Government or any agency thereof. 
ORNL/TM-2003/246

Metals Processing Laboratory Users (MPLUS) Facility

\title{
ANNUAL REPORT \\ OCTOBER 1, 2001, THROUGH SEPTEMBER 30, 2002
}

\author{
Compiled by \\ P. Angelini \\ M. L. Atchley
}

Published December 2003

\author{
Research sponsored by the \\ U.S. Department of Energy \\ Office of Energy Efficiency and Renewable Energy \\ Industrial Technologies Program \\ Industrial Materials for the Future (IMF) \\ and Industries of the Future (IOF) Activities \\ 1000 Independence Avenue NW \\ Washington, DC 20585-0121
}

OAK RIDGE NATIONAL LABORATORY

P.O. Box 2008

Oak Ridge, Tennessee 37831-6285

managed by

UT-Battelle, LLC

for the

U.S. DEPARTMENT OF ENERGY under contract DE-AC05-00OR22725 



\section{CONTENTS}

INTRODUCTION .

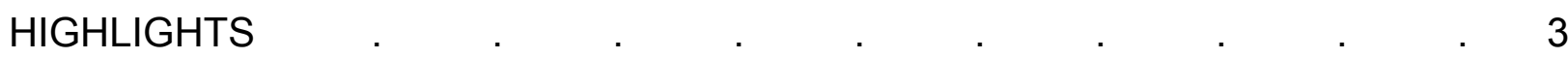

Grader Moldboard Weld Cracking Problem

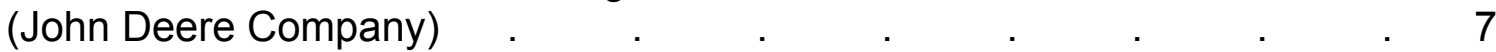

Characterization of Metal Filling and Gas Permeability in Lost Foam Casting (Walford Technologies) . . . . . . . . . . . 11

Modeling of $\gamma^{\prime}$ Phase precipitation from $\gamma$ Phase in Nickel-base

Superalloy toward Understanding Strain Age Cracking

(Edison Welding Institute).

Report on Validation of the Low-Temperature Extrapolation of

Thermodynamic Parameters (E. I. du Pont de Nemours and Co. Inc.) 17

Characterization of Laser Clads Made on Steel Substrates

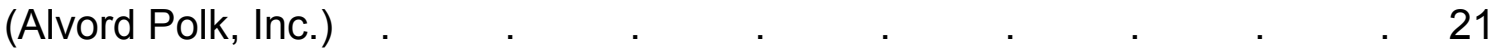

Improved Alloys for Coiler Drums for Plate Reversing Mills

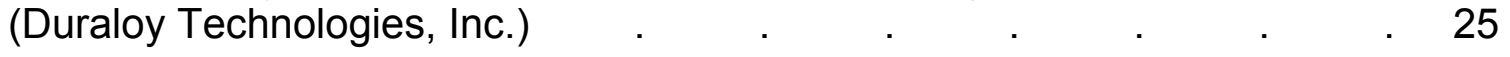

Die Casting Performance Testing of H13 Samples Processed with

HYBron $^{\text {TM }}$ Boron-Based Coating Technology

(HY-Tech Research Corporation) . . . . . . . . . . 29

A Noncontact, Very Rapid Surface Temperature Measurement

using Advanced Infrared Imaging (Inductoheat). . . . . . . 33

Comparison of Tempering Response of Steels form Induction Heating

Versus Conventional Heating (Inductoheat) . . . . . . 35

Stress Rupture Testing of $9 \mathrm{Cr}$ Steel Weldment

(ITW - Hobart Brothers Company) . . . . . . . . . . . . $\quad$. 39

Silicon Powder Melt Process and Equipment Development Project

(Matrix Solar Technologies Inc.) . . . . . . . . . . 43

Forming Porous Metal Filters (Chand Metallurgical) $\quad$. $\quad$. $\quad$. $\quad$. 45

Infrared Processing for Conditioning and Repair of Forming Dies

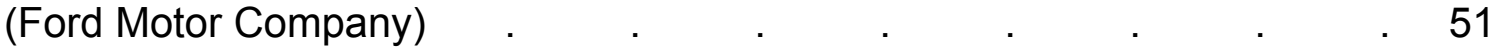


Thermochemical Optimization of Float Glass Composition: Low-Alumina Glass Development (Visteon Glass Systems) . . . . . 53

The Effect of Austenitizing Temperature and Time on the Formation of Ultrasonic Welding of Aluminum Alloys

(The University of Tennessee)

Physical, Mechanical, and Microstructural Characterization of Ultrasonic Welding of Aluminum Alloys (Ford Research Laboratory - Ford Motor Company) . . . . . . . 63

Heat Treatment Optimization for Steam Trap Seat of AISI 420F

Stainless Steel (Spirax Sarco Inc.) . . . . . . . . . 67

Hot-Hardness Data on Wear and Corrosion-Resistant Alloy (Deloro Stellite Group, Ltd.)

Effect of Forging and Heat Treating on Residual Stress in Aluminum Forgings (Scot Forge) . . . . . . . . . . . . 73

Effects of Process Variables on Shaped Castings of Fe-Si Alloys (CC Metals and Alloys Inc.)

Creep Rupture Behavior of Modified 9Cr-1Mo Flux-Cored Arc Weldments (Stoody Company)

Effect of Processing/Microstructure on the Corrosion Polarization

Response of a Corrosion-Resistant Alloy (ALLVAC) . . . . . 85

Modeling of Elemental Segregation in Alloy Ingots and Thermal

Treatments for Homogenization (Scot Forge) . . . . . . . . $\quad$. 89

Sanitization Wood Treatment (West Virginia University) _ . . . . 93

Evaluation of Ceramic Seal Disks for Thermodynamic Steam Traps

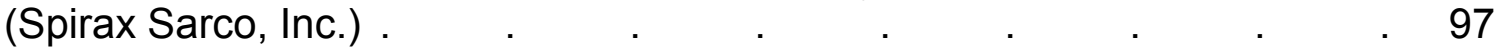

Infrared Heating of Polymers (H.B. Fuller Company) . _ . . . . 99

Identification of Process Parameters for Ease of Compaction and

Sintering of Tool Steel (M2) Powders (Ametek) . . . . . . . 105

Characterization of Iron Oxide Powder from Steel Acid Pickling

Process at Weirton Steel (Weirton Steel Corporation) . . . . . 109 
Rapid Infrared Fusing of $\mathrm{C}^{3}$ Coatings

(Component Composite Coatings International, LLC) . . . . . . 113

Particle Effects on Texture Development during Processing of

Aluminum Sheet (Alcoa Technical Center) . . . . . . . . 117

Quantitative Characterization of the Phase Transformation Kinetics and

Dilation Strains of a Hyper-eutectoid SAE 41XX Steel Alloy for

Incorporation into a Process Optimization Simulation Tool

(Caterpillar, Inc.)

High Temperature Mechanical Properties Testing for Finite Element Prediction of Residual Stress in a Spot Weld

(University of Missouri - Columbia)

Analysis of Aluminum Sheet Materials (Secat, Inc.) . . . . . 127

Modeling to Identify Causes for Hot Cracking in Cobalt-Based Alloy

FSX-414 during Investment Casting (Gray-Syracuse, Inc.) . . . 131

Effect of Fluidized Bed-Based Heat Treatment on Microstructure of

431 Stainless Steel (Metal-Tech of Tennessee, LLC) . . . . . . 135

Reducing Dross Formation during Remelting of Aluminum Sows (Logan Aluminum) .

The Effect of Boron and Zirconium on the Resistance of HAYNES ${ }^{\circledR}$ $214^{\mathrm{TM}}$ Alloy to Strain Age Cracking (Haynes International Inc.)

Detection of Cracks in Green Powder Metallurgy Compacts

(Caterpillar, Inc.)

Characterization of Viscoplastic Behavior of Nodular Cast Iron for

Life Prediction Modeling (NW Numerics and Modeling, Inc.) .

TEM Investigation into the Mechanism of Composite Membrane

Cracking in Kraft Recovery Boilers (MeadWestvaco Research)

Prediction of Elemental Segregation and Phase Formation in

Aluminum 5754 Alloy (Commonwealth Aluminum)

Ferrite Prediction in Type 316 Stainless Steel

(Carpenter Specialty Alloys) 
Creep Influence on Low-Cycle Fatigue and Fatigue Crack-Propagation Behaviors of Superalloy Haynes ${ }^{\circledR} 230$ in a Vacuum Environment

(The University of Tennessee)

Defining the Instrumental Measurements and Procedures Required to Properly Control the Lost Foam Casting Process (Walford Technologies)

Quantifying and Correlating Lost Foam Pattern Properties with Metals

Fill Casting Performance: Understanding the Process

(Foseco-Morval, Inc.)

Qualifying Production Grade Foam and Coatings with Optical and Infrared Methods for the Lost Foam Casting Process (GM Powertrain)

LIST OF PROJECTS $\quad . \quad$. $\quad . \quad$. . . . . . . . 173

STAFF CONTACTS AND GENERAL INFORMATION . . . . . . . 179

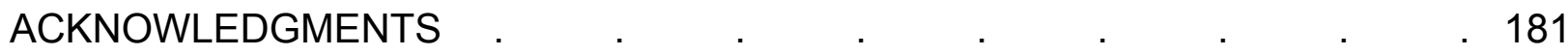




\section{INTRODUCTION}

\section{Metals Processing Laboratory Users Facility (MPLUS)}

The Metals Processing Laboratory Users Facility (MPLUS) is a Department of Energy (DOE), Energy Efficiency and Renewable Energy, Industrial Technologies Program, user facility designated to assist researchers in key industries, universities, and federal laboratories in improving energy efficiency, improving environmental aspects, and increasing competitiveness. The goal of MPLUS is to provide access to the specialized technical expertise and equipment needed to solve metals processing issues that limit the development and implementation of emerging metals processing technologies. The scope of work can also extend to other types of materials.

MPLUS has four primary user centers (Fig. 1):

1. Processing - casting, powder metallurgy, deformation processing (including extrusion, forging, rolling), melting, thermomechanical processing, and high-density infrared processing

2. Joining - welding, monitoring and control, solidification, brazing, and bonding

3. Characterization - corrosion, mechanical properties, fracture mechanics, microstructure, nondestructive examination, computer-controlled dilatometry, and emissivity

4. Materials/Process Modeling - mathematical design and analyses, highperformance computing, process modeling, solidification/deformation, microstructure evolution, thermodynamic and kinetic, and materials databases

A fully integrated approach provides researchers with unique opportunities to address technologically related issues to solve metals processing problems and probe new technologies. Access is also available to 16 additional Oak Ridge National Laboratory (ORNL) user facilities ranging from state-of-the-art materials characterization capabilities, and high-performance computing to manufacturing technologies.

MPLUS can be accessed through a standardized user-submitted proposal and a user agreement. Nonproprietary (open) or proprietary proposals can be submitted. For open research and development, access to capabilities is provided free of charge, while for proprietary efforts, the user pays the entire project costs based on DOE guidelines for ORNL costs. 


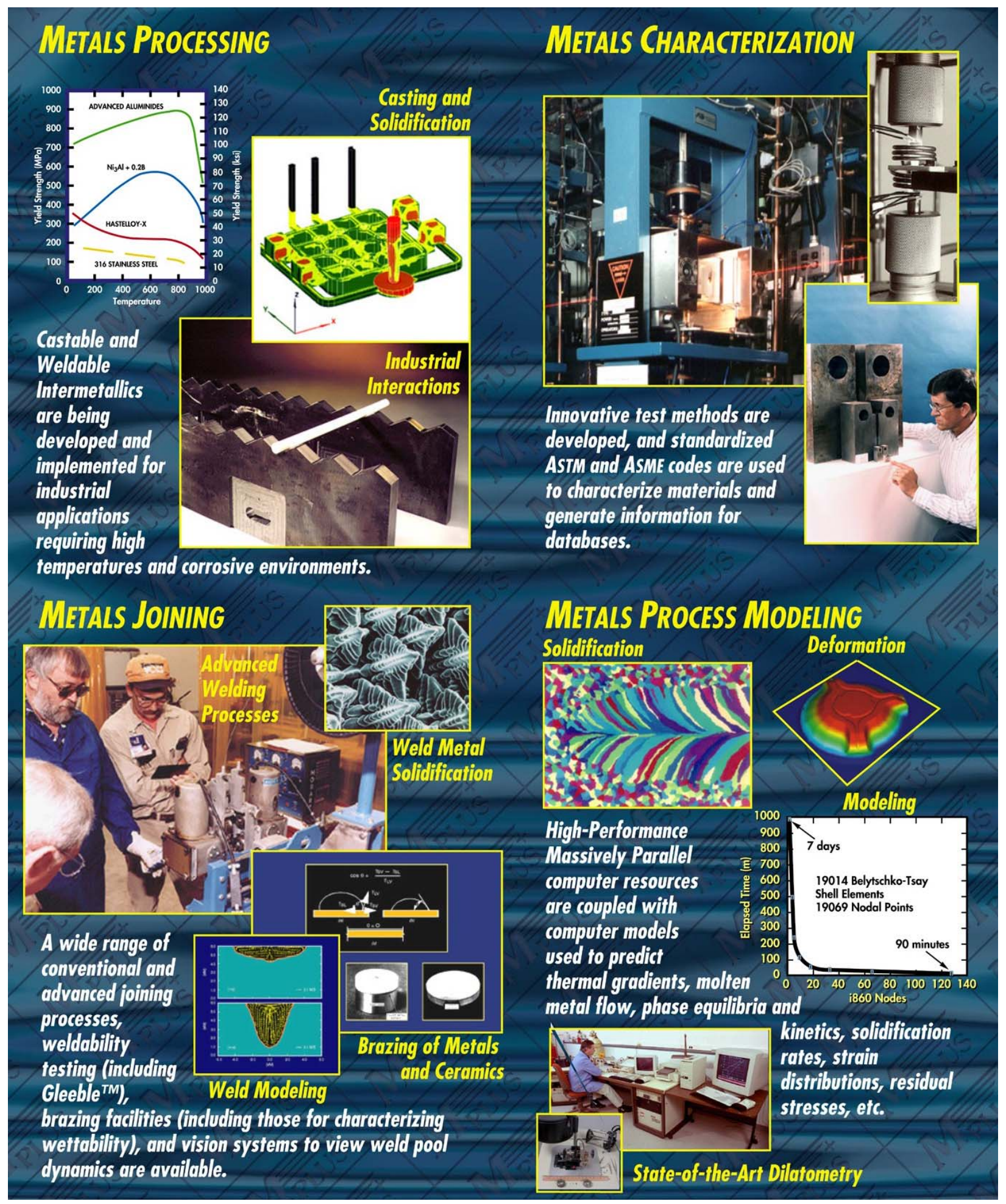

Fig. 1. The MPLUS user facilities. 
The Materials Processing Laboratory Users (MPLUS) activity is an officially designated U. S. DOE, Office of Energy Efficiency and Renewable Energy, Industrial Technologies Program, Industrial Materials for the Future user facility at the Oak Ridge National Laboratory. The goal of MPLUS is to work with industries, universities, and other organizations in helping to meet the mission of Industries of the Future efforts. The MPLUS efforts are typically high risk feasibility research and development (R\&D) activities that can help the development and implementation of new and emerging technologies. MPLUS projects can lead to improved understanding or show feasibility of materials technologies and processing methods in specific applications in various industries of the future areas. In this way the initial MPLUS results often identify significant materials issues and a path forward to improved energy, environmental, and economic benefits. There were 46 MPLUS user projects in FY 2002 and examples of energy benefits are presented below.

1. The MPLUS project with Scot Forge focused on modeling the segregation and homogenization thermal treatment in order to evaluate the optimum homogenization process. In the U.S., $3.72 \times 10^{5}$ tons of steel forgings and $1.76 \times$ $10^{6}$ tons of steel castings are homogenization heat treated per year. A $10 \%$ reduction in homogenization time for steel forgings and castings can lead to energy savings of nearly 60 trillion Btu/year and a cost savings of nearly $\$ 200$ million/year. Homogenization is also used in the aluminum and iron industries; however, these industries are not included in the above estimates. An approach was developed and validated that successfully predicted segregation and homogenization in 4340 steel. Further work is required in order to generalize, evaluate, and implement the technique in commercial casting and solidification packages.

2. The MPLUS with Component Composite Coatings International, LLC (C3) focused on rapid infrared fusing of $\mathrm{C}^{3}$ coatings. Zirconia or similar surface treatments are used to treat material surfaces to enhance wear properties and improve resistance to erosion, corrosion, and soldering from molten-metal attack. The infrared- (IR) modified surface is highly durable and provides improved surface properties, extending the performance and life of the products. This is of particular interest to the metal-working, forging, casting, internal combustion, and turbine engines industries where elevated wear due to the above conditions is common. This project produced zirconia-coated inserts that allowed spindle speeds to increase from 4100 to $8000 \mathrm{rpm}$ without reducing the life of the insert; additionally, a $1000 \%$ extension of the tool life was observed when milling aluminum 356. Zirconia treatments generated up to $3000 \%$ increase in the life of core pins used in aluminum die casting, increasing the sheath life by $850 \%$.

3. The MPLUS project with Gray-Syracuse, Inc. focused on identifying causes for hot cracking in cobalt-based alloy FSX-414. During investment casting cracks in steel or aluminum castings can lead to significant yield reductions and high rework of 
materials. The industrial system that was modeled in this project had a low yield rate due to cracking during solidification. A cracking criteria was successfully developed that enabled an absolute increase in yield of nearly $30 \%$. The modeling approach is very general and may be able to be extended to other industrial-based alloy systems. Minimizing crack formation in castings can lead to direct energy benefits, cost, and environmental benefits.

4. In the MPLUS project with Duraloy Technologies the objective was to determine the primary cause of failure in coiler drums that are used to handle rolled plates in Steckel reversing mills. Improving the life of coiler drums can dramatically improve the efficiency of steel processing and help reduce the frequency of unscheduled outages. Phase equilibria calculations were performed to examine the effects of alloy composition on freezing range and phase stability. Based on these and additional thermodynamic calculations, examination of metallographically prepared specimens, and various discussions between Duraloy, Whemco (parent company) and ORNL staff, a set of new alloy compositions were proposed.

5. MPLUS projects with GM Powertrain, Foseco-Morval, Inc., and Walford Technologies focused on the Quantifying and Correlating Lost Foam Pattern Properties with Metals Fill Casting Performance: Understanding the Process. The Infrared imaging technology utilized at ORNL has provided a unique insight into the lost foam casting process to understand the behavior of the metal fill and pattern decomposition process. This work has led directly to address issues concerning casting defects, effects of foam and coating properties and opportunities concerning the casting of magnesium and steel. It is anticipated that casting yields, quality and the opportunity to develop new, more complex and lighter weight castings will result because of improved process understanding and optimization.

6. The MPLUS project with Inductoheat evaluated the comparison of tempering response of steels to induction heating versus conventional heating. The U.S. produces approximately 100 million tons of steels per year. In most cases, steels are heat-treated in order to derive their strength and desired property level for specific applications. Heat treatment is very energy intensive, and there is a continuing effort in industry to replace the conventional and inefficient heat-treating process by new rapid processes that can be carried out by induction or other methods. The tempering response of 1050 steel subjected to oven tempering versus its response to induction heating was determined through use of optical microscopy, hardness measurements, and atom probe field ion microscopy. The results demonstrate that a strong possibility exists for replacing the conventional heat-treating process with a highly efficient induction heating process.

7. The MPLUS efforts with Spirax Sarco, Inc. focused on: (1) heat-treatment optimization of stainless steel steam traps - Steam trap seats of AISI $420^{\circ} \mathrm{F}$ stainless steel are used extensively in the chemical, petrochemical, and mining industries. The low toughness becomes an important concern in the threaded 
region where it can cause premature failures. The outcome of this MPLUS included recommendations for a selective heat treatment of threaded regions by using an infrared-based heating system. The effectiveness was verified by Spirax on steam traps that were heat treated at ORNL. (2) Use of ceramics in steam traps - Thermodynamic steam traps are an essential device for assuring efficient heat transfer in distribution and process steam lines used throughout industry. By eliminating water and incondensable gases from the process steam, these traps minimize energy waste and improve heat transfer. As wear occurs on the contact surfaces of mating components in the trap, sealing becomes imperfect and efficiency is degraded. In time, this leads to steam losses which can result in significant energy losses. Silicon nitride, $\mathrm{Si}_{3} \mathrm{~N}_{4}$, and zirconia, $\mathrm{ZrO}_{2}$ seal disks were made at ORNL and evaluated at Spirex. The results of the study show promise in the use of ceramics in this application

8. The MPLUS project with CC Metals and Alloys, Inc evaluated the effects of process variables on shaped castings of $\mathrm{Fe}-\mathrm{Si}$ Alloys. Iron-silicon master alloys are widely used in the steel and metal-casting industries for adjusting composition and refining grain size. The existing production method involves large, gas-fired twostory furnaces loaded with iron and silica; reactions lead to the formation of a liquid $\mathrm{Fe}-\mathrm{Si}$ alloy, which is then cast into large ingots. The ingots are then subsequently jaw crushed extensively and screened (energy-intensive operations). A large amount of fines is produced that also needs to be reprocessed. This project successfully evaluated the net-shape casting of the Fe-Si liquid alloys in order to eliminate the jaw-crushing and screening operations and also to avoid the formation of fines, leading to substantial energy savings. The laboratory-based results are very positive and show promise for implementation.

9. The MPLUS with ALLVAC identified the extent of variation in corrosion resistance that can result in alloy 734 with a different processing history. Corrosion of components is critical for chemical, petrochemical, forest products, and many other industries. Pitting and crevice corrosion are common causes for failure resulting from corrosion fatigue. Alloys such as type 304 are commonly used for these applications. However, for more severe applications, modifications of type 304 such as alloy 734 are used. Although highly resistant to corrosion, a large variability in their response is noted based on the material processing history. Further work was recommended to optimize the alloy processing steps that would result in consistent corrosion-resistant performance from batch to batch of the alloy.

10. The focus of the MPLUS project with Alcoa was to use a computational modeling in order to evaluate the influence of hard particles on the microstructure during hot deformation of aluminum alloys. The formability or shaping behavior of aluminum alloy sheet is strongly affected by the microstructure of the sheet. The product yield from this process may be improved if one understands the impact of various sheet features like hard particles on the formability of the sheet. The results of the model indicate that hard particles may lead to shorter processing times at temperature of 
aluminum sheet and may promote new grain orientations, which will impact the formability of aluminum sheet.

11. The project with Commonwealth Aluminum predicted the trend of segregation and phase formation behavior in aluminum 5754 alloy to better understand and minimize the formation of brittle particles. Twin-belt continuous casting of aluminum 5754 alloy is a much more energy- and cost-efficient process than the direct chill method. However, segregation and second phase formation in the aluminum limits the use of twin-belt-produced products. Thermodynamic simulations were carried out in order to determine the partition coefficient and the segregation ratio of each element in the alloy. Phase evolution during solidification was also predicted. Evaluations were made to determine the minimization of elemental segregation and second phase formation during solidification in order to shorten the heat treating homogenization time of the alloy. 
MPLUS No.: MC-02-001

Title: Grader Moldboard Weld Cracking Problem

User Organization: John Deere Company Moline, IL 61265

User Contacts: Daniel Hartschuh, 563-388-4127 hartschuhdana@johndeere.com

Robert J. Gaster, 309-765-3741 GasterRobertJ@JohnDeere.com

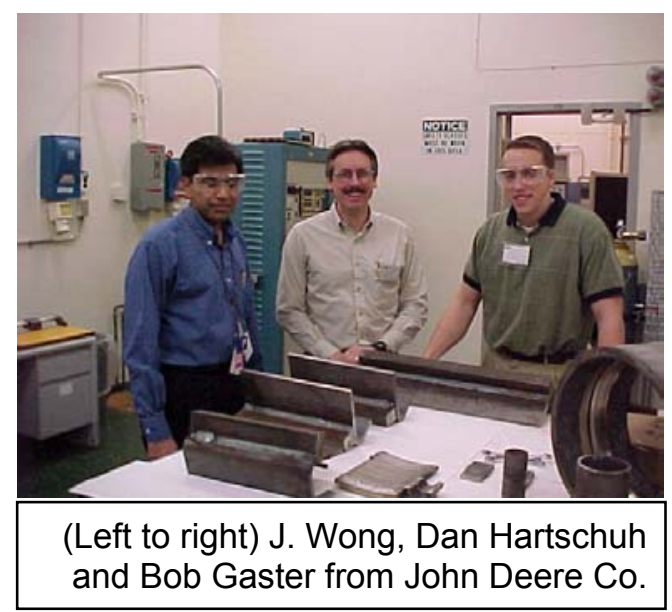

ORNL R\&D Staff: $\quad$ S. Suresh Babu, 865-574-4806

babuss@ornl.gov

Gorti Sarma, 865-574-5147

sarmag@ornl.gov

Relevance to OIT: Integrity of steel welds is important for fabrication of earth moving equipment used in the mining industry. For increasing the payload capacity and thereby increasing the energy efficiency of these equipments, there is a need to use high strength steels. However, use of high strength steels with high heat input welding processes leads to cracks in the weld region, thereby limiting the use of these high strength steels. The project pertains to computational modeling of the welding process and stress evolution in order to alleviate this cracking problem in steel welds. This project is directly related to the mining and welding industries.

Significance of the Results: In this work, we have successfully identified the generation of tensile stresses and the presence of liquid regions between the solid dendrites to the cracking in high strength steel welds. Based on the analysis, new welding procedures and material combinations were suggested. The above methodology potentially will eliminate the need for inefficient trial and error experimentation, as well as, allow for the utilization of high-strength steels in the mining, chemical, forest products, and steel industries.

Objective: The tandem gas metal arc welding process was used for production of moldboard cracking. On some occasions, cracking was observed. The goal of this research was to understand this weld cracking by computational thermomechanicalmetallurgical analysis.

Results: Thermomechanical-metallurgical models were used to understand the cracking tendency in a fillet weld between A572 and 1045 steel (see Fig. 1). Tensile stress evolution was observed at the onset of weld solidification (Fig. 2). Thermodynamic analysis showed that during weld cooling, the weld metal region has a large freezing range. In addition, liquid is present while tensile stresses develop in 
these regions. The combination of tensile stresses and liquid is attributed to cracking tendencies. The model also showed qualitative agreement for the increased cracking tendencies near the 1045 steel region (Fig. 3).

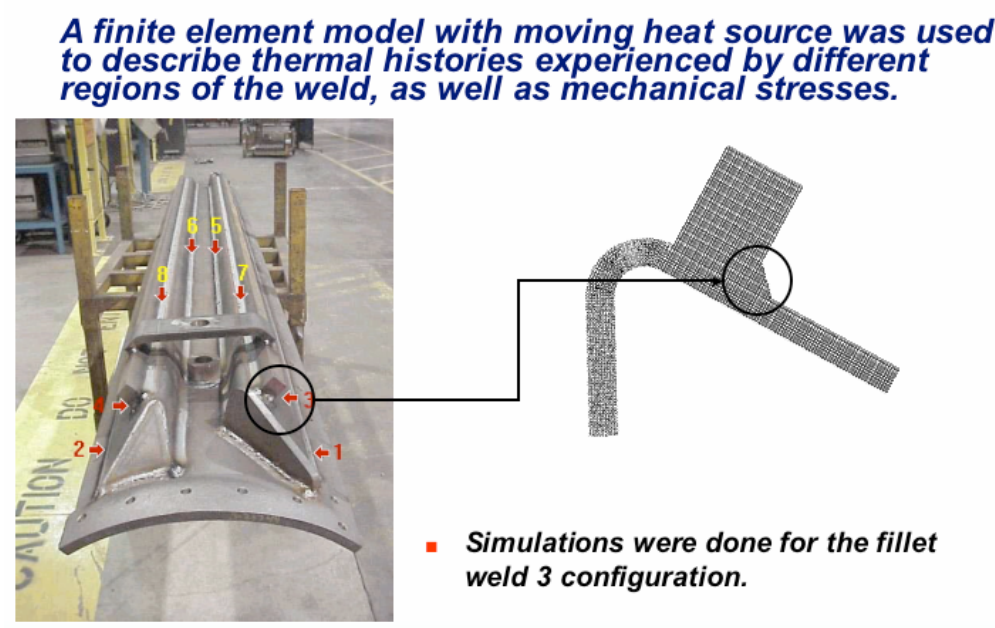

Fig. 1. The part and the finite element model mesh used in the research.

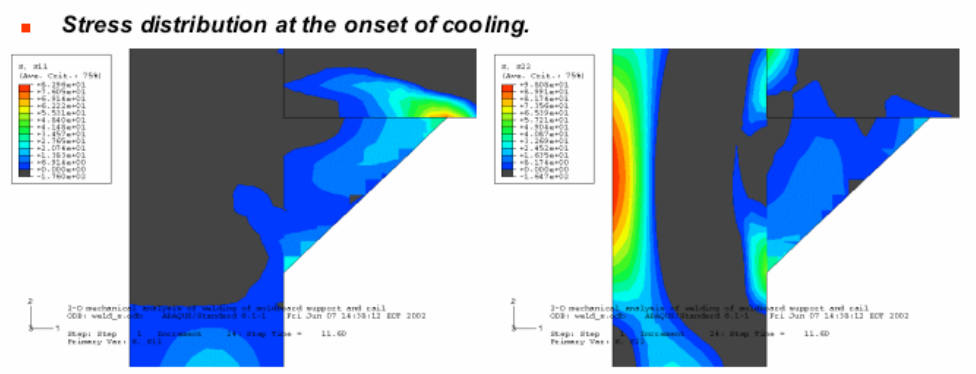

Fig. 2. Tensile stress distributions at various regions of the weld.

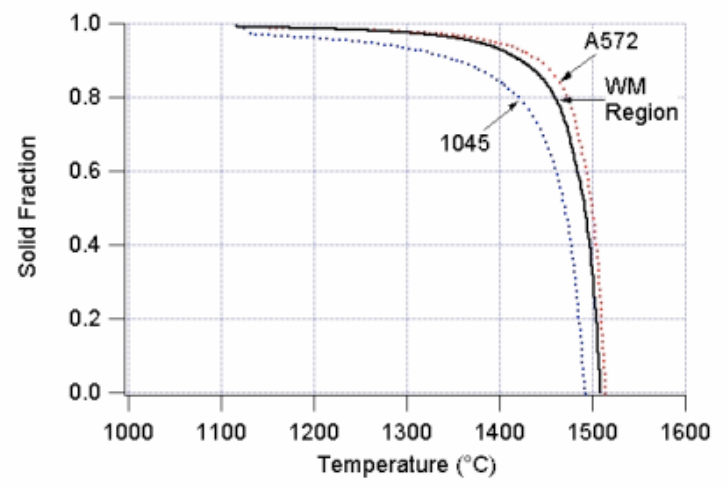

\begin{tabular}{|l|l|}
\hline Steel & $\begin{array}{l}\text { Solidification } \\
\text { Temperature } \\
\text { Range }\end{array}$ \\
\hline 1045 & $368 \mathrm{~K}$ \\
\hline A572 & $379 \mathrm{~K}$ \\
\hline WM & $392 \mathrm{~K}$ \\
\hline
\end{tabular}

Fig. 3. Calculated solidification temperature range for different steel compositions. 
The following potential solutions were proposed based on the results of the research:

1. Modify the weld metal composition such that "sulfur" levels are kept to bare minimum (being tested at John Deere).

2. Modify the inclusions and reduce the cooling rate to fix the "sulfur" on oxide inclusions (needs further work).

3. Reduce the tensile stress evolution by modifying the weld geometry.

4. Develop fixtures that impose compressive stresses on welds in such a way that the tensile stresses do not develop.

5. Evaluate the tendency for change in primary phase solidification mode from ferrite to austenite at rapid weld cooling. The results are being used by John Deere Company to develop optimum base-metal and filler-metal combinations as a function of joint configurations.

\section{Reports/Publications/Awards:}

D. Hartschuh, B. Gaster, J. Wong, S. S. Babu, and G. Sarma, "Collaborative MPLUS Research on Grader Moldboard Cracking Problem with John Deere," MPLUS report, April 2003. 
MPLUS No.: MC-02-002

Title: Characterization of Metal Filling and Gas

Permeability in Lost Foam Casting

User Organization: Walford Technologies Oak Ridge, TN 37830

User Contact: Graham Walford, 865-482-4995

photonx@vol.com

walfordgv@ornl.gov

ORNL R\&D Staff: Ralph B. Dinwiddie, 865-574-7599

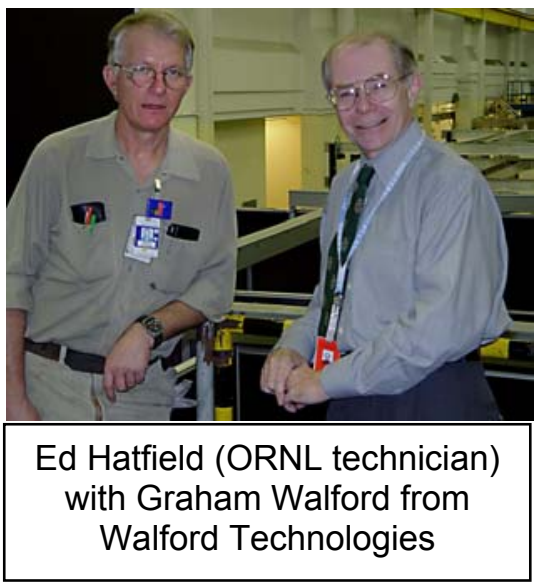

dinwiddierb@ornl.gov

Relevance to OIT: The Infrared imaging technology has provided a unique insight into the lost foam casting process to understand the behavior of the metal fill and pattern decomposition process. This work has addressed issues concerning casting defect, effects of foam and coating properties and opportunities concerning the casting of magnesium and steel. It is anticipated that casting yield, quality and the opportunity to develop new, more complex and lighter weight castings will result because of this process understanding and optimization. Such development has attendant energy savings. This project is directly relevant to the aluminum and metal casting industries.

Objective: The objective of this effort was to visualize the decomposition process for the foam pattern and to better understand the primary parameters important to the process.

Results: Walford Technologies undertook the MPLUS activity to study the decomposition of polystyrene foam patterns in the lost foam metals casting process. An infrared camera was used to view a foam pattern placed in a sandfilled flask that also incorporated a quartz viewing window.

Liquid aluminum was introduced into the pattern, and the metal front progression through the foam was recorded. Primary pattern behavior was observed, showing the effects of coating, side and top pouring, bead collapse, and disintegration. Gas flow behavior was observed, together with the generation of liquid pyrolysis product. Both of these components have helped to define the primary decomposition process of the foam.

Liquid products were observed to be difficult to remove from the foam volume. Breakdown and instability were also observed at the metal/foam front, leading to the development of a concept for such behaviors. Subsequent work has been developed from these initial studies that are providing correlation between structural properties of the pattern and its metals fill characteristics. The infrared imaging capability has been 
the primary analytic tool utilized in this study. This, through interpretation of the thermal image has identified progression of the metal front, location of the decomposition products, correlation between the pattern properties, and the metals fill behavior.
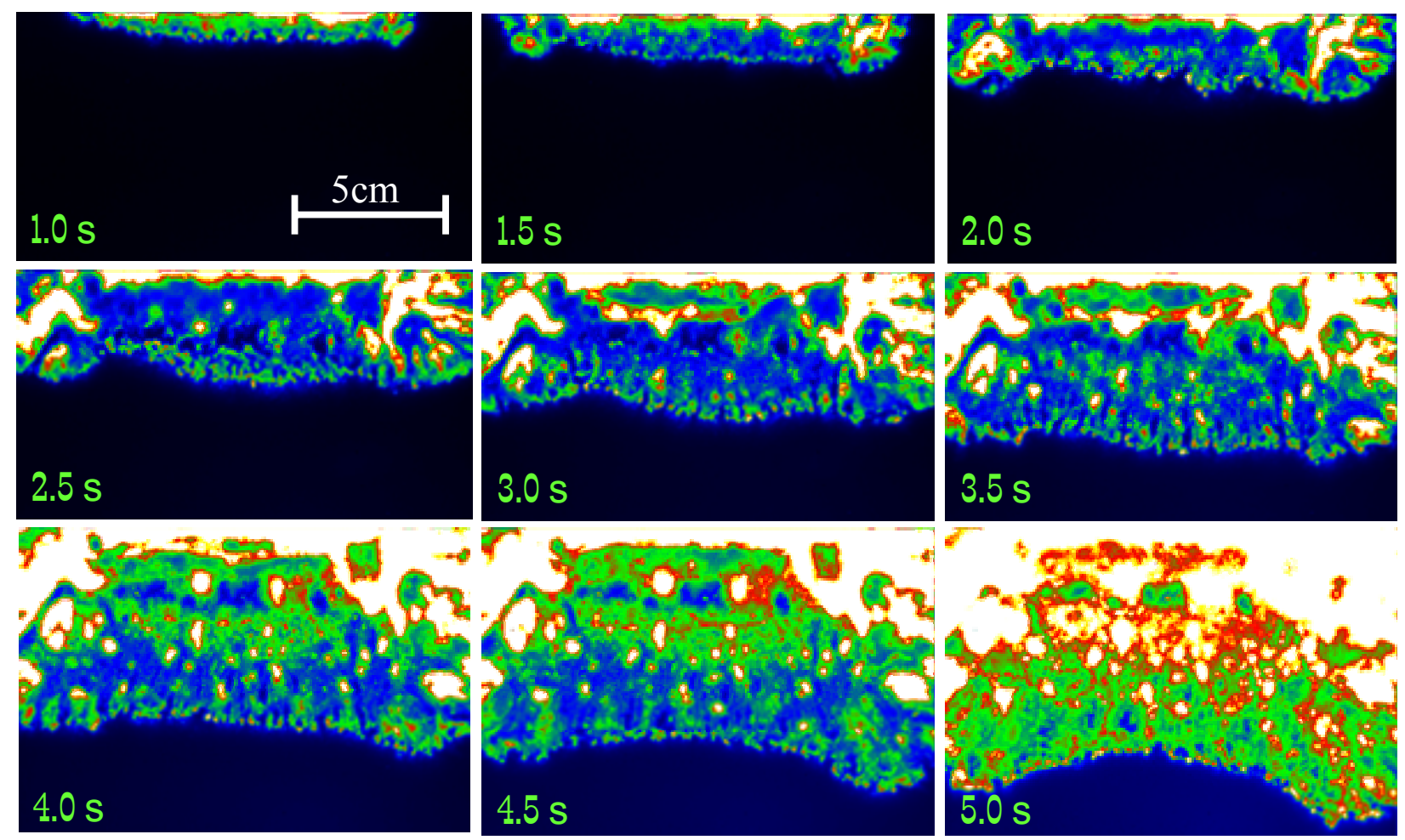

Fig. 1. Thermal image sequence of molten aluminum burning uniformly into a highdensity foam pattern.

\section{Reports/Publications/Awards:}

These data have been presented at several Lost Foam Consortium presentations in 2002 and 2003. This approach has now been studied by several other participants, including General Motors, Foseco-Morval, the University of Alabama - Birmingham, and $\mathrm{MCT}$, and will be the subject of a panel discussion at the forthcoming World Casting Congress in 2004. 
MPLUS No.: MC-02-003

Title: Modeling of $\gamma^{\prime}$ Phase Precipitation from $\gamma$ Phase in Nickel-Base Superalloy toward Understanding Strain Age Cracking

User Organization: Edison Welding Institute Columbus, $\mathrm{OH} 43221$

User Contacts: Victor Li, 614-688-5237 victor@ewi.org

S. P. Khurana, 614-688-5250 Shuchi_Khurana@ewi.org

J. R. Dydo, 614-688-5250 Jim_Dydo@ewi.org

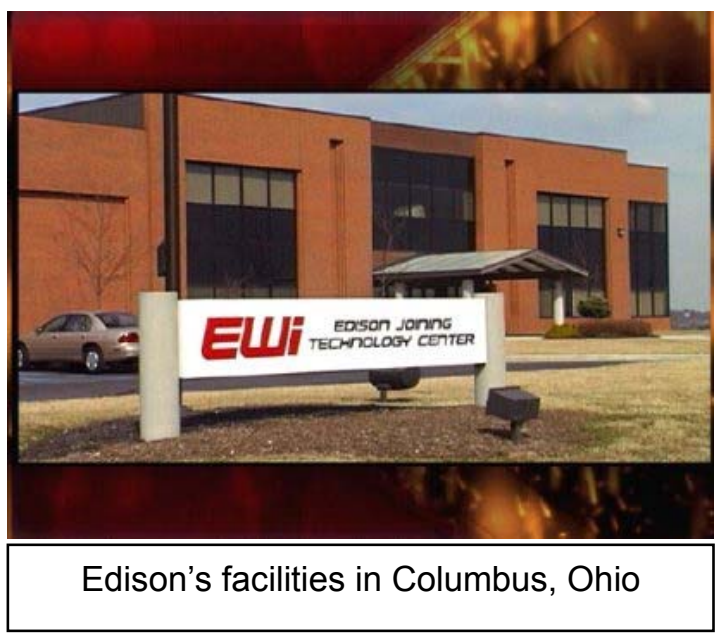

\section{ORNL R\&D Staff: S. Suresh Babu, 865-574-4806 babuss@ornl.gov}

Relevance to OIT: Nickel base superalloys are being considered for the chemical industry infrastructure fabrication for both high temperature and corrosion resistance applications. By increasing the operating temperature of chemical processes, it is possible to increase the process efficiency and thereby increase energy savings. However, fabrication of these alloys by fusion welding processes leads to strain age cracking in the heat-affected-zone of the welds leading to failure of the components, thereby limiting the use of these alloys. This project is directly related to the chemical industry.

Significance of the Results: In this research, computational thermodynamic and kinetic modeling was used to determine if the kinetics of $L 1_{2}$ ordered $\gamma^{\prime}$ precipitates might be leading to rapid strain aging in the heat-affected zone. The results showed that by modification of the transformation kinetics through composition and thermal cycle modifications, it is possible to reduce the tendency for strain age cracking. This shows it is indeed possible to use high-temperature and corrosion-resistant nickel-base superalloys in chemical industries, thereby achieving high-energy efficient process cycles.

Objective: The objectives of the study were: (1) predict the transformation kinetics of $\gamma^{\prime}$ precipitation from the $\gamma$ phase using computational thermodynamics and kinetics models and (2) provide this information to EWI for modeling the strain age cracking (SAC) by coupling the transformation kinetic model with finite element models for stress evolution during welding. 
Results: Nickel-base superalloys show strong sensitivity to SAC after welding during post-weld heat treatment. These post-weld heat treatments are performed to relieve residual stresses. However, during the heat treatments $\gamma^{\prime}$ precipitation also occurs, strengthening the interior of grains, and leading to excessive stress along the grain boundaries that may cause intergranular cracking. These cracking tendencies are exacerbated by an increase in aluminum and titanium, as shown in Fig. 1. In this work, the precipitation of the $\gamma^{\prime}$ phase was modeled using ThermoCalc ${ }^{\mathrm{TM}}$ and DicTra software in two nickel-base superalloys, Rene 41 and Waspalloy (see Table 1).

The results, shown in Fig. 2, indicate that the Rene 41 alloy has a tendency to form a slightly larger fraction of the $\gamma^{\prime}$ phase at all temperatures. This suggests that Rene 41 will have a higher probability of cracking than Waspalloy. It is interesting to note that Rene 41 alloys are just on the boundary between readily weldable stress-assisted corrosion-free and difficult to weld stress-assisted-corrosion materials.

In the next series of calculations, the $\gamma^{\prime}$ growth kinetics was compared in these two alloys at $1073 \mathrm{~K}\left(800^{\circ} \mathrm{C}\right)$. The calculations were performed with DicTra software but considering only a Ni-Al-Ti-Cr system for simplicity. The results are shown in Fig. 3.

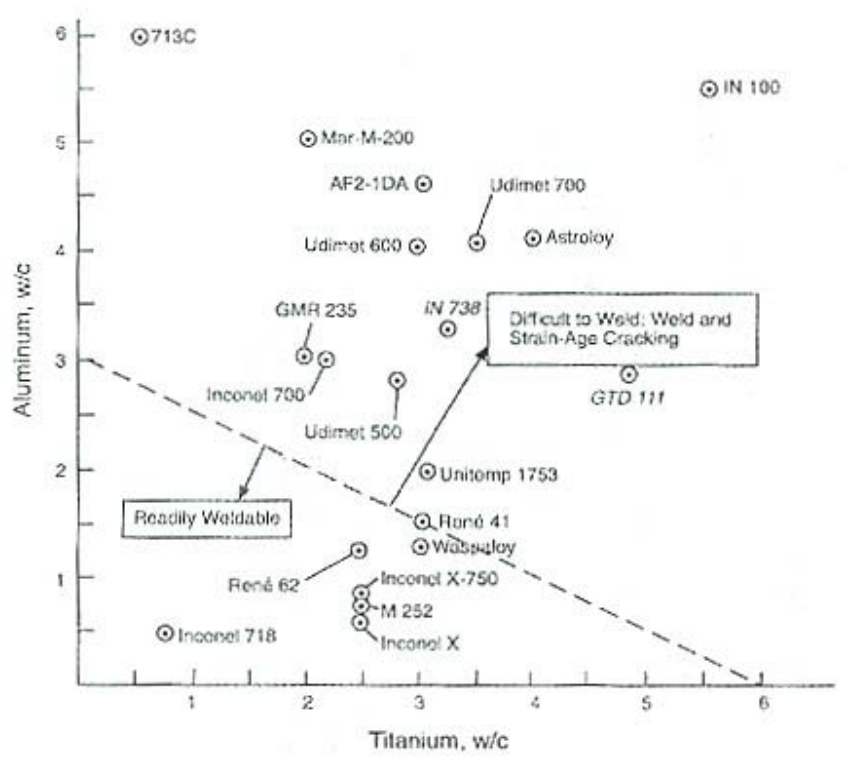

Fig. 1. Variation of strain age cracking tendency as a function of titanium and aluminum in nickel base.

Table I. Composition of R41 and Waspalloy

\begin{tabular}{llllllllll}
\hline ID & $\mathrm{C}$ & $\mathrm{Cr}$ & $\mathrm{Mo}$ & $\mathrm{Fe}$ & $\mathrm{Co}$ & $\mathrm{Al}$ & $\mathrm{Ti}$ & $\mathrm{B}$ & $\mathrm{Zr}$ \\
\hline R41 & 0.1 & 19 & 10 & 1 & 10 & 1.5 & 3.0 & 0.005 & 0.0 \\
Waspalloy & 0.08 & 19.5 & 4.0 & 0.0 & 13.5 & 1.3 & 3.0 & 0.006 & 0.06 \\
\hline
\end{tabular}


The results show that a slight change in composition may lead to acceleration of the $\gamma^{\prime}$ precipitation. This suggests that the strain age cracking can be related to kinetics of the $\gamma^{\prime}$ precipitation.

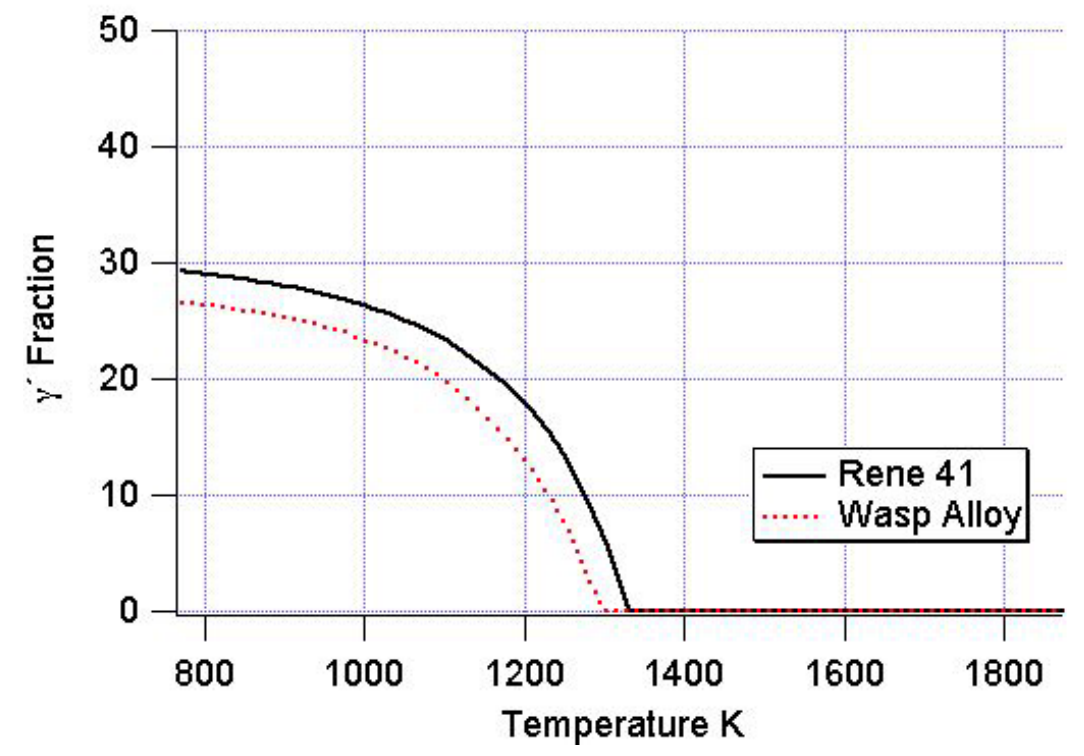

Fig. 2. Variation of $\gamma^{\prime}$ phase fraction as a function of temperature for both Rene 41 and Waspalloy compositions.

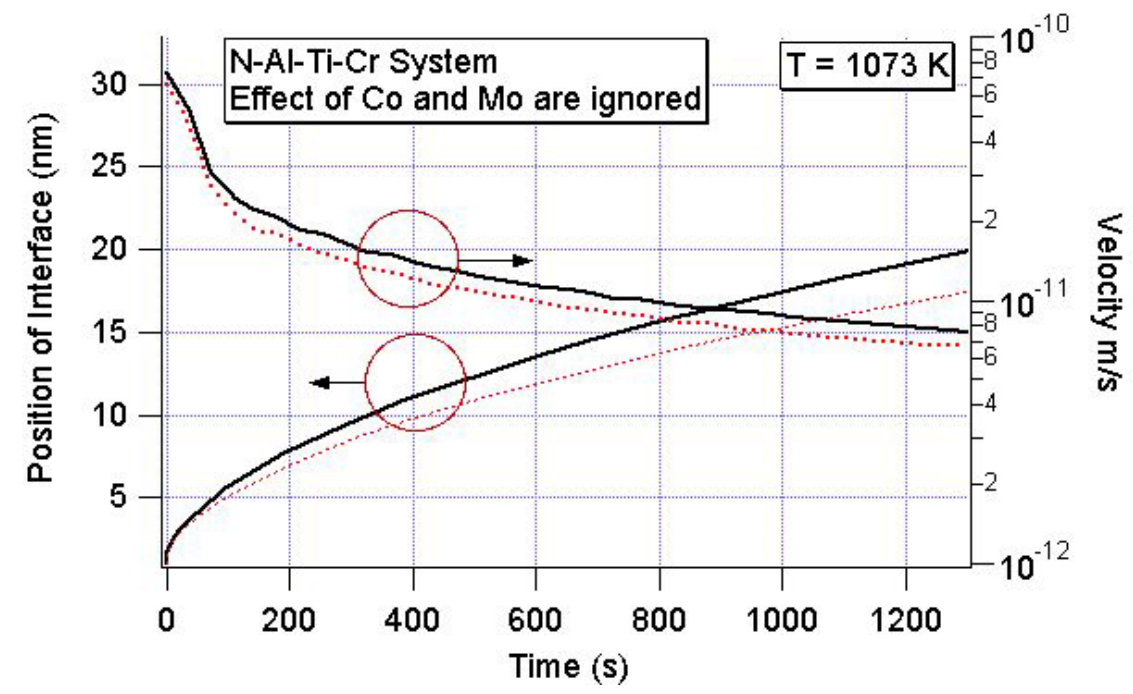

Fig. 3. Variation of $\gamma^{\prime}$ phase fraction as a function of time for $\mathrm{Ni}-\mathrm{Al}-\mathrm{Ti}-\mathrm{Cr}$ system predicted by diffusion-controlled growth model. The effect of Co and Mo are ignored. 


\section{Reports/Publications/Awards:}

S. S. Babu, S. P. Khurana, and J. R. Dydo, "Modeling of $\gamma^{\prime}$ Phase Precipitation from $\gamma$ Phase in Nickel-base Superalloy towards Understanding Strain Age Cracking," MPLUS report, 2003. 
MPLUS No.: MC-02-004

Title: Report on Validation of the LowTemperature Extrapolation of Thermodynamic Parameters
User Organization: E. I. du Pont de Nemours and Co. Wilmington, DE 19898

$\begin{array}{ll}\text { User Contact: } & \text { S. L. Grise, 302-774-4653 } \\ \text { steven.I.grise@usa.dupont.com }\end{array}$

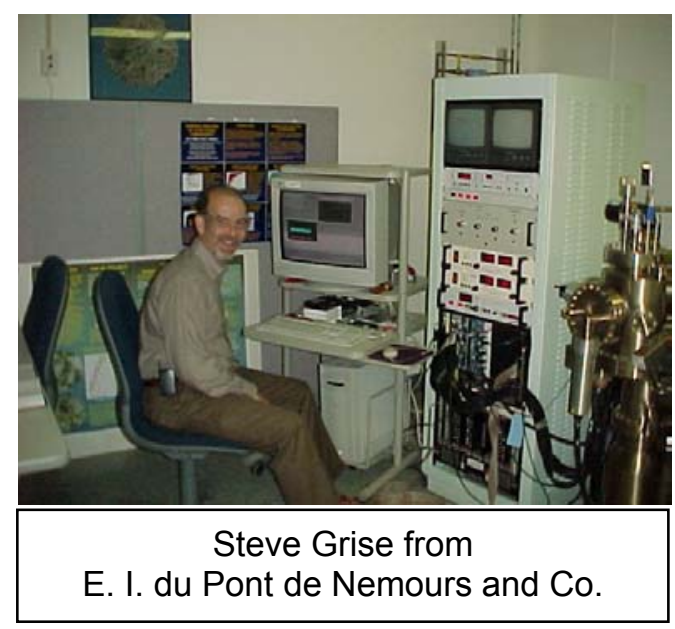

ORNL R\&D Staff: S. Suresh Babu, 865-574-4806 babuss@ornl.gov

Mike K. Miller, 865-574-4719

millermk@ornl.gov

Relevance to OIT: Most of the chemical industry process efficiency is related to the performance of metallic structures under aqueous corrosion conditions. Currently these materials are being designed by models that extrapolate the high temperature thermodynamic data to low temperature. However, there is no published work on the validity of these extrapolations. Therefore, as a result, the alloy design for energy efficient chemical industry infrastructure may be related to the validity of this extrapolation. This project is directly related to the chemical industry.

Significance of the Results: Atomic scale imaging and chemical analysis of steels after low temperature tempering showed that the partitioning of elements between ferrite and carbide indeed occur as expected from thermodynamic predictions. However, the extent of partitioning was quite far from the predictions. This indicated that kinetics may have a vital role in the performance of alloys used in the chemical industry infrastructure. The result also suggested, by slowing down the kinetics at low temperature through barrier methodologies, that it is possible to design improved alloys.

Objective: The goal is to validate low-temperature thermodynamic properties determined by extrapolation of high-temperature data with experimental phase stability measurements from atom probe field ion microscopy. Atom probe analysis is a quantitatively accurate tool for determining the amount and structure of metal alloy phases formed from sample heat treatment at moderate temperatures $\left(<0.5^{\star}\right.$ alloy melting point temperature).

Results: In this research, two steels were used: a 1018 type with a composition of Fe$0.15 \mathrm{C}-0.68 \mathrm{Mn}-0.18 \mathrm{Si}-0.013 \mathrm{P}-0.013 \mathrm{~S}$ (wt \%) and a 1045 type with a composition of Fe$0.48 \mathrm{C}-0.7 \mathrm{Mn}-0.24 \mathrm{Si}-0.006 \mathrm{P}-0.015 \mathrm{~S}$ (wt \%). Both steels were austenitized at $1200^{\circ} \mathrm{C}$ for $10 \mathrm{~min}$ and quenched in water to form martensite. This martensite was then 
tempered at $300^{\circ} \mathrm{C}$. This tempering is expected to produce cementite in the martensite. During such transformation, the carbide was expected to be enriched in manganese if the low-temperature thermodynamic extrapolations were correct. Atom probe microanalysis failed to detect any carbide in 1018 steels due to experimental difficulty. However, the atom probe analysis was able to detect carbides in 1045 steel and showed indications of manganese enrichment in the carbide and depletion of the carbides (Fig. 1).

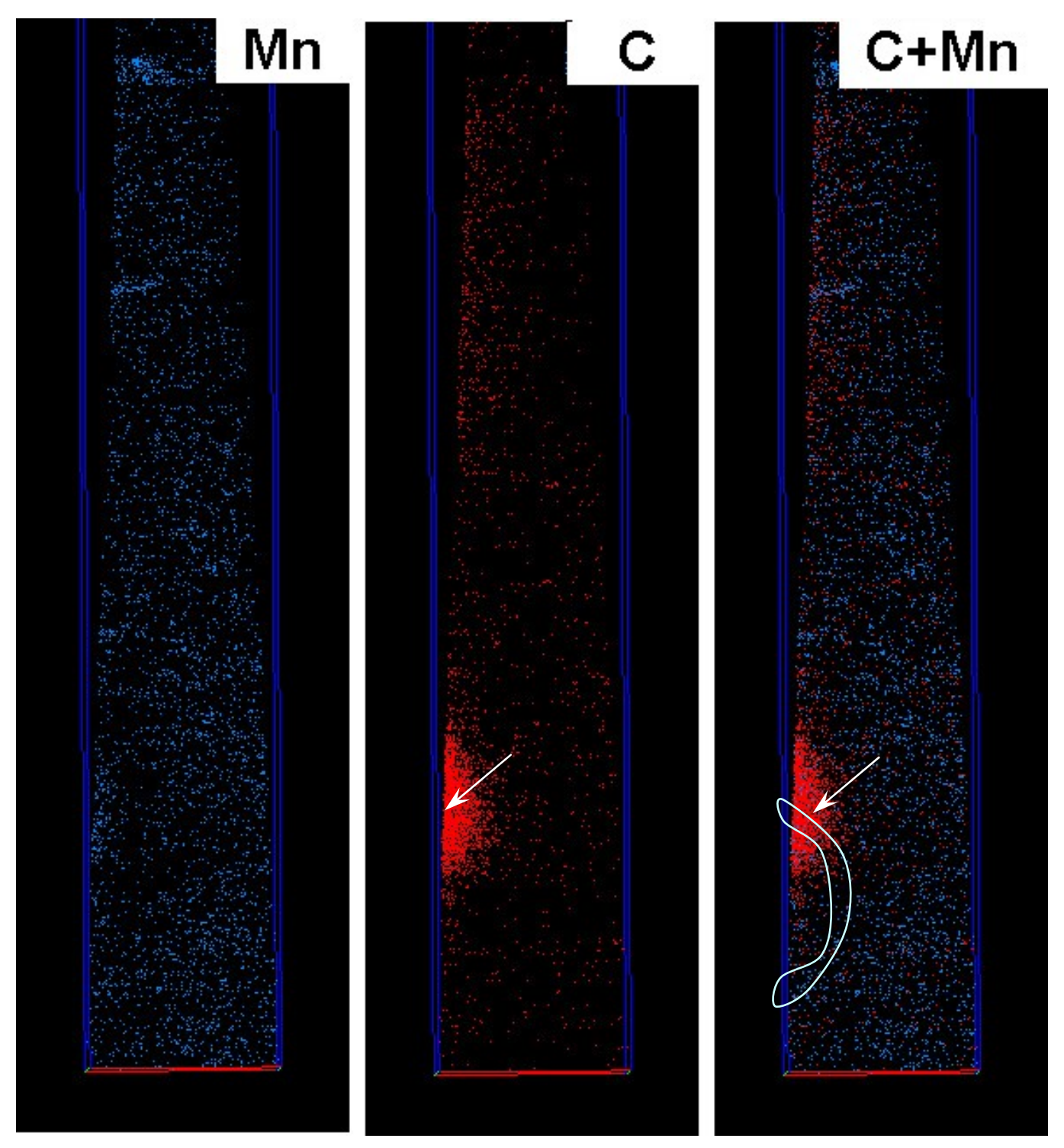

Fig. 1. Atom maps of manganese and carbon from 1045 steel after tempering at $300^{\circ} \mathrm{C}$. The carbide region is marked by white arrow in the carbon maps. The $\mathrm{C}+\mathrm{Mn}$ maps show the small amount of manganese depletion due to enrichment of manganese in the carbide. 
The results essentially showed that the low-temperature extrapolation of thermodynamic data in Fe-Mn-C systems is valid. However, the results also showed interesting phenomena with respect to kinetics of carbide growth. The predicted interface concentration of manganese was not in agreement with measurements. This is associated with solute drag phenomena during diffusion-controlled growth. Future research will be pursued with kinetic models.

This effort is related to the Office of Industrial Technology's (OIT's) Industries of the Future initiative, specifically, to the DOE-funded project "Prediction of Corrosion of Alloys in Mixed Solvent Environments." However, the results of the research will be of broad use for other industries of future including steel, metal-casting, mining, and petrochemical industries.

\section{Reports/Publications/Awards:}

S. L. Grise, S. S. Babu, and M. K. Miller, "Report on Validation of the Low Temperature Extrapolation of Thermodynamic Parameters," MPLUS report, 2003. 
MPLUS No.: MC-02-005

Title: Characterization of Laser Clads Made on Steel Substrates

User Organization: Alvord Polk, Inc. Millersburg, PA 17061

User Contact: $\quad$ Z. "Henry" Peng, 717-362-6962 hpeng@alvordpolk.com

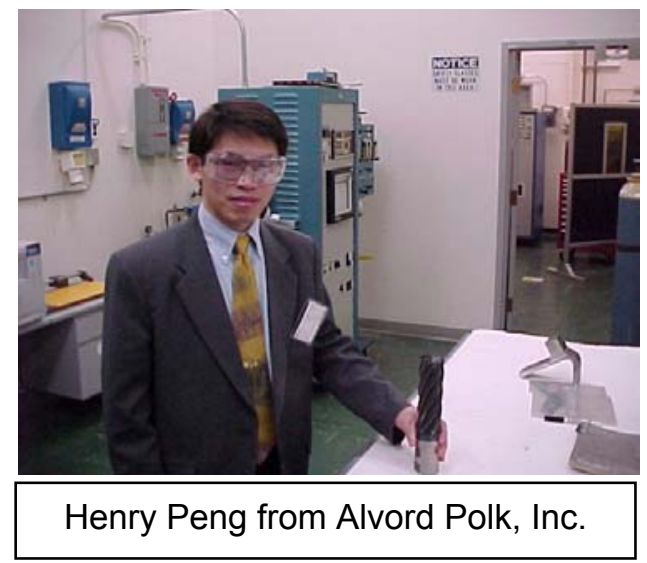

ORNL R\&D Staff: $\quad$ S. Suresh Babu, 865-574-4806 babuss@ornl.gov

E. A. Kenik, 865-574-5066 kenikea@ornl.gov

E. A. Payzant, 865-574-6538 payzanta@ornl.gov

Relevance to OIT: The energy efficiency of the mining industry often relies on the effective operation of cutting equipment used in earth moving. The downtime of this equipment is related to failure of the cutting edge. The energy efficiency of various mining operations can be improved by laser alloying of steel substrates. The project pertains to characterization of coatings produced by the industry which makes cutting tool for the mining industry.

Significance of the Results: X-ray diffraction and scanning electron microscopy results indicated that the carbide and nitride formation during laser clad processing may occur in liquid steel before the onset of predominant phase (austenite or ferrite) solidification. The microstructure evolution was found to be complex and very sensitive to the local composition. The results showed that it is possible to tailor the composition of these surface layers thereby enhancing the surface microstructures in order to improve the wear surface and at the same time provide tough microstructure near the substrate to avoid failure. The results will lead to better design of cutting tools that will improve energy efficiency as well as life of the cutting tools.

Objective: Characterize the hard particles in laser clad specimens used in cutting tools using X-ray diffraction and scanning electron microscopy.

Results: The laser cladding on steel substrates was characterized by X-ray diffraction $(X R D)$. To isolate the diffraction patterns from phases in the cladding, lead or silicon masks were used to cover the substrate. Therefore, XRD patterns contain extraneous peaks from the masking material. 
A typical X-ray diffraction spectrum is shown in Fig. 1. In A03369, peaks at $31.42^{\circ}$, $36.4^{\circ}, 52.341^{\circ}, 62.26^{\circ}, 65.359^{\circ}, 77.081^{\circ}, 85.518^{\circ}$, and $88.281^{\circ} 2 \theta$ were created by the lead tape used to mask the substrate. The background in each XRD pattern consisted of an amorphous hump from the polymer in which the sample was embedded. The background also contained fluorescence contributions created by the excitation of iron atoms by copper-wavelength X-radiation. These sources of background noise, combined with the small size of the sample, led to poor signal-to-noise ratios. XRD patterns were collected on a Scintag PadV using copper Ka radiation and BraggBrentano parafocusing geometry. Phase analysis indicated that a steel phase was present. This phase was indicated with PDF \#34-0396, the card for 434L $\mathrm{Fe}-\mathrm{Cr}$ stainless steel. Peak positions were not accurate enough to quantify differences in the lattice parameters of the steel in the cladding and the PDF card due to compositional differences. Peaks such as the one at $43.279^{\circ} 2 \theta$ may have indicated the presence of a $\mathrm{Cr}-\mathrm{Fe}-\mathrm{Mo}$ type phase, such as $\mathrm{Cr}_{12} \mathrm{Fe}_{36} \mathrm{Mo}_{10}$ (PDF \#31-0401). This phase has a cubic $143 \mathrm{~m}$ unit cell with $\mathrm{a}=8.9 \AA$. Other constituents, such as $\mathrm{Ti}$ or $\mathrm{Ni}$, can be accommodated in this phase (e.g., PDF \#33-0395 and \#16-0443). Alternatively, a phase like $\mathrm{Fe}_{2} \mathrm{C}$ (PDF \#36-1249) may have been present instead. This phase has a hexagonal $\mathrm{P}_{3} / \mathrm{mmc}$ unit cell with $2.754 \times 4.349 \AA$ lattice parameters. The $\mathrm{Cr}-\mathrm{Fe}-\mathrm{Mo}$ phase seemed more likely, but no conclusive identification could be made.

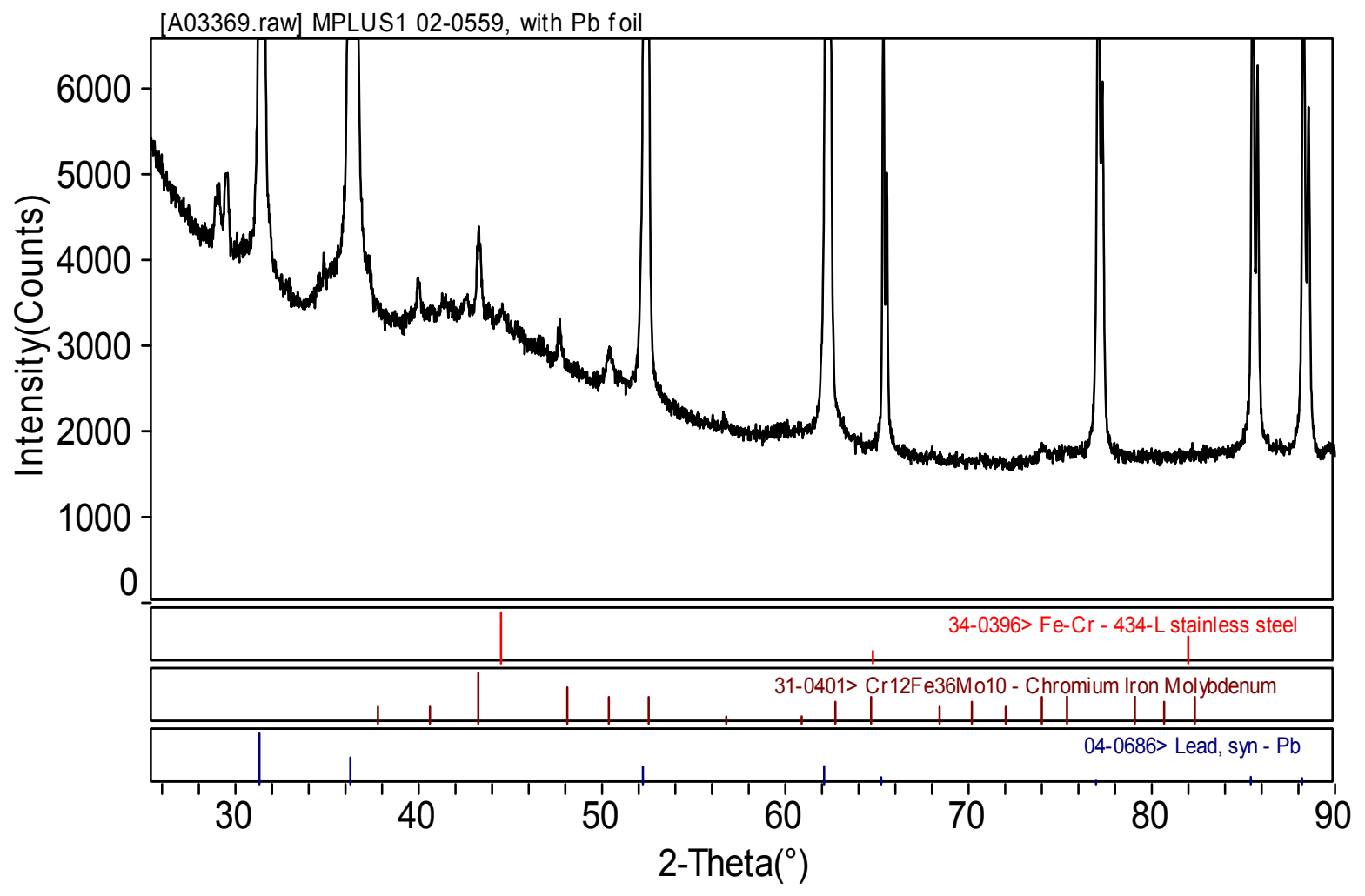

Fig. 1. Phase analysis of MPLUS 1. 
Scanning electron microscopy analysis was in agreement with XRD analysis showing multiple phases and the evolution of a complex microstructure (Fig. 2).

Analyses from other samples are presented in the final report. Each of these phase analyses leaves at least one phase, and probably multiple phases unidentified. Background, sample size, and fluorescence all contribute to limit the amount of information that can be provided by XRD with a laboratory diffractometer. Additional characterization through SEM/EDS, microfocus XRD with a non-copper radiation source, microfocus synchrotron diffraction, or other means is necessary to fully analyze these samples.

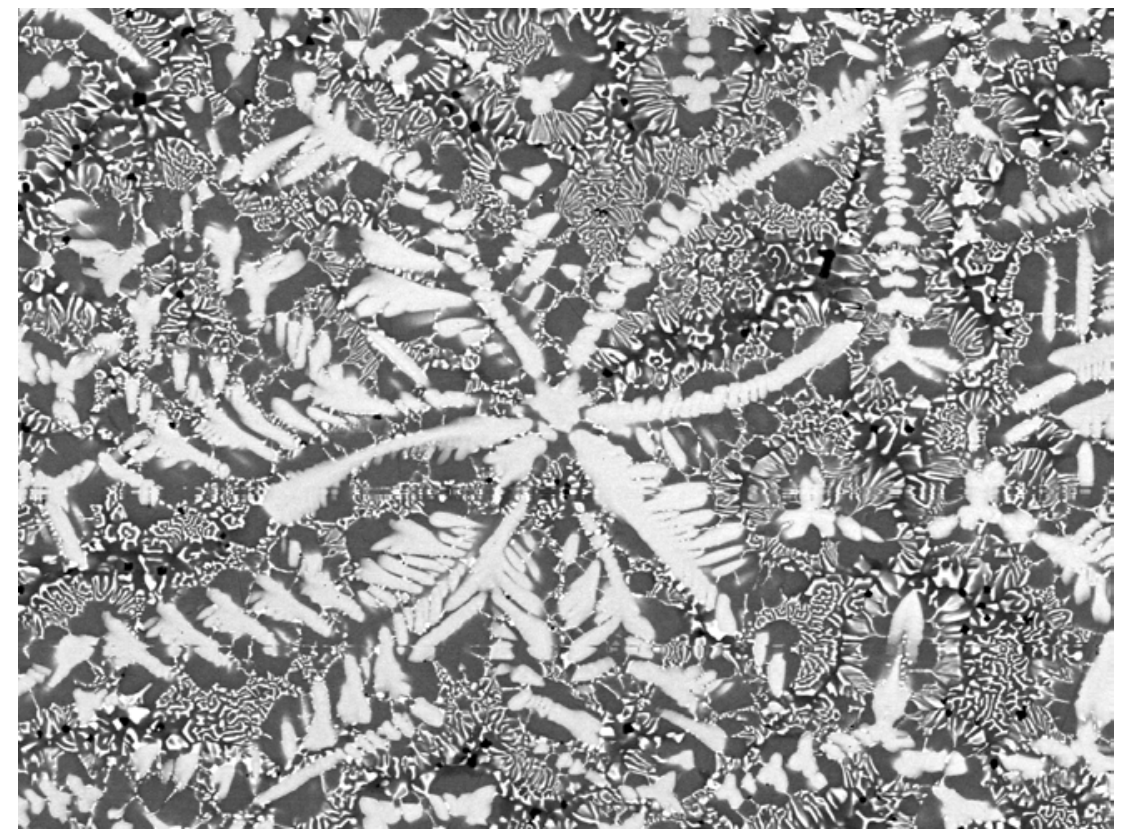

Fig. 2. Scanning electron micrograph showing complex microstructures in laser clad samples.

\section{Reports/Publications/Awards:}

Suresh Babu, "Characterization and Particle Thermal Stability Modeling of Laser Cladded Coatings," MPLUS report, 2003. 
MPLUS No.: MC-02-006

Title: Improved Alloys for Coiler Drums for Plate Reversing Mills

User Organization: Duraloy Technologies, Inc. Scottdale, PA 15683

User Contacts: Roman Pankiw, 724-887-5100, ext. 188 techmgr@duraloy.com

Roman Pankiw from Duraloy Technologies, Inc.

Donald P. Voke, 724-887-5100, ext. 155

dvoke@duraloy.com

Kevin Marsden, 412-476-1581

protech@whemco.com

ORNL R\&D Staff: Mike Santella, 865-574-4805

santellaml@ornl.gov

Relevance to OIT: We are trying to determine the primary cause of failure in coiler drums that are used to handle rolled plates in Steckel reversing mills. Determining the cause of failure is the first step to identifying casting process or alloy modifications that could improve coiler drum life. Improving the life of coiler drums will dramatically improve the efficiency of steel processing and help reduce the frequency of unscheduled outages.

Objective: We are trying to determine the primary cause of failure in coiler drums that are used to handle rolled plates in Steckel reversing mills. Improving the life of coiler drums will dramatically improve the efficiency of steel processing and help reduce the frequency of unscheduled outages.

Results: It was believed that cracking of the coiler drums (Fig. 1) is related to the solidification cracking tendencies of the alloys used for these large castings. Consequently, a large number of phase equilibria calculations were done, using ThermoCalc ${ }^{\mathrm{TM}}$ software, to examine the effects of alloy composition on freezing range and phase stability. The freezing range is important because the size of the freezing range has a strong correlation with solidification cracking susceptibility. The predictions for six alloys that are candidates for the coiler drums are given in Table 1. This table shows the equilibrium liquidus, $T_{L}$, and solidus, $T_{S}$, temperatures, the equilibrium freezing range, $T_{f, e q}=\left(T_{L}-T_{S}\right)$, and the freezing range predicted for nonequilibrium solidification assuming the usual Scheil conditions, $T_{f, S c h}$. The nonequilibrium solidification condition more closely approximates the actual solidification of castings. For these conditions the liquidus temperature is identical to the equilibrium $T_{L}$, but the solidus temperature will be lower than the equilibrium $T_{S}$. This extends the freezing range and increases the probability of solidification cracking. 


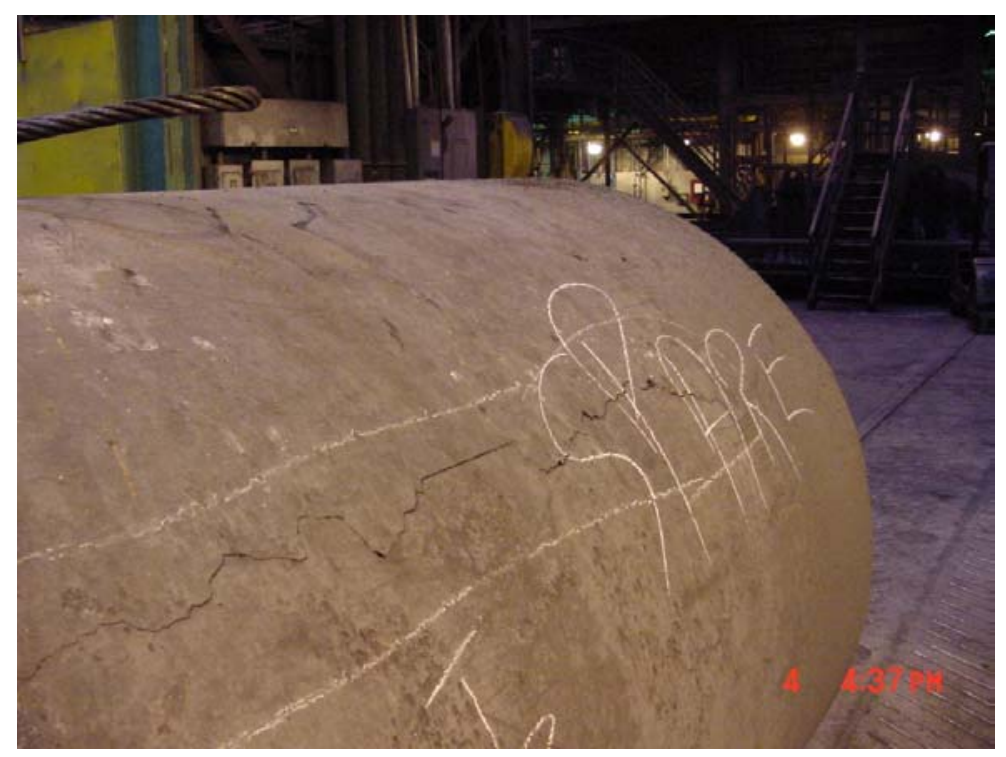

Fig. 1. Coiler drum showing large cracking running along outside surface.

Table 1. Liquidus, solidus, and freezing ranges determined using ThermoCalc ${ }^{\mathrm{TM}}$

\begin{tabular}{lcccc}
\hline Alloy & $\boldsymbol{T}_{\mathbf{L}}{ }^{\circ} \mathbf{C}$ & $\boldsymbol{T}_{\boldsymbol{s}},{ }^{\circ} \mathbf{C}$ & $\boldsymbol{T}_{\boldsymbol{f}, \mathrm{eq}},{ }^{\circ} \mathbf{C}$ & $\boldsymbol{T}_{\boldsymbol{f}, \boldsymbol{S c h},}{ }^{\circ} \mathbf{C}$ \\
\hline HTNb & 1374 & 1296 & 78 & 275 \\
MORE10 & 1351 & 1283 & 68 & 200 \\
MORE10CD & 1367 & 1292 & 75 & 270 \\
MORE15CD & 1391 & 1324 & 67 & 300 \\
HK40Nb & 1360 & 1269 & 91 & 120 \\
HK15Nb & 1374 & 1296 & 78 & 155 \\
\hline
\end{tabular}

Additional calculations were also done to examine the effects of composition in reference alloys on freezing range and phase stability. The results for calculation of equilibrium freezing range in an HKNb $(0.8 \mathrm{wt} \% \mathrm{Nb})$ base alloy are shown in Fig. 2. They show that the equilibrium freezing range passes through a minimum just above $0.1 \mathrm{wt} \% \mathrm{C}$, and it is relatively constant above about $0.28 \mathrm{wt} \% \mathrm{C}$. The predicted stable phases in $\mathrm{HKNb}$ at the solidus temperatures are shown in Table 2. Below a carbon concentration of about $0.175 \mathrm{wt} \%, \delta$ ferrite is predicted to form in the microstructure of the alloy. The $\delta$ ferrite phase is detrimental to strength properties. Above about $0.425 \mathrm{wt} \% \mathrm{C}$, the $\mathrm{M}_{7} \mathrm{C}_{3}$ carbide forms, and this phase is also detrimental to strength. 


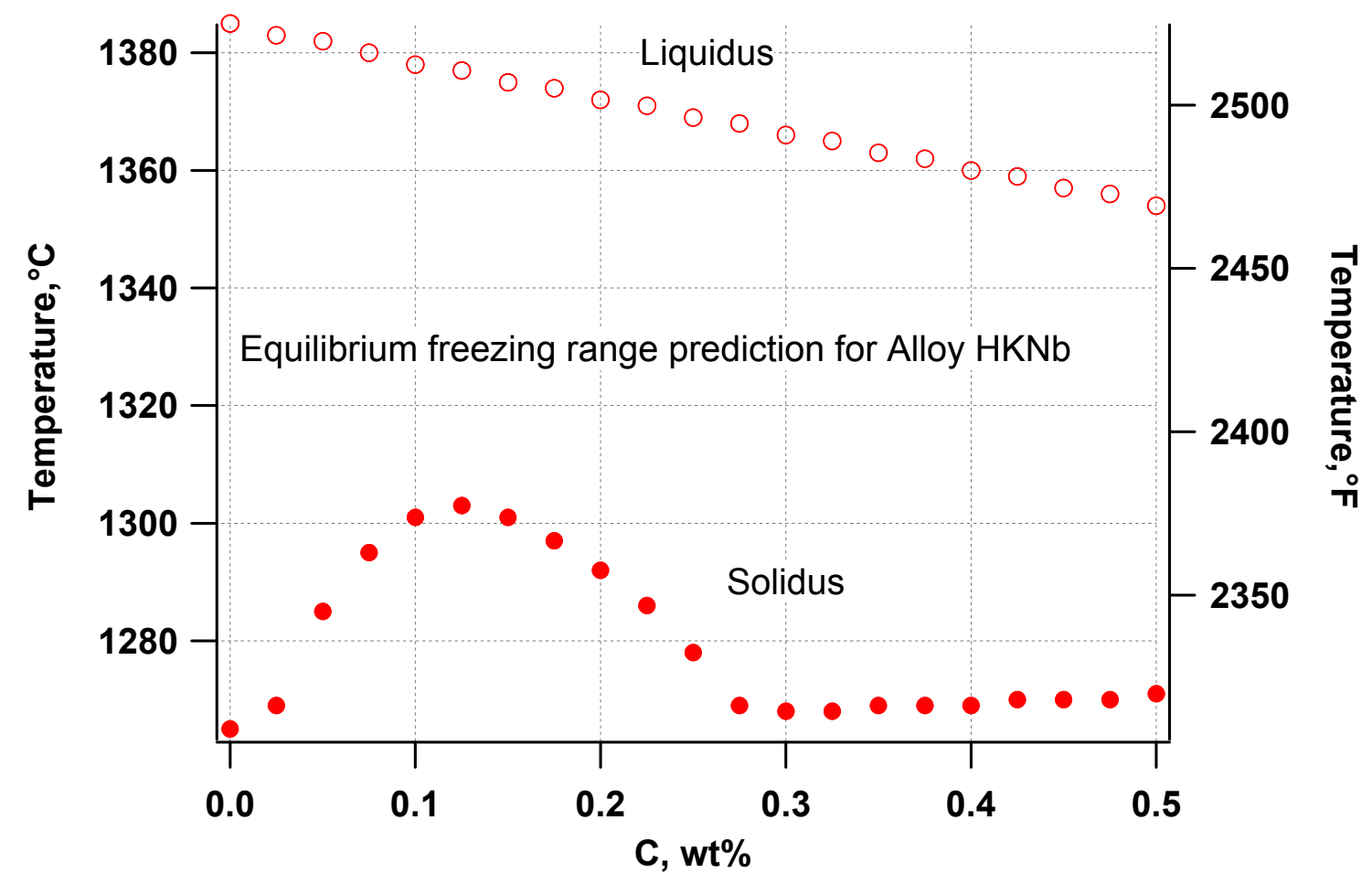

Fig. 2. Variation of equilibrium freezing range with carbon concentration for an $\mathrm{HK}+$ $0.8 \mathrm{wt} \% \mathrm{Nb}$ alloy.

Table 2. Predicted stable phases in HKNb at the solidus temperature

\begin{tabular}{ll}
\hline \multicolumn{1}{c}{ C, wt \% } & \multicolumn{1}{c}{ Phases } \\
\hline 0.0 & $\gamma+\delta$ \\
$0.025-0.175$ & $\gamma+\delta+\mathrm{NbC}$ \\
$0.2-0.275$ & $\gamma+\mathrm{NbC}$ \\
$0.3-0.4$ & $\gamma+\mathrm{NbC}+\mathrm{M}_{23} \mathrm{C}_{6}$ \\
$0.425-0.45$ & $\gamma+\mathrm{NbC}+\mathrm{M}_{23} \mathrm{C}_{6}+\mathrm{M}_{7} \mathrm{C}_{3}$ \\
$0.475-0.5$ & $\gamma+\mathrm{NbC}+\mathrm{M}_{7} \mathrm{C}_{3}$ \\
\hline
\end{tabular}

Based on these and additional thermodynamic calculations, examination of metallographically prepared specimens, and various discussions between Duraloy, Whemco (parent company), and ORNL staff, we proposed the alloy compositions listed in Table 3 to improve the performance of coiler drum castings. 
Table 3. Proposed chemical compositions for coiler drum alloys with improved performance

\begin{tabular}{cccccccccccc}
\hline & & \multicolumn{1}{c}{ Composition, wt \% } \\
Alloy ID & Fe & $\mathbf{C}$ & $\mathbf{C r}$ & $\mathbf{M n}$ & $\mathbf{M o}$ & $\mathbf{N}$ & $\mathbf{N b}$ & $\mathbf{N i}$ & $\mathbf{S i}$ & $\mathbf{T i}$ \\
\hline Whemcornl-1 & Bal. & 0.18 & 20.0 & 2.0 & 0.3 & --- & 0.5 & 30.0 & 0.5 & -- \\
Whemcornl-2 & Bal. & 0.4 & 20.0 & 2.0 & 0.3 & --- & 0.5 & 30.0 & 0.5 & --- \\
Whemcornl-3 & Bal. & 0.18 & 20.0 & 2.0 & 0.3 & --- & 0.5 & 30.0 & 0.5 & 0.1 \\
Whemcornl-4 & Bal. & 0.4 & 20.0 & 2.0 & 0.3 & --- & 0.5 & 30.0 & 0.5 & 0.1 \\
Whemcornl-5 & Bal. & 0.18 & 20.0 & 2.0 & 0.3 & --- & 0.25 & 30.0 & 0.5 & 0.1 \\
Whemcornl-6 & Bal. & 0.18 & 20.0 & 2.0 & 0.3 & 0.02 & 0.5 & 30.0 & 0.5 & 0.1 \\
Whemcornl-7 & Bal. & 0.18 & 20.0 & 2.0 & 0.3 & 0.02 & 0.25 & 30.0 & 0.5 & 0.1 \\
Whemcornl-8 & Bal. & 0.3 & 25.0 & 0.5 & 0.3 & -- & -- & 15.0 & 0.5 & -- \\
Whemcornl-9 & Bal. & 0.15 & 25.0 & 0.5 & 0.3 & --- & --- & 15.0 & 0.5 & -- \\
\hline
\end{tabular}

Reports/Publications/Awards:

M. L. Santella, Roman Pankiw, and Kevin Marsden, "Improved Alloys for Coiler Drums for Plate Reversing Mills," MPLUS report, 2003. 
MPLUS No.: MC-02-007

Title: Die Casting Performance Testing of $\mathrm{H} 13$ Samples Processed with HYBron ${ }^{\mathrm{TM}}$ BoronBased Coating Technology

\section{User Organization: HY-Tech Research Corp. Radford, VA 24141}

User Contact: C. C. Klepper, 540-639-4019 cklepper@hytechresearch.com

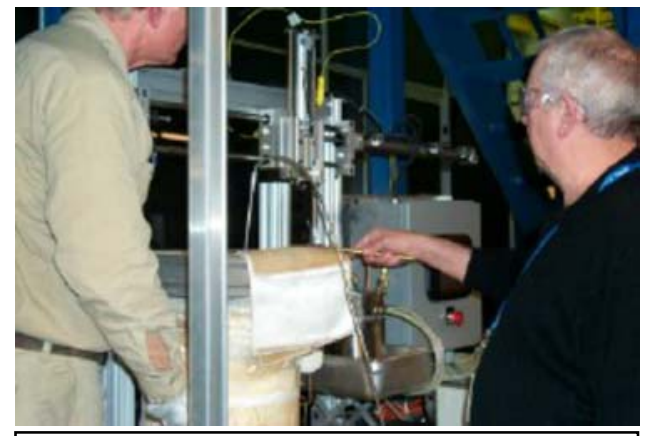

Jim Williams (right), Consultant from HY-Tech Research Corp., working with ORNL technician Ed Hatfield

J. Williams, 205-222-7419

williamsjm@ornl.gov

ORNL R\&D Staff: G. Mackiewicz-Ludtka, 865-576-4652 ludtkagm@ornl.gov

Relevance to OIT: Die soldering, a common phenomenon in die casting of aluminum alloys, is a coating defect in which melting aluminum "welds" to the surface of a ferrous die. It results in damage to the die surface and casting surface, thus causing significant decreases in productivity and efficiency of casting operations. Soldering and thermal fatigue significantly reduces the efficiency of the die casting process, and increases scrap rate. The die casting industry currently ships about 1.7 billion pounds of aluminum alloy castings per year [ref. - Metalcasting Industry Technology Roadmap]. If the yield on the process is improved by $20 \%$ by the application of coatings, surface treatments, and improved process parameters, the energy saved due to this is equal to $0.2 \times 1.5 \times 10^{6}$ ton $\times 9 \times 10^{6} \mathrm{BTU} /$ ton $=2.7 \times 10^{12} \mathrm{BTUs} /$ year. The overall purpose of this project was to determine whether HY-Tech's boron-based coating technology could be used in die-casting applications for cast aluminum alloys used in the automotive industry. This project supported the main premise that the boron coating would strongly adhere to the substrate, while resisting wetting by aluminum. In fact, the most important results were that a $0.5-\mu \mathrm{m}$-thick B-coating sample provided over four times the soldering resistance of uncoated $\mathrm{H} 13$ steel. The improvement was both quantitatively and qualitatively striking.

Objective: The aim of this project was to experimentally determine and compare the extent of die soldering that occurs when molten aluminum alloy contacts a bare steel die versus a boron-coated steel using a cathodic arc deposition technique. The main premise was that the boron coating would strongly adhere to the substrate, while resisting wetting by aluminum.

Results and Conclusions: One sample of bare $\mathrm{H} 13$ steel was run as a control. Previous runs and prior testing results indicated that soldering behavior was expected and soldering was confirmed. The data for the H13 (Fig. 1) shows that the time for soldering was relatively short - about $450 \mathrm{~s}$. There was considerable soldering on the 
very first cycle. By the sixth cycle the sample was heavily caked on the whole area of the cylinder wall and on the end, and the sample jammed with the attempt to withdraw. The sample was finally extracted after dwelling in the melt for several seconds to allow for more melting.

The most important results for the boron-coated sample (\#28-4), which had a $0.5-\mu \mathrm{m}$ thick reacted layer, demonstrated that the boron provided over four times the soldering resistance of the $\mathrm{H} 13$ steel (testing was stopped at $2000 \mathrm{~s}$ ). The improvement was both quantitatively and qualitatively striking (Figs. 2 and 3 ).

Specifically, the results and conclusions for the boron-coated sample were as follows:

- Large areas of the sample were never wetted.

- Soldering, when it did occur, was quite likely on partially defected areas, resulting from the still developmental character of the process.

- No cracking in either the coating or the substrate was observed.

- The boron coating has other highly desirable properties for the die application. The cathodic arc coating process is the most economical and the most suitable for the application.

- Macroparticle management will be the biggest disadvantage of the deposition process, but should be solvable.

Bare Steel, H13

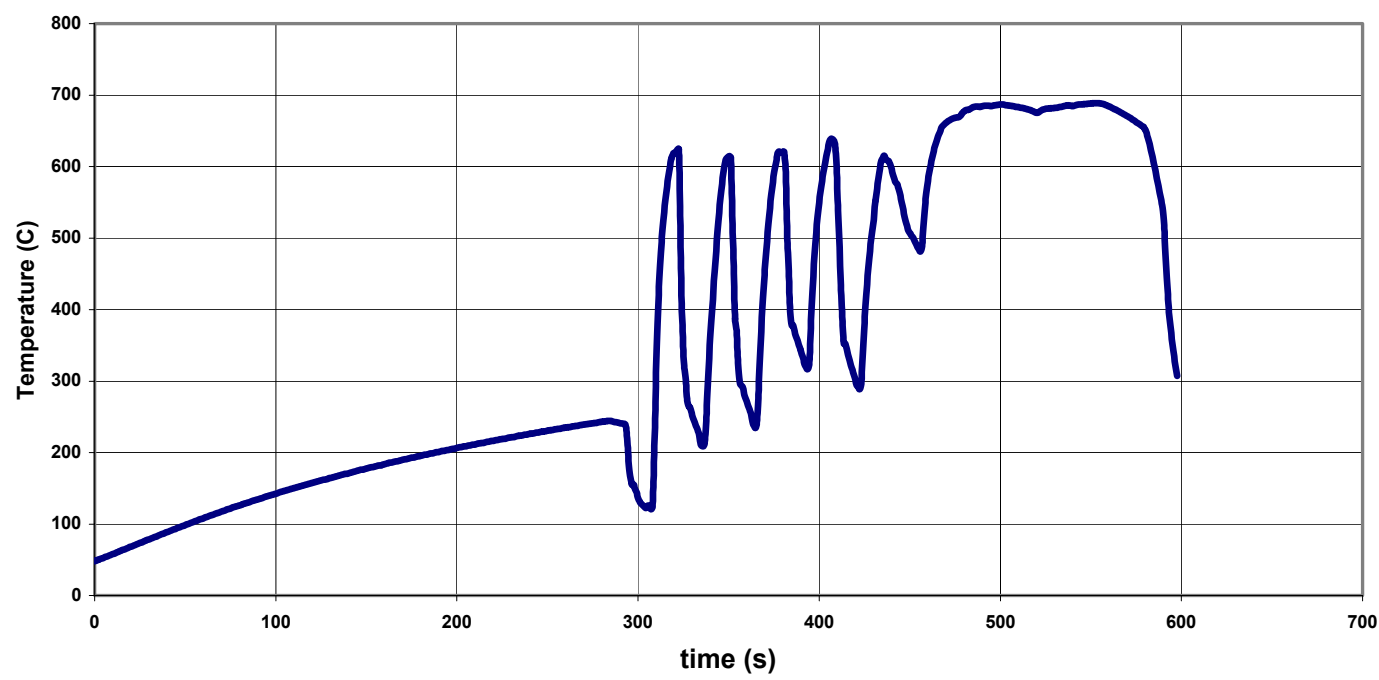

Fig. 1. Time-temperature plot for the control (bare) $\mathrm{H} 13$ sample. 


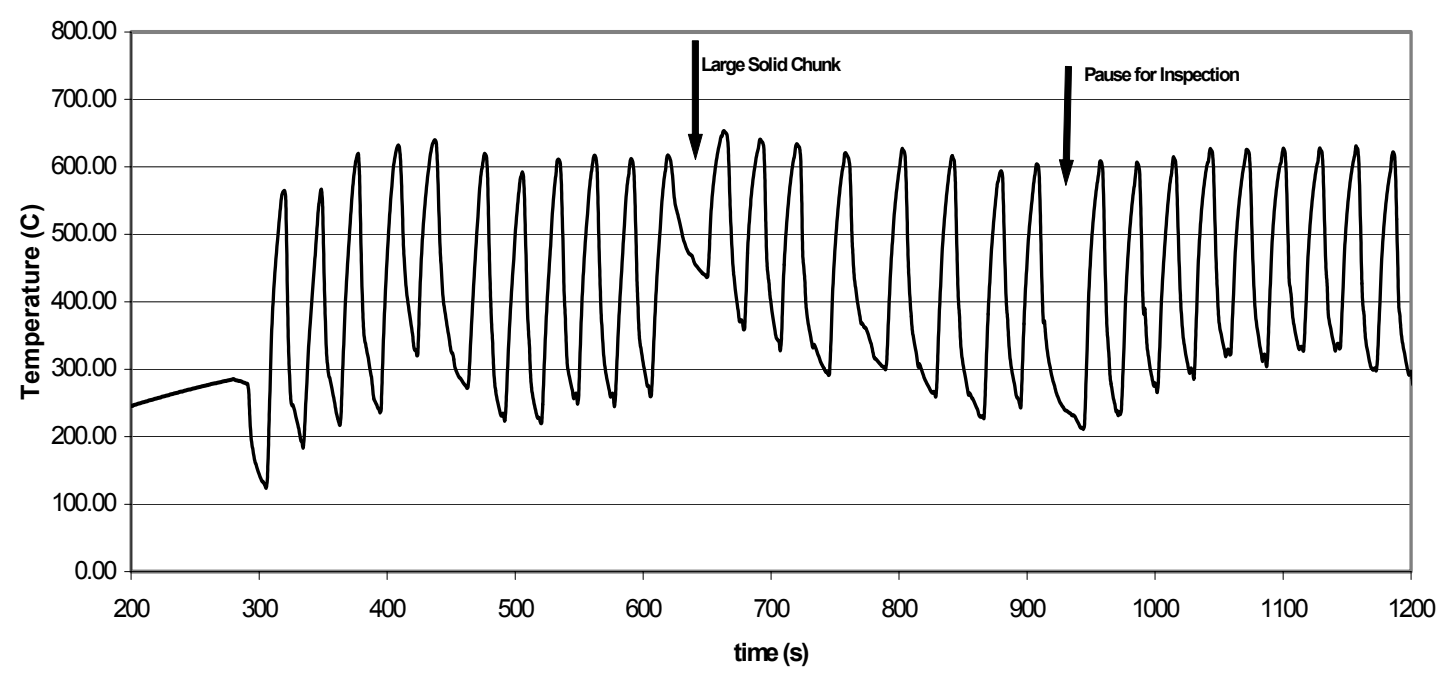

Fig. 2. Time-temperature plot for the first half of the test for sample 28-4.

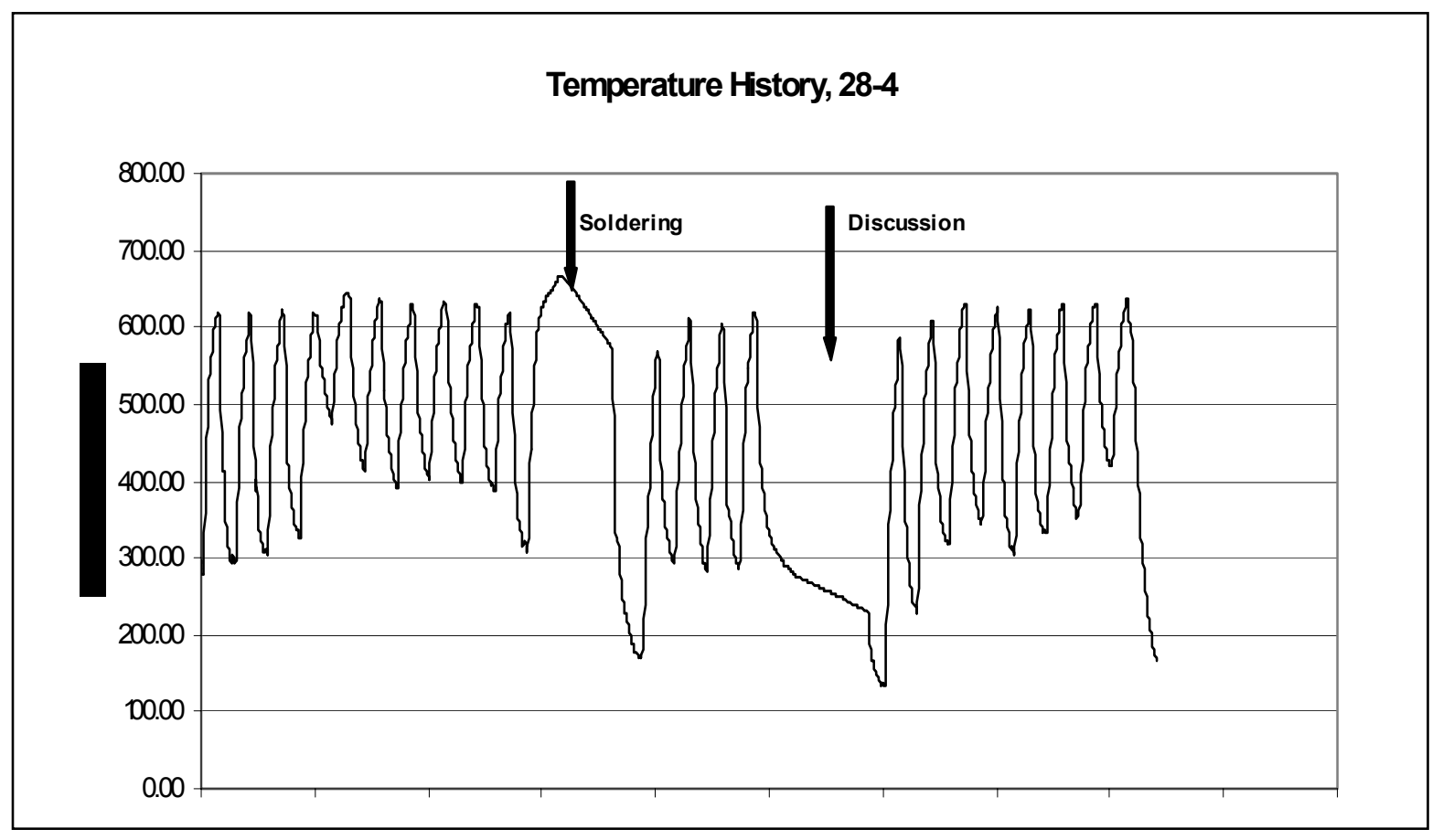

Fig. 3. Time-Temperature plot for the second half of the test for Sample 28-4.

\section{Reports/Publications/Awards:}

J. M. Williams, C. C. Klepper, R. C. Hazelton, E. J. Yadlowsky, G. M. Ludtka, E. Hatfield, and V. Sikka, "Die Casting Performance Testing of H13 Samples Processed with HYBron ${ }^{\mathrm{TM}}$ Boron-based Coating Technology," preliminary MPLUS report, March 2003. 
MPLUS No.: MC-02-010

Title: A Noncontact, Very Rapid Surface Temperature Measurement using Advanced Infrared Imaging

User Organization: Inductoheat Madison Heights, MI 48071

User Contact: M. S. Chatterjee, (248) 629-5004 mchatterjee@inductoheat.com

ORNL R\&D Staff: Ralph Dinwiddie, 865-574-7599

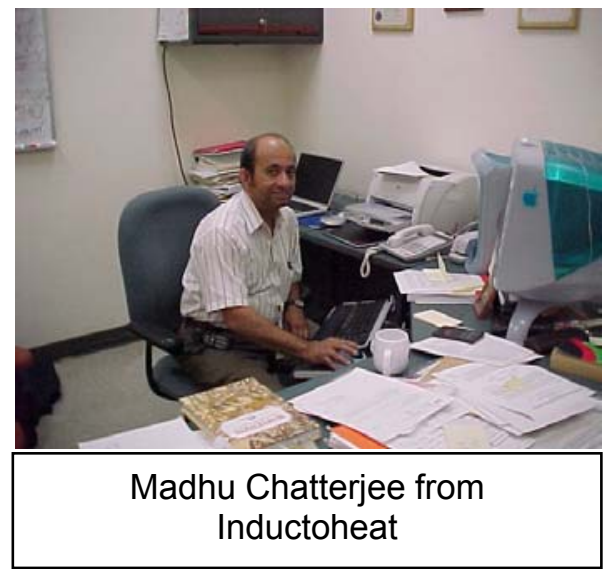
dinwiddierb@ornl.gov

Relevance to OIT: Induction heating is commonly used in surface hardening a large number of steel components. The process involves rapid heating of a narrow volume of material near the surface to above austenitizing temperature followed by polymer quenching, thus resulting in profile hardening of gear teeth. This project provides a good way to measure the surface temperature during rapid heating and rotation of the part. This measurement may allow the induction heating process to be able to compete with gas carburizing process and thus would save energy and would be environmentally friendly. This project is directly relevant to the metal processing industries including heat treatment.

Objective: Induction heating is commonly used in surface hardening for a large number of steel components. Currently, there is no acceptable way to measure the surface temperature during rapid heating and rotation of the part. If such a measurement could be made, the induction-heating process would be able to compete with the gas-carburizing process, would save energy, and would be environmentally friendly. Thus, the objective of this project was to determine whether ORNL's advanced infrared imaging capability can measure the temperature of the gear teeth during RF heating.

Results: In order to focus on the small gear teeth, the infrared camera was equipped with an extender ring. The high temperatures required the use of two glass filters in front of the lens. A camera boom was used to place the infrared camera in close proximity to the RF-heated gear. A thermocouple attached to a stationary gear was used to calibrate the infrared camera. It was found that the infrared camera could indeed measure the temperature profile of individual gear teeth while the gear was rotating and undergoing induction heating. The industrial partner is evaluating the use of the technique. 


\section{High Temperature Gear Tooth Calibration}

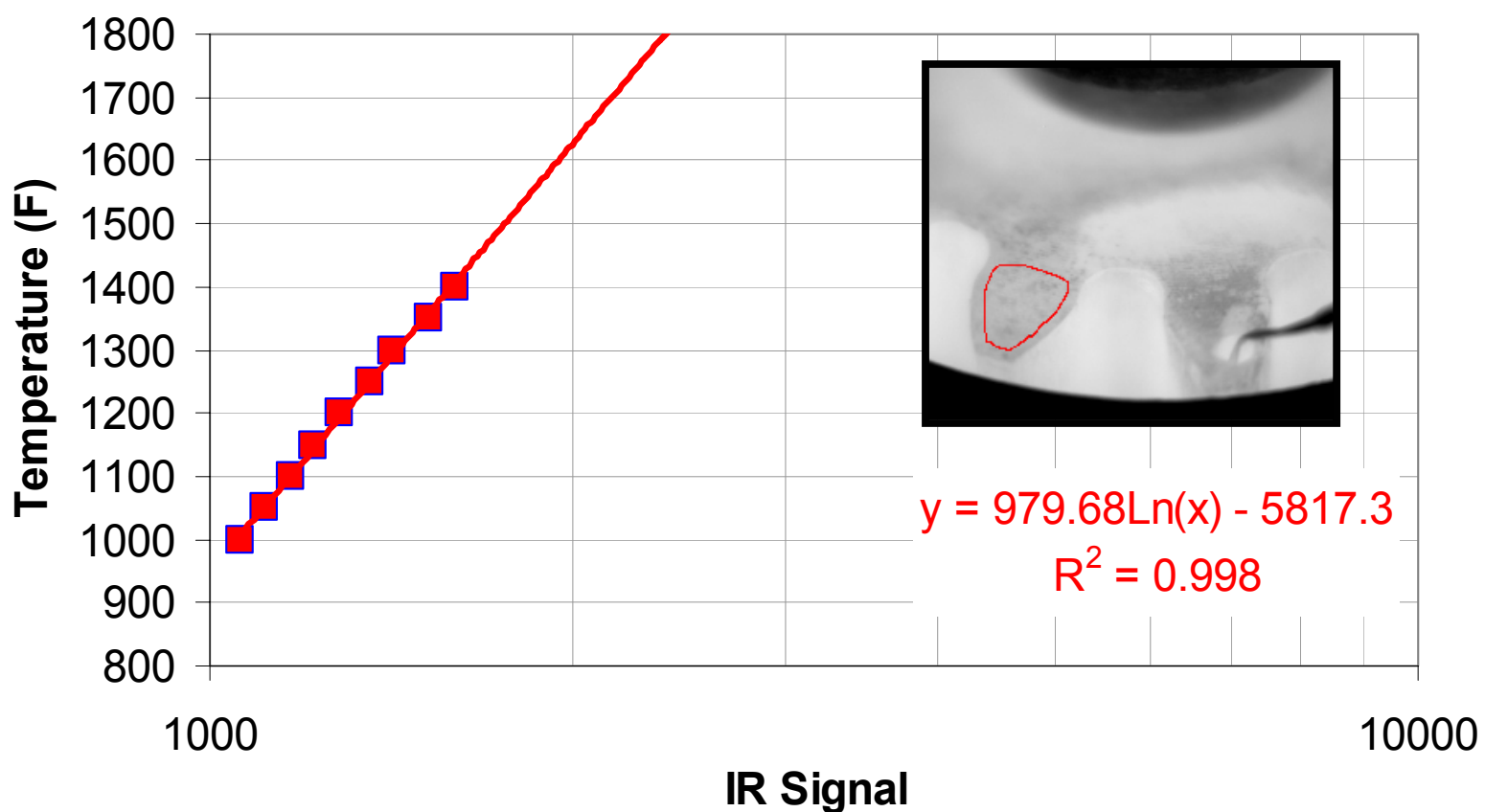

Fig. 1. Infrared camera calibration of an inductively heated gear using a type $\mathrm{K}$ thermocouple.

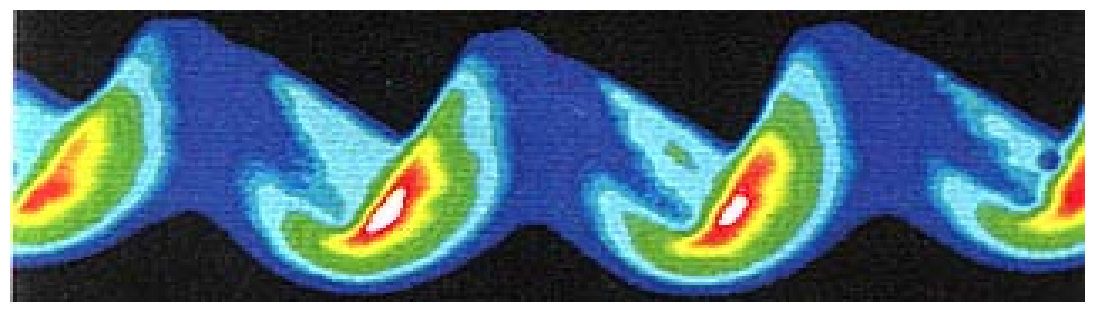

Fig. 2. Thermal image of gear teeth during induction heating. Hottest areas appear white, followed by red, yellow, green, cyan, and blue.

\section{Reports/Publications/Awards:}

This project was presented at the 2003 Global Powertrain Congress in Ann Arbor, Michigan. 
MPLUS No.: MC-02-011

Title: Comparison of Tempering Response of Steels to Induction Heating versus Conventional Heating

User Organization: Inductoheat Madison Heights, MI 48071

User Contact: $\quad$ Madhu Chatterjee, (248) 629-5004 mchatterjee@inductoheat.com

ORNL R\&D Staff: Suresh S. Babu, 865-574-4806

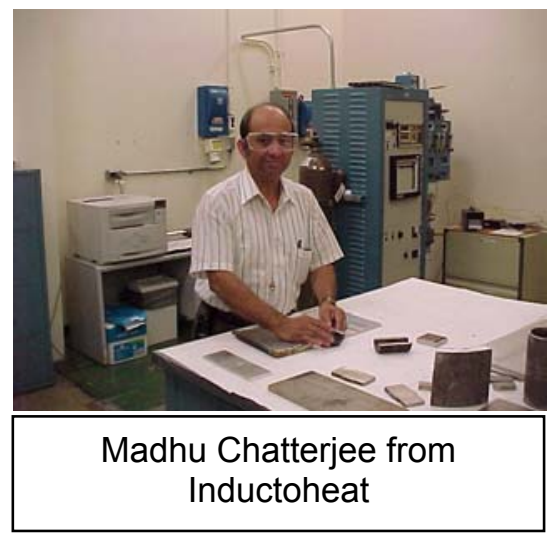
babuss@ornl.gov

M. K. Miller, 865-574-4719 millermk@ornl.gov

Vinod K. Sikka, 865-574-5112 sikkavk@ornl.gov

Relevance to OIT: The U.S. produces approximately 100 million tons of steels per year. In most cases, steels are heat-treated in order to derive their strength and desired property level for specific applications. Heat treatment uses large amounts of energy, and there is a continuing effort in industry to replace the conventional and inefficient gas-fired furnace heat-treating processes by rapid processes that can be carried out by induction or other rapid methods. This MPLUS project demonstrated that a strong possibility exists for replacing the conventional (inefficient) heat-treating process with a highly efficient induction heating process. This project is directly related to the steel and heat treating industries.

Significance of the Results: The optical microscopy, hardness and atom probe field ion microscopy showed that the microstructural evolution during furnace tempering and induction tempering are indeed different. This is due to differences in the thermal cycles and associated kinetics of steel transformations. However, the final hardness of samples subjected to both heat treatments was similar. This suggests that we can replace the furnace tempering by induction tempering and save energy as long as the final property is met and there are no unexpected effects due to differences in microstructures.

Objective: To compare the tempering response of 1050 steel subjected to gas furnace tempering versus its response to rapid induction heating through use of optical microscopy, hardness measurements, and atom probe field ion microscopy.

Results: In the first part of the research, optical microscopy showed extensive macrostructural differences between induction-tempered and gas furnace-tempered steels. In the next step, the induction-tempered parameters, including temperature and time, were 
modified to attain similar hardness (Fig. 1). Optical microscopy analysis showed no differences in the microstructures of gas furnace-tempered and induction-tempered steels (Fig. 2). As a result, atom probe field ion microscopy was used to look at the carbon redistribution during tempering.

The results (Fig. 3) showed that even though the hardness may be similar (Fig.1), the microstructures are slightly different. Currently, Inductoheat is evaluating the response of such microstructures on other mechanical properties and also performing induction tempering at high temperatures. On establishing this relation, one can consider replacing gas furnace tempering with an improved energy-efficient process (rapid induction tempering).

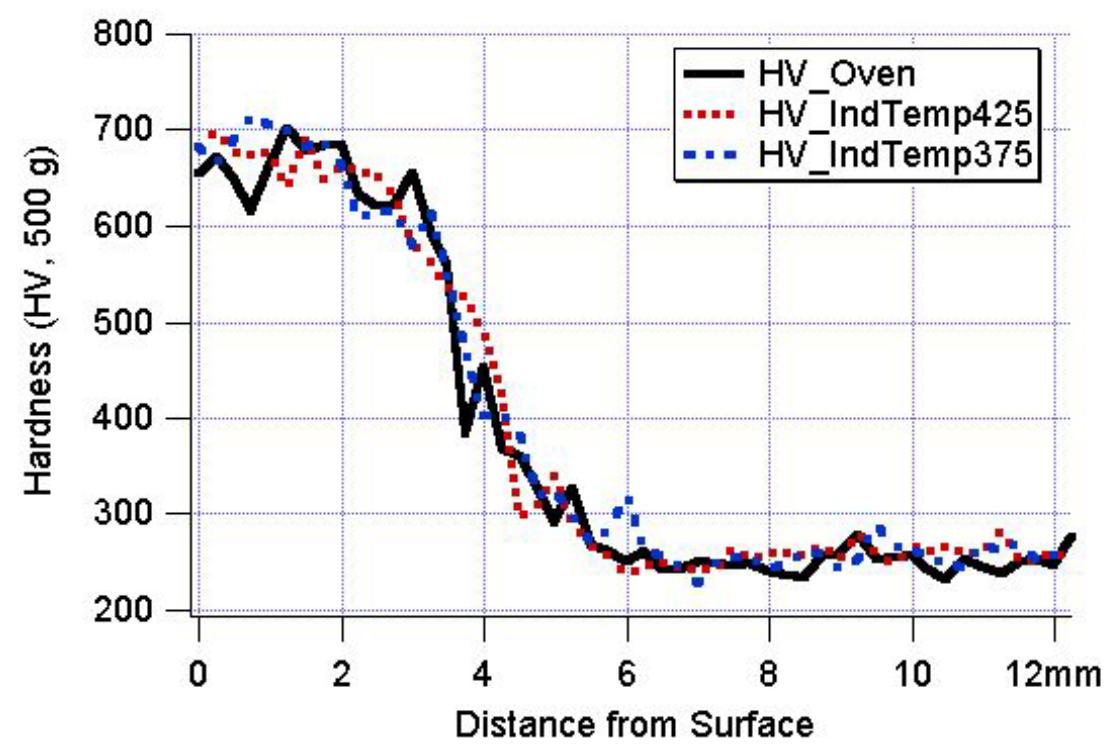

Fig. 1. Comparison of hardness from samples heat-treated at different conditions that includes oven tempering and induction tempering.
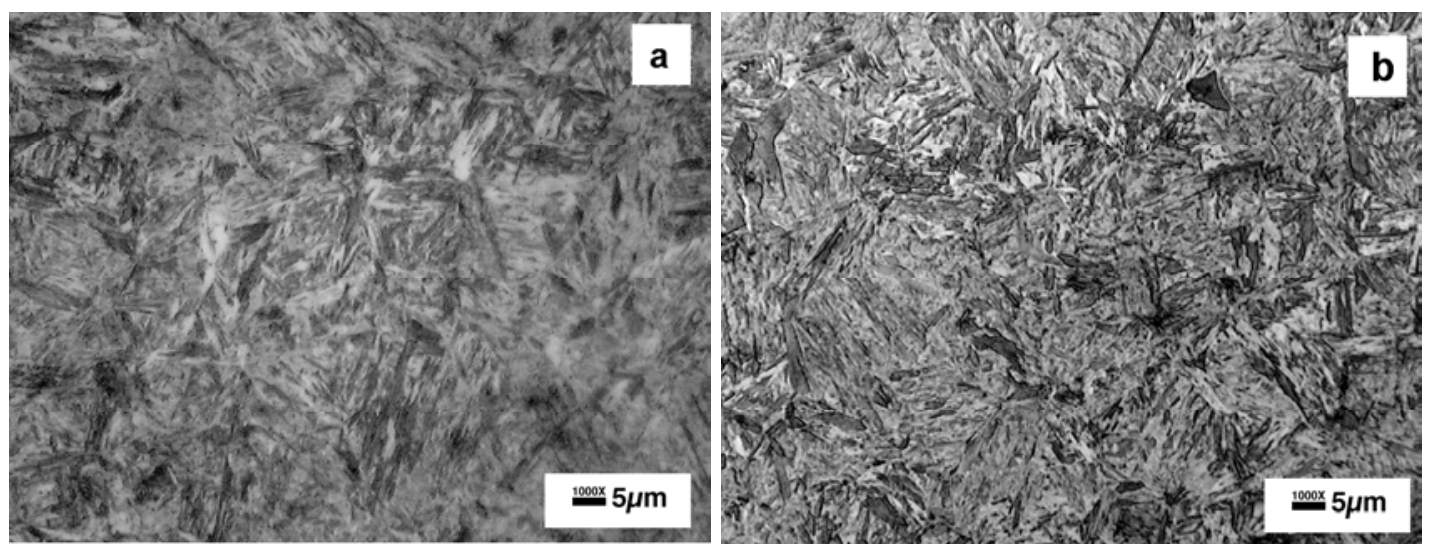

Fig. 2. Optical microscopy comparison of (a) oven-tempered and (b) inductiontempered steel microstructure shows no major differences. 

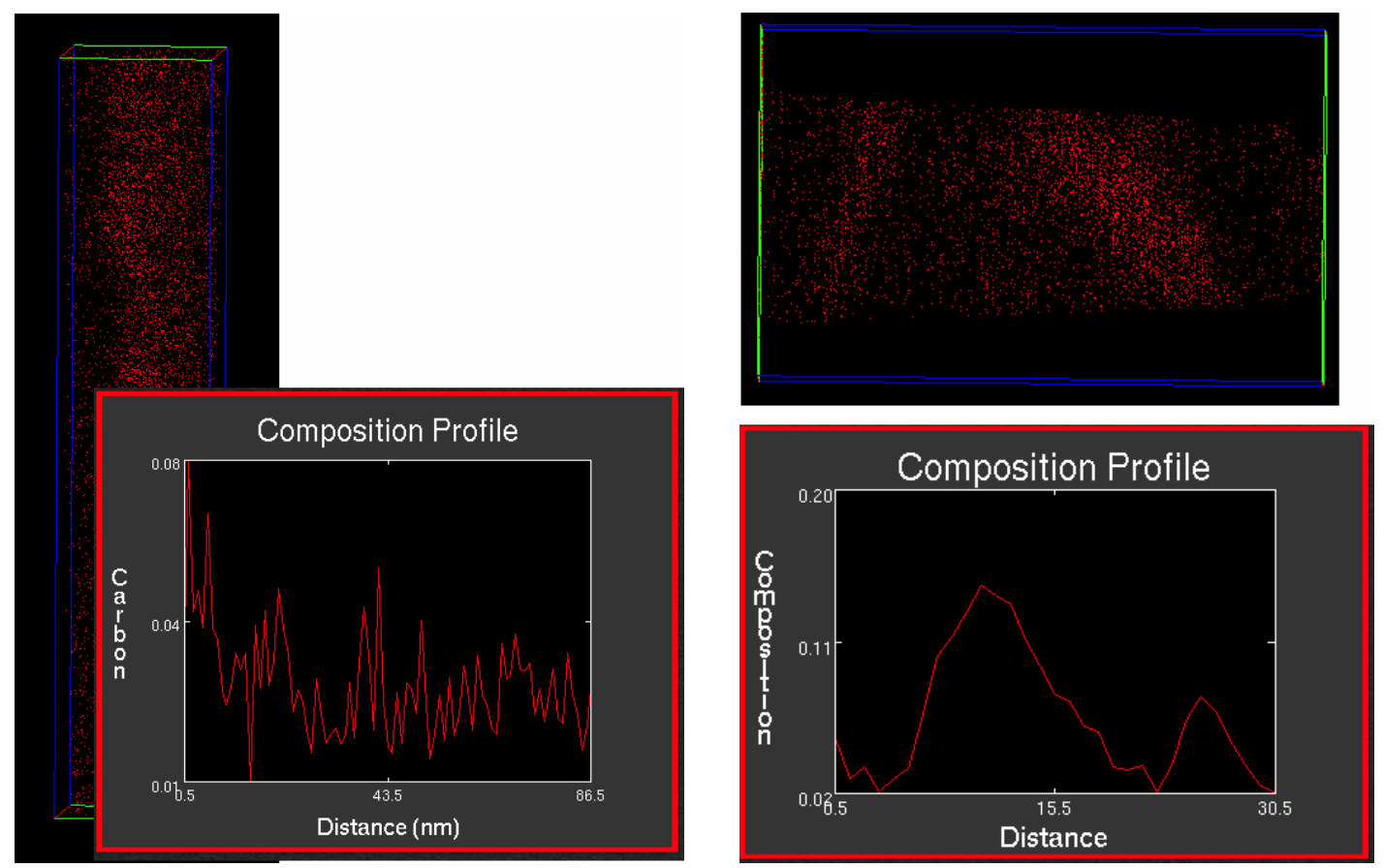

Fig. 3. Results from 3-D atom probe tomography results show the supersaturation of carbon in the ferrite matrix in the oven-tempered samples (on the left). The induction-tempered samples (on the right) show the presence of carbonenriched austenite carbide and also carbon depleted ferrite.

\section{Reports/Publications/Awards:}

S. S. Babu, M. K. Miller, and V. K. Sikka, "Comparison of Tempering Response of Steels from Induction Heating versus Conventional Heating," MPLUS report, 2003. 
MPLUS No.: MC-02-013

Title: Stress-Rupture Testing of 9Cr Steel Weldment

User Organization: ITW - Hobart Brothers Company Troy, $\mathrm{OH} 45373$

User Contact: Fuhu Chen, 937-332-5233

chenfuh@hobartbrothers.com

ORNL R\&D Staff: $\quad$ Mike Santella, 865-574-4805

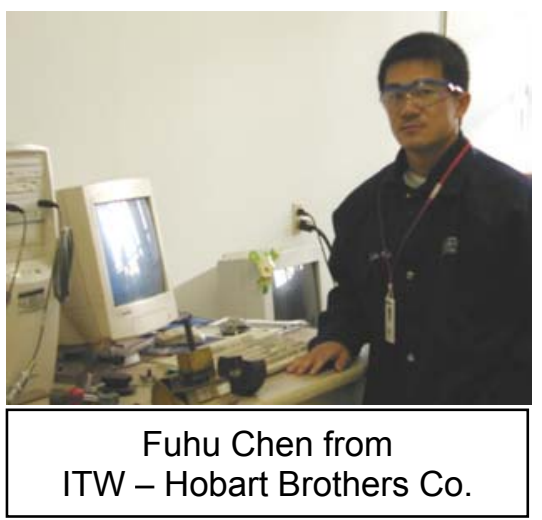
santellaml@ornl.gov

Relevance to OIT: Creep/stress rupture testing of $9 \mathrm{Cr}-1 \mathrm{Mo}$ steel weldments was done to establish their suitability for elevated temperature and compliance with design allowable requirements of ASME construction codes. The $9 \mathrm{Cr}-1 \mathrm{Mo}$ steels are highstrength alloys with considerable potential for improving the reliability and efficiency of heat recovery boilers used in pulp and paper operations and chemical reaction vessels and piping systems used by the chemical and petrochemical industries. This information will guide optimization of filler metal alloys and will provide a scientific basis for evaluating mechanical testing data.

Objective: Creep/stress rupture testing of $9 \mathrm{Cr}-1 \mathrm{Mo}$ steel weldments was done to establish their suitability for elevated temperature and compliance with design allowable requirements of ASME construction codes. This information will guide further optimization of filler metal alloys and will provide a scientific basis for evaluating mechanical testing data.

Results: A welded plate was supplied for testing. The weld metal used was a fluxcored wire that was deposited using the flux-cored arc welding (FCAW) process. Traditionally, 9Cr-1Mo welding wire is made as solid wire for welding applications and is not produced as flux-cored wires for welding. The flux-cored welding wire is a new product for ITW-Hobart. The motivation for using flux-cored wires is to increase productivity and to provide versatility in the selection of welding processes for these alloys. Development of FCAW processing for $9 \mathrm{Cr}-1$ Mo alloys will also facilitate wider use in applications for power generation such as heat recovery boilers used in the pulp and paper industry, and for chemical and petrochemical processing such as for reactor vessels.

Tensile testing was done to determine reference behavior for the weld deposit. The tensile test results are shown in Fig. 1. At each test temperature the tensile specimens broke in the base metal. Selected conditions were also used to determine reference stress-rupture behavior. The results for the test done at $1200^{\circ} \mathrm{F}$ under a stress of $15 \mathrm{ksi}$ are shown in Fig. 2; those done at $1100^{\circ} \mathrm{F}$ under a stress of $25 \mathrm{ksi}$ are shown in Fig. 3. In both cases, the specimens failed in the base metal. Photographs of the stressrupture specimens are shown in Figs. 4 and 5. The fracture behavior illustrated in Fig. 4 
is characteristic of Cr-Mo steels under lower stresses. Failure of welds generally occurs by fracture in the heat-affected zone of the weld (i.e., in the base metal adjacent to the weld deposit). The weld deposit is clearly visible in Fig. 4, and it has experienced little deformation relative to the weld heat-affected zone. The higher stress condition of the specimen shown in Fig. 5 produced a result similar to that of tensile testing. Failure in this case was also in the base metal.

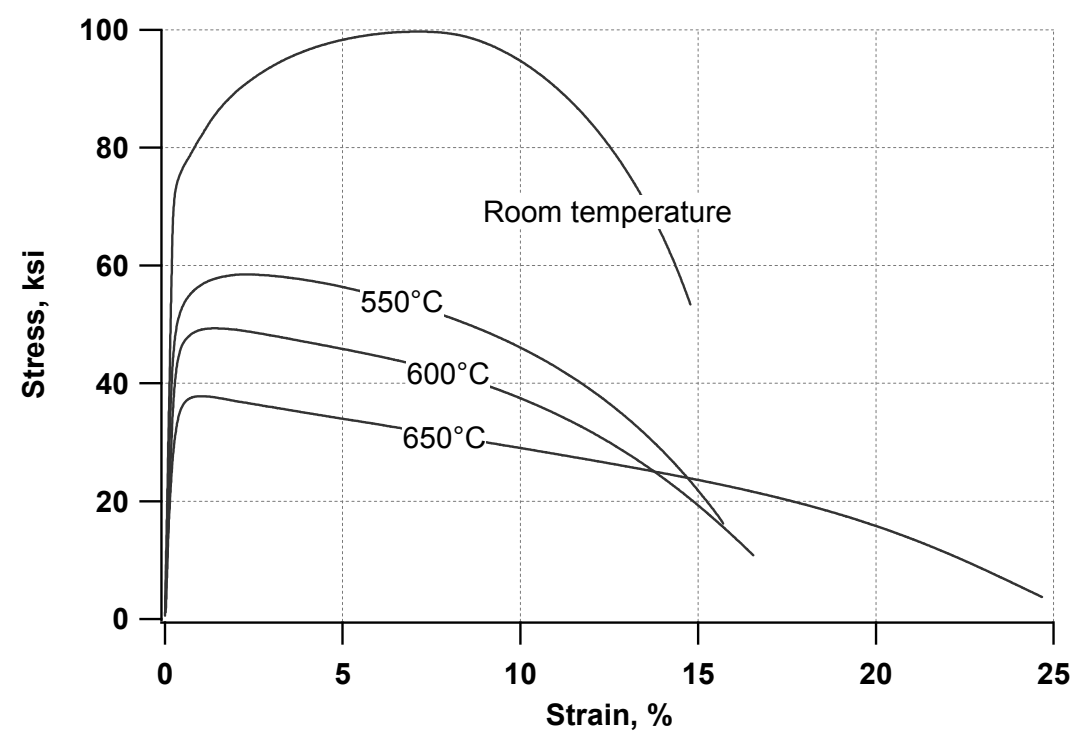

Fig. 1. Variation of tensile behavior with test temperature for 9Cr FCAW specimens.

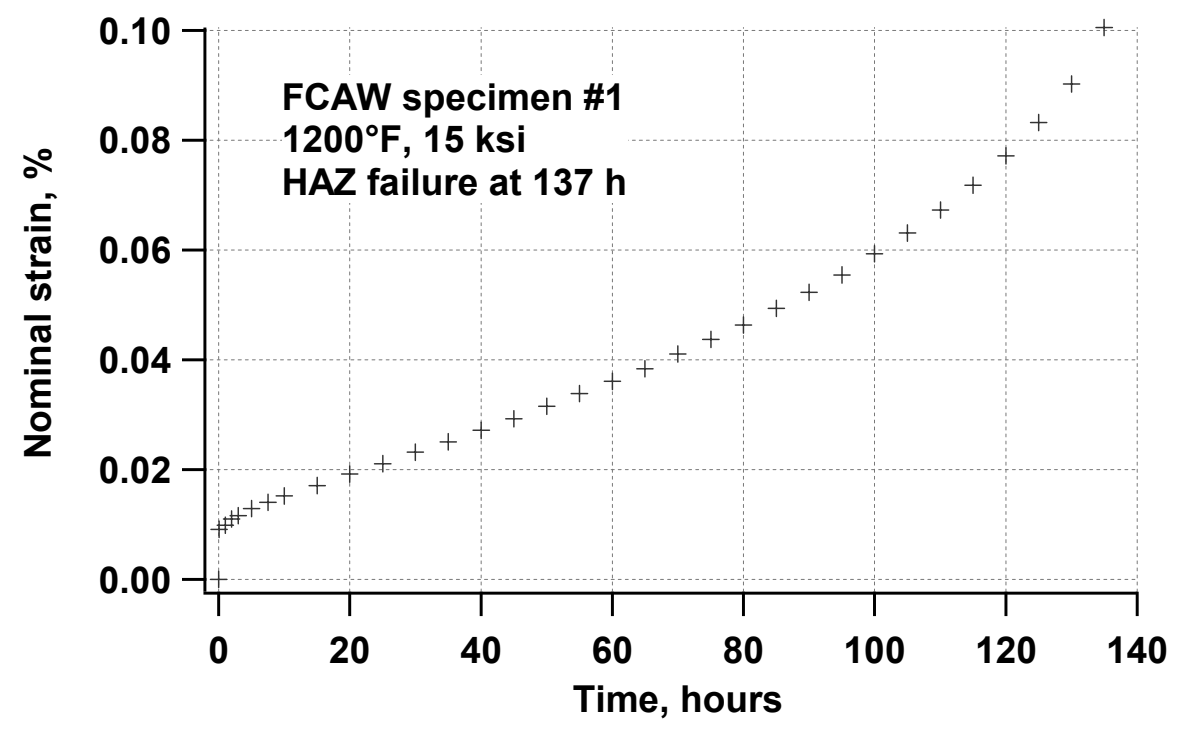

Fig. 2. Variation of creep strain with time for 9Cr FCAW specimen tested under condition of $15 \mathrm{ksi}$ at $1200^{\circ} \mathrm{F}$. 


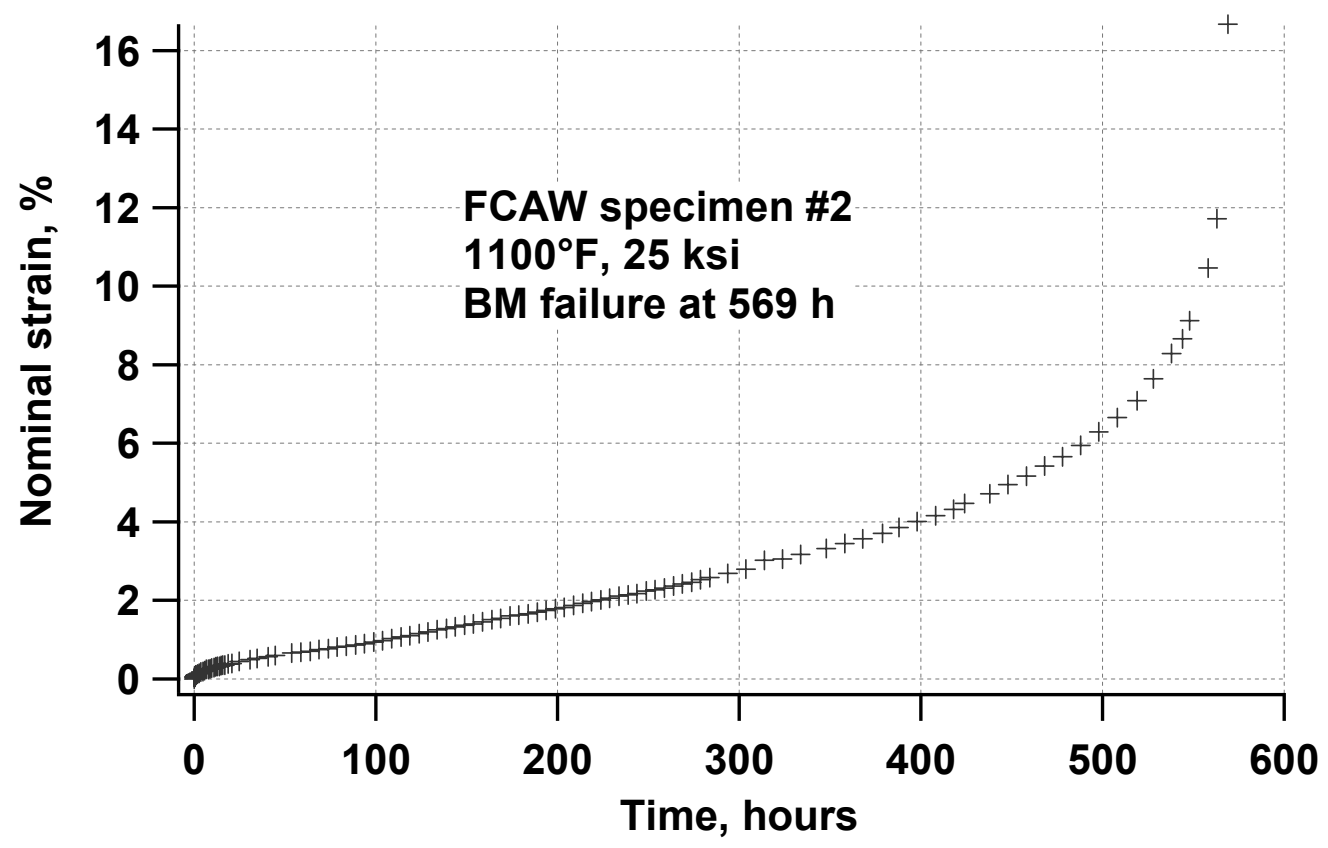

Fig. 3. Variation of creep strain with time for 9Cr FCAW specimen tested under condition of $25 \mathrm{ksi}$ at $1100 \mathrm{~F}$.

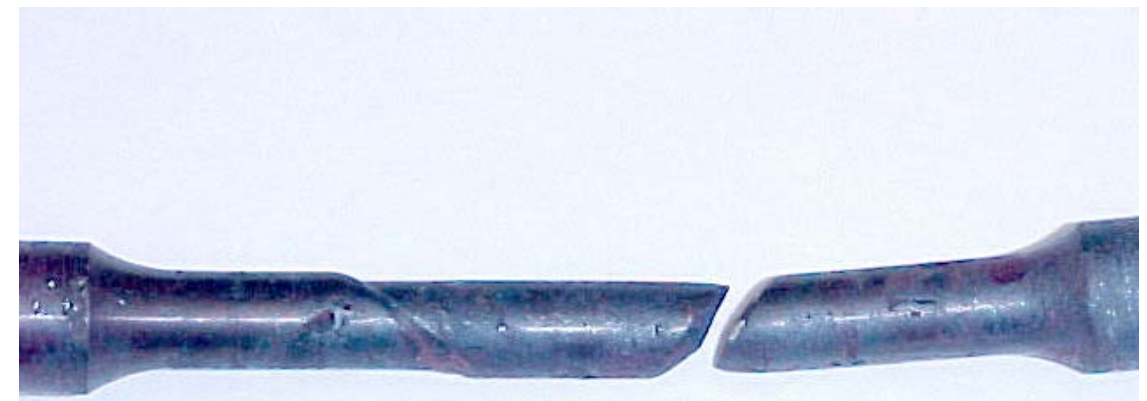

Temperature: $1200^{\circ} \mathrm{F}$

Stress: $15 \mathrm{ksi}$

Rupture Life: $137 \mathrm{~h}$

Fig. 4. Photograph of showing fracture of $9 \mathrm{Cr}$ stress rupture specimen tested under conditions of $15 \mathrm{ksi}$ at $1200^{\circ} \mathrm{F}$. 


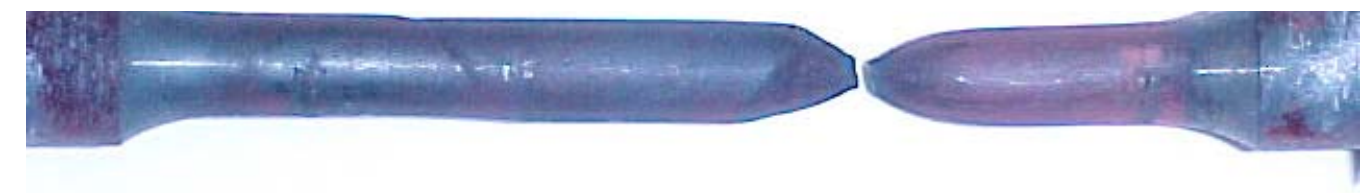

Temperature: $1100^{\circ} \mathrm{F}$

Stress: $25 \mathrm{ksi}$

Rupture Life: $569 \mathrm{~h}$

File: TN30006

Fig. 5. Photograph of showing fracture of $9 \mathrm{Cr}$ stress rupture specimen tested under conditions of $25 \mathrm{ksi}$ at $1100^{\circ} \mathrm{F}$.

These results clearly show that the flux-cored $9 \mathrm{Cr}$-1Mo welding wire is capable of producing weld joints with strength characteristics similar to those of welds made by more traditional welding processes.

\section{Reports/Publications/Awards:}

Mike Santella and Fuhu Chen, "Stress-Rupture Testing of $9 \mathrm{Cr}$ Steel Weldment," MPLUS report, 2003. 
MPLUS No.: MC-02-014

Title: Silicon Powder Melt Process and Equipment Development Project

User Organization: Matrix Solar Technologies, Inc. Albuquerque, NM 87121

User Contact: $\quad$ G. Stevens, 205-222-7419 gstevens@atsautomation.com

ORNL R\&D Staff: G. Mackiewicz-Ludtka, 865-576-4652 ludtkagm@ornl.gov

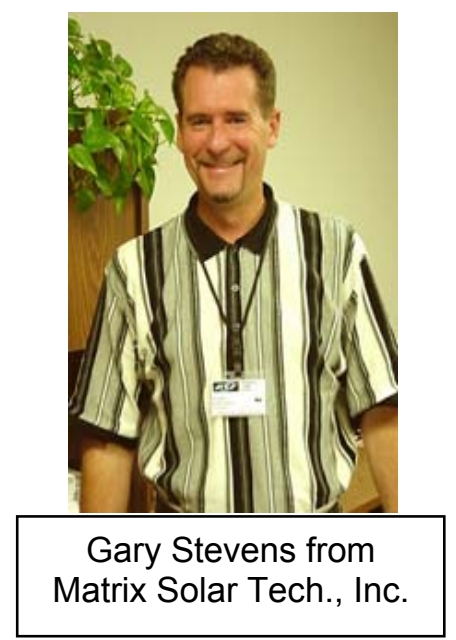

Relevance to OIT: The overall purpose of this project was to study the likelihood of replacing Globar furnace with more cost and energy efficient Tungsten-Halogen Furnace which would result in lower processing costs for manufacture of energy storage devices. This project resulted in a successful prototype configuration which has provided the necessary information for the design of a fully automated manufacturing system which is now in progress. This project fits within the Cross-cut technologies area by providing more energy efficiency and an alternate energy source for energy storage manufacturing industries. The generation of more efficient solar power ultimately could be used to reduce costs for other materials processing industries.

Objective: The goal of the project was to evaluate the effect of different substrates on preparing silicon powders for use in energy-efficient power panels. The first task planned in the original proposal was to melt silicon powders on various hot/cold substrates with the Vortek arc lamp. This project focused on the use of thermal management to prevent silicon attachment to the substrate but also explored the use of thin coatings to inhibit thermal losses into the substrates.

Results: Water-Cooled Substrates. Coarse and fine powders were readily melted on both aluminum and copper plates, with or without coatings, with no evidence of problems with overheating or silicon attachment. Attempts to collect calorimetric data for quantification of thermal losses into the substrates were plagued by difficulties in estimating water flow and pressure. Thin plates that would simulate a belt conveyor would buckle from the heat, and all indications were that considerable difficulty would be encountered with uniformly cooling such materials to the degree required to prevent buckling. Included in these tests was a drilled aluminum plate to test the concept of doctor-blading the powder into cups rather than stenciling onto a flat surface. The cup approach demonstrated the formation of granules with round bases (shaped by the cup) as opposed to the flat bases on granules formed from stenciling.

Mass-Cooled Substrates. A 1-in.-thick copper block was used as a large thermal mass. Melt runs at the translation limit of $35 \mathrm{~mm} / \mathrm{s}$ and at power levels of $500 \mathrm{~W} / \mathrm{cm}^{2}$ readily melted all material except the bottom layer of particles, with only a $10^{\circ} \mathrm{C}$ rise in block 
temperature. Tests with continuous layers of submicron silicon dusts showed that approximately $0.1 \mathrm{~mm}$ of unmelted material would be left on the substrate. The presence of an unmelted layer of particles directly in contact with the substrate demonstrates that there is very little surface heating and fully explains the absence of any silicon attachments. This block also had some small cups drilled into the surface, which formed silicon granules that could be readily removed. Heat capacity calculations indicate that aluminum could easily be used in the place of copper.

Coatings. Slurries of silica flour and silicon flour were painted onto the plates and the copper block for many of the experimental runs. Temperature rise data for the copper block runs indicates that these thin coatings do not significantly inhibit the absorption of heat. As the tests without coatings did not show any silicon adhesion problems, the use of a coating is concluded to be of no benefit.

Conclusions: The data showed that it is possible to design a fused powder system that can function without the use of a protective silica layer. A prototype system based on this concept was subsequently constructed and tested, further verifying this conclusion. An automated factory-scale system is now in design to serve the 20-MW Spheral Solar ${ }^{\mathrm{TM}}$ factory. This system is expected to show significant improvements in yields and energy efficiency, compared to the original conveyor approach.

\section{Reports/Publications/Awards:}

Gary Stevens, Gail Mackiewicz-Ludtka, and Craig Blue, "Silicon Powder Melt Process and Equipment Development Project," MPLUS report, April 2003. 
MPLUS No.: MC-02-015

Title: Forming Porous Metal Filters

User Organization: Chand Metallurgical

Worchester, MA 01603-1252

User Contact: $\quad$ Ronald H. Chand, 508-791-9549

rchand@chandassociates.com

ORNL R\&D Staff: Claudia Walls, 865-574-3177 wallsca@ornl.gov

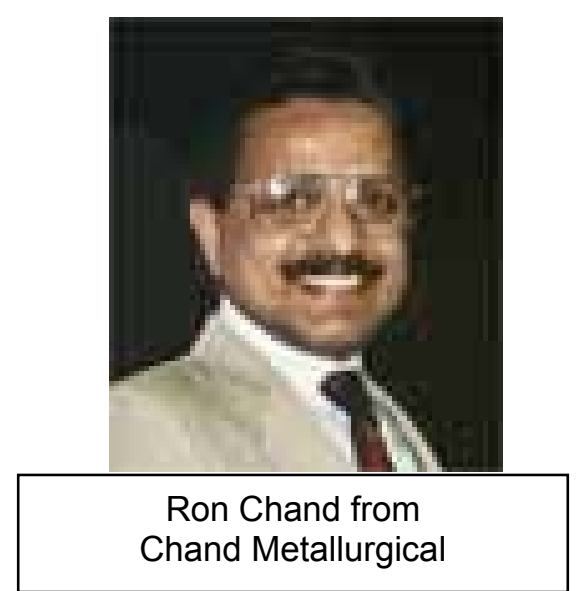

Relevance to OIT: The project focused on a chemical process designed to fabricate near-net-shape formed porous metal structures or porous metal structures with either layered or graded porosity. The process should allow for near-net-shape forming of porous metal forms that would be used for filtration and for fluid flow control in a variety of systems that require both the strength and chemical resistance of steel. This project is directly related to the chemical industry.

Objective: Three objectives of the MPLUS project were to: (1) select appropriate powders for gelcasting filters, chemistry, size, morphology, etc.; (2) develop gel chemistry appropriate to selected powders; and (3) develop binder burnout/sintering schedules to produce desired filter properties.

Results: In order to evaluate gelcasting as a method for fabricating complex $316 \mathrm{~L}$ stainless steel filters, four grits of stainless steel powder were gelcast into simple pucks. The $15 \mathrm{vol} \%$ methacrylamide, $\mathrm{N}$-vinylpyrrolidone, methylenebisacrylamide gelcasting monomer system was chosen for this work because of the high density of the powder and the need for strength sufficient for machining in the finished part. These pucks were sectioned and delivered to Chand Metallurgical for firing and evaluation as filters.

Among expected obstacles were the settling of the powder in the gelcasting premix and inhibition of gelation due to metals chemistry.

For trial 1 , we added thickening agents and NTC-80 microcrystalline cellulose to the premix, and for trial 2, a blend of hydroxyethyl cellulose 100 and 44,000 molecular weights.

Both of these additives greatly reduced the settling of the steel powders. Controlling gelation was very tricky in the small samples where dispersal of the initiation chemistry into the mix of monomers and steel powders was poor. The solution was very thick, and the coarser powders in particular were difficult to stir. When sufficient shear to mix was used, the solution would trap air, leaving voids behind in the gelled part. This was true in all size ranges but most evident in the coarser grits. 
Attempting to section the dried parts showed that the strength was not sufficient to allow machining. The pucks were so loosely bonded in the coarser sizes as to be friable when handled. This was due to the very high solids loading and the density of the metal powder.

After evaluation of this work, the four steel powders were recast into pucks with a 25 vol \% methacrylamide, N-vinylpyrrolidone, methylenebisacrylamide gelcasting monomer system and a blend of hydroxyethyl cellulose 100 and 44,000 molecular weights as the thickening agent. As Fig. 1 shows, the steel powders were successfully gelcast in this stronger formulation.

Discussion of the work with staff fluent in gelcasting and knowledgeable of filtration was held.

Conclusions: For the fabrication of complex-shaped filters, there is evidence of benefits to using gelcasting for this application. Specifically, gelcasting would benefit the production of metal filters where a large or complex filter is desired, since this process will fabricate the steel powder in the four selected grit sizes with relative ease. In fact, larger batch sizes (>150 $\mathrm{g}$ at a pour) would make processing easier in this case. If the end use is for simple shaped filters, gradients of particle sizes must be cast in stages to tailor the porosity from coarse to fine within one filter for gelcasting to benefit the process.
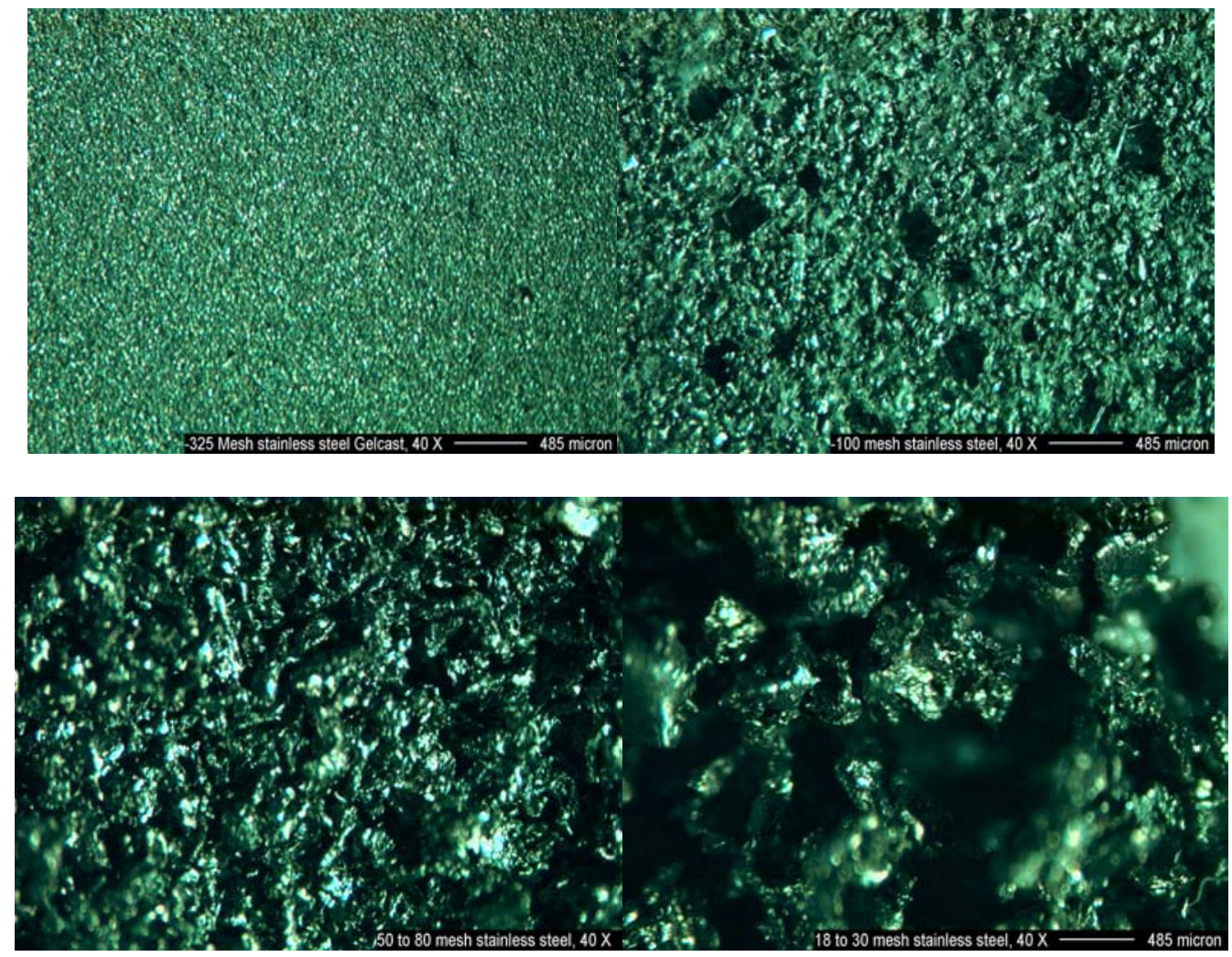

Fig. 1. Steel powder in gelcast polymer matrix. 


\section{Reports/Publications/Awards:}

C. Walls and R. H. Chand, "Forming Porous Metal Filters," MPLUS report, May 2003. 
MPLUS No.: MC-02-016

Title: Infrared Processing for Conditioning and Repair of Forming Dies

User Organization: Ford Motor Company Ford Research Laboratory Dearborn, Ml 48124

User Contacts: Armando Joaquin, 313-845-9497 ajoaquin@ford.com

Allen D. Roche, 313-390-8889 aroche1@ford.com

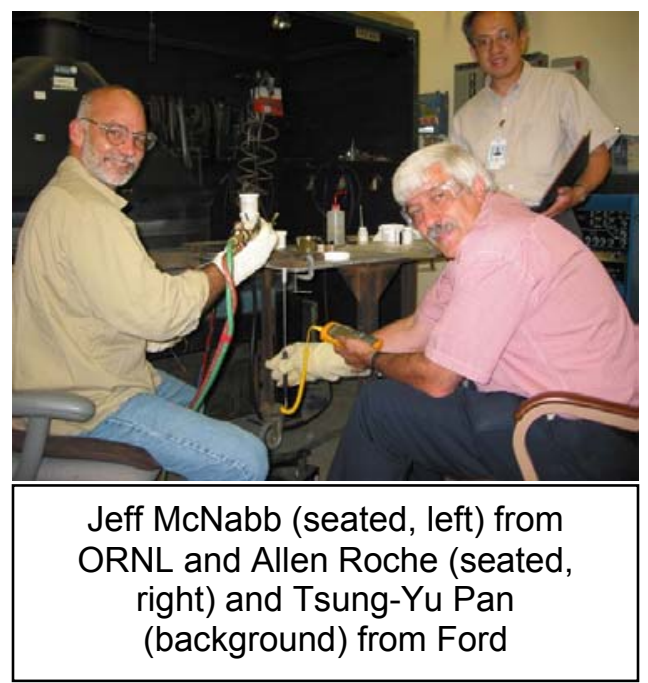

ORNL R\&D Staff: Mike Santella, 865-574-4805 santellaml@ornl.gov

Relevance to OIT: A promising new method of producing forming dies is to build them by thermal spraying steel onto ceramic molds. We want to use the plasma infrared system to fuse the forming surface of dies produced by this technique, and to explore the various options for making repairs to the thermally-sprayed dies. The intention is to improve die life and surface quality of formed parts. Successful development of this technology could significantly reduce the time required to make forming and forging dies by traditional methods. This could lead to significant economic advantages for the U.S. forging industry

Objective: One method of producing forming dies is to build them by thermal spraying of steel onto ceramic molds. We wanted to use the plasma infrared (IR) system to fuse the forming surface of dies produced by this technique and also to explore the various options for making repairs to the thermally sprayed dies. The intention was to improve die life and the surface quality of formed parts.

Results: We conducted number of experiments to evaluate the ability of plasma infrared surface heating to fuse the forming die surfaces. These were somewhat successful, but we decided that it would be more productive in the remainder of the project to focus on die repair issues.

The thermally sprayed die material is basically a composite of high-carbon steel containing 20 to $30 \%$ iron oxides. This material is very hard and is abrasion-resistant, but it is brittle. We decided to attempt repairs to the die material by both welding and brazing. Both gas tungsten arc (GTA) welds and shielded metal arc (SMA) welds were attempted because of their ability to be used for shop repairs in the manufacturing environment. Both welding processes resulted in inferior welds. 
The brazing trials were made using torch heating because of its general availability and relative simplicity. A large number of braze filler metal/flux combinations $(\sim 24)$ were evaluated. The evaluation consisted of filling a groove approximately $3 \mathrm{~mm}$ deep $x$ $50 \mathrm{~mm}$ long with filler metal. Figure 1 shows a specimen from one set of trials. Appearance was the criterion used to judge acceptability. Based on these trials, it was determined that fluxes that are compatible with steels produce acceptable protection for brazing the die material. The braze filler metal that produced deposits with the best appearance was BAg-7, an alloy of Ag-22Cu-17Zn-5Sn, wt \%. This filler metal was then used to successfully produce torch-brazed butt joints of the die material, as shown in Fig. 2.

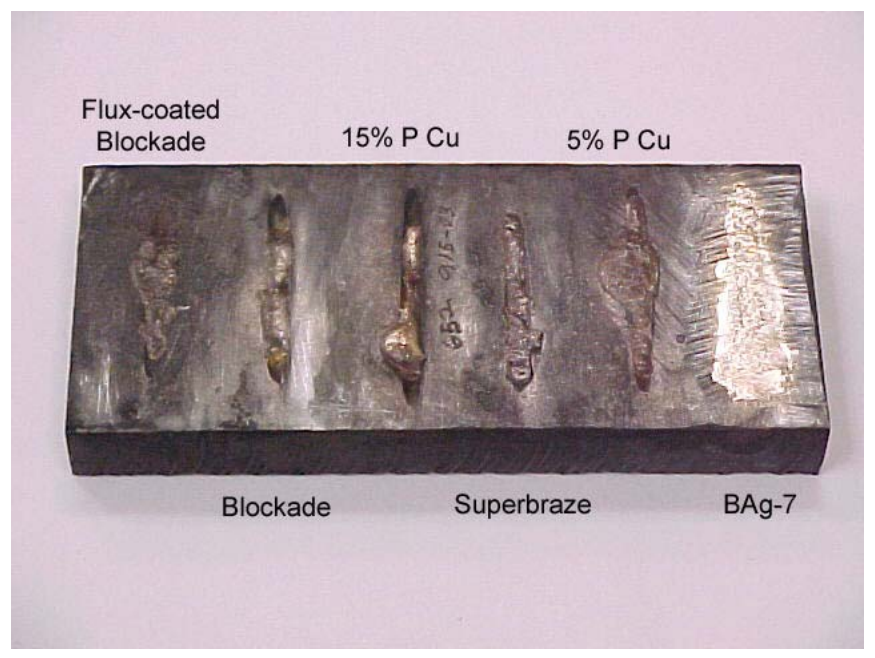

Fig. 1. Photograph of one of the die material coupons used for evaluating its compatibility with various braze filler metal/flux combinations on the die material.

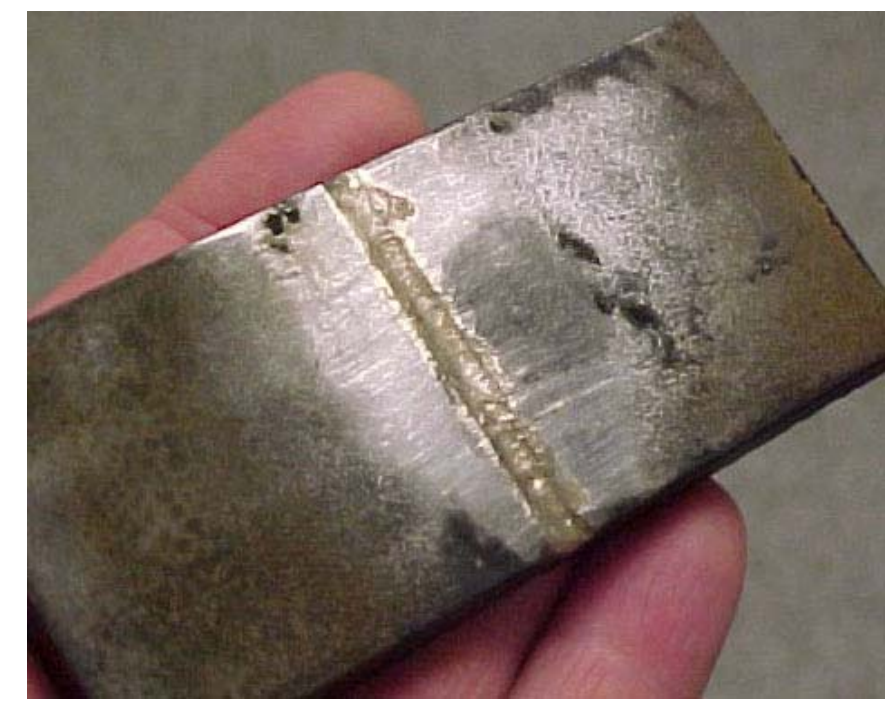

Fig. 2. Photograph showing a butt joint in $\sim 9$-mm-thick die material made by torchbrazing with BAg-7 filler metal. 
Metallographic examination was used to verify that adequate bonding without excessive porosity or flux entrapment was achieved (Fig. 3). Additional coupons are being made to assess joint strength.

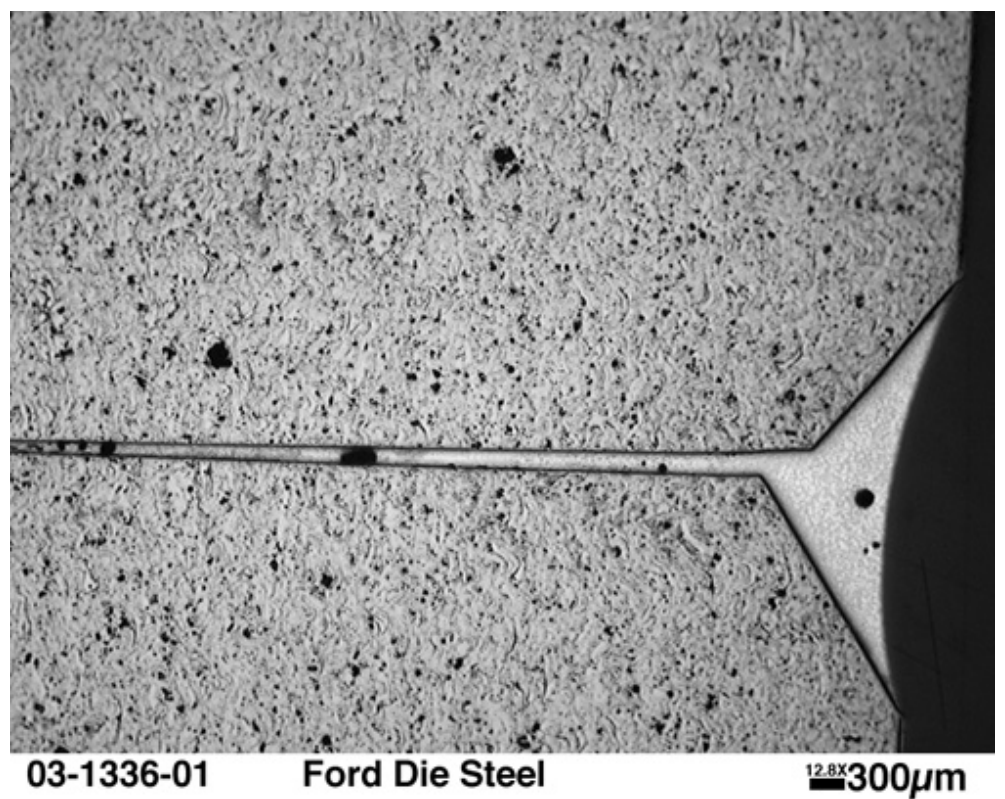

Fig. 3. Optical photomicrograph showing a cross-sectional view of a torch-brazed butt joint. The type and amount of porosity are characteristic of torch-brazed joints.

These experiments confirm that the thermally sprayed die material can be brazed with commercially available braze filler metals and fluxes. They also show that brazing represents a viable option for bonding and repairing the die material.

\section{Reports/Publications/Awards:}

M. L. Santella, J. McNabb, A. Joaquin, and A. Roche, "Infrared Processing for Conditioning and Repair of Forming Dies," MPLUS report, September 2003. 
MPLUS No.: MC-02-018

Title: Thermochemical Optimization of Float Glass Composition: Low-Alumina Glass Development

User Organization: Visteon Glass Systems Allen Park, MI 48101

User Contacts: Edward N. Boulos, 313-755-1539 eboulos@visteon.com

Pavel Hrma, 309-376-5092 pavel.hrma@pnl.gov

ORNL R\&D Staff: T. M. Besmann, 865-574-6852

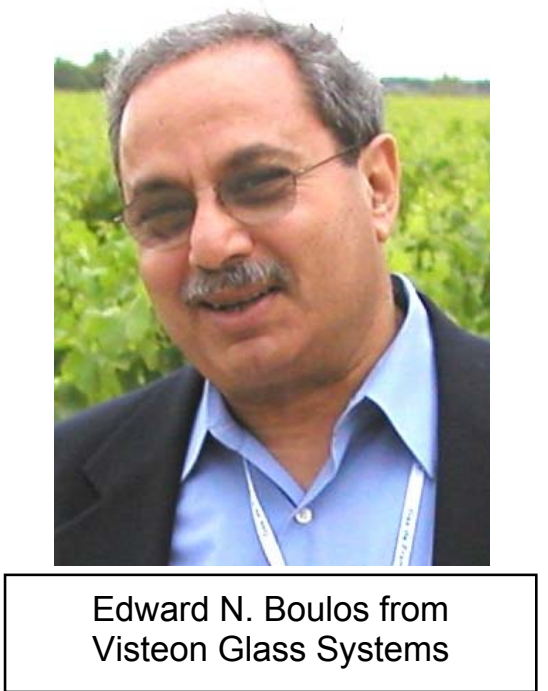
besmanntm@ornl.gov

Relevance to OIT: The objective of this MPLUS project was to reduce the needed amount of $\mathrm{Al}_{2} \mathrm{O}_{3}$ in float glass in order to reduce cost and energy usage. Visteon Glass Systems uses 0.5 wt $\% \mathrm{Al}_{2} \mathrm{O}_{3}$ for the purpose of keeping the primary phase in the $\mathrm{B}$-Wilostonite compositional region and thus avoid formation of tridymite. The formation of the crystalline tridymite phase causes silica devititrification (i.e., crystals forming in the glass creating flaws). The objective was to remove/optimize or minimize the $\mathrm{Al}_{2} \mathrm{O}_{3}$ to save money and energy by optimizing the $\mathrm{SiO}_{2} / \mathrm{MgO} / \mathrm{CaO}$ ratios in the glass. This project is directly related to the glass industry.

Objective: Visteon Corporation proposed to decrease the $\mathrm{Al}_{2} \mathrm{O}_{3}$ content in its float glass from the original 0.45 to 0.10 mass \%. However, the removal of alumina from the current composition must not negatively impact liquidus temperature and should not result in a glass that forms silica as the primary crystallization phase. The objective of the project was to measure the liquidus temperature of 17 float glasses with composition variations around two levels of $\mathrm{Al}_{2} \mathrm{O}_{3}(0.45$ and 0.10 mass \%), as listed in Table 1, and to determine the primary crystallization phase for each glass.

Results: Figures 1 to 4 show examples of crystalline phases formed on the glasses upon heat treatment. Table 2 shows the results of liquidus temperature measurements (in bold) and the temperatures at which secondary phases began to form. Table 3 lists the corresponding component coefficients based on the oxide mass fractions. These results are graphically displayed in Figures 5 and 6.

It was concluded that formulating glasses with a reduced level of $\mathrm{Al}_{2} \mathrm{O}_{3}$ will keep the primary phase in the wollastonite field and will slightly reduce liquidus temperature based on the adjustment of other key components. 
Table 1. Composition of test glass in mass fractions of oxides

\begin{tabular}{|l|llll|}
\hline Glass ID & $\mathrm{SiO}_{2}$ & $\mathrm{Na}_{2} \mathrm{O}$ & $\mathrm{CaO}$ & $\mathrm{MgO}$ \\
\hline A-BL & 0.7318 & 0.1363 & 0.0845 & 0.0347 \\
A-LNa & 0.7368 & $\underline{0.1313}$ & 0.0845 & 0.0347 \\
A-HNa & 0.7268 & $\underline{0.1413}$ & 0.0845 & 0.0347 \\
A-LCa & 0.7368 & 0.1363 & $\underline{0.0795}$ & 0.0347 \\
A-HCa & 0.7268 & 0.1363 & $\underline{0.0895}$ & 0.0347 \\
$\mathrm{~A}-\mathrm{LMg}$ & 0.7368 & 0.1363 & 0.0845 & $\underline{0.0297}$ \\
$\mathrm{~A}-\mathrm{HMg}$ & 0.7268 & 0.1363 & 0.0845 & $\underline{0.0397}$ \\
\hline $\mathrm{B}-\mathrm{BL}$ & 0.7353 & 0.1370 & 0.0845 & 0.0347 \\
$\mathrm{~B}-\mathrm{LNa}$ & 0.7403 & $\underline{0.1320}$ & 0.0845 & 0.0347 \\
$\mathrm{~B}-\mathrm{HNa}$ & 0.7303 & $\underline{0.1420}$ & 0.0845 & 0.0347 \\
$\mathrm{~B}-\mathrm{LCa}$ & 0.7403 & 0.1370 & $\underline{0.0795}$ & 0.0347 \\
$\mathrm{~B}-\mathrm{HCa}$ & 0.7303 & 0.1370 & $\underline{0.0895}$ & 0.0347 \\
$\mathrm{~B}-\mathrm{LMg}$ & 0.7403 & 0.1370 & 0.0845 & $\underline{0.0297}$ \\
$\mathrm{~B}-\mathrm{HMg}$ & 0.7303 & 0.1370 & 0.0845 & $\underline{0.0397}$ \\
\hline
\end{tabular}

\begin{tabular}{|c|llllll|}
\hline $\mathrm{Glass} \mathrm{ID}^{(\mathrm{b})}$ & $\mathrm{SiO}_{2}$ & $\mathrm{Na}_{2} \mathrm{O}$ & $\mathrm{K}_{2} \mathrm{O}$ & $\mathrm{CaO}$ & $\mathrm{MgO}$ & $\mathrm{Al}_{2} \mathrm{O}_{3}$ \\
\hline $\mathrm{C}-\mathrm{HAl}$ & 0.7334 & 0.1315 & 0.0008 & 0.0845 & 0.0347 & 0.0045 \\
C-MAl & 0.7253 & 0.1379 & 0.0004 & 0.0865 & 0.0367 & 0.0025 \\
C-LAl & 0.7231 & 0.1383 & 0.0000 & 0.0885 & 0.0387 & 0.0006 \\
\hline
\end{tabular}

(a) All $\mathrm{A}$ and $\mathrm{B}$ glasses contain 0.01 mass $\% \mathrm{TiO}_{2}$ and 0.71 mass $\% \mathrm{Fe}_{2} \mathrm{O}_{3}$; A glasses contain 0.45 mass $\% \mathrm{Al}_{2} \mathrm{O}_{3}$ and 0.10 mass $\% \mathrm{~K}_{2} \mathrm{O}$, B glasses contain 0.10 mass $\% \mathrm{Al}_{2} \mathrm{O}_{3}$ and 0.03 mass $\% \mathrm{~K}_{2} \mathrm{O}$.

(b) All $\mathrm{C}$ glasses contain 0.01 mass $\% \mathrm{TiO}_{2}, 0.15$ mass $\%$ $\mathrm{MnO}_{2}, 0.19$ mass $\% \mathrm{SO}_{3}$, and 0.71 mass $\% \mathrm{Fe}_{2} \mathrm{O}_{3}$.

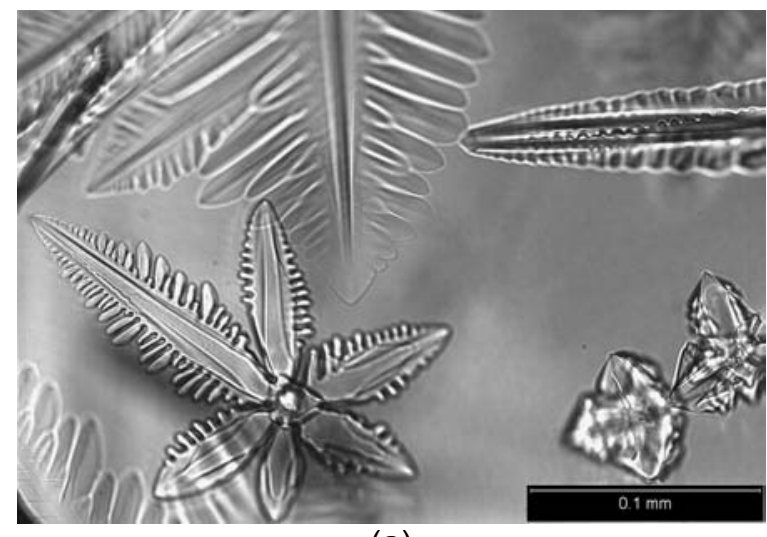

(a)

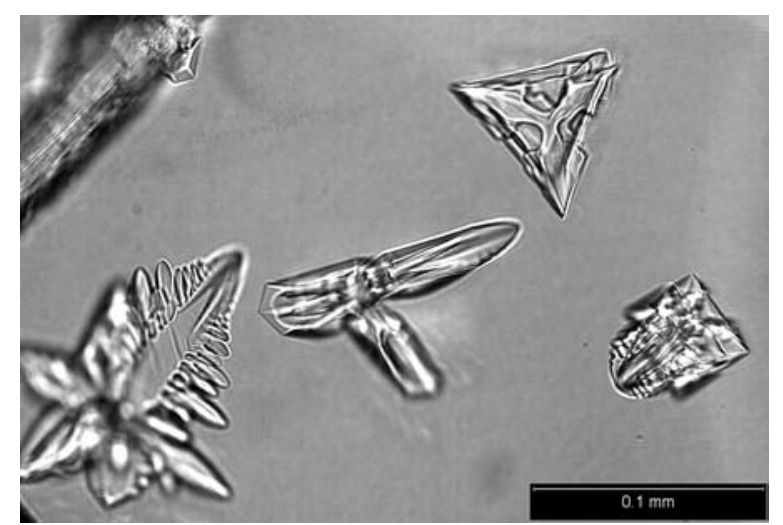

(b)

Fig. 1. Silica crystals (both tridymite and cristobalite) on the surface of $\mathrm{C}-\mathrm{Hal}$ (the perforated-plate method, top view) at (a) $991^{\circ} \mathrm{C}$ and (b) $997^{\circ} \mathrm{C}$. 


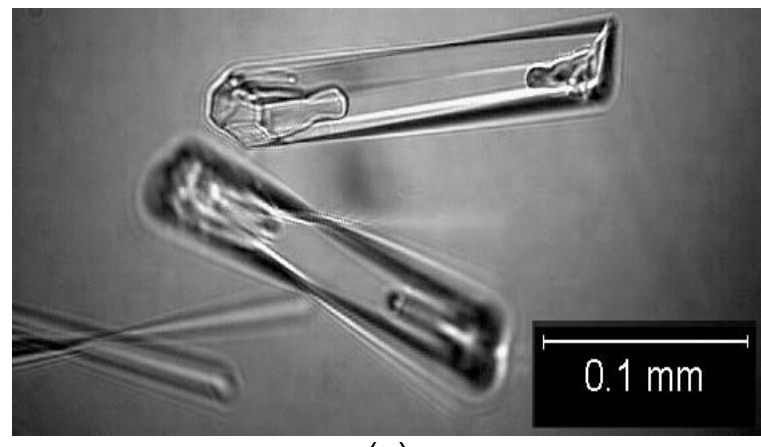

(a)

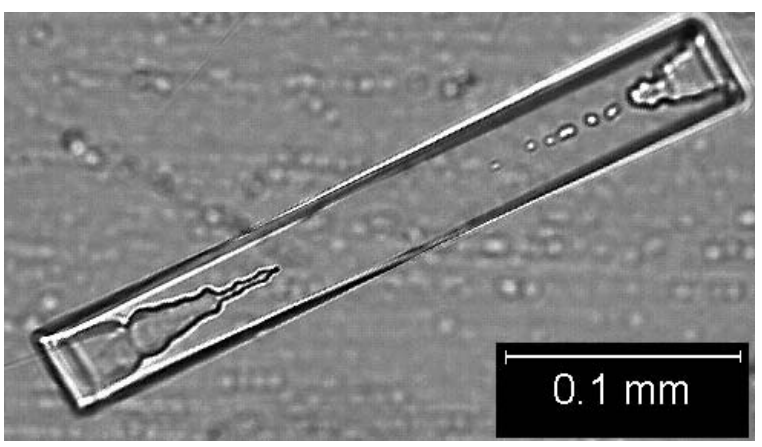

(b)

Fig. 2. Crystals of $\beta$-wollastonite in C-Mal glass at (a) $993^{\circ} \mathrm{C}$ and (b) $978^{\circ} \mathrm{C}$.

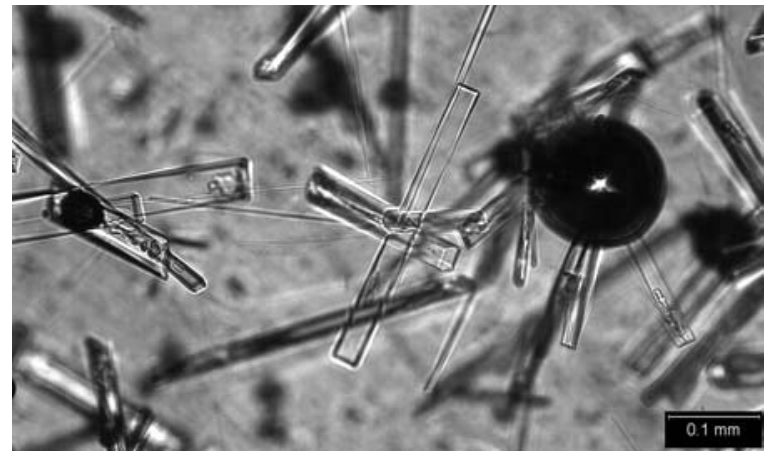

(a)

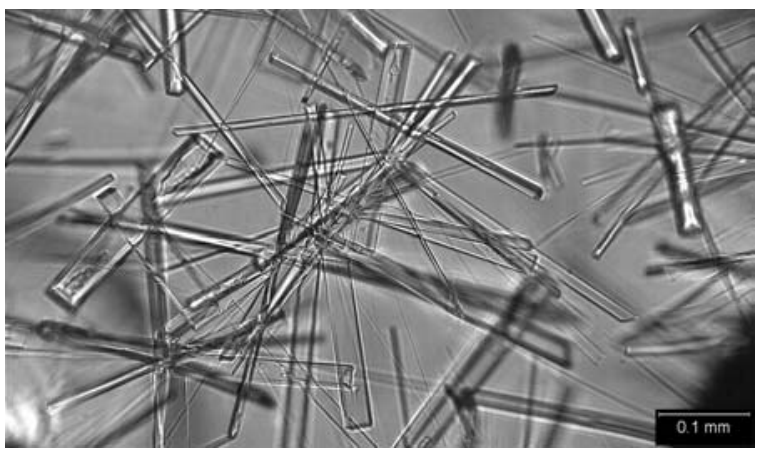

(b)

Fig. 3. Wollastonite in the bulk A-HCa glass at (a) $991^{\circ} \mathrm{C}$ and on the surface of C-Mal glass at (b) $980^{\circ} \mathrm{C}$ (the perforated-plate method).

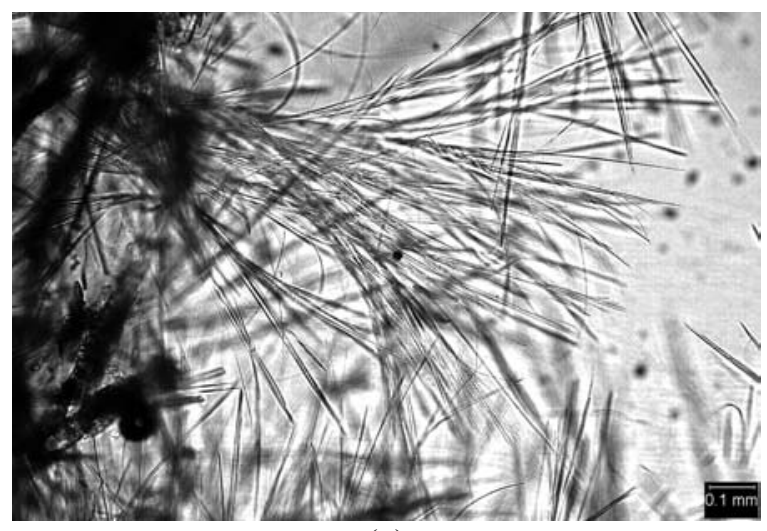

(a)

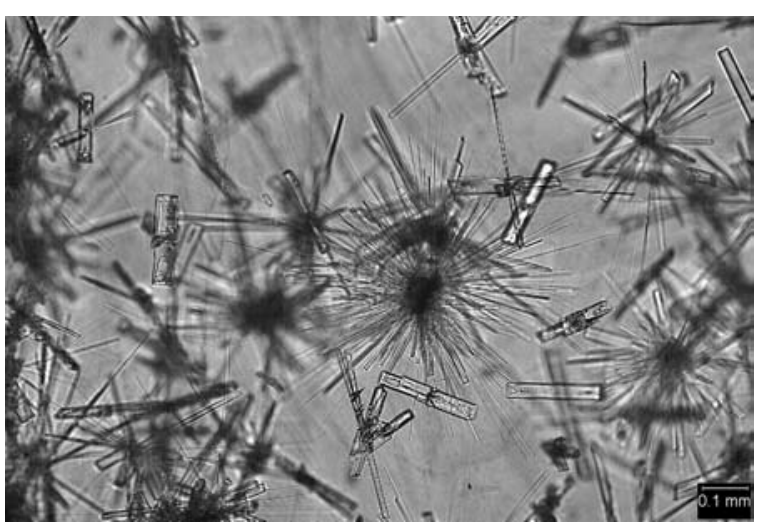

(b)

Fig. 4. Crystals of devitrite in A-BL glass at (a) $963^{\circ} \mathrm{C}$ and (b) wollastonite at $975^{\circ} \mathrm{C}$. 
Table 2. Maximum temperatures $\left({ }^{\circ} \mathrm{C}\right)$ at which individual crystalline phases occurred in float glasses ${ }^{(a)(b)}$

\begin{tabular}{|c|c|c|c|}
\hline Glass ID & $T_{S}$ & $T_{D}$ & $T_{W}$ \\
\hline$A-B L$ & & 967 & 995 \\
\hline A-LNa & 1011 & 952 & 998 \\
\hline A-HNa & & 967 & 989 \\
\hline A-LCa & 993 & 956 & 977 \\
\hline $\mathrm{A}-\mathrm{HCa}$ & & 974 & 1011 \\
\hline A-LMg & 997 & 963 & 982 \\
\hline $\mathrm{A}-\mathrm{HMg}$ & & 964 & 1001 \\
\hline B-BL & 997 & 965 & 982 \\
\hline $\mathrm{B}-\mathrm{LNa}^{(\mathrm{c})}$ & 1044 & 957 & 992 \\
\hline $\mathrm{B}-\mathrm{HNa}$ & & 971 & 980 \\
\hline B-LCa & 1044 & 968 & 971 \\
\hline $\mathrm{B}-\mathrm{HCa}$ & & 971 & 1001 \\
\hline B-LMg & 1026 & 970 & 979 \\
\hline B-HMg & & 965 & 995 \\
\hline $\mathrm{C}-\mathrm{HAl}{ }^{(\mathrm{d})}$ & $\begin{array}{c}\mathbf{1 0 1 7} \\
(1015) \\
{[1017]}\end{array}$ & 978 & 1009 \\
\hline C-MAI ${ }^{(d)}$ & & 964 & $\begin{array}{c}1000 \\
(998) \\
{[9981}\end{array}$ \\
\hline C-LAI ${ }^{(d)}$ & & 972 & $\begin{array}{c}1002 \\
(998) \\
{[1000]}\end{array}$ \\
\hline
\end{tabular}

(a) The minimum temperature at which glasses were evaluated was $936^{\circ} \mathrm{C}$.

${ }^{(b)}$ Bold numbers indicate $T_{L}$; subscripts $S, D$, and $W$ stand for silica, devitrite, and wollastonite.

(c) The maximum temperature at which glasses were evaluated was $1044^{\circ} \mathrm{C}$; repeated tests showed that this was also the $T_{L}$ value for the B-LNa glass.

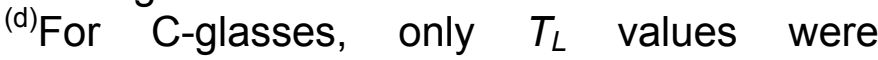
determined and checked using the perforated Pt plate method (in parentheses) and the uniform-temperature heat-treatment method [in square brackets]. 
Table 3. Component coefficients $\left(T_{i j}\right)$ and the response surface slopes $\left(S_{i j}\right)$ for the maximum temperatures at which silica and wollastonite exist in float glasses at equilibrium (in $\left.{ }^{\circ} \mathrm{C}\right)^{(a)}$

\begin{tabular}{|c|c|c|c|c|c|c|}
\hline & $T_{i s}$ & $s_{i s}$ & $S_{i s}$ & $T_{i w}$ & $s_{i w}$ & $s_{i w}$ \\
\hline $\mathrm{SiO}_{2}$ & 3275 & 492 & 8785 & 797 & 33 & -729 \\
\hline $\mathrm{Al}_{2} \mathrm{O}_{3}$ & -7409 & 1919 & -8414 & 2944 & 305 & 1961 \\
\hline $\mathrm{CaO}$ & -4733 & 2124 & -6263 & 3974 & 200 & 3266 \\
\hline $\mathrm{MgO}$ & -3343 & 2124 & -4497 & 2534 & 200 & 1604 \\
\hline $\mathrm{Na}_{2} \mathrm{O}+\mathrm{K}_{2} \mathrm{O}$ & -6520 & 2124 & -8724 & -246 & 200 & -1429 \\
\hline $\begin{array}{l}R^{2} \\
R^{2} \mathrm{Adj} \\
s_{i}\end{array}$ & $\begin{array}{r}0.953 \\
0.860 \\
8.29\end{array}$ & & & $\begin{array}{r}0.978 \\
0.969 \\
2.01\end{array}$ & & \\
\hline
\end{tabular}
respectively) are valid for the experimental composition region shown in Table 3. Standard errors are denoted as $s_{i j}(j \equiv S, W)$ for components and $s_{j}$ for the estimated $T_{j}$ values.

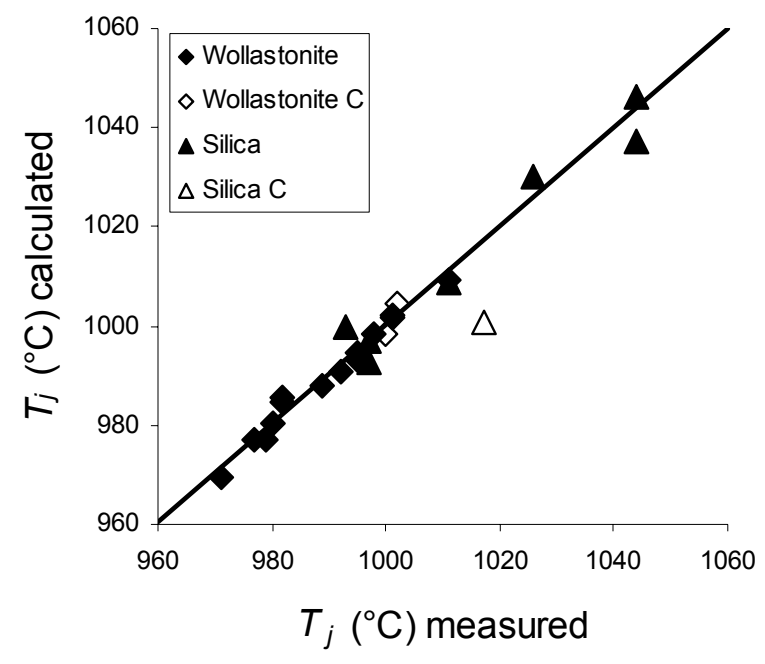

Fig. 5. Liquidus temperature, calculated versus measured. Hollow data points represent verification glasses $\mathrm{C}$.

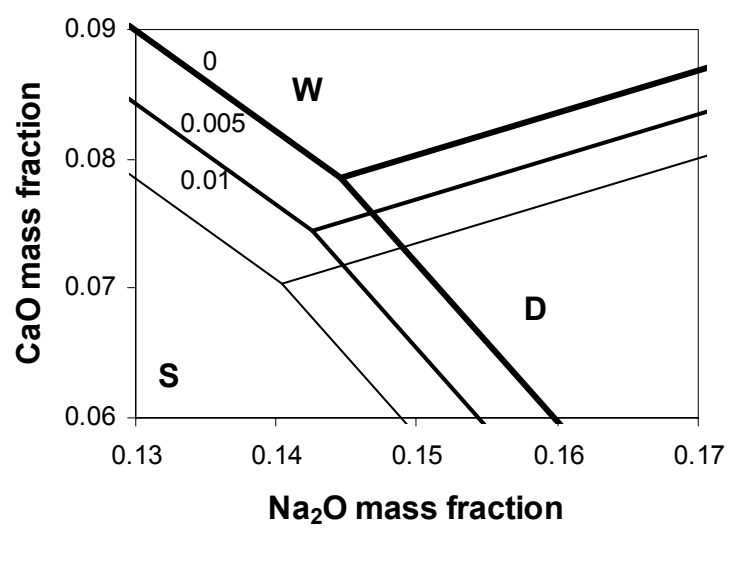

Fig. 6. Effect of mass fraction of $\mathrm{Al}_{2} \mathrm{O}_{3}$ (the parameter values on the boundaries between primary phase fields). 


\section{Reports/Publications/Awards:}

P. Hrma, D. E. Smith, J. Matyas, J. D. Yeager, J. V. Jones, and E. N. Boulos, "Effect of Float Glass Composition on Liquidus Temperature and Devitrification Behavior," MPLUS report, 2003. 
MPLUS No.: MC-02-019

Title: The Effect of Austenitizing Temperature and Time on the Formation of Martensite in Steels

User Organization: The University of Tennessee Knoxville, TN 37996-2200

User Contact: Charlie R. Brooks, 865-974-5336 jbrooks7@utk.edu

ORNL R\&D Staff: Gerard M. Ludtka, 865-574-5098

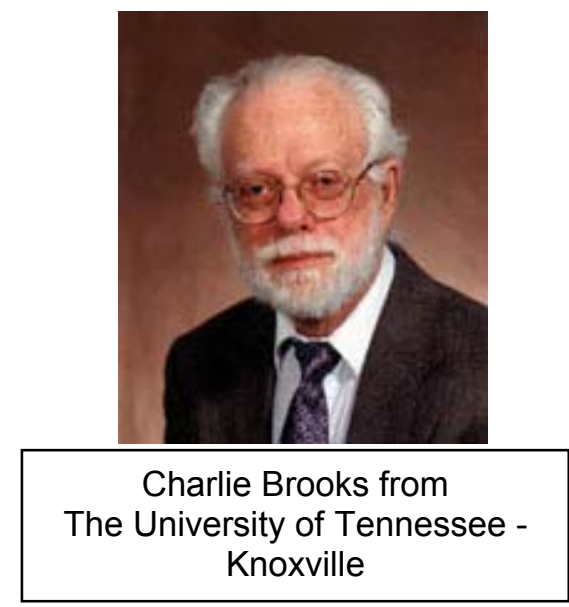
ludtkagm1@ornl.gov

Relevance to OIT: Induction hardening of steels is a widely used process to produce machine components with high fatigue life, wear resistance, and a favorable residual stress pattern. Some steels exhibit an unusually high surface hardness, called superhardness, which is extremely beneficial in terms of enabling component size reduction and longer life resulting in significant energy savings in the fabrication and use of these components. However, the process control parameters are not understood well enough from a microstructural standpoint to develop superhardness in a broader range of materials and applications. This MPLUS activity is directed at studying the origin of this superhardness phenomenon. By using the ORNL high speed quenching dilatometer to duplicate induction hardening cycles, the potential for superhardness was studied by relating the kinetics of the martensite formation from inhomogeneous austenite to the austenitizing temperatures and short austenitizing times associated with induction hardening process control parameters.

Objective: A common method of producing machine components (e.g., automobile axles) with high fatigue life is induction hardening of steels. The surface of the component is heated rapidly by a high-frequency induced current, then cooled rapidly by heat transfer to the cold interior of the part or by water quenching the surface. During this surface-hardening process, the surface forms hard martensite with an accompanying expansion. However, this phase-transformation-related expansion is resisted by the adjacent core and thus a high longitudinal compressive stress forms at the subsurface. This stress state improves the fatigue resistance of the component. Induction hardening of certain steels has produced an unusually high hardness (referred to as superhardness) if a relatively short austenitizing time is used. The development of superhardness may be related to several factors. These include the kinetics of the formation of martensite from inhomogeneous austenite that is a consequence of the short austenitizing times, local grain size refinement (by an order of magnitude), martensite autotempering (ultra fine carbide precipitation), and/or a residual stress impact on hardness. Through this MPLUS project, we examined the first of these parameters as the potential origin of this phenomenon. This was accomplished using a high-speed quenching dilatometer to simulate the induction heating process followed by a rapid helium gas quench. 
Results: For this investigation, the AISI 4140 alloy steel was chosen since it represents high-production volume steel that is induction hardened in industrial practice. The nominal composition (wt \%) for this steel is Fe-0.4C-0.85Mn-0.2Si-1.1 Cr, 0.2Mo-0.3Cu. The initial as-received microstructure is shown in Fig. 1 and consists of proeutectoid ferrite and pearlite characteristics of an annealed bar product. The experimental plan involved rapidly heating the cylindrical dilatometer samples ( $3 \mathrm{~mm}$ diam by $8 \mathrm{~mm}$ long) to different austenitization temperatures, holding at these temperatures for different times representative of the induction hardening process, and then followed by rapid helium gas quenching to convert the high-temperature austenite phase to martensite. The temperature versus dilation strain and temperature versus time curves were recorded and examined to determine the influence of austenitization temperature and hold time on the martensite start temperature $\left(M_{S}\right)$ and completeness of the final transformation since these influence the properties in the final product. Typically, the specimens reached the austenitization temperatures in less than $10 \mathrm{~s}$.

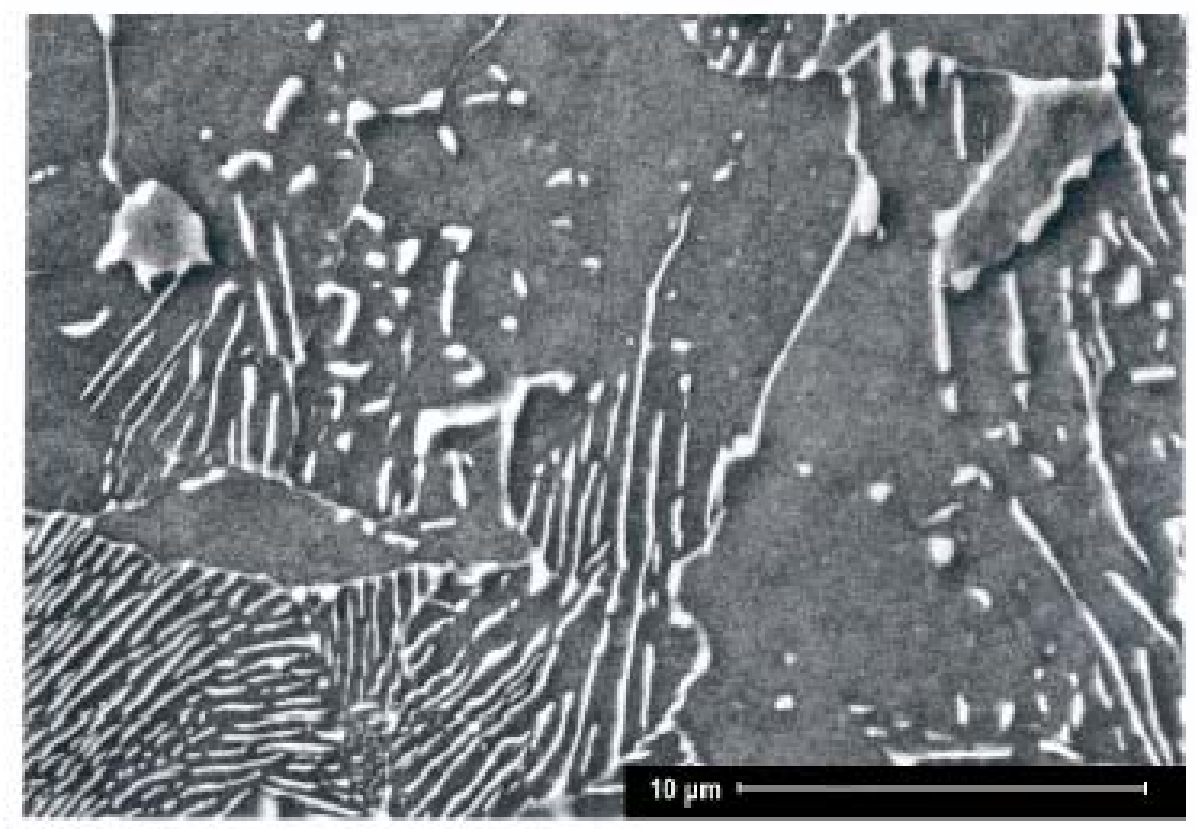

Fig. 1. Starting microstructure of the AISI 4140 alloy steel exhibiting primary (proeutectoid) ferrite and pearlite.

Some of the results of this investigation are shown in Figs. 2(a) and (b). The experimental conditions for these phase transformation dilatometer experiments involved austenitization temperatures of either 850 or $950^{\circ} \mathrm{C}$. 


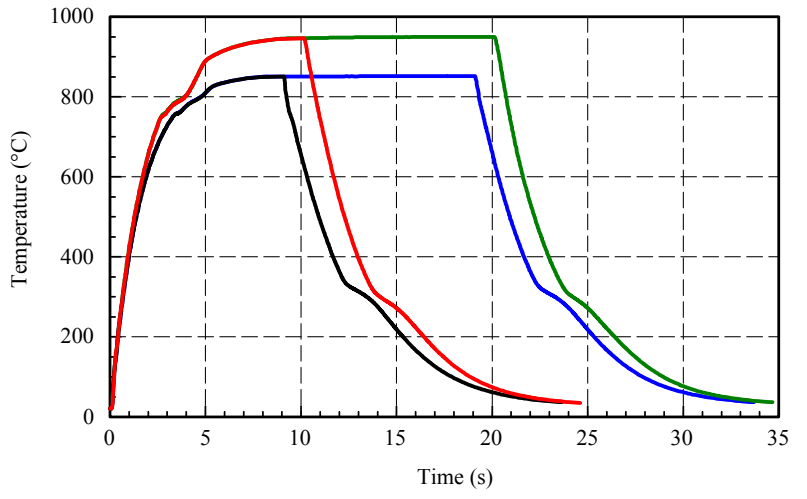

(a)

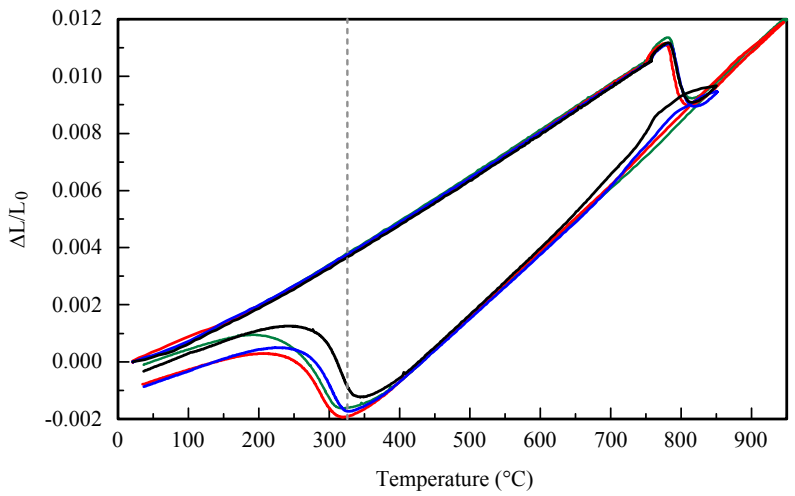

(b)

Fig. 2. Temperature versus time (a) and dilation strain versus temperature (b) plots showing the influence of austenitization temperature and hold time on the martensite transformation in AISI 4140 alloy steel under rapid cycle conditions typical of induction hardening. Dotted line in (b) is the $M_{S}$ calculated from the Andrews product formula.

These results clearly indicate that upon heating the austenite microstructure has completely formed for the longer hold times and for the higher austenitization temperature even with no isothermal hold. The higher $M_{S}$ temperature for the $850^{\circ} \mathrm{C}$ treatment with no hold at temperature indicates that complete dissolution of the prior ferrite and pearlite microstructure had not occurred since this would cause the austenite to be lower in carbon content, which would give it the higher $M_{\mathrm{s}}$. Therefore, from these results, it appears that for superhardness to occur (because higher hardness correlates with higher martensite carbon content), either a high austenitization temperature or some finite time at the lower austenitization temperature is required to completely dissolve the carbon during an induction-hardening cycle.

\section{Reports/Publications/Awards:}

Gerard M. Ludtka, "The Effect of Austenitizing Temperature and Time on the Formation of Martensite in Steels," MPLUS report, 2003. 
MPLUS No.: MC-02-020

Title: Physical, Mechanical, and Microstructural Characterization of Ultrasonic Welding of Aluminum Alloys

User Organization: Ford Research Laboratory Dearborn, Ml 48121

User Contact: R. Jahn, 313-323-8930 rjahn1@ford.com

ORNL R\&D Staff: $\quad$ E. A. Kenik, 865-574-5066 kenikea@ornl.gov

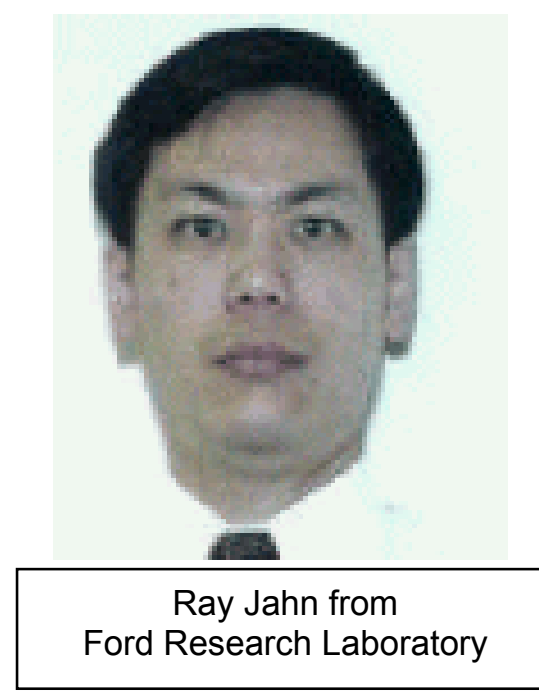

Relevance to OIT: Ultrasonics is an advanced technology being evaluated for improved materials processing including casting, hydrogen removal, and joining (welding). This project focused on ultrasonic joining (a non-fusion welding technique) of an aluminum alloy in order to understand its feasibility as an industrial process. Microstructural analysis of ultrasonically joined aluminum alloy specimens showed a continuous interface between the original components "spot-welded" and significant grain size reduction at that interface. The excellent metallurgical bonding of the weld was stronger than the adjacent matrix. This project is relevant to the aluminum and joining industries.

Objective: To investigate the microstructural evolution and defect structure of ultrasonic welds of aluminum alloys as a function of ultrasonic welding conditions (e.g., power, pressure, time). Electron backscatter diffraction (EBSD) and orientation imaging microscopy (OIM) in a scanning electron microscopy (SEM) were employed to characterize the microstructure and microtexture of the weld zone.

Results: In order to obtain good quality EBSD patterns from the welded materials, a specimen preparation technique had to be developed that produced a flat, essentially damage-free surface. The OIM maps revealed the grain and subgrain structure of both the base metal and the weld zone. Specific observations included the following:

1. A final, short (10- to 20-s) electropolish of a metallographically polished specimen produced the required flat and essentially damage-free surface.

2. The welded materials exhibited a complex microstructure near the weld zone. Figure 1(a) shows a secondary electron image of the weld interface. Slight surface relief highlights some grains in the base metal. Figure 1(b) shows an image quality (IQ) map at $0.5-\mu \mathrm{m}$ pixel spacing. Dark lines are grain or subgrain boundaries where local lattice rotations result in poor image quality. An inverse pole figure (IPF) of the same area is shown in Fig. 1(c), where color indicates the orientation of a particular direction (e.g., the surface normal) in the 001/101/111 standard triangle. Some of the 


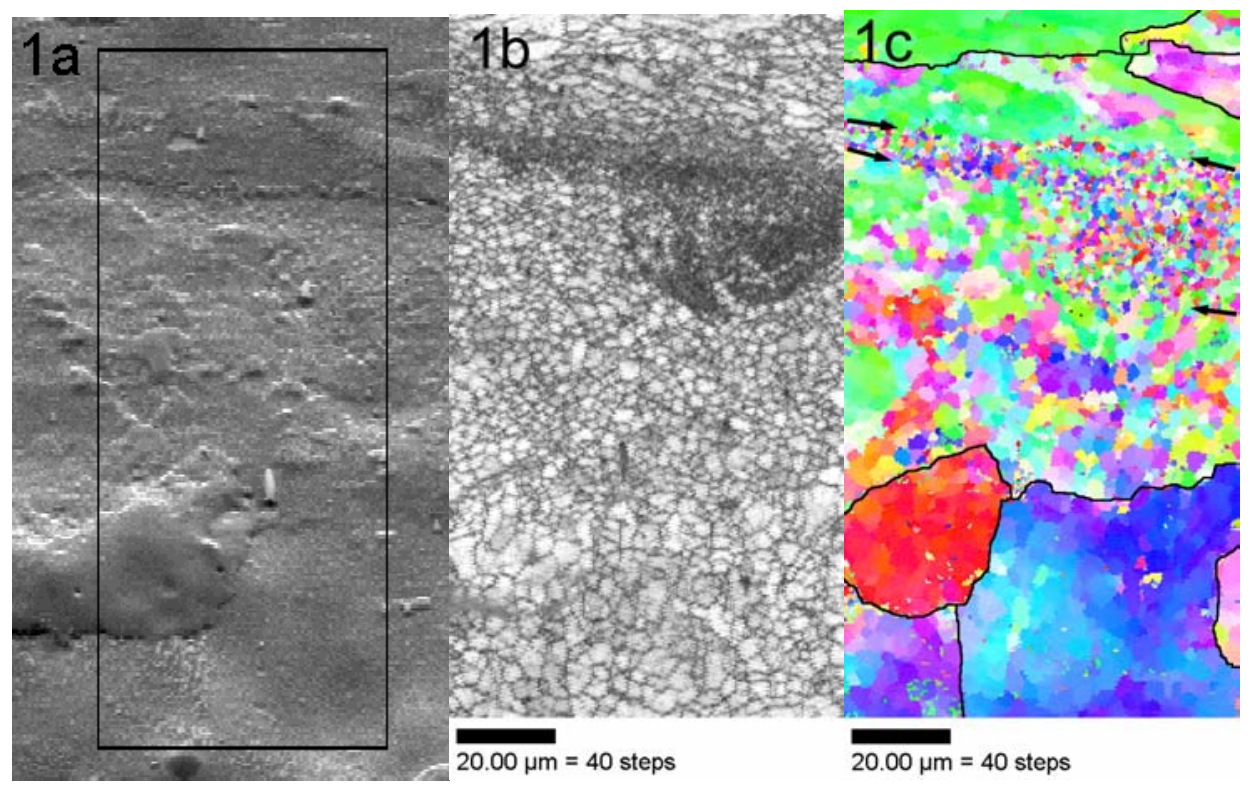

Fig. 1. (a) SEM image of weld zone. (b) Image quality map showing boundaries.

(c) Inverse pole figure showing the crystallographic orientation of the local surface normal.

original coarse grain structure of the base metal is highlighted. Within each of these coarse grains, the dominant color indicates similar orientation. The local rotations are in general less than $10^{\circ}$ in such grains. Therefore, the lines in the IQ map of such grains are subgrain boundaries. Their presence indicates that some recovery process occurs in parallel with the deformation induced by the ultrasonic welding.

3. Near the weld zone (top), the grain size decreases as boundary misorientation increases. There is a band of fine-grained material (arrowed) with diameters down to $<1 \mu \mathrm{m}$ and an abrupt change in the grain size near the upper edge of the weld zone.

4. Figure 2(a) is higher-magnification IPF of the fine-grained region of a second weld taken at $0.2-\mu \mathrm{m}$ pixel spacing to better sample the fine-grained region. This weld had shorter exposure to ultrasonic energy than the weld in Fig. 1. However, the microstructures were similar, with subgrains in the base metal, fine grains in the weld zone, and an abrupt change in grain size near one edge of the weld zone. Submicron grains are observed throughout this region. Pole figures from such areas show the random orientation to these fine grains, indicating the nucleation of recrystallized grains in the highly deformed material of the weld zone. The nearambient temperature of the ultrasonic welding process limits the growth of these fine, new grains. 


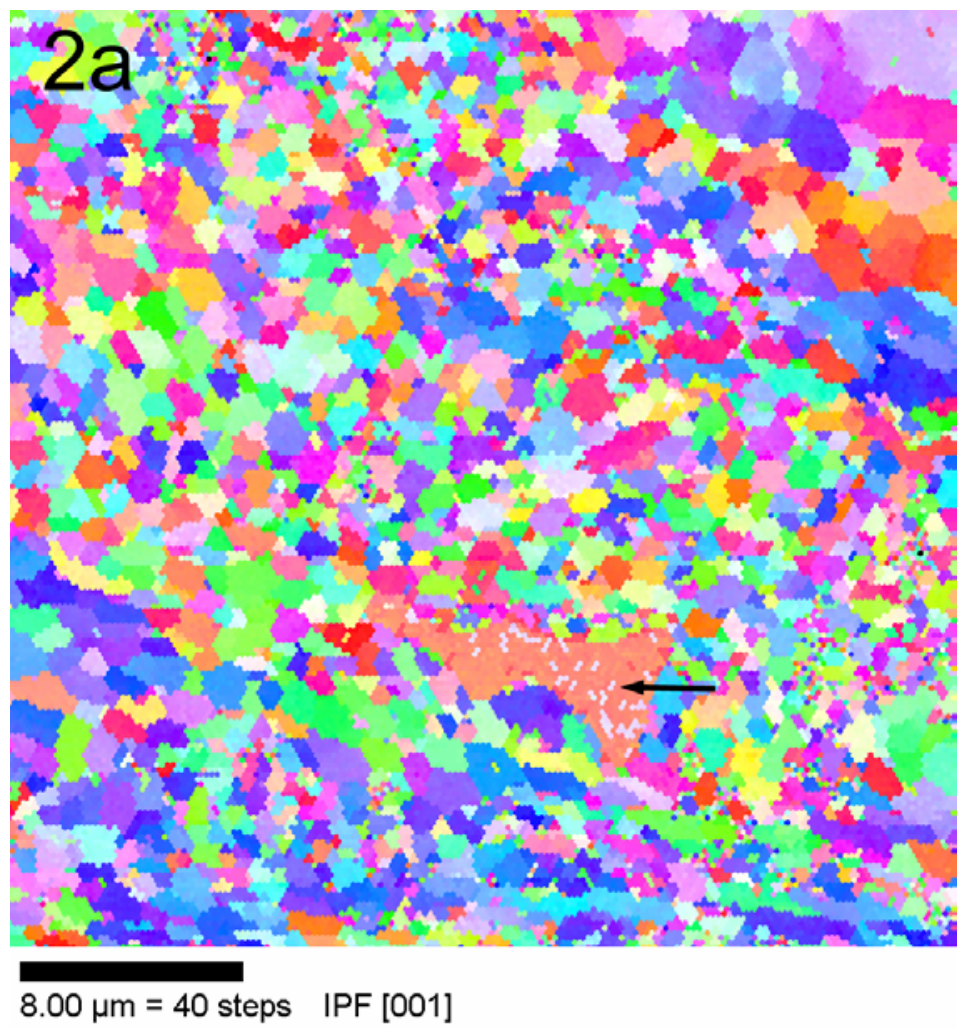

Fig. 2. Inverse pole figure showing the crystallographic orientation of the local surface normal. Arrowed region is a coarse Al-Fe intermetallic phase.

\section{Reports/Publications/Awards:}

E. A. Kenik and R. Jahn, "Microstructural Characterization of Ultrasonic Welding of Aluminum Alloys," MPLUS report, May 2003.

E. A. Kenik and R. Jahn, "Microstructure of Ultrasonic Welded Aluminum by Orientation Imaging Microscopy," Microscopy and Microanalysis, Cambridge University Press (in press), 2003. 
MPLUS No.: MC-02-021

Title: Heat Treatment Optimization for Steam Trap Seat of AISI $420^{\circ} \mathrm{F}$ Stainless Steel

User Organization: Spirax Sarco, Inc. Blythewood, SC 29016

User Contacts: Robert Jacenko, 803-714-2051 rjacenko@spirax.com

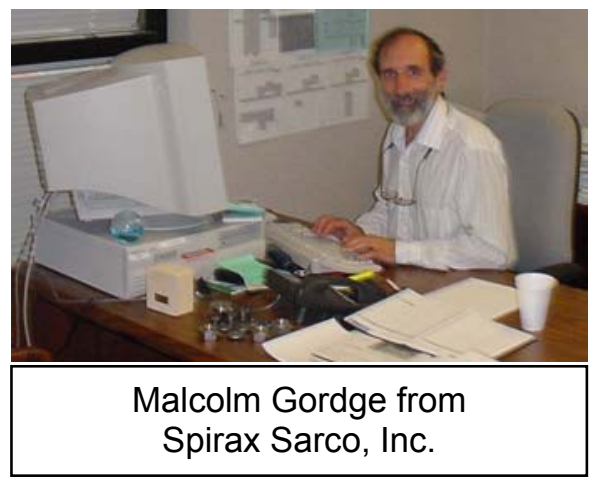

Malcolm P. Gordge, 803-714-2172 mgordge@spirax.com

ORNL R\&D Staff: Vinod K. Sikka, 865-574-5112 sikkavk@ornl.gov

Relevance to OIT: Heat-treatable stainless steels of 12 to $14 \% \mathrm{Cr}$ are used extensively in the chemical, petrochemical, and mining industries. These steels provide the best combination of hardness through heat treatment for wear- and corrosion resistance because of their chromium content. While heat-treating of these steels is simple, the high hardness achieved in the component such as steam traps can result in low toughness. The low toughness becomes an important concern in the threaded region where it can cause premature failures. The outcome of this MPLUS has recommended a selective heat treatment of threaded regions by the infrared-based heating system. Such selective heat treatments of the notch-sensitive areas of components from heat-treatable stainless steels can prevent unwanted failures with advantages of down time, energy savings, and reduced replacement of components. The project has direct relevance to steel, chemical, petrochemical, and mining industries.

Objective: The objective of this project was to identify heat treatment for steam traps fabricated from AISI 420F stainless steel that eliminates the thread failures.

Results: This project identified three possible causes for failures in steam traps fabricated from AISI 420F stainless steel of nominal compositions given in Table 1: (1) high notch sensitivity of the threaded region (where failures occurred) because of its high hardness (see Fig. 1), (2) further increase in notch sensitivity from possible generation of hydrogen in steam application, and (3) presence of MnS stringers, especially when it is machined at the thread route.

It was concluded from this research that reducing the notch sensitivity of the threaded region is the most acceptable option to eliminate thread failures. A systematic study was conducted to reduce the notch sensitivity of the threaded region. This was accomplished by selective heat treating of the threaded region by using the infraredbased heating system. Several traps were selectively heat treated (Table 2), and it was 
shown that the hardness of the threaded region could be lowered to approximately $R_{C}$ 34 while maintaining a hardness of approximately $R_{C} 45$ in the seat area. Such a drop in hardness will reduce the notch sensitivity, reduce hydrogen embrittlement, and reduce the crack growth in the thread root even when a MnS stringer ends in the root.

The recommended process of selective heat treating is simple, and its effectiveness was verified by Spirax on steam traps that were heat treated at ORNL.

Table 1. Nominal composition of type 420F stainless used in steam traps ${ }^{a}$

\begin{tabular}{|c|c|}
\hline Element & Weight Percent \\
\hline $\mathrm{C}$ & $0.3-0.4$ \\
\hline $\mathrm{Mn}$ & 1.25 \\
\hline $\mathrm{P}$ & 0.06 \\
\hline $\mathrm{S}$ & $0.15 \mathrm{~min}$ \\
\hline $\mathrm{Si}$ & $1.0 \mathrm{max}$ \\
\hline $\mathrm{Cr}$ & $12-14$ \\
\hline $\mathrm{Ni}$ & 0.5 optional \\
\hline $\mathrm{Cu}$ & 0.6 optional \\
\hline $\mathrm{Fe}$ & Balance \\
\hline
\end{tabular}

${ }^{a}$ Typical heat treatment used for steam traps: heating to $1400^{\circ} \mathrm{F}$ for $1 \mathrm{~h}$ followed by heating to $1750^{\circ} \mathrm{F}$ for $1 \mathrm{~h}$ and air cooling.

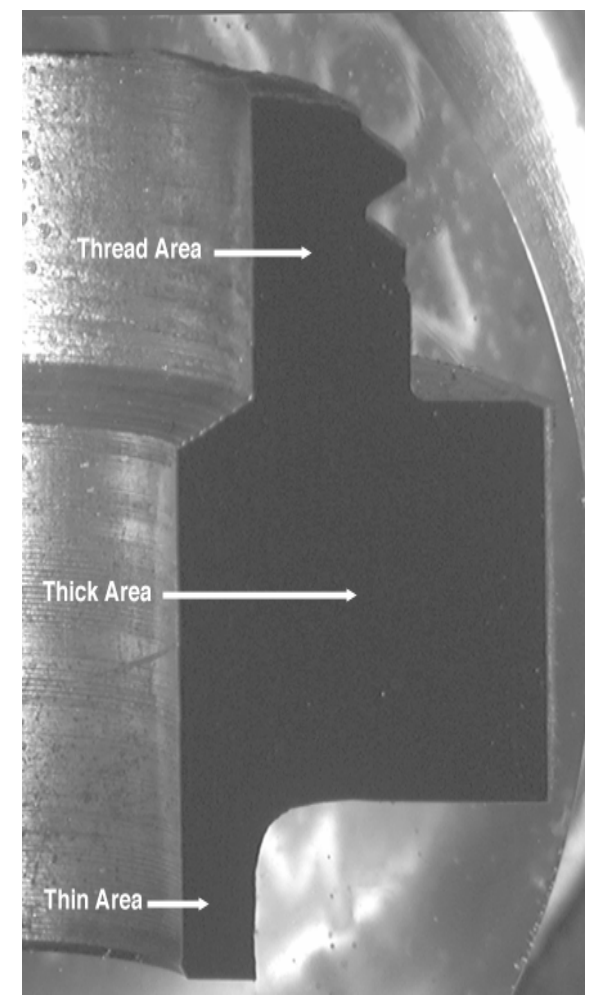

Fig. 1. Failed steam trap and its microhardness in various regions: thread area (536 HV), thick area (536 HV), and thin area (542 HV). 
Table 2. Change in hardness of various regions of the steam trap from selective heat treatment using infrared heating

\begin{tabular}{|c|c|c|c|}
\hline & & Hardness & well C) \\
\hline Treatment & & Threaded End & Nut Enc \\
\hline \#1 & & & \\
\hline $700^{\circ} \mathrm{C} / 5$ min. in Circular IR Furnace Air & Initial & 39.7 & 44.5 \\
\hline & After Treatment & 26.4 & 37.4 \\
\hline \#2 & & & \\
\hline $700^{\circ} \mathrm{C} / 5 \mathrm{~min}$. in Flat-Bed IR Furnace Air & Initial & 42.4 & 45.6 \\
\hline & After Treatment & 24.7 & 34.2 \\
\hline \#3 & & & \\
\hline $725^{\circ} \mathrm{C} / 30 \mathrm{sec}$. in Flat-Bed IR Furnace Air & Initial & 40.1 & 42.7 \\
\hline insulated nut end & After Treatment & 37.3 & 43.7 \\
\hline \#4 & & & \\
\hline $700^{\circ} \mathrm{C} / 2.5 \mathrm{~min}$. in Flat-Bed IR Furnace Air & Initial & 42.5 & 45.0 \\
\hline insulated nut end & After Treatment & 34.4 & 46.0 \\
\hline \#5 & & & \\
\hline $954^{\circ} \mathrm{C} / 2 \mathrm{~min}$. Flat-Bed IR Furnace & Initial & $\underline{-}$ & 45.5 \\
\hline & After Treatment & 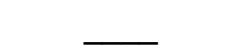 & 50.8 \\
\hline \#6 & & & \\
\hline $1000^{\circ} \mathrm{C} / 2 \mathrm{~min}$. Flat-Bed IR Furnace & Initial & - & 44.8 \\
\hline & After Treatment & & 54.4 \\
\hline
\end{tabular}

\section{Reports/Publications/Awards:}

Vinod K. Sikka, "Heat Treatment Optimization for Steam Trap Seat of AISI 420F Stainless Steel," MPLUS report, 2003. 
MPLUS No.: MC-02-023

Title: Hot-Hardness Data on Wear- and Corrosion-Resistant Alloy

User Organization: Deloro Stellite Group, Ltd. St. Louis, MO 63141

User Contact: James B.C. Wu, 314-514-7665 jwu@stellite.com

ORNL R\&D Staff: Vinod K. Sikka, 865-574-5112 sikkavk@ornl.gov

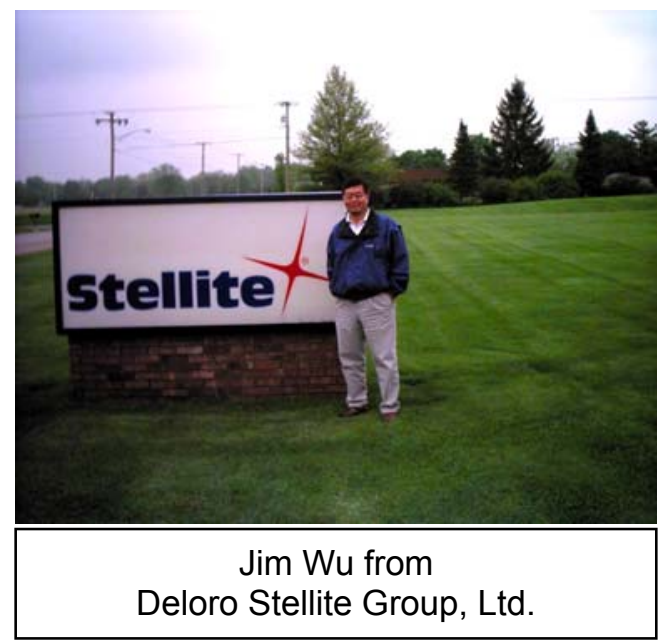

Relevance to OIT: Wear- and corrosion-resistant materials such as stellites and their variants including triballoys are often used for very demanding applications in many industries including mining, chemical, steel, and pulp and paper. Wear resistance of the alloys is typically related to their hardness. Although these alloys are used at higher than room temperature, their selection is based only on room-temperature data. It is recognized that the operating temperatures or the surface heating from frictional forces may change the hardness of these alloys at operating temperatures and thus result in improper alloy selection based on room-temperature hardness. This MPLUS generated the hot-hardness (hardness at temperature) as a function of temperature for several wear- and corrosion-resistant alloys. This data will help to better select the alloys and thus improve performance. The outcome of this MPLUS is directly related to steel, chemical, pulp and paper, and mining industries.

Objective: The objective was to use the specialized equipment available in the MPLUS User Center for developing hot-hardness data for wear- and corrosion-resistant alloys developed by the Deloro Stellite Group. These alloys are commonly used for many of the IOF industry manufacturing processes. It is not always predictable if a high roomtemperature hardness alloy will also retain its high hardness at high (use) temperature. In most processes, alloy use temperature is above room temperature because of the frictional heat that is generated. In other cases, the alloy is used at high temperature (e.g., galvanizing bath where Stellite alloys operate in molten zinc at $465^{\circ} \mathrm{C}$ ).

Results: Hot-hardness data were generated on the alloys provided by Deloro Stellite. These included Stellite 21, Triballoy 400, and Triballoy 800 . Data were generated from room temperature to $1000^{\circ} \mathrm{C}$ at approximately $100^{\circ} \mathrm{C}$ intervals. Data were presented in both tabulated and graphical forms. Figure 1 shows typical data. The results from this study were also compared with data that was generated on some of the wear-resistant alloys from the Stoody Company under a separate MPLUS project. A report of the data was prepared jointly with the user, James Wu. Deloro Stellite is providing the results of this study to its customers. 


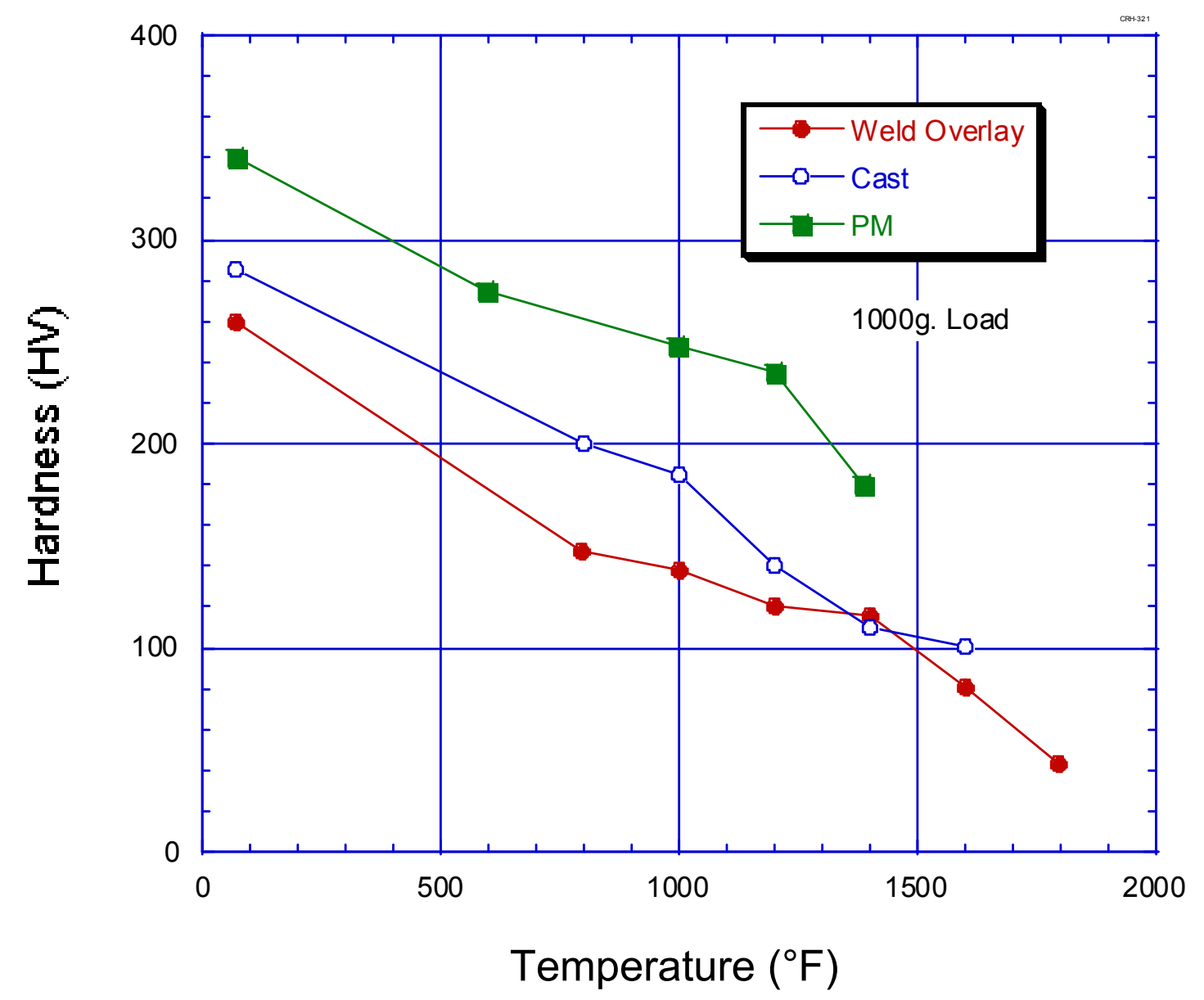

Fig. 1. Hardness as a function of temperature for Stellite 21. Data are compared for Stellite in three different forms: weld overlay, cast, and powder metallurgy.

\section{Reports/Publications/Awards:}

Results of this study were prepared as a PowerPoint report. No other publications have been decided upon. 
MPLUS No.: MC-02-024

Title: Effect of Forging and Heat Treating on Residual Stress in Aluminum Forgings

User Organization: Scot Forge Spring Grove, IL 60081

User Contact: Bob Krysiak, 847-587-1000 bkrysiak@scotforge.com

ORNL R\&D Staff: Thomas Watkins, 865-574-2046 watkinstr@ornl.gov

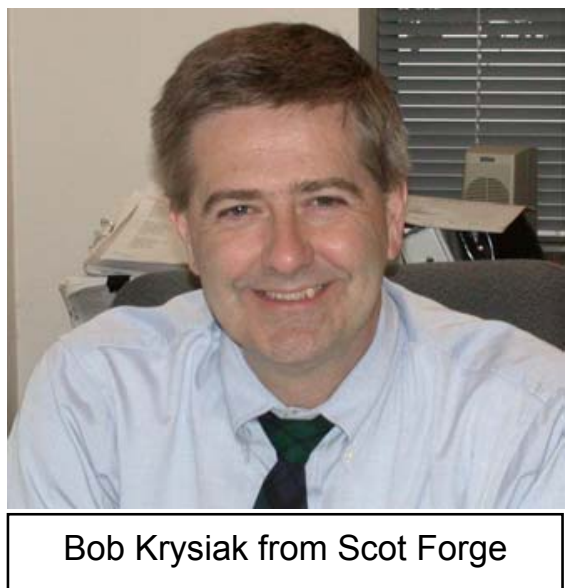

Relevance to OIT: Forging is a major energy intensive industry where large billets are heated for homogenization and forging. Forgings are frequently reheated for heat treating. During the forging of large components and their subsequent heat treating, they undergo large residual stresses from uneven cooling that occurs from surface to the component thickness dimensions. An understanding of residual stresses distribution can assist in modifying both the forging process and the heat-treatment cycle in order to utilize the residual stresses. The results from this project will help Scot Forge improve the forging and heat-treating process with substantial savings in energy and improvement in component properties.

Objective: The objective of this work was to examine three aluminum forgings in order to understand the effects of processing and heat-treating parameters on the residual stresses.

Results: The microstructure and residual stresses were characterized for 7075-T753 aluminum samples A, B, and C supplied by Scot Forge.

In Fig. 1, the microstructures of samples $A$ and $C$ both show the elongation of grains in the hoop direction (see Fig. 2) indicative of the squeezing and stretching employed to make the rings. As the microstructures from samples $B$ and $C$ were indistinguishable, only those from samples $A$ and $C$ are presented. The microstructure from Sample $A$ appears to be heavily cold worked and fine grained with little evidence of recrystallization. The low-magnification image of sample $\mathrm{C}$ shows large oval domain features of 300 to $500 \mu \mathrm{m}$ surrounded by regions of alloy undergoing recrystallization. At the highest magnification, the grain size in sample $A$ is nominally half that of the recrystallized grains shown in sample $C$. Microstructurally, sample A was quite different from samples $\mathrm{B}$ and $\mathrm{C}$.

X-ray diffraction (XRD) was employed to understand the crystalline nature of the samples. The X-ray peaks are often described by three key features: width, position, and intensity (height), which are functions, in part, of the amount of cold work, residual stress and number of diffracting planes, respectively. The widths or the full width at half 
maximums (FWHMs) of the (311) aluminum peak are listed in Table 1. The axial-hoop surfaces of samples $A$ and $B$ have slightly more cold work than $C$, while the radial-hoop surface of sample $A$ has much more cold work than either $B$ or $C$, perhaps reflecting the as-received surface finish of sample A. The measured hardness increase, observed at Scot Forge, agrees with the FWHM X-ray results from the radial-hoop surfaces, suggesting a greater quantity of cold work or plastic deformation in sample $A$ than in sample B (or C).

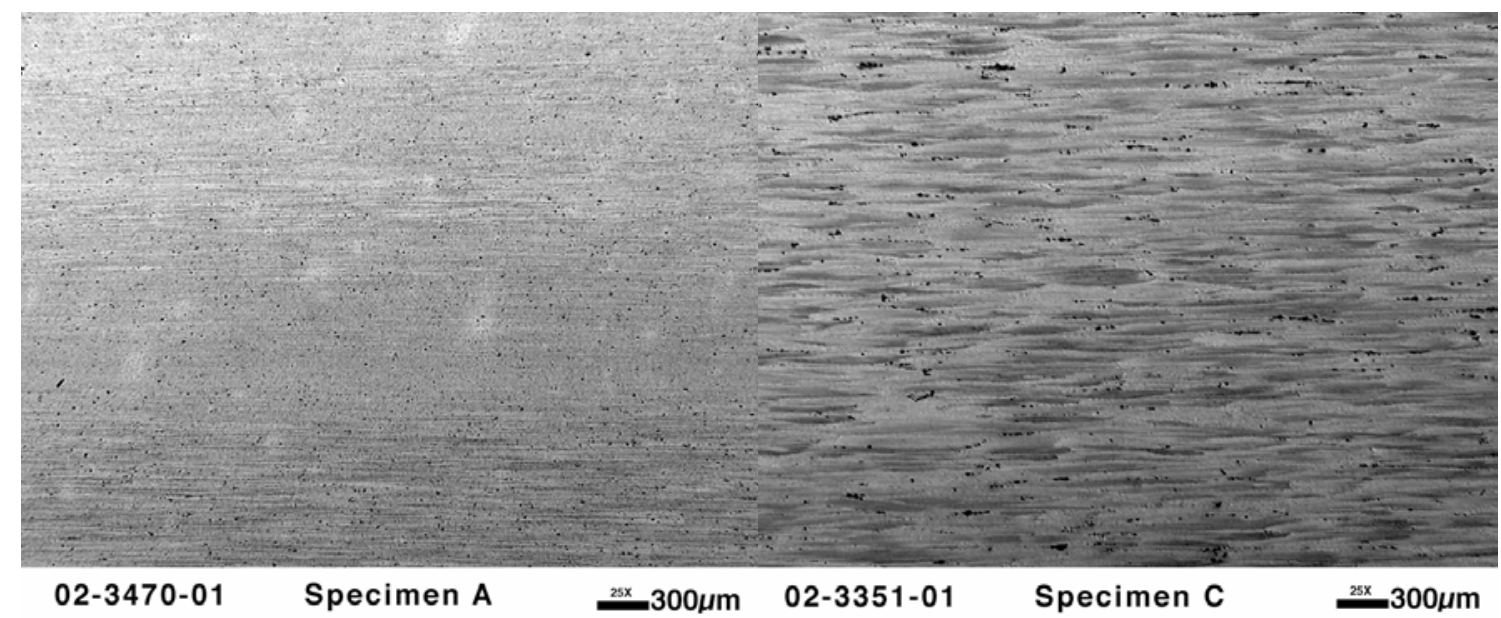

(a)

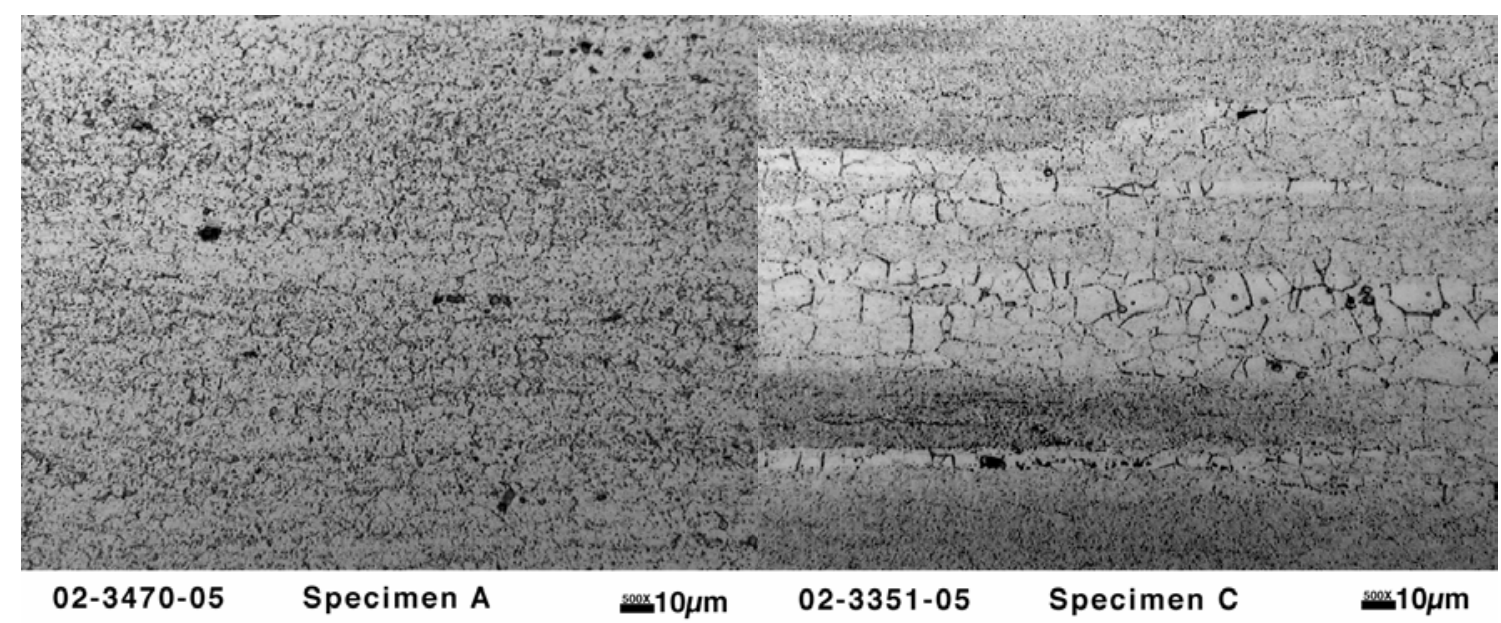

(b)

Fig. 1. Optical micrographs (a) and (b) at two magnifications in the radial-hoop surfaces.

Overall, the arithmetic average residual stresses in the samples, taken at several locations per surface, were low (see Table 2). Comparatively, sample A displayed a fair amount of stress anisotropy, which may be due to the as-received surface finish. All of the average residual stresses were compressive, except in the hoop direction on the radial-hoop face of sample $A$. The small mechanical property differences measured at 
Scot Forge in samples B and C suggest that they be considered identical. However, while the residual stresses in these samples on the radial-hoop surface were effectively the same, the residual stresses on the axial-hoop surface of sample B were inexplicably approximately 2.5 times larger than those in sample $\mathrm{C}$. This could be due to differences of the final surface finishes, despite electropolishing. The axial-hoop surface of sample $B$ possessed clean machined grooves while that of sample $C$ had a dull semi-burnt finish. Perhaps the depth of machining deformation damage in sample $B$ exceeded the approximately $75-\mu \mathrm{m}$ electropolishing depth. All of the average residual stresses were compressive, except in the hoop direction on the radial-hoop face of sample A. This result is rather interesting in that one would expect a compressive residual stress resulting from any polishing or finishing. Typically, when metals are plastically deformed in tension, the resulting residual stress is compressive and vice versa. This suggests that the forging process somehow achieved compressive deformation in the hoop direction in the middle of the ring.

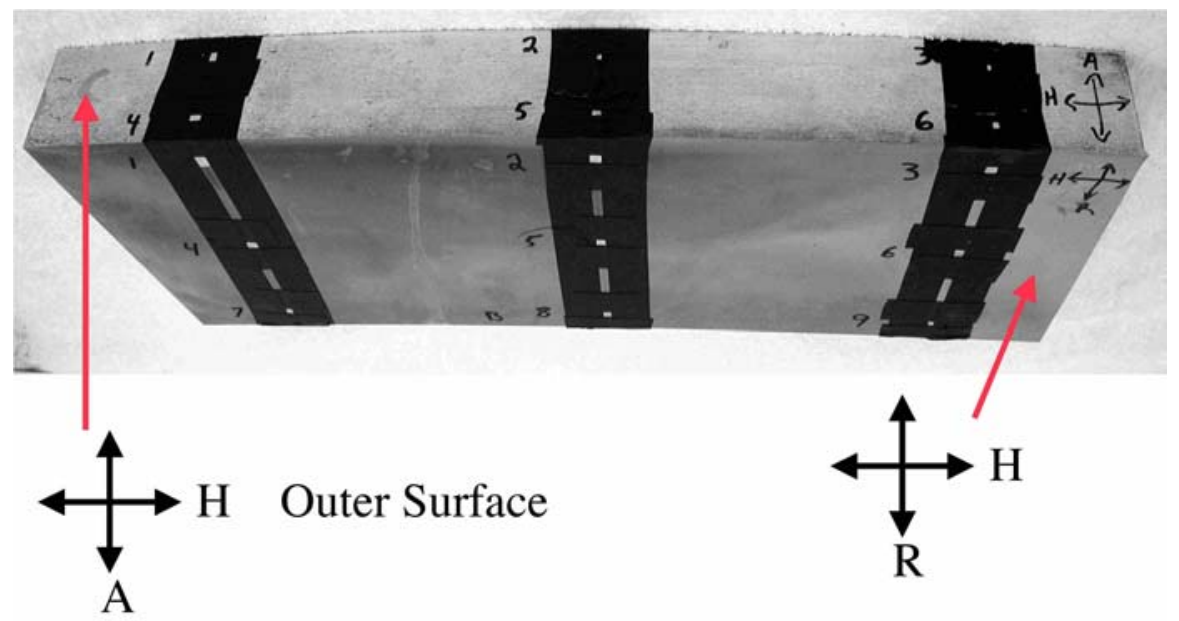

Fig. 2. Sample $B$ with grid. X-ray residual strain measurements were performed on the radial-hoop $(\mathrm{R}-\mathrm{H})$ and axial-hoop $(\mathrm{A}-\mathrm{H})$ surfaces of all three samples. Electrical tape was used to mask off nonelectropolished regions so that diffraction from these regions did not occur.

Table 1. Average FWHM and standard deviations (in parentheses) for the samples and surfaces examined

\begin{tabular}{|c|c|c|c|}
\hline \multirow{2}{*}{$\begin{array}{c}\text { Surface/ } \\
\text { Direction }\end{array}$} & \multicolumn{3}{|c|}{ FWHM $\left({ }^{\circ} \mathbf{2} \Theta\right)$} \\
\hline A-H/Axial & Sample A & Sample B & Sample C \\
\hline A-H/Hoop & $1.33(0.11)$ & $1.28(0.04)$ & $1.14(0.07)$ \\
\hline R-H/Radial & $1.29(0.09)$ & $1.27(0.04)$ & $1.15(0.06)$ \\
\hline R-H/Hoop & $1.90(0.07)$ & $1.09(0.06)$ & $1.07(0.04)$ \\
\hline
\end{tabular}


Table 2. Average residual stress and standard deviations (in parentheses) for the samples and surfaces examined

\begin{tabular}{|c|c|c|c|}
\hline \multirow{2}{*}{$\begin{array}{c}\text { Surface/ } \\
\text { Direction }\end{array}$} & \multicolumn{3}{|c|}{ Residual Stress (ksi) } \\
\cline { 2 - 4 } A-H/Axial & Sample A & Sample B & Sample C \\
\hline A-H/Hoop & $-04.7(6.5)$ & $-19.3(7.3)$ & $-7.2(6.2)$ \\
\hline R-H/Radial & $-10.3(6.6)$ & $-18.4(3.2)$ & $-7.9(2.9)$ \\
\hline R-H/Hoop & $-03.9(4.6)$ & $-04.9(4.7)$ & $-5.5(2.8)$ \\
\hline & $11.3(5.3)$ & $-06.6(5.0)$ & $-7.4(5.0)$ \\
\hline A-H/Axial & $-32(45)$ & $-133(50)$ & $-50(43)$ \\
\hline A-H/Hoop & $-71(46)$ & $-127(22)$ & $-55(20)$ \\
\hline R-H/Radial & $-27(32)$ & $-33(32)$ & $-38(20)$ \\
\hline R-H/Hoop & $78(37)$ & $-46(34)$ & $-51(34)$ \\
\hline
\end{tabular}

\section{Reports/Publications/Awards:}

T. R. Watkins, "Effect of Forging and Heat Treating on Residual Stress in Al Forgings," MPLUS report, 2003. 
MPLUS No.: MC-02-025

Title: Effects of Process Variables on Shaped Castings of Fe-Si Alloys

User Organization: CC Metals and Alloys, Inc. Calvert City, KY 42029

User Contact: Edward S. Bredniak, 270-395-2121 esbredniak@ccmetals.com

ORNL R\&D Staff: $\quad$ Qingyou Han, 865-574-4352

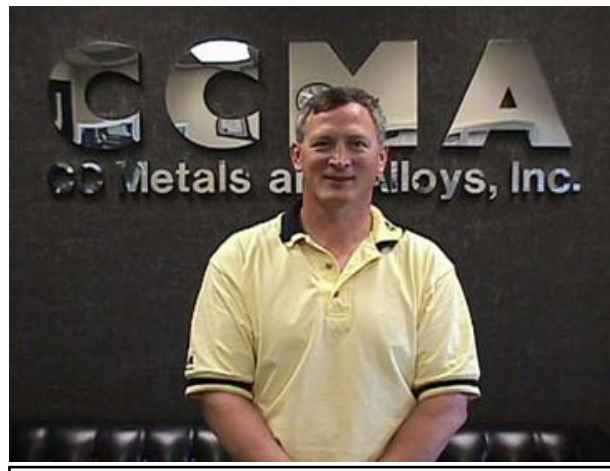

Ed Bredniak from CC Metals and Alloys, Inc. hanq@ornl.gov

Relevance to OIT: Iron-silicon master alloys are widely used in the steel and metalcasting industries for adjusting composition and refining grain size. The existing production method involves large, gas-fired two-story high furnaces loaded with iron and silica; reactions lead to the formation of a liquid Fe-Si alloy, which is then cast into large ingots. The ingots are subsequently jaw crushed extensively and screened (energyintensive operations), and this yields a large amount of fines that are required to be reprocessed. This project evaluated the net-shape casting of the Fe-Si liquid alloys in order to eliminate the jaw-crushing and screening operations and also to avoid the formation of fines, leading to substantial energy savings. The laboratory-based results are very positive and show great promise for implementation. At this time, industry is evaluating the cost benefits of the new technology. The project is directly related to the steel and metal-casting industries.

Objective: CC Metals and Alloys, Inc. is the largest producer of Fe-Si master alloys in the U.S. The end users of our product required the master alloys in a variety of shapes and sizes. Our interest was to find out if the Fe-Si alloys could be cast into near-net shapes of various sizes and if such processes are commercially viable. This proposal explored effects of various process variables for shaped castings of Fe-Si alloys.

Results: Some of the economic ways of making net-shape castings of Fe-Si alloys have been tested. These include permanent mold casting of various cubes and hemispheres of Fe-Si alloys, cone-shaped ingots using a chill, and a new method termed "die press/sand casting". All of these methods can produce the required sizes and shapes. No crushing and screening were needed, and little fines were produced.

Permanent mold castings of Fe-Si alloy are shown in Fig. 1. Figure 1(a) shows 2-in. cubes or hemispheres, and Fig. 1(b) shows 1-in. rods of different lengths. Cubes and short rods are ideal shape for industrial applications. Long rods can also be broken easily into short rods of fairly uniform sizes. 


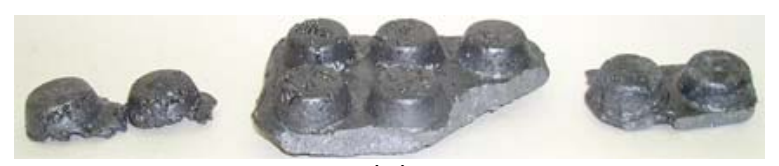

(a)

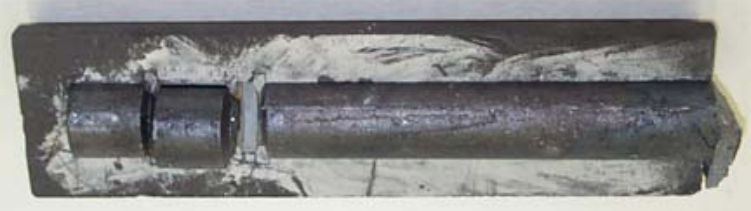

(b)

Fig. 1. Permanent mold casting of (a) cubes, and (b) rods.

The idea of making cone-shaped ingots shown in Fig. 2(a) has been tried. It involves pouring melt in a mold with a cone-shaped cavity. The cone is chilled at the bottom. After the cone has solidified, the chill is withdrawn and the cone can be easily removed from the mold (if the mold is filled from the smaller end of the cone, the cone may drop as soon as the chill is withdrawn). Figure 2(b) shows cones made using this idea. The cones can be made on a turning table or a conveyor belt. The idea can be scaled up for industrial applications.

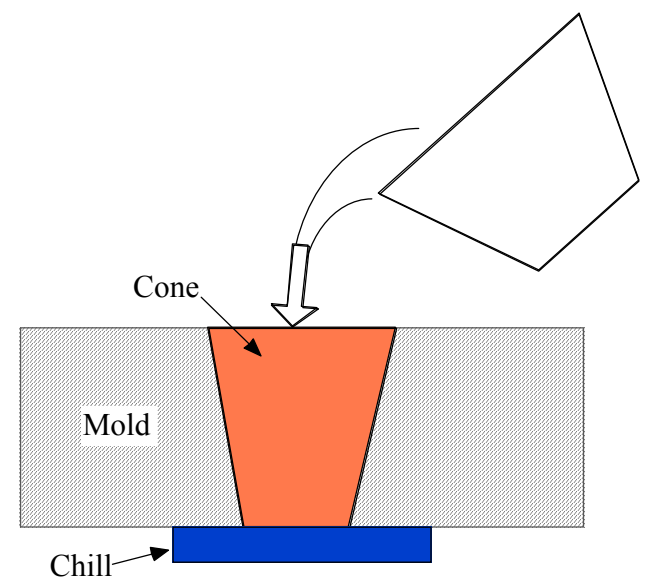

Fig. 2. Schematic illustration of making Fe-Si cones.

Another new idea of "die press/sand casting" has been proposed and tested. The idea, shown in Fig. 3(a), is identical to sand casting. The sand can be used for many times for making open top molds. A metal pattern is made, which is pressed into a bed of green sand to form cavities of hemispheres or rods. A liquid metal distributor is used to feed melt into the cavities. Molten Fe-Si is poured through the distributor and fills the cavities of various sizes. This novel idea has been used successfully in making hemispheres of 1-in. size, shown in Fig. 3(b). The idea should be more promising for large hemispheres. 


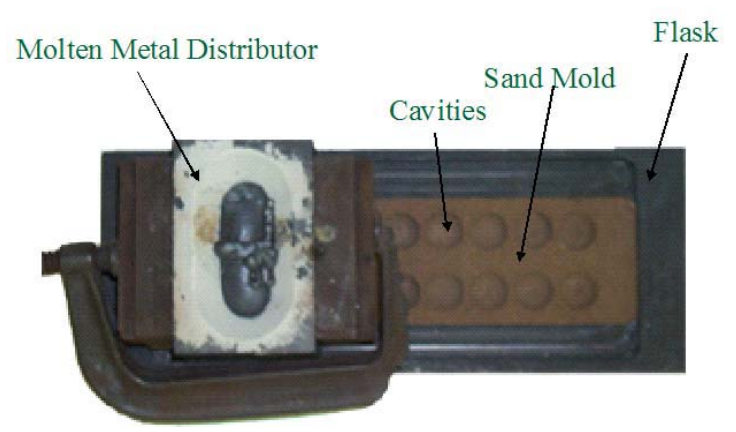

(a)

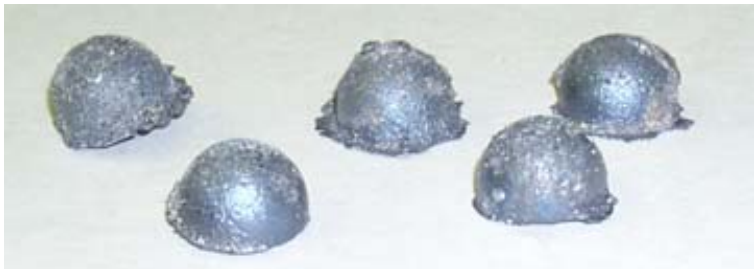

(b)

Fig. 3. "Die press/sand casting": (a) the mold, and (b) Fe-Si hemispheres made using the new method.

\section{Reports/Publications/Awards:}

Qingyou Han, Vinod K. Sikka, and Edward S. Bredniak, "Effects of Process Variables on Shape Castings of Fe-Si Alloys," MPLUS report, October 2002. 
MPLUS No.: MC-02-026

Title: Creep Rupture Behavior of Modified 9Cr-1Mo Flux-Cored Arc Weldments

User Organization: Stoody Company

Bowling Green, KY 42101

User Contact: Ravi Menon, 270-781-9777

ravi_menon@thermadyne.com

Jack Wallin, 270-781-9777 ext. 2042

jack_wallin@thermadyne.com

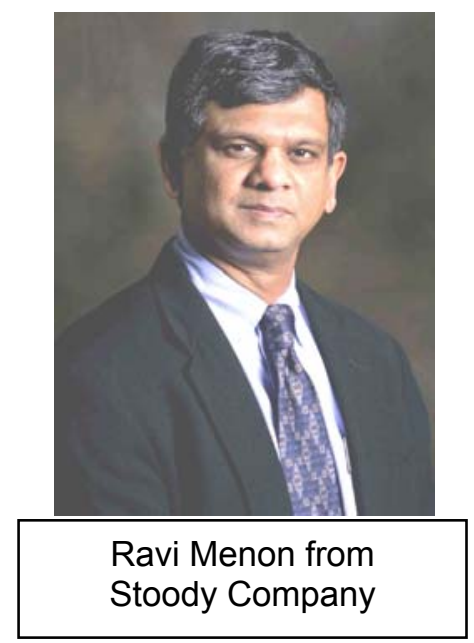

ORNL R\&D Staff: Edgar Lara-Curzio, 865-574-1749

laracurzioe@ornl.gov

Kenneth C. Liu, 865-574-5116

liukc@ornl.gov

Relevance to OIT: Components with complex shapes are often manufactured by joining or welding smaller parts with simpler geometry. Increases in the efficiency of industrial processes that incorporate these components are often associated with increases in operating temperature. The availability of high-temperature filler materials could enable the manufacture of components that would operate at higher service temperature.

Objective: To develop creep rupture data for modified $9 \mathrm{Cr}$-1Mo flux cored arc weldments being developed by Stoody Company and to learn the morphology of carbides and distribution changes that occur during exposure to elevated temperatures. The information will be used to validate the viability of this process and product.

Results: Specimens tested were made of two types of modified $9 \mathrm{Cr}-1 \mathrm{Mo}$ steels fabricated with flux-cored filler metals designated as F1 and F2. All the specimens were tested in tension at $1200^{\circ} \mathrm{F}$. Tensile tests were performed on all-weld specimens under elongation control to determine the maximum tensile strength. Creep rupture strengths at 100,500 , and $1000 \mathrm{~h}$ were then estimated for creep rupture tests. Because of the innate nonisotropic properties of the weldments, creep rupture tests must be performed for all-weld specimens and transverse creep-rupture specimens.

1. The characteristic features of stress-strain behavior in tension are similar for both types of weldments tested at $1200^{\circ} \mathrm{F}$, as shown in Fig. 1. Both specimens show elastic behavior followed by abrupt yielding and monotonic strain softening; therefore, the ultimate tensile strength is not significantly higher than the yield strength. 
2. The ultimate tensile strength of the F-1 specimen and that of the F-2 specimen are nominally equal but the ductility is higher for the former.

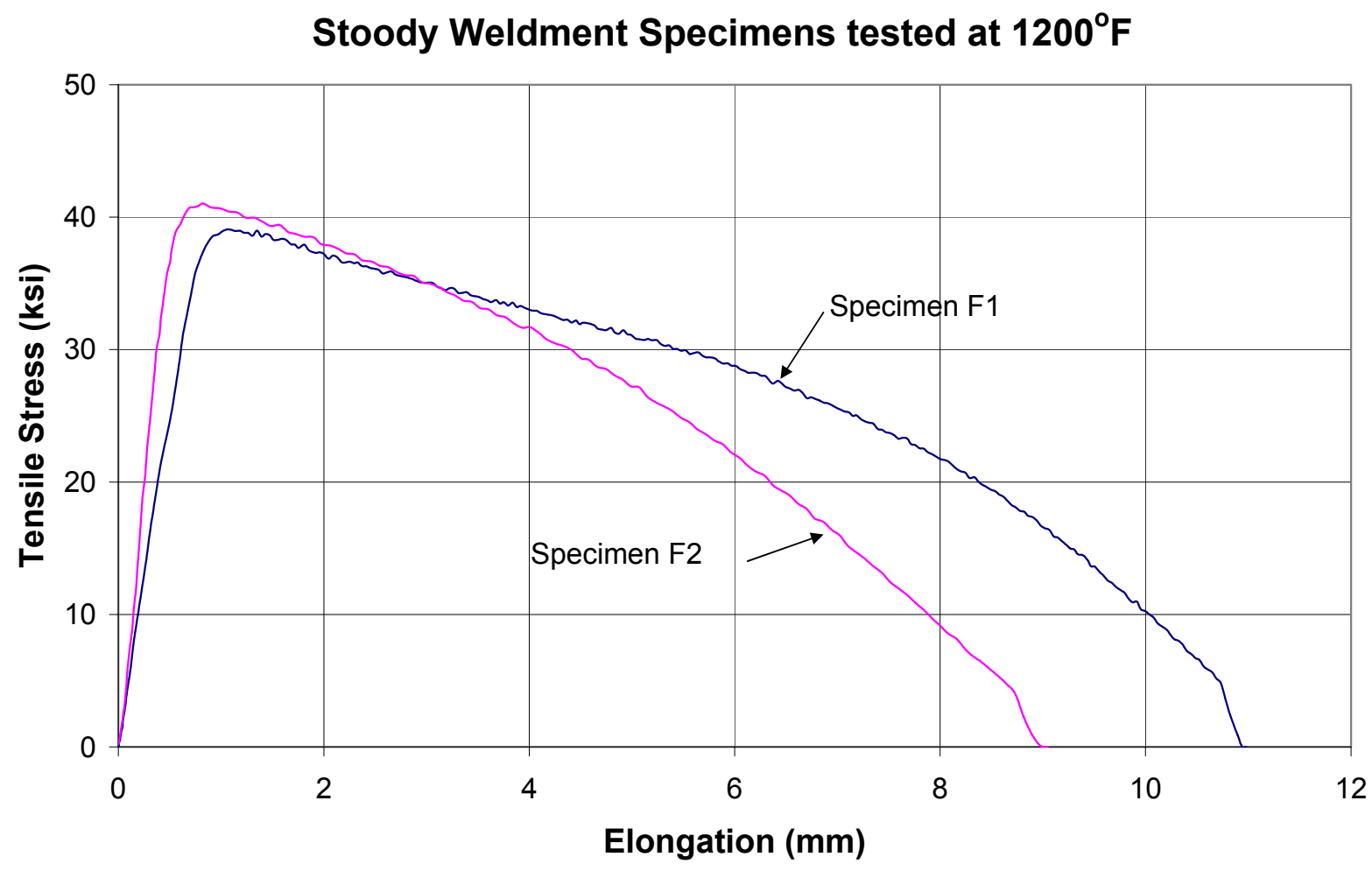

Fig. 1. Comparison of tensile behavior of specimens F1 and F2 tested at $1200^{\circ} \mathrm{C}$.

Four creep test conditions were then identified for testing three all-weld creep specimens and a transverse creep specimen at 1100 and $1200^{\circ} \mathrm{C}$. An all-weld specimen was tested at $1100^{\circ} \mathrm{C}$ under a constant stress of $172 \mathrm{MPa}(25 \mathrm{ksi})$ for $332 \mathrm{~h}$ until the heating element burned out inadvertently. Although the test was not carried out to the final rupture, essential creep behavioral features such as primary, secondary, and tertiary creep behavior were discernible from the creep curve, as shown in Fig. 2 . The minimum creep rate was determined from data acquired in the time period between 100 to $200 \mathrm{~h}$, yielding a creep rate of $1.72 \times 10^{-8} / \mathrm{s}$. The test will be restarted to complete a total of $1000 \mathrm{~h}$ of testing or to rupture, whichever comes first. A creep test will be performed for the single transverse specimen under the same condition for comparison. 


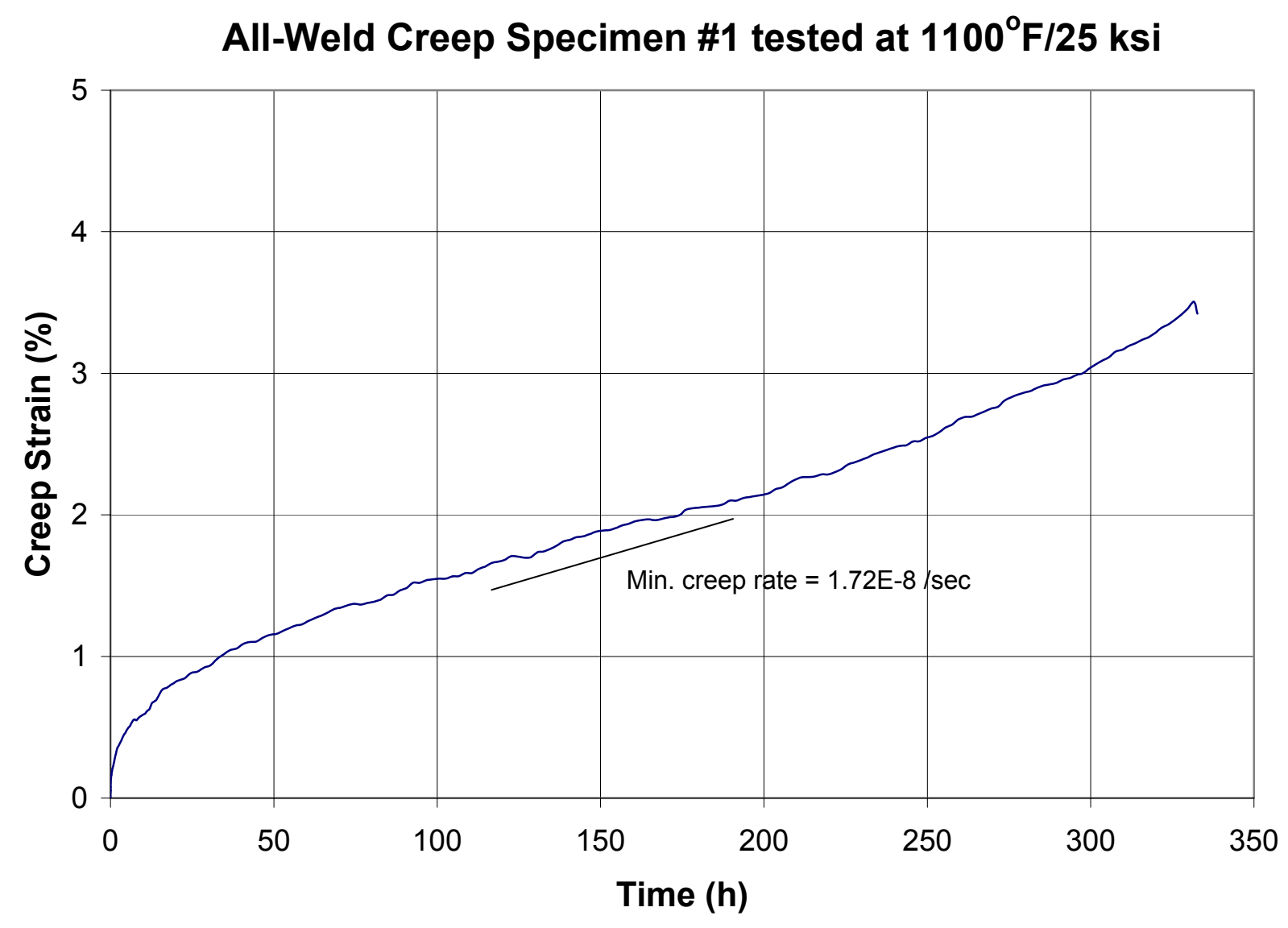

Fig. 2. Creep curve of an all-weld specimen tested at $1100^{\circ} \mathrm{C}$ with a constant stress of $25 \mathrm{ksi}$.

\section{Reports/Publications/Awards:}

E. Lara-Curzio and K. C. Liu, "Creep Rupture Behavior of 9Cr-1Mo Flux-Cored Arc Weldments," MPLUS report, 2003. 
MPLUS No.: MC-02-027

Title: Effect of Processing and Microstructure on the Corrosion Polarization Response of a Corrosion-Resistant Alloy

User Organization: ALLVAC Monroe, NC 28111-5030

User Contact: John Pridgeon, (704) 289-4511 John.pridgeon@allvac.com

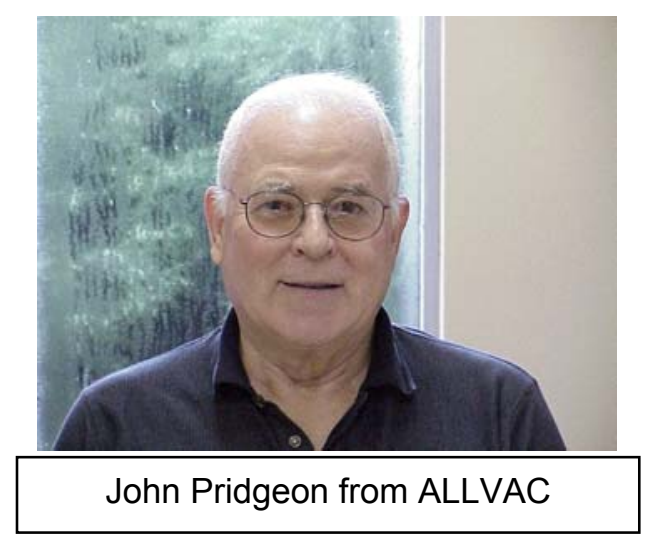

ORNL R\&D Staff: Vinod K. Sikka, (865) 574-5112 sikkavk@ornl.gov

Steve J. Pawel, (865) 574-5138 pawelsj@ornl.gov

Dane F. Wilson, (865) 576-4810 wilsondf@ornl.gov

Relevance to OIT: Corrosion of components is critical for chemical, petrochemical, forest products, and many other industries. Pitting and crevice corrosion are common causes for failure resulting from corrosion fatigue. Alloys such as type 304 are commonly used for these applications. However, for more severe applications, modifications of type 304 such as alloy 734 are used. Although high resistant to corrosion, a large variability in their response is noted based on the material processing history. This MPLUS identified the extent of variation in corrosion resistance that can result in alloy 734 with a different processing history. Further work was recommended to optimize the alloy processing steps that would result in consistent corrosion-resistant performance from batch to batch of the alloy.

This task was designed to tailor the microstructure of the material for better corrosion performance, which would allow U.S. industry to compete with the foreign producer of equivalent material that exhibited better corrosion performance. Better corrosion performance would also allow U.S. industry to be more energy efficient from reduced scrap and reduced in-house recycle, and be more competitive from reduced production cost and improved productivity.

This project is directly related to chemical, petrochemical, and forest product industries.

Objective: A high-nitrogen alloy (734), similar to type 304 stainless steel, is well known for its resistance to pitting, crevice corrosion, and corrosion fatigue. The corrosion performance as determined by the polarization measurement is highly inconsistent. The objective of this work was to understand the processing and microstructure control required for consistent corrosion performance. 
Results: The electrochemical performance of 734 stainless steel was evaluated in a deaerated, $\mathrm{pH} 4,0.9 \%$ sodium chloride solution. Significant variations in open circuit potential, passive current density, and potential for a critical current density of $10 \mu \mathrm{A} / \mathrm{cm}^{2}$ were observed for ALLVAC's material compared with those of a competitor's material. Evaluation of the microstructures revealed a relatively large variation in the grain size of ALLVAC material across a cross section and between orthogonal sections as compared to the competitor's material (see Fig. 1). However, no correlation between grain size, or range of grain sizes and potential at critical current density was found. The variability of open circuit potential as well as passive current density and the potential at which current density exceeds $10 \mu \mathrm{A} / \mathrm{cm}^{2}$ as determined from the polarization curve is normally associated with differences in the chemical composition of the surfaces of the material exposed to the test solution or of the test solution. Because the temperature, composition, and $\mathrm{pH}$ of the test solution were controlled, compositional variation associated with specimen surfaces is the most likely cause. As the current criterion is achieved in the transpassive region of the polarization curve, the voltage at which it is achieved will decrease with increasing chromium content of the tested surface. Because a definitive resolution to the poor performance of the materials was not obtained, further avenues of investigation were suggested.

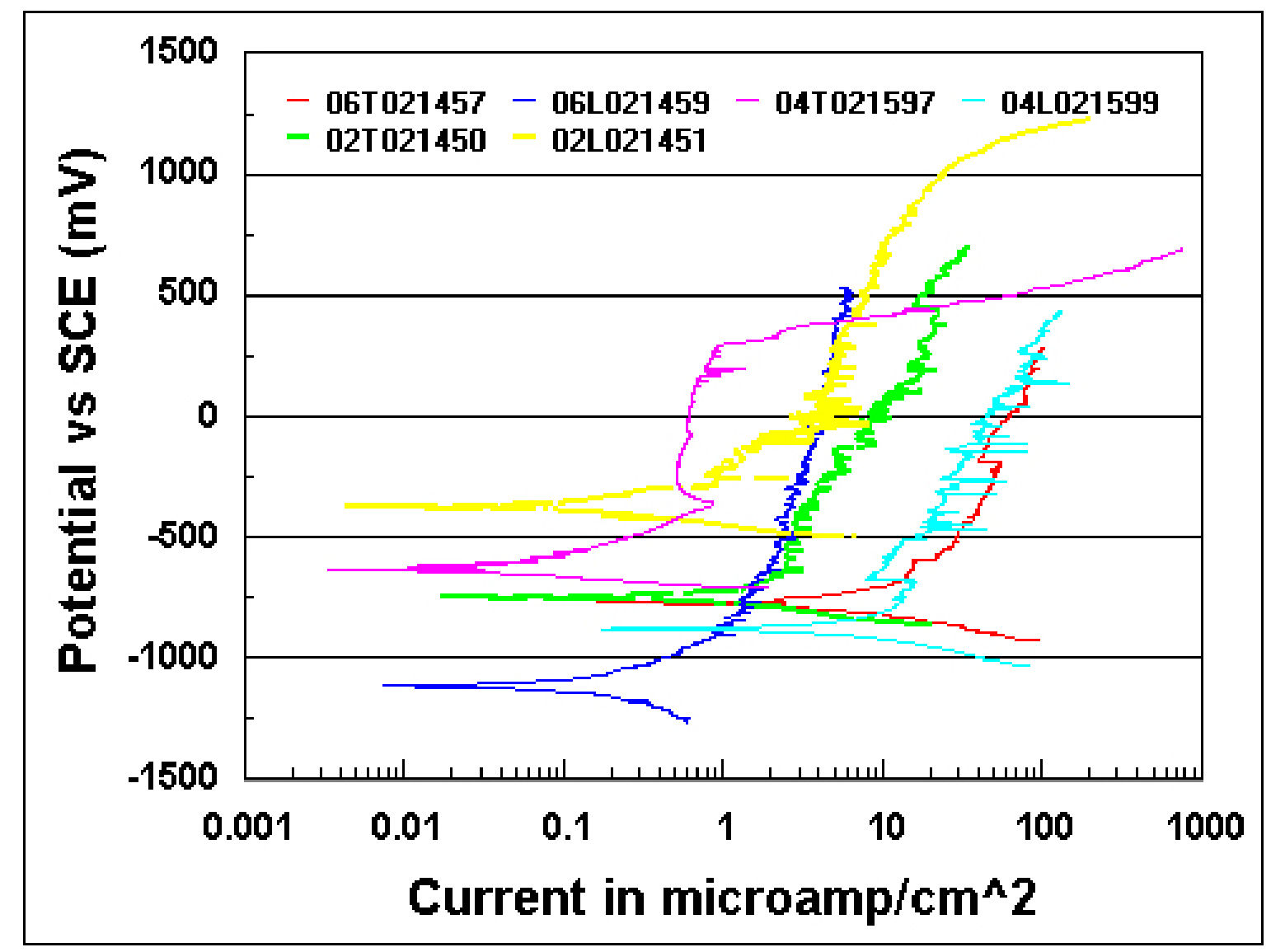

Fig. 1. Large variation observed in open circuit potential for alloy 734 processed by different methods. 


\section{Reports/Publications/Awards:}

D. F. Wilson, S. J. Pawel, V. K. Sikka, and H. F. Longmire, "Effect of Processing/Microstructure on the Corrosion Polarization Response of a CorrosionResistant Alloy," MPLUS report, August 2002. 
MPLUS No.: MC-02-028

Title: Modeling of Elemental Segregation in Alloy Ingots and Thermal Treatments for Homogenization

User Organization: Scot Forge Spring Grove, IL 60081

User Contact: Anthony J. Biell, 800-435-6621 tbiell@scotforge.com

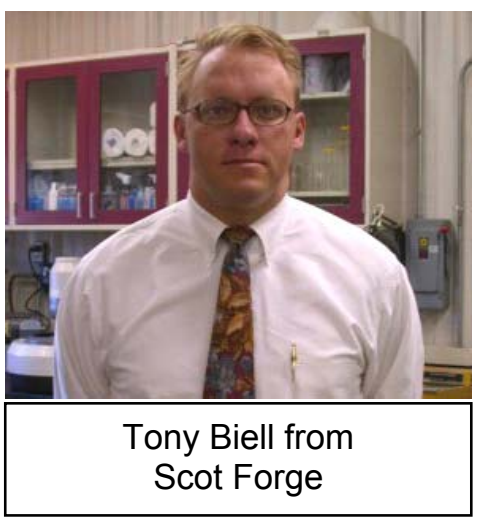

ORNL R\&D Staff: Qingyou Han, 865-574-4352 hanq@ornl.gov

Relevance to OIT: In the U.S., $3.72 \times 10^{5}$ tons of steel forgings and $1.76 \times 10^{6}$ tons of steel castings are homogenization heat treated per year. A $10 \%$ reduction in homogenization time for steel forgings and castings can lead to energy savings of nearly 60 trillion BTU/year and a cost savings of nearly $\$ 200$ million/year. Homogenization is also used in the aluminum and iron industries; however, these industries were not included in the above estimates. This project focused on modeling the segregation and homogenization thermal treatment in order to evaluate the optimum homogenization process. An approach was developed and validated that successfully predicted segregation and homogenization in 4340 steel. Further work is required in order to generalize, evaluate, and implement the technique in commercial casting and solidification packages. This project has direct relevance to the steel and metal-casting industries.

Objective: We homogenize steel alloy ingots at temperatures approaching $1300^{\circ} \mathrm{C}$ for periods of over $24 \mathrm{~h}$. These treatments have developed from experience and rule of thumb. The purpose of this proposal is to model the segregation and to define the thermal treatments needed for each composition and ingot size.

Results: An approach has been developed for the prediction of segregation and homogenization. A relationship between dendrite arm spacing and cooling conditions for multicomponent alloys has been developed. Segregation and homogenization are then related to the secondary dendrite arm spacing, holding temperature, and time. Thermodynamic and kinetic simulations have been utilized for the prediction of segregation and homogenization. Preliminary results indicate that the residual segregation index is a function of temperature, time, and secondary arm spacing. Small residual segregation ratios can be achieved at high temperature, long time, and small secondary dendrite arm spacing. 
Figure 1 shows the comparison between the analytical prediction of the secondary dendrite arm spacing and the experimental data as a function of cooling rate in a 4340 steel ingot. Our model is the first that predicts secondary dendrite arm spacing in multicomponent alloys.

Figure 2 shows a comparison of the predicted segregation profiles of nickel with experimental measurements. The $\mathrm{X}$-axis is a dimensionless distance from the center of a dendrite $(0$ represents the center of a dendrite and 1 represents the edge of a dendrite). When normalized the diffusion distance against the secondary dendrite arm spacing, $d_{2}$, the composition profiles are insensitive to the cooling rates in an ingot. The prediction fits well with experiments.

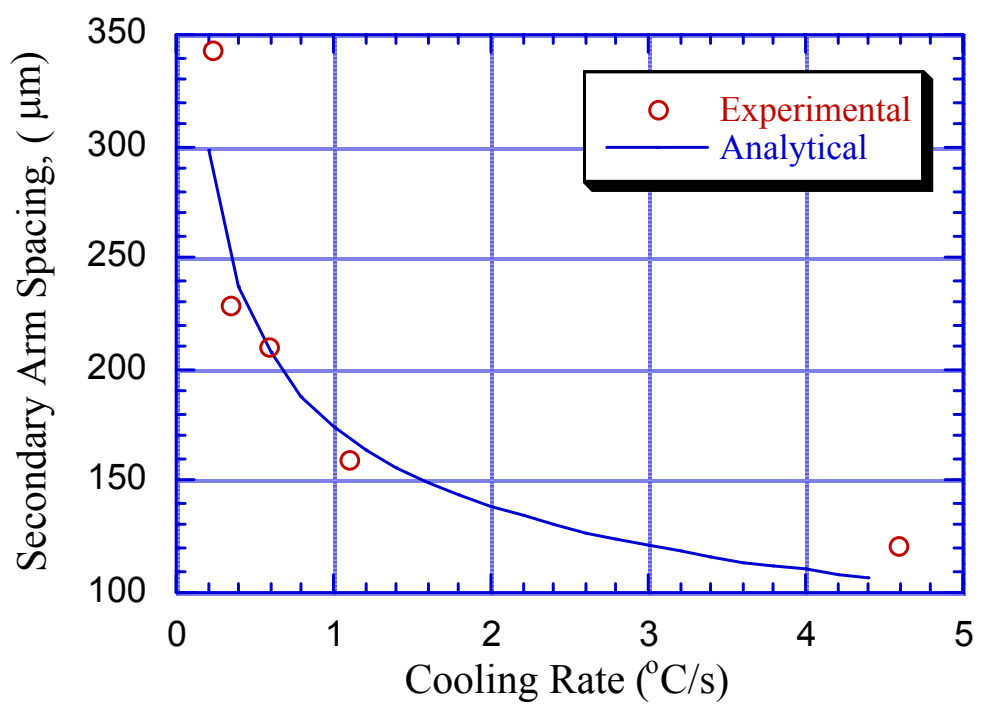

Fig. 1. Relationship between secondary dendrite arm spacing and cooling rate.

Figure 3 shows the changes of the nickel concentration profile during homogenization processes. The dendrite arm spacing is $340 \mu \mathrm{m}$ in Fig. 3(a) and $88 \mu \mathrm{m}$ in Fig. 3(b). Homogenization is sensitive to the holding time and secondary dendrite arm spacing. When $d_{2}$ is about $88 \mu \mathrm{m}$, nickel is homogenized in $24 \mathrm{~h}$ at $1260^{\circ} \mathrm{C}$. However, when $d_{2}$ is about $340 \mu \mathrm{m}$, nickel is not homogenized in $48 \mathrm{~h}$.

Increasing holding temperature promotes elemental homogenization. This is shown in Fig. 4 for $d_{2}=160 \mu \mathrm{m}$. Homogenization can be achieved in $24 \mathrm{~h}$ at a temperature of $1320^{\circ} \mathrm{C}$. At low temperatures, the nickel profiles are much steeper than that at $1320^{\circ} \mathrm{C}$, indicating it takes much longer to achieve homogenization at low temperatures. 


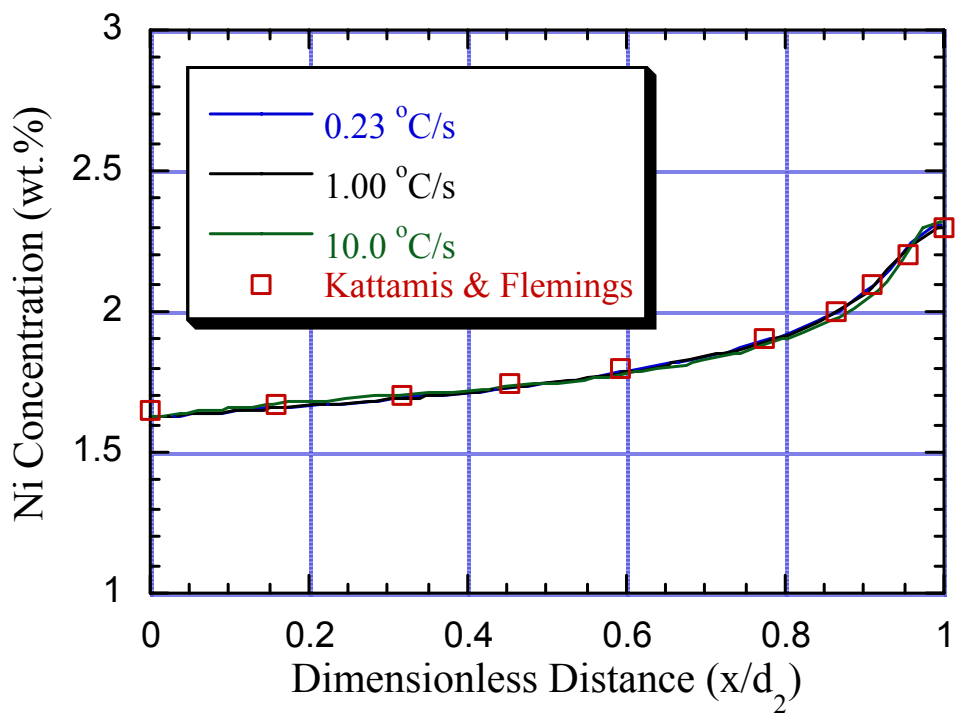

Fig. 2. The segregation profile of nickel under as-cast condition.

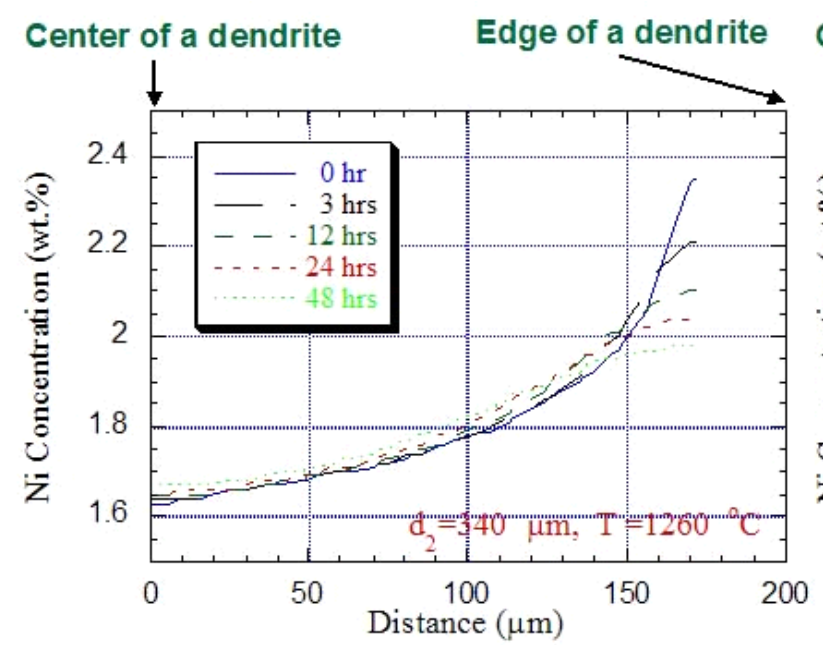

(a)

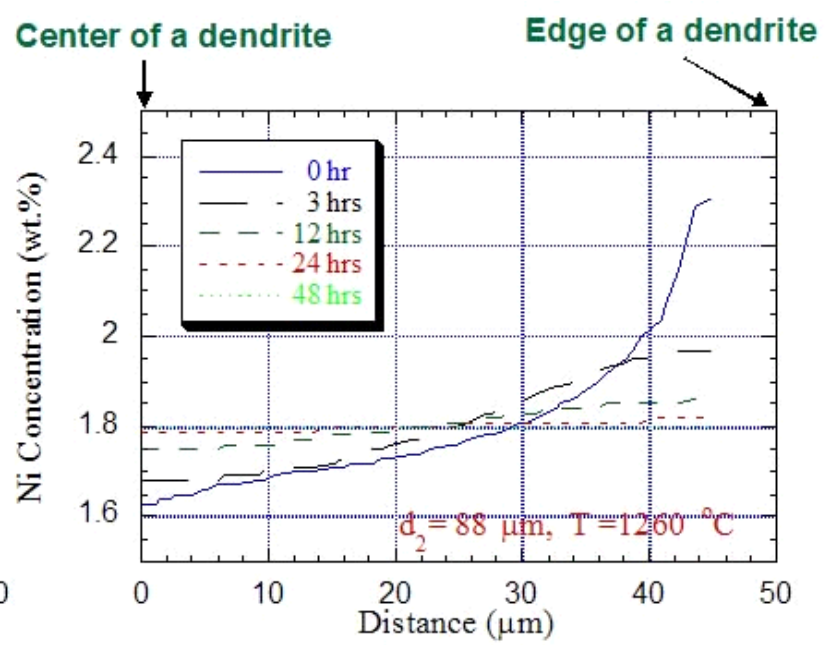

(b)

Fig. 3. The changes in a nickel profile during the homogenization processes: (a) $d_{2}=$ $340 \mu \mathrm{m}$, and (b) $d_{2}=88 \mu \mathrm{m}$. 


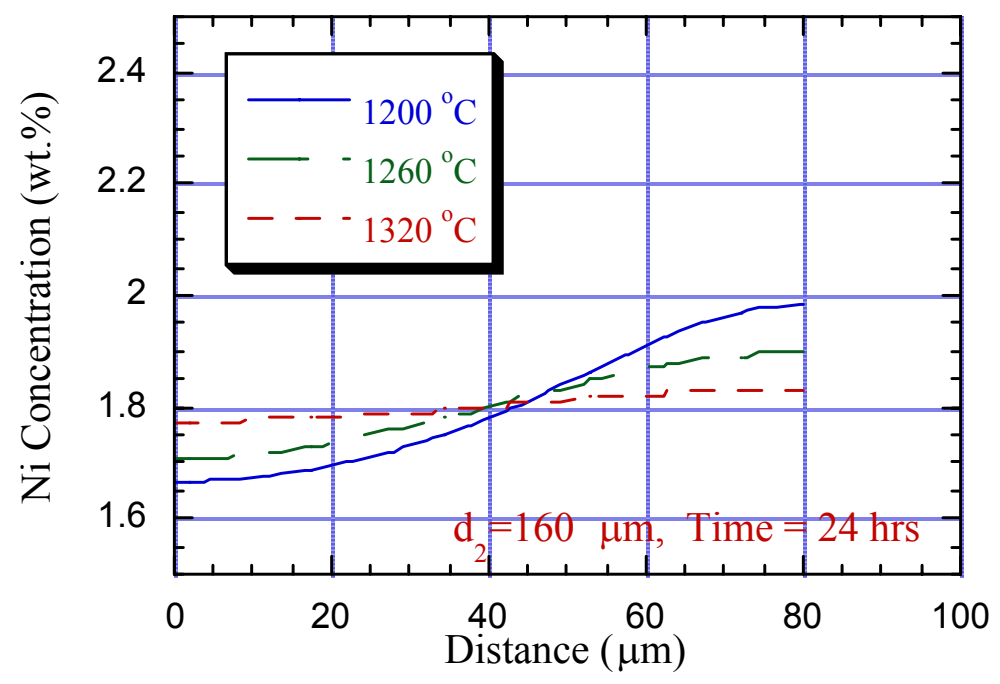

Fig. 4. The changes in nickel profiles during homogenization at various temperatures.

\section{Reports/Publications/Awards:}

Q. Han, V. K. Sikka, and Anthony J. Biell, "Modeling of Elemental Segregation in Alloy Ingots and Thermal Treatments for Homogenization," MPLUS report, October 2003. 
MPLUS No.: $\quad$ MC-02-029

Title: Sanitization Wood Treatment

User Organization: West Virginia University

Morgantown, WV 2606-6125

User Contacts: Jeffrey Slahor, 304-293-7550

jslahor@wvu.edu

J. F. McNeel, 304-293-2941, ext. 2471

jmcneel@wvu.edu

Ed Cesa, 304-293-7550

Jeffrey Slahor from

West Virginia University

Ben Dawson-Andoh, 304-293-7550

bdawson@wvu.edu

Elmer Lang, 304-293-7550

elang@wvu.edu

ORNL R\&D Staff: Craig Blue, 865-574-4351

blueca@ornl.gov

Alicia L. Compere, 865-574-4970

compereal@ornl.gov

Relevance to OIT: The pulp and paper industry has been looking for new methods to provide effective sanitization of wood products used in international trade. Current state-of-the-art methods include heat treating and fumigation, which can take up to three days. Using infrared and microwave methods, this project was successful in reducing the time for heat treatment by a factor of 144 , and cost analysis has shown a worst-case scenario of $\$ 0.89 / \mathrm{Kw} / \mathrm{h}$. In countries where gas and electricity are expensive or are not readily available, a low-energy alternative such as a borate dip treatment will provide a viable alternative.

Objectives: Several technologies (hot water bath, microwave, infra-red, borate-dip diffusion) were investigated to sanitize wood pallets to International Plant Protection Convention (IPPC) standards. The hope was to identify one or two commercially viable methods that effectively sanitize wood pallets in an energy-efficient and economical way. Current state-of-the-art treatments to sanitize wood are heat treating and fumigation. The goals of this proposal were to identify alternative treatment methods that have the potential to lower energy consumptions, reduce treatment time, and be more economical (i.e., heat treatment requires approximately three hours; insecticide treatment can take three days and includes transportation time and costs to and from the treater). 
Phase I: Objectively analyze five alternative treatment methods in regards to sanitizing wood to meet the requirements of IPPC while not impacting the performance of wooden pallets and crating, saving energy, and providing pallet manufacturers with economical alternatives.

Phase II: Work in partnership with the U.S. Department of Agriculture, Animal and Plant Health Inspection Service, American Lumber Standards Committee, pallet and container industry, pallet and container users/customers, and the IPPC working group to obtain approval of potential new treatment methods identified in Phase I.

Phase III: Demonstrate and commercialize potential new treatment methods identified in Phase I. Primary focus will be energy savings, economics, and improving the competitiveness of the wooden pallet and container industry.

Two Experimental Approaches: (1) Microwave treatment of pallet parts and (2) Infrared treatment of pallet parts and finished pallets.

1. Microwave treatment of pallet parts: Will a microwave treatment effectively sanitize wood components? If so, what is the most energy-efficient and cost-effective process? Phase I research focused on (a) test effectiveness of microwave treatment against insects (ants/termites/bark beetles); (b) test the effectiveness of microwave treatment on diseases (decay, fungi); (c) analyze wood parts for alterations in mechanical properties; (d) identify energy requirements and costs; (e) identify the most energy-efficient and cost-effective treatment procedure; (f) identify, analyze and provide possible solutions to secondary environmental issues (if any); ( $\mathrm{g}$ ) conduct market acceptance analysis; (h) if research results are positive, develop a basic treatment schedule; and (i) initiate and implement Phases II and III.

2. Infrared treatment of pallet parts and finished pallets: Can pallet parts and finished pallets be sanitized using an infrared treatment process? If so, what is the most energy-efficient and cost-effective method? Phase I research will focus on following similar steps as identified in method 1 . If the first three steps followed in method 1 are effective, conduct similar steps on finished pallets.

Conclusions: Market share for any given technology will depend on costs and the available energy resources. No data are available for the microwave processing of the pallets because no method was available for measuring the internal temperature of the wood. However, from the number of surviving mealworms after each test, it is obvious that the required temperature can be reached within seconds. Table 1 shows the cost analysis for using infrared to treat pallets. Figure 1 compares the time required for different wood species to reach the required temperature. In countries where electricity or gas is not cheap or readily available, a low-energy alternative such as insecticide treatment or a borate dip treatment will be the most viable alternative. 
It is not possible to estimate the year of commercial introduction of emerging technologies such as microwave or infrared treatment. Borate treatment is already a commercially viable treatment. Total market saturation may not be a reality.

Table 1. Power and cost analysis for heating hardwoods with infrared

\begin{tabular}{|c|c|c|c|c|c|c|}
\hline \multirow{2}{*}{ Sample } & \multirow{2}{*}{$\begin{array}{c}\text { Seconds to } \\
56^{\circ} \mathrm{C} \text { or } \\
\text { Highest } \\
\text { Temperature }\end{array}$} & \multirow{2}{*}{$\begin{array}{c}\text { Percentage } \\
\text { of Full } \\
\text { Power } \\
\text { (88 kW) }\end{array}$} & \multirow[b]{2}{*}{$\begin{array}{l}\text { kW/h } \\
\text { Used }\end{array}$} & \multicolumn{3}{|c|}{ Cost Based on kW/h @ } \\
\hline & & & & $\$ 0.05$ & $\$ 0.10$ & $\$ 0.15$ \\
\hline Maple1 & 945.60 & 20 & 4.62 & 0.23 & 0.46 & 0.69 \\
\hline Maple2 & 962.07 & 20 & 4.70 & 0.24 & 0.47 & 0.71 \\
\hline Maple3 & 380.85 & 20 & 1.86 & 0.09 & 0.19 & 0.28 \\
\hline RedOak1 & 1198.42 & 20 & 5.86 & 0.29 & 0.59 & 0.88 \\
\hline RedOak2 & 311.48 & 20 & 1.52 & 0.08 & 0.15 & 0.23 \\
\hline RedOak3 & 454.45 & 40 & 4.44 & 0.22 & 0.44 & 0.67 \\
\hline RedOak4 & 603.63 & 40 & 5.90 & 0.30 & 0.59 & 0.89 \\
\hline
\end{tabular}

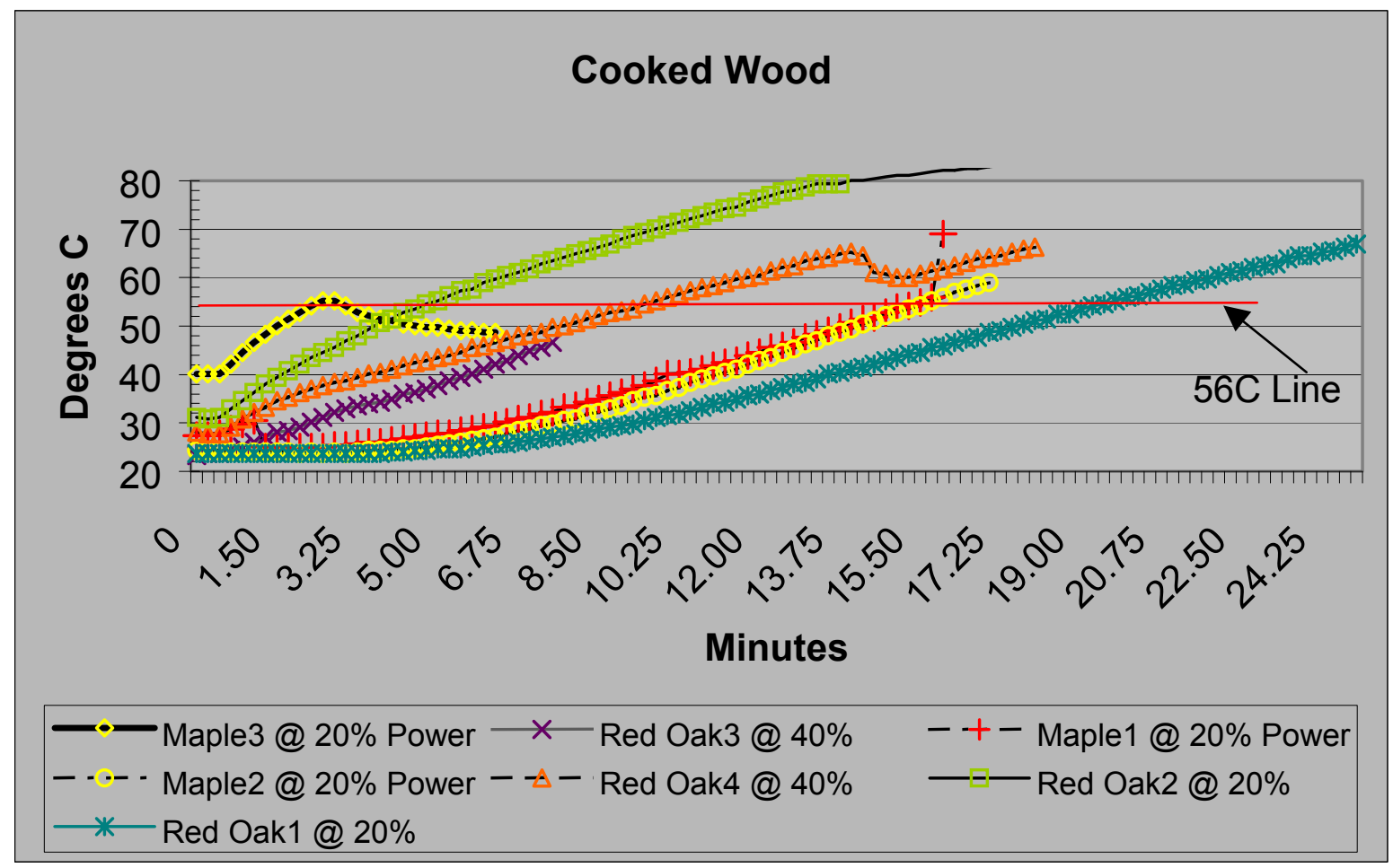

Fig. 1. Graph comparing the heating times for different woods to reach $56^{\circ} \mathrm{C}$. 


\section{Reports/Publications/Awards:}

C. A. Blue, P. G. Engleman, A. L. Compere, J. Slahor, J. F. McNeel, E. Cesa, B. Dawson-Andoh, and E. Lang, "Sanitization Wood Treatment," MPLUS report, 2003. 
MPLUS No.: MC-02-030

Title: Evaluation of Ceramic Seal Disks for Thermodynamic Steam Traps

User Organization: Spirax Sarco, Inc. Blythewood, SC 29016

User Contact: $\quad$ M. P. Gordge, (803) 714-2172 mgordge@spirax.com

ORNL R\&D Staff: S. D. Nunn, (865) 576-1668

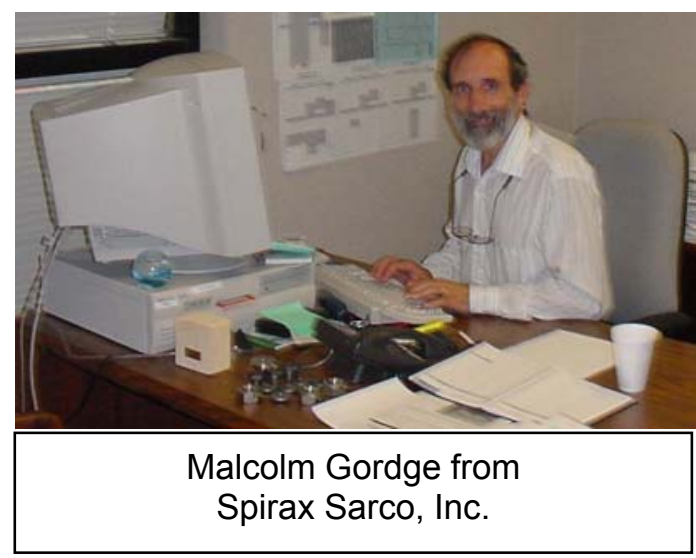
nunnsd@ornl.gov

Relevance to OIT: Cross-cutting technology. Thermodynamic steam traps are an essential device for assuring efficient heat transfer in distribution and process steam lines used throughout industry. By eliminating water and incondensable gases from the process steam, these traps minimize energy waste and improve heat transfer. As wear occurs on the contact surfaces of mating components in the trap, sealing becomes imperfect and efficiency is degraded. In time, this leads to steam losses which can result in significant energy waste. Modern ceramic materials have distinct advantages over metals in many applications. Ceramics are exceptionally hard and resistant to wear. In addition, many ceramics have the unique advantage of being inherently oxidation and corrosion resistant in severe environments. The use of advanced ceramic materials for seal disks in thermodynamic steam traps may substantially reduce component wear and corrosion, thus improving the efficiency and extending the life of the traps. The results of the present study are preliminary in nature, but show promise for the successful implementation of this technology.

Objective: The objective of the project was to evaluate the feasibility of using advanced ceramic materials to replace the metallic seal disk in thermodynamic steam traps to improve the wear resistance of the component and to extend the service life of the steam trap.

Results: Two ceramic materials were evaluated for replacement of steel seal disks in thermodynamic steam traps: silicon nitride, $\mathrm{Si}_{3} \mathrm{~N}_{4}$, and zirconia, $\mathrm{ZrO}_{2}$. The measured density and strength of these materials are shown in Table 1.

Table 1. Measured properties of the hot-pressed ceramic materials

\begin{tabular}{|c|c|c|}
\hline Material & Archimedes Density & Fracture Strength \\
\hline Silicon Nitride, $\mathrm{Si}_{3} \mathrm{~N}_{4}$ & $3.17 \mathrm{~g} / \mathrm{cm}^{3}(100 \%)$ & $661 \mathrm{MPa}(96 \mathrm{ksi})$ \\
\hline Zirconia, $\mathrm{ZrO}_{2}$ & $5.37 \mathrm{~g} / \mathrm{cm}^{3}(100 \%)$ & $1068 \mathrm{MPa}(155 \mathrm{ksi})$ \\
\hline
\end{tabular}


Examples of the machined ceramic disks are shown in Fig. 1. Two disk sizes were fabricated: 1.015 and 1.156 in. diam.

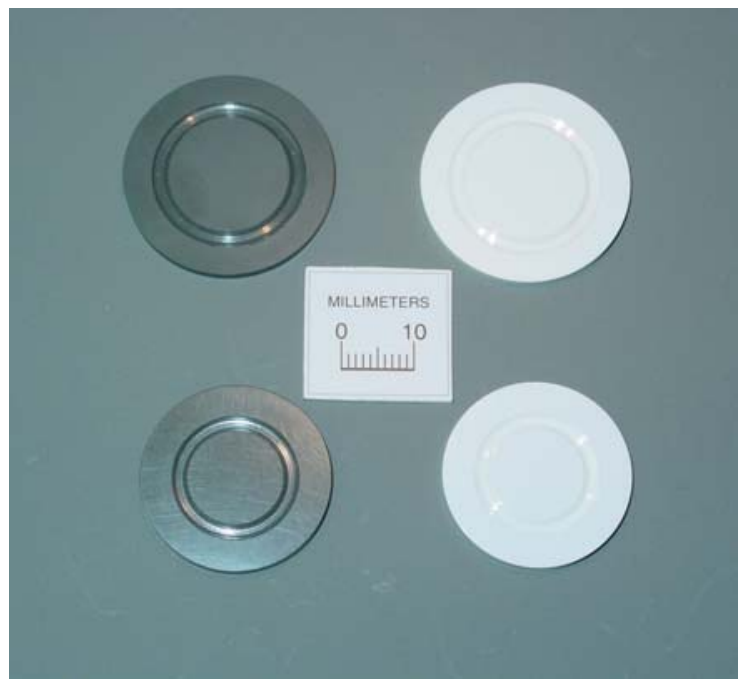

Fig. 1. Machined seal disks made of ceramic material. The disks on the left are made of $\mathrm{Si}_{3} \mathrm{~N}_{4}$, and the disks on the right are made of $\mathrm{ZrO}_{2}$.

The ceramic disks were installed in thermodynamic steam traps at Spirax Sarco and underwent accelerated testing. A summary of the test results is shown in Table 2.

The results of the study are preliminary in nature but show promise for the successful implementation of this technology. One of the disks survived the equivalent of five months of normal operation at 125 psi and was still functioning normally when it was removed from testing.

Table 2. Summary of accelerated functional testing of ceramic disks in steam traps

\begin{tabular}{|c|c|c|c|c|c|}
\hline Material & $\begin{array}{c}\text { Diameter } \\
\text { (in.) }\end{array}$ & $\begin{array}{c}\text { Pressure } \\
\text { (psi) }\end{array}$ & Lifetime & Damage & Cause \\
\hline $\mathrm{ZrO}_{2}$ & 1.015 & 125 & 5 Months & Chipping & Tilt \\
\hline $\mathrm{ZrO}_{2}$ & 1.015 & 230 & $<24$ Hours & Fracture & Internal Flaw \\
\hline $\mathrm{Si}_{3} \mathrm{~N}_{4}$ & 1.015 & 230 & $<24$ Hours & Fracture & Machining \\
\hline $\mathrm{Si}_{3} \mathrm{~N}_{4}$ & 1.156 & 230 & $<24$ Hours & Fracture & Machining \\
\hline $\mathrm{ZrO}_{2}$ & 1.156 & 230 & 1 Week & Chipping & Tilt \\
\hline
\end{tabular}

\section{Reports/Publications/Awards:}

S. D. Nunn and M. P. Gordge, "Evaluation of Ceramic Seal Disks for Thermodynamic Steam Traps," MPLUS report, 2003. 
MPLUS No.: MC-02-031

Title: Infrared Heating of

\section{H.B. Fuller}

Polymers

User Organization: H. B. Fuller Co.

Saint Paul, MN 55164-0683

User Contacts: Charles W. Graves, 651-236-5051

chuck.graves@hbfuller.com

Shelley Kueppers

ORNL R\&D Staff: Craig Blue, 865-574-4351

blueca@ornl.gov

Relevance to OIT: This project focused on reducing the activation time for polyamide adhesives used in the chemical, forest products, and heat-treating industries to produce an energy-efficient lamination process. The concept of using focused infrared (IR) energy to activate the adhesive and produce a fiber-tear bond was brought to practice. Three different IR units were tested on different combinations of five adhesives and two substrates. The project was successful in attaining a $100 \%$ fiber tear using a commercially available IR line source with exposure times of $1 \mathrm{~s}$ and no damage to the substrate. This project is directly relevant to chemical, forest products, and heattreating industries.

Objective: The objective of this project was to determine if it is possible to very rapidly melt polymeric coatings on wood-fiber-based substrates without damaging the substrate. In order to accomplish this, different commercially available IR light sources needed to be evaluated for their ability to focus the light to fit the coating pattern, to optimize various process parameters (e.g., speed, light intensity, coating thickness), and to determine polymer "melt 'open-time'."

The optimum system should have a flux (watts per square inch per second) that would operate at around $50 \%$ of maximum power. This feature would increase the life of the bulb and would open up the processing window.

Experimental: Four hot melt and one water-based adhesive were preapplied to standard corrugated substrates, Inland (hot melt) and (CCNB) (water-based), prior to the visit to ORNL. These substrates were cut down to 4- by 2-in. coupons for testing. Samples of each hot-melt adhesive were preapplied at 1 and 0.5 mil thicknesses; the water-based adhesive was applied at 2 and 4 mils wet. 
The adhesives included HM-1559 standard hot melt packaging adhesive, HL-9256 high heat-resistant Advantra product, NP-2068 water-sensitive polyamide, HM-6278 delayed recrystallization hot melt from Assembly, and S 3879 standard water-based packaging product.

Three IR units were tested on the adhesive substrates at ORNL. These included a spot heater, a line heater, and a flat-bed heater. Each setup consisted of a bulb or bulbs in a ceramic or metal reflector assembly and a power controller ranging from 0 to $100 \%$ of the line voltage.

Initial testing with the spot and line heaters was inconsistent. There were issues with the standby mode on the controller preheating the sample. The procedure was changed so that the lamp was taken up to the desired power and the sample was slid under it for the desired amount of time. When the sample was removed, it was quickly mated and cooled, and the amount of fiber tear achieved was observed.

The intensity of the lamps was increased to get reactivation times of less than $1 \mathrm{~s}$ and still provide $100 \%$ fiber tear. To increase the intensity of the unit even more, another bulb with a higher wattage or a more powerful controller would have to be used. Neither piece was available.

Results: A major concern prior to the visit was whether it would be possible to activate the adhesive without causing the substrate to be significantly affected, including bursting into flames. None of the samples showed any evidence of overheating or approaching the flame point. The CCNB with the water-based adhesive coating distorted with several seconds of IR exposure, but that may have been due to vaporization of retained water. It was estimated that since the adhesives are semiclear, they are probably absorbing about 10 to $20 \%$ of the light, while 70 to $80 \%$ is being absorbed at the corrugated interface.

Spot Heater: HM-1559 (1 mil) was exposed for $2 \mathrm{~s}$ at $100 \%$ power. Only $50 \%$ fiber tear was achieved. Four seconds were needed to obtain 100\% fiber tear. A duration of $4 \mathrm{~s}$ is outside of the window for practical application, so we moved to the next lamp.

Line Heater: The results from the tests using the line heater are summarized in Table 1.

Conclusion: The general concept of using IR energy to activate a preapplied adhesive to permit formation of a bond to a second substrate was reduced to practice. One of the hot-melt adhesives produced excellent bonds at low power settings and 1-s exposure. A couple of adhesives produced acceptable bonds at 2-s exposure times. The waterbased adhesive showed no response under the tested conditions. Higher-power light sources may make it possible to achieve activation times shorter than one $1 \mathrm{~s}$, but, due to equipment configuration, it was not possible to expose samples for less than $1 \mathrm{~s}$. These issues will be addressed before another visit is made to ORNL. 
Table 1. Test results using the line heater at ORNL to process adhesive coatings

\begin{tabular}{|c|c|c|c|c|}
\hline Adhesive & $\begin{array}{c}\text { Percent } \\
\text { Power }\end{array}$ & Dwell(s) & $\begin{array}{c}\text { Focus: Distance from } \\
\text { Substrate (in.) }\end{array}$ & $\begin{array}{c}\text { Percent } \\
\text { Fiber Tear }\end{array}$ \\
\hline HM-1559 (1 mil) & 100 & 2 & 3.5 & 100 \\
\hline & 90 & 2 & 3.5 & 70 \\
\hline & 80 & 2 & 3.5 & 10 \\
\hline & 100 & 1 & 3.5 & 0 \\
\hline & 100 & 1 & 2.5 & 50 \\
\hline S3879 (2 mil wet) & 100 & 2 & 3.5 & 0 \\
\hline & 100 & 4 & 3.5 & 0 \\
\hline & 100 & 6 & 3.5 & $20^{\text {a }}$ \\
\hline & 100 & 8 & 3.5 & 0 \\
\hline & 100 & 2 & 2.5 & 5 \\
\hline NP-2068 (1 mil) & 100 & 4 & 2.5 & 100 \\
\hline & 100 & 2 & 3.5 & 100 \\
\hline & 100 & 4 & 3.5 & 0 \\
\hline & 100 & 2 & 2.5 & 100 \\
\hline HL-9256 & 100 & 1 & 2.5 & 2 \\
\hline & 100 & 2 & 2.5 & 100 \\
\hline HL-6278 & 100 & 1 & 2.5 & 30 \\
\hline & 100 & 2 & 2.5 & 100 \\
\hline & 100 & 1 & 2.5 & 100 \\
\hline & 100 & 0.5 & 2.5 & 20 \\
\hline & 75 & 1 & 2.5 & 2.5 \\
\hline
\end{tabular}

${ }^{a}$ Substrate smoking, curling, discoloration.

The flat-bed and spot heaters were not effective for producing the results required for our application. The flat bed was inadequate because the bed configuration is inappropriate for packaging applications. The spot heater was inadequate because it was incapable of producing the dwell times required for this application. The line heater was identified as the heater of choice.

Flat Bed: The results of the tests using the flat-bed furnace are summarized in Table 2.

Future Work: Application of this technology to other substrates will need to be tested for substrate compatibility on a case-by-case basis.

We believe that these results show the following product/market application possibilities:

1. Activate preapplied hot-melt and polyamide adhesives in $1 \mathrm{~s}$ or less to form fibertear bonds in rigid packaging.

2. Develop superior heat-resistant hot melts $\left(160^{\circ} \mathrm{F}\right.$ or higher) that can be preapplied and subsequently activated to form fiber-tear bonds. 
Table 2. Results of tests performed at ORNL using the flat bed furnace

\begin{tabular}{|c|c|c|c|c|}
\hline Adhesive & $\begin{array}{c}\text { Percent } \\
\text { Power }\end{array}$ & Dwell(s) & $\begin{array}{c}\text { Distance from } \\
\text { Substrate (in.) }\end{array}$ & $\begin{array}{c}\text { Percent } \\
\text { Fiber Tear }\end{array}$ \\
\hline HL-9256 & 60 & 2 & 11 & 5 \\
\hline & 60 & 2 & 6 & 30 \\
\hline & 60 & 2 & 6 & 20 \\
\hline & 60 & 2 & 4 & 20 \\
\hline & 80 & 2 & 5 & $100^{a}$ \\
\hline HM-1559 & 60 & 2 & 5 & 20 \\
\hline NP-2068 & 80 & 2 & 5 & 25 \\
\hline & 60 & 2 & 5 & 0 \\
\hline & 80 & 2 & 5 & 50 \\
\hline
\end{tabular}

${ }^{a}$ Peaks, 0 valley.

3. Use IR to enhance the drying of lamination adhesives in flexible packaging.

4. Pursue other market opportunities, identified in Project Raven, where line-of-sight between the IR source and the adhesive is possible.

To continue this effort, a detailed program plan will be prepared. However, we plan to continue pursuing this concept, including the following activities in the near term:

1. Evaluate high-molecular-weight polymer packaging adhesive formulations (5000 to $10,000 \mathrm{cp} @ 350^{\circ} \mathrm{F}$ ) for IR activation. The objective is to improve heat resistance to more than $160^{\circ} \mathrm{F}$.

2. Identify IR-absorbing additives to reduce activation time. These materials can either be used as simple "solution" additives or appended onto the polymer backbone.

3. Return to ORNL to evaluate new adhesive formulations and to test new IR lamp systems they will acquire.

4. Initiate an analysis of the market to determine customer need and fit, including financial considerations.

We will also test a high-viscosity version of HM-1559 to see how it compares with the standard adhesive in its ability to reactivate. If the comparison is favorable, these adhesives have the potential to provide increased heat resistance of the final bond.

These product and process enhancements may have the potential to be commercialized as specialty or full-value offerings. 


\section{Reports/Publications/Awards:}

C. A. Blue, P. G. Engleman, C. W. Graves, and S. Kueppers, "Infrared Heating of Polymers," MPLUS report, September 2003. 
MPLUS No.: MC-02-032

Title: Identification of Process Parameters for Ease of Compaction and Sintering of Tool Steel (M2) Powders

User Organization: Ametek

Eighty Four, PA 15330

User Contact: George Jucha, 724-225-8400

george.jucha@ametek.com

Dick Mason, 724-250-5182

dick.mason@ametek.com

ORNL R\&D Staff: Vinod K. Sikka, 865-574-5112

sikkavk@ornl.gov

Terry N. Tiegs, 865-574-5173

tiegstn@ornl.gov

G. Muralidharan, 865-574-4281

muralidhargn@ornl.gov

Relevance to OIT: This project is directly relevant to powder metallurgy, steel, and heat-treating industries. Large tonnage of machining in the U.S. is done by the use of tool steel tools. The most common of the steels used is known as M2 and is used in the powder form for the production of final tool. The manufacturing of tools from M2 requires a very long and expensive heat treatment of M2 powders for its compaction. Currently, there is no supplier of easily compactable powders in the U.S. This project effort resulted in two new possible processing options for commercial production of compactable M2 powders in the U.S. The economics of these options are being studied by Ametek.

Objective: The M2 tool steel that is produced in the U.S. does not compact readily because of its high alloying content and yield stress. One method to improve the compaction is a high-temperature vacuum treatment with a very slow cooling rate. The objective of this project was to determine alternate methods to improve compaction of M2 tool steel powder. If successful, it would help Ametek to become a U. S. supplier of tool steel powder. Currently, there is no U.S. supplier of such easily compressible powders.

Over the years there have been several attempts to develop this powder. However, the vacuum-annealing cycle that is currently used is a very long process, requiring up to a 45-h cycle time. Most of this time is due to a slow cooling rate. In addition, the annealing process has not consistently yielded good powder properties. It was 
therefore desirable to develop an annealing cycle to yield good consistent powder properties and be economical. In addition to vacuum annealing, alternative techniques and annealing methods were explored. One alternative method to improving compaction was the addition of ductile iron powders to the tool steel. The yield stress of pure iron is approximately $250 \mathrm{MPa}$, and since the pressing pressures are higher, the iron particles should deform to achieve higher densities.

There are two relatively high volume tool steel powders in use today. These are M2 and M3-2. They are similar in composition. The work for this project concentrated on the M2 powder. The Ametek test powder has the correct M2 chemistry with the exception that it was a little low in carbon. This was done on purpose so that graphite could be added before annealing to better hit the exact final chemistry, since there is carbon loss in annealing. If necessary, other material with the correct carbon levels can be manufactured.

The final material should meet the following specifications:

\begin{tabular}{|c|c|}
\hline Element & Contents (wt \%) \\
\hline $\mathrm{C}$ & $0.75-0.85$ \\
\hline $\mathrm{Cr}$ & $3.75-4.5$ \\
\hline $\mathrm{Mn}$ & $0.25-0.45$ \\
\hline $\mathrm{Mo}$ & $4.75-5.5$ \\
\hline $\mathrm{O}$ & $0.085(\max )$ \\
\hline $\mathrm{P}$ & $0.03(\max )$ \\
\hline $\mathrm{Si}$ & $0.5(\max )$ \\
\hline $\mathrm{S}$ & $0.03(\max )$ \\
\hline $\mathrm{V}$ & $1.6-2.05$ \\
\hline $\mathrm{W}$ & $6.2-6.8$ \\
\hline $\mathrm{Fe}$ & Balance \\
\hline
\end{tabular}

Compressibility: $6.80 \mathrm{~g} / \mathrm{cc}$ minimum @ $120 \mathrm{kpsi}$ and $1 \%$ lithium stearate addition Green Strength: 2750 psi minimum @ 120 kpsi and 1\% lithium stearate addition

\section{Experimental}

Addition of ductile iron powders - Three different types of iron powder additions were made to determine the behavior of each type. These were carbonyl iron ( 1 to $3 \mu \mathrm{m})$, carbonyl iron (6 to $10 \mu \mathrm{m})$, and electrolytic iron (-325 mesh). These were mixed at a concentration of $10 \mathrm{wt} \%$ with the $\mathrm{M} 2$ tool steel powder by dry blending with polymer media for $4 \mathrm{~h}$. In addition, the carbonyl iron (6 to $10 \mu \mathrm{m})$ was also mixed at contents of 5 and $20 \mathrm{wt} \%$. Compaction studies were done in a uniaxial die. Stearic acid was used with sidewall lubrication. No lubricant additions were made to the powder blends. 


\section{$\underline{\text { Heat Treatment }}$}

The principal objective of the heat treatment was to enable easier compaction by reducing the hardness of these powders. The effect of two variables (temperature of heat treatment and postheat-treatment cooling rate) were examined during these studies. Temperatures in the range 750 to $1100^{\circ} \mathrm{C}$ were selected for heat treatment. Thermodynamic calculations available in the literature and supporting experiments show that the lower temperatures in the selected range are typical of a tempering treatment while the higher temperatures are more typical of an austenitizing treatment, as explained later.

Results and Discussion: Results from the two approaches used during this MPLUS project are shown in Figs. 1 and 2. These figures show that the compactable M2 powders are feasible by both approaches, which have a strong potential for commercial scale-up.

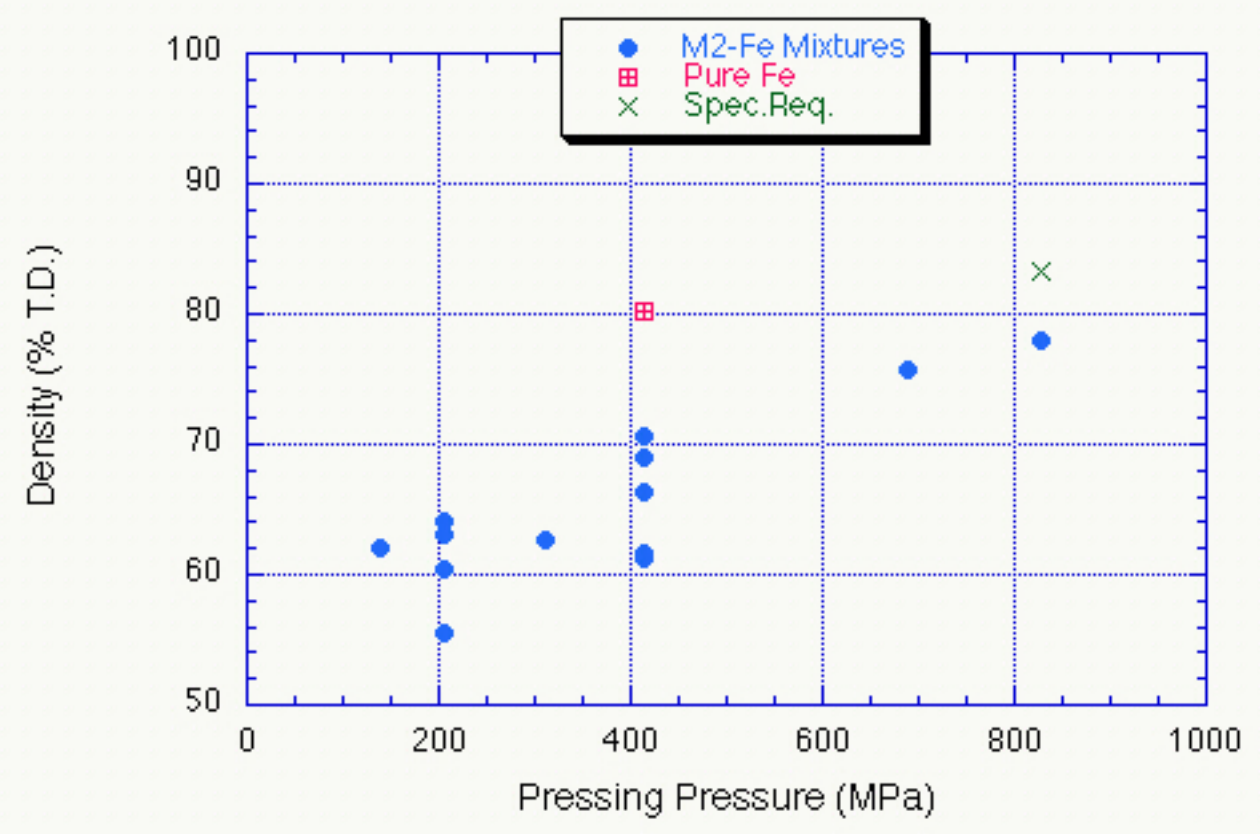

Fig. 1. Compaction behavior of M2 tool steel powder with ductile iron at different pressing pressures. Note the compaction of the pure ductile iron and the M2 specification. Only an addition of $5 \mathrm{wt} \%$ of iron powder will achieve the desired compaction for commercialization. 


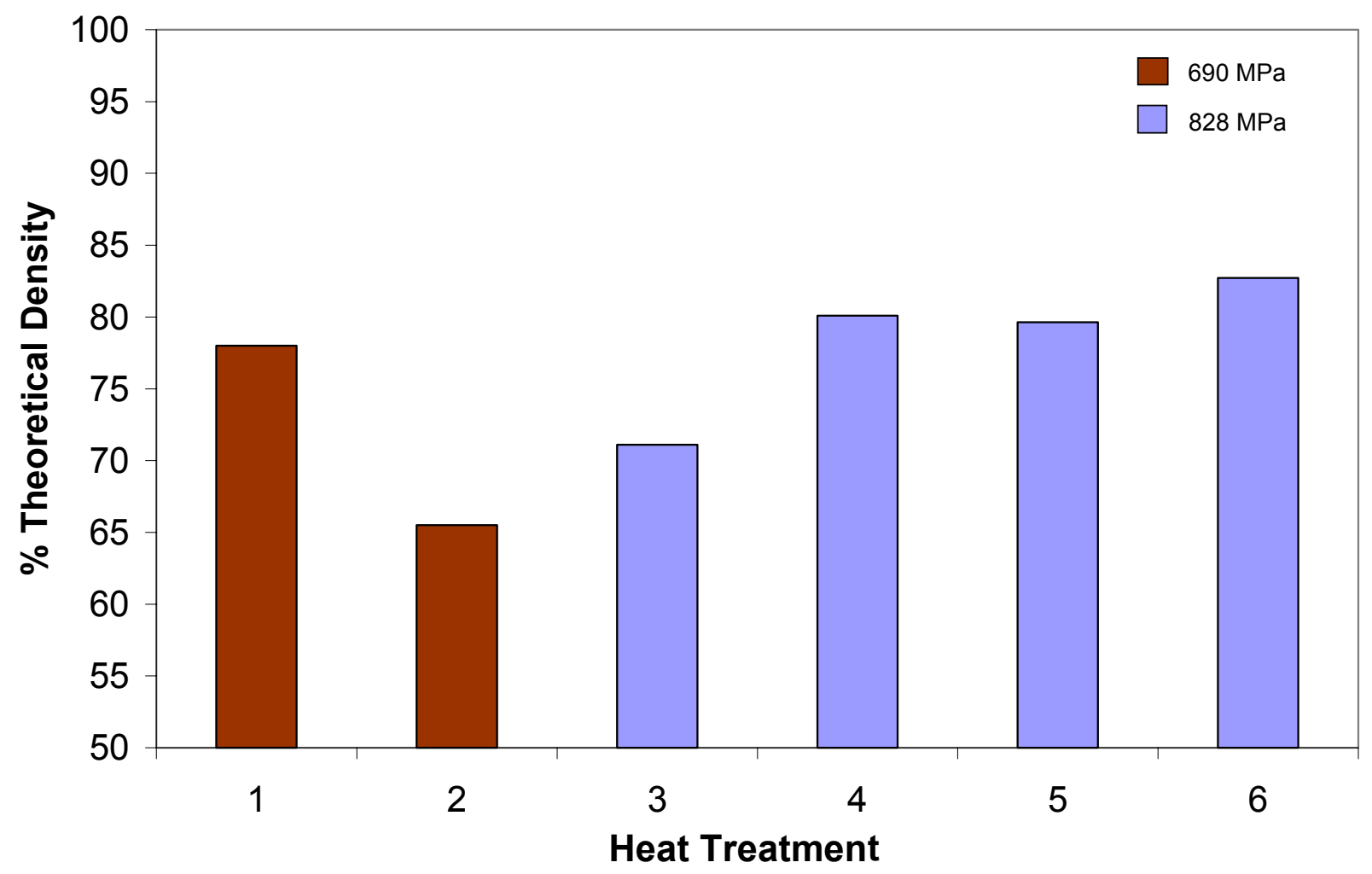

(1) $870^{\circ} \mathrm{C}$ for $2 \mathrm{~h}$, slow cool at $15^{\circ} \mathrm{C} / \mathrm{h}$ to $535^{\circ} \mathrm{C}$, cool to room temperature (RT)

(2) $800^{\circ} \mathrm{C}$ for $15 \mathrm{~min}$, cool to RT

(3) $750^{\circ} \mathrm{C}$ for $2 \mathrm{~h}, \mathrm{Ar}+\mathrm{H}_{2}$, cool to $\mathrm{RT}$

(4) $870^{\circ} \mathrm{C}$ for $2 \mathrm{~h}$, slow cool at $15^{\circ} \mathrm{C} / \mathrm{h}$ to $535^{\circ} \mathrm{C}$, cool to RT [same as (1)]

(5) $1000^{\circ} \mathrm{C}$ for $0.5 \mathrm{~h}$, cool at $10^{\circ} \mathrm{C} / \mathrm{min}$ to $850^{\circ} \mathrm{C}$, slow cool to $535^{\circ} \mathrm{C}$ at $12^{\circ} \mathrm{C} / \mathrm{h}$, cool to RT

(6) $1100^{\circ} \mathrm{C}$ for $0.5 \mathrm{~h}$, cool at $12^{\circ} \mathrm{C} / \mathrm{h}$ to $535^{\circ} \mathrm{C}$, cool to RT

Fig. 2. Compaction behavior of M2 tool steel powder after different annealing conditions. Heat treatment (6) clearly exceeds the production requirements.

\section{$\underline{\text { Reference }}$}

1. J. Golczewski and H. Fischmeister, "Calculation of Phase Equilibria for AISI M2 High-Speed Steel," Steel Research 63 (1992) No. 8, pp. 354-360.

\section{Reports/Publications/Awards:}

T. N. Tiegs, G. Muralidharan, and V. K. Sikka, "Identification of Process Parameters for Ease of Compaction and Sintering of Tool Steel (M2) Powders," MPLUS report, October 2003. 
MPLUS No.: MC-02-033

Title: Characterization of Iron Oxide Powder from Steel Acid Pickling Process at Weirton Steel

User Organization: Weirton Steel Corporation Weirton, WV

User Contact: Howard M. Snyder, 304-797-4999

howard.snyder@weirton.com

Phil Elbaz, 304-797-2738

phil.elbaz@weirton.com

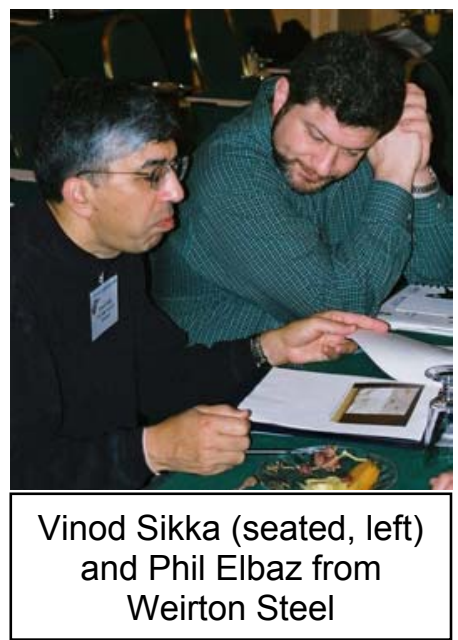

ORNL R\&D Staff: V. K. Sikka, 865-574-5112

sikkavk@ornl.gov

G. Muralidharan, 865-574-4281

muralidharag@ornl.gov

Relevance to OIT: Weirton Steel Corporation produces 7000 to 8000 tons of iron oxide granules every year. They are generated in the form of spheroidal granules in the acid regeneration process used to regenerate the acid to the pickling line. The granules are of high purity compared with competing products but are of a relatively coarse structure and lack fine particle sizes. If no use for these granules is found, they have to be landfilled at a cost of about \$26/ton. However, there are a number of potential applications for these particles including abrasives, animal feed, catalysts, cement additives, coatings, ferrites, foundry sand, iron powder production, pigments, and sinter feed. However, for most applications, the particles were found to be too coarse in size and hence needed to be processed through either a coarse or fine grinding step. An economic analysis showed that use of these materials in pigments and coatings after grinding could result in a profitable use. Development of an appropriate use for these granules will benefit the steel industry and is relevant to Steel IOF and OIT.

Objective: The purpose of this study was to do analyze the phase structure of the granules and to examine the effect of grinding on the purity of the resulting fine powder. In addition, the phases present in a commercially available coloring agent were studied in an effort to understand the path toward using the iron oxide powder as pigments.

Results: To understand the phases present in the particles, X-ray diffraction (XRD) studies at room temperature were carried out on the granules. To study the effect of grinding, XRD was carried out after the completion of the grinding process. To compare the available granules with commercially available coloring agents, a comparative study using XRD was carried out as outlined below. 
Figure 1 shows an XRD pattern from the coarse granules. Clearly, hematite is the major phase present in the material. It was decided that the powder from a different batch would be ground to a finer powder, as is required for some of the potential applications. Some of the coarser powder from a different batch of samples was ground by Weirton Steel and supplied to ORNL. XRD spectra from the finer powder supplied by Weirton Steel were obtained and compared with that found in Quickrete ${ }^{\mathrm{TM}}$. Quickrete ${ }^{\mathrm{TM}}$ is a commercially available cement color used for addition to concrete, mortar, sand, stucco, and other cement mixes. It is available in the form of a liquid. The objective of this was to compare the powder produced by Weirton Steel with that found in commercial coloring agents. The liquid Quickrete ${ }^{\mathrm{TM}}$ was allowed to dry under a hood and the residue that remained after the evaporation of the solvent was collected for further analysis. The XRD spectrum obtained from the powder supplied by Weirton Steel is shown below in Figure 2. Clearly, it is quite similar to the one previously obtained from the coarser powder, although a few additional peaks that are not associated with Hematite are present in the diffraction pattern. Figure 3 shows the spectrum obtained from dried Quickrete ${ }^{\mathrm{TM}}$. Clearly, hematite is present along with hydrated $\mathrm{FeO}$ (Goethite). Further analysis can be done to quantify the amounts of the two compounds present.

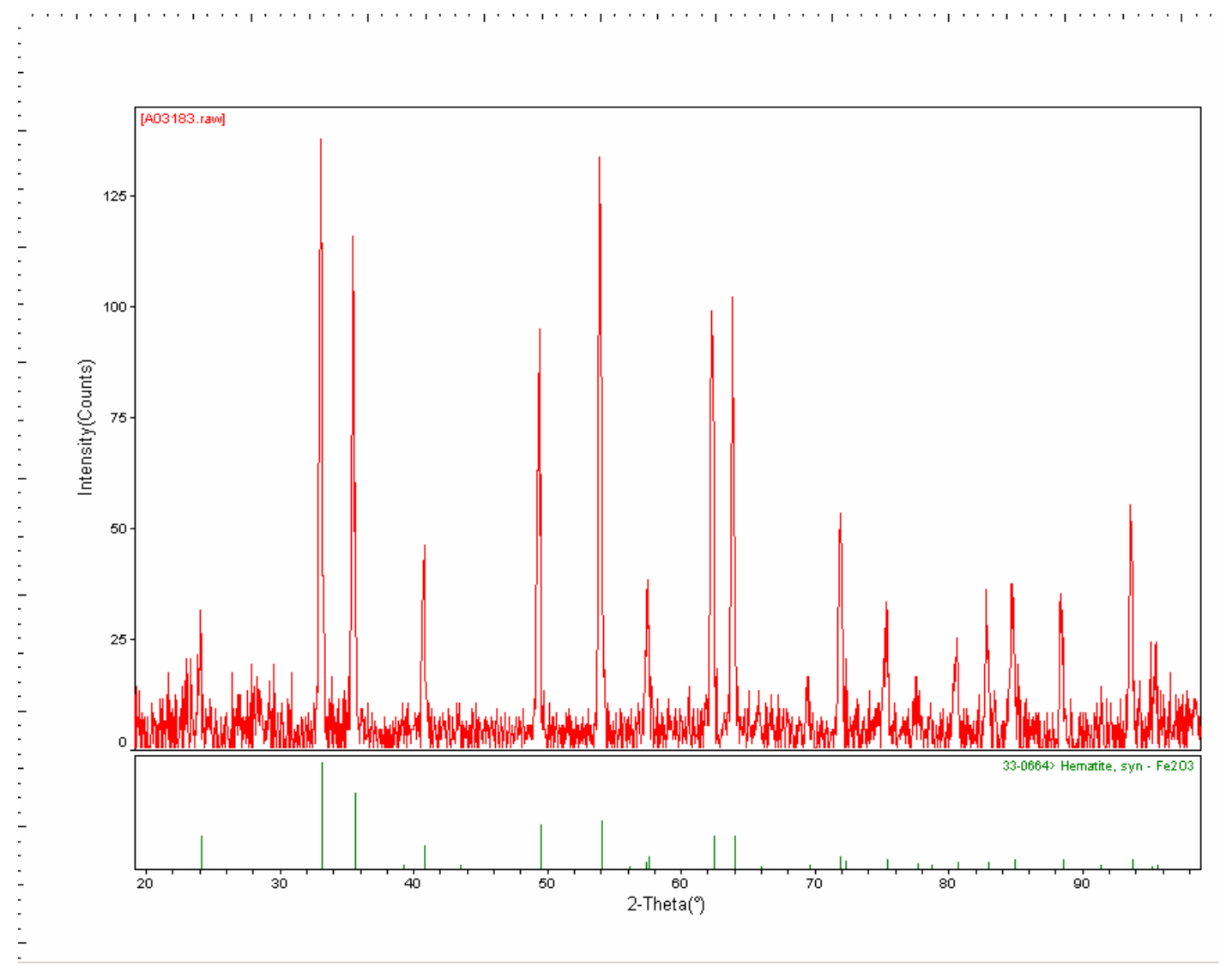

Fig. 1. X-ray diffraction pattern from as-received granules showing predominantly the presence of iron oxide $\left(\mathrm{Fe}_{2} \mathrm{O}_{3}\right)$. 


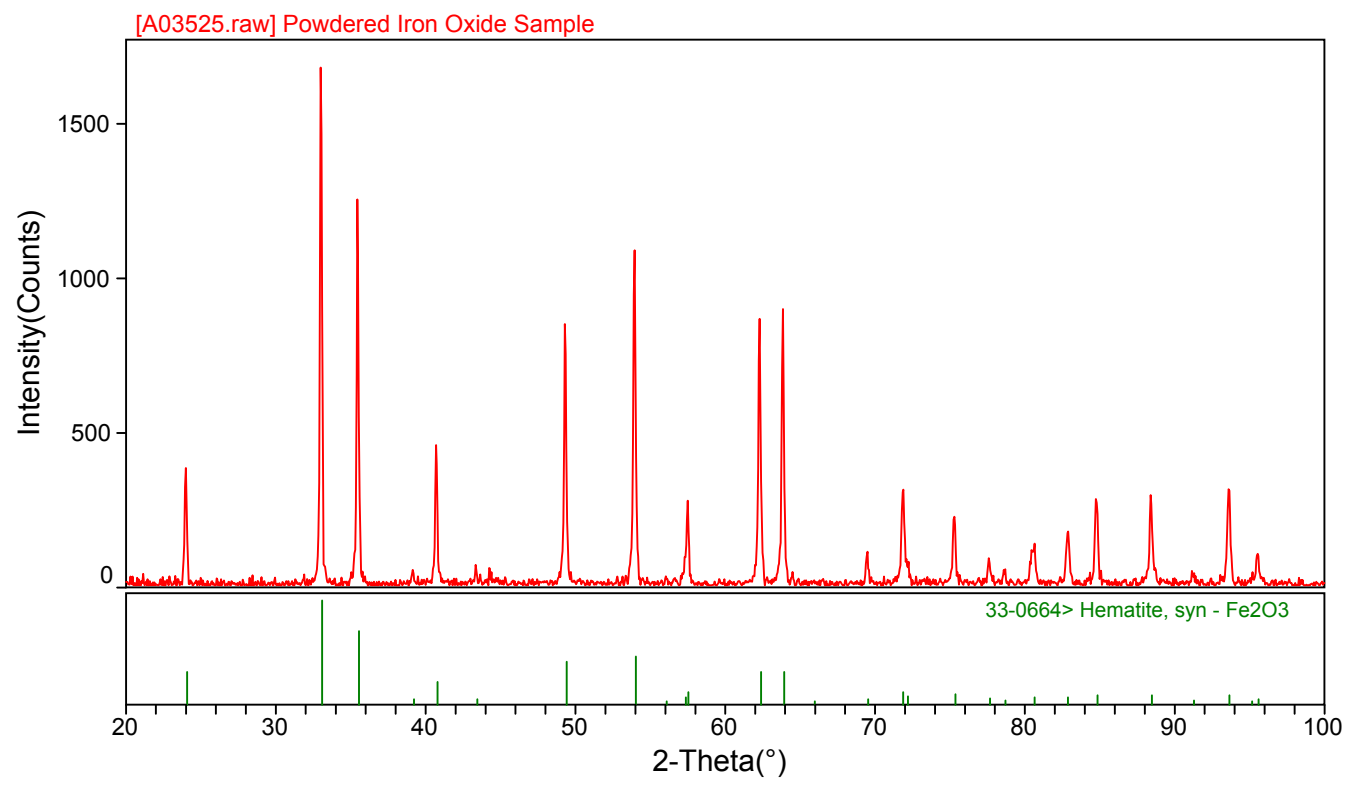

Fig. 2. XRD spectrum obtained from the ground powder supplied by Weirton Steel.

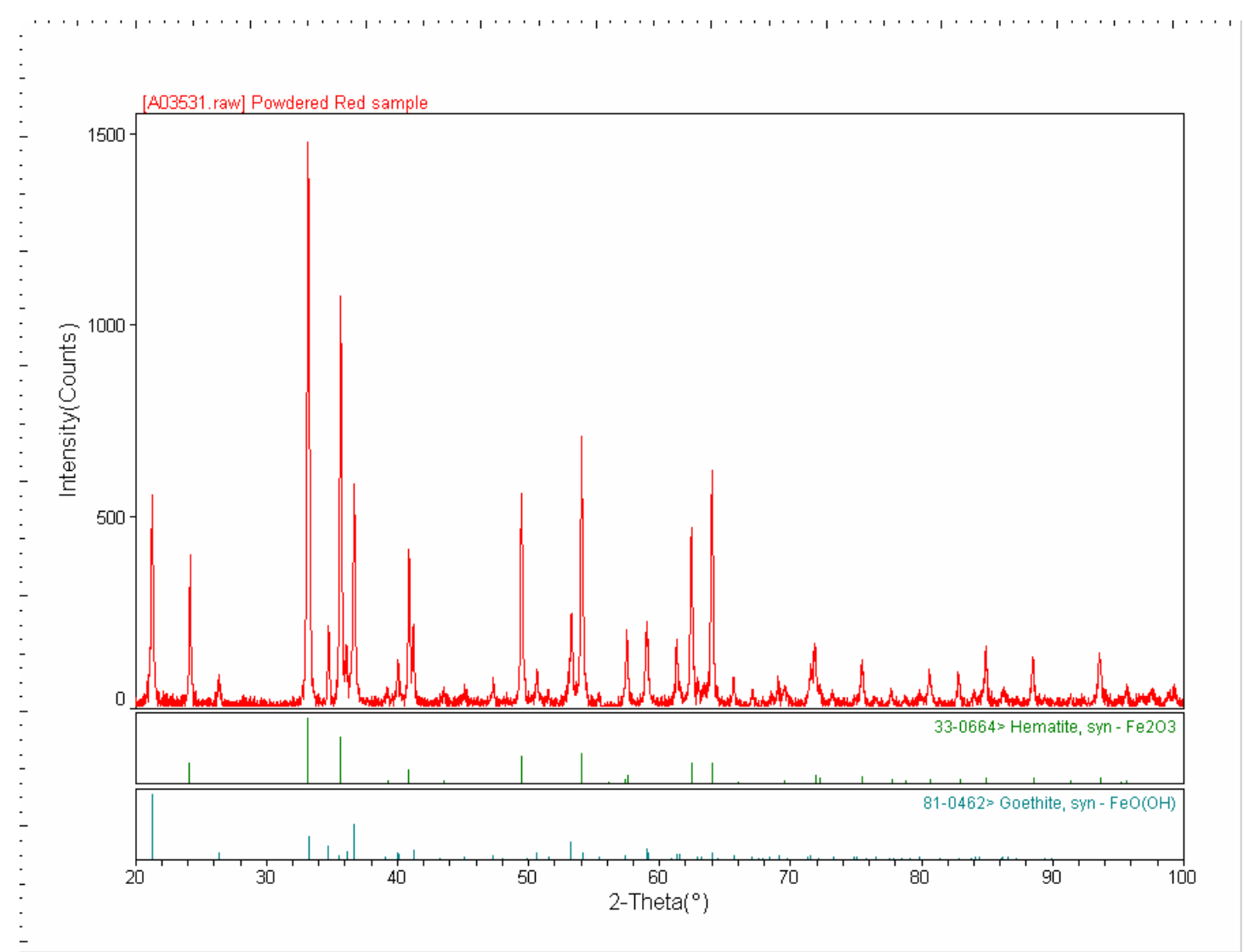

Fig. 3. XRD spectrum obtained from the powder recovered from dried Quickrete ${ }^{T M}$ (a commercially available cement coloring agent). 
The present study clearly shows that the granules produced by Weirton Steel Corporation consist predominantly of $\mathrm{Fe}_{2} \mathrm{O}_{3}$. Two different batches of the material (both before and after grinding) show consistently similar constituents. Comparison with commercially available coloring agent shows that a similar iron oxide is also present in the commercial product. However, in addition to the iron oxide, additional phases are present. This information can be used to formulate coloring agents with the iron oxide produced by Weirton Steel Corporation.

\section{Reports/Publications/Awards:}

G. Muralidharan, V. K. Sikka, and P. Elbaz, "A Study of Iron Oxide Produced by Weirton Steel during Pickling Acid-Regeneration," MPLUS report, 2003. 
MPLUS No.: MC-02-034

Title: Rapid Infrared Fusing of $C^{3}$ Coatings

User Organization: Component Composite Coatings International, LLC (C3)

Roswell, GA 30076-2627

User Contacts: Mann Aner Shoffner, 404-876-4351

shoffner@mindspring.com

Mark Deininger, 770-998-6392

mark.deininger@cccintl.com

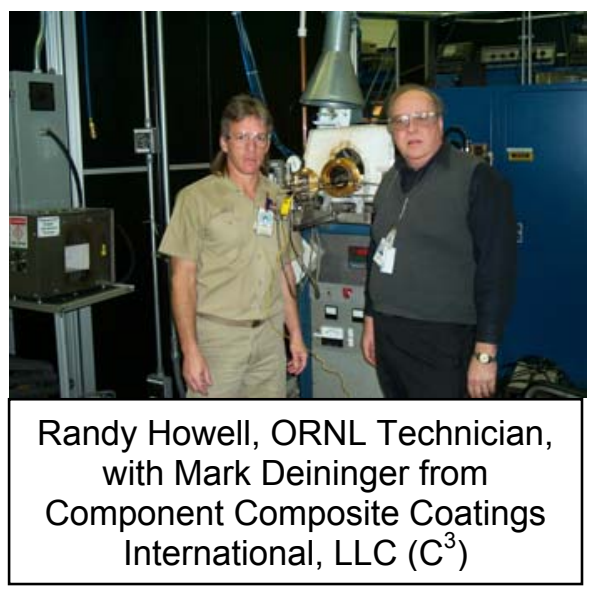

ORNL R\&D Staff: $\quad$ Craig A. Blue, 865-574-4351

blueca@ornl.gov

Relevance to OIT: Zirconia or similar surface treatments is used to treat material surfaces to enhance wear properties and improve resistance to erosion, corrosion, and soldering from molten-metal attack. The infrared- (IR) modified surface is highly durable and provides improved surface properties, extending the performance and life of the products. This is of particular interest to the metal-working, forging, casting, internal combustion, and turbine engines industries where elevated wear due to the above conditions is common. This project produced zirconia-coated inserts that allowed spindle speeds to increase from 4100 to $8000 \mathrm{rpm}$ without reducing the life of the insert; additionally, a $1000 \%$ extension of the tool life was observed when milling aluminum 356. Zirconia treatments generated up to $3000 \%$ increase in the life of core pins used in aluminum die casting, increasing the sheath life by $850 \%$.

Objective: To investigate if rapid infrared treatment can substitute the conventional overtreatment to fuse Component Composite Coatings International, LLC $\left(\mathrm{C}^{3}\right)$ coatings. Infrared treatment can help reduce treatment times and costs and can allow treatment of much larger surfaces.

Results: $C^{3}$ s zirconia surface treatment on tool inserts extended tool life up to $1000 \%$ and increased the production by $10.3 \%$.

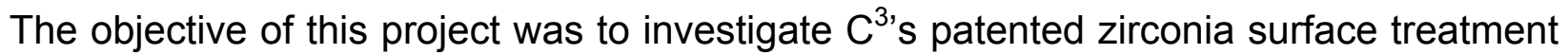
using rapid infrared processing. The surface treatment is essentially a coating technique that involves dipping or brushing the parts in a zirconia-based solution, which, when subjected to a heat treatment, forms a molecular bond on the surface of the substrate. This modified surface is highly durable and provides improved surface properties such as resistance to wear, corrosion, and erosion, thereby extending the performance and life of the components in service. The components that were coated and field tested as a part of this MPLUS project include cutting tool inserts and thermal sheaths, and core pins used in the aluminum casting industry. 
The parts to be coated were cleaned, dipped in $\mathrm{C}^{3}$ 's zirconia-based solution and then heated in a circular water-cooled infrared furnace to temperatures as high as $425^{\circ} \mathrm{C}$. The infrared furnace (Fig. 1) is a 33-KW unit that contains a circular array of tungsten halogen lamps enclosing a quartz tube that facilitates containment of various atmospheres in addition to air, such as argon, argon plus hydrogen, and vacuum. The sample is placed inside this tube for heating. The unique features of the furnace (such as the ability of the tungsten halogen lamps to go from cold to full emission in a few seconds and vice versa and its cold wall design) allow for very fast processing rates. In this present test, the coated samples were heated up to $450^{\circ} \mathrm{C}$ at $17^{\circ} \mathrm{C} / \mathrm{min}$, held at that temperature for $10 \mathrm{~min}$ and cooled down to room temperature immediately after the hold time. The heating was carried out in an argon atmosphere, and before every heating cycle the furnace was pumped down to vacuum (250 millitorr) and back-filled with argon three times to avoid any contamination.

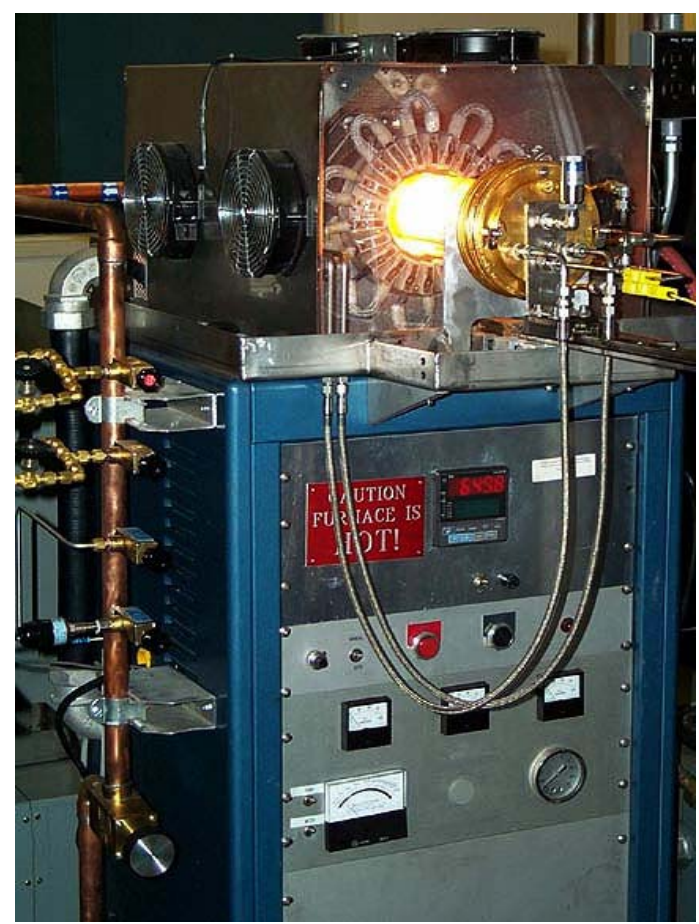

Fig. 1. ORNL's circular infrared furnace used to heat the parts after they were coated with zirconia-based solution.

Characterization of this coated surface using scanning Auger microanalysis showed that zirconia penetrates the metal substrate in the order of 200 to $300 \mathrm{~nm}$. Fig. 2 shows the change in the composition of zirconia as a function of depth through the coating and into the substrate. X-ray analysis conducted on a similar coating when applied to an austenitic steel coupon indicated that within the depth of X-ray penetration, the major phases present were austenitic steel, zirconia, and carbide precipitates. Detailed analysis of the X-ray pattern showed that the zirconia is crystalline and has a cubic crystal structure with a 3-nm crystallite size. 


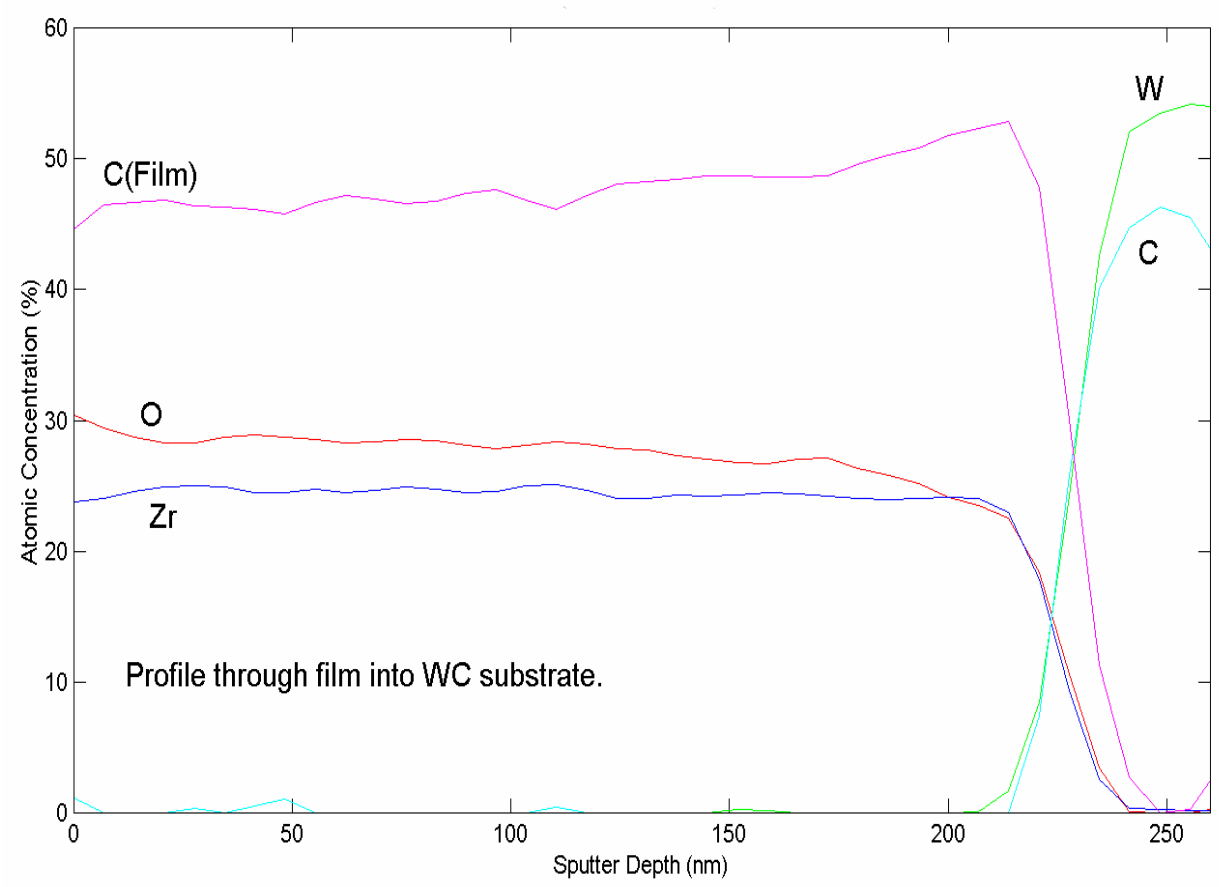

Fig. 2. Depth profile of $C^{3}$ 's zirconia coating on WC substrate.

Field Testing: Figures 3(a), (b), and (c) illustrate the results obtained from the zirconiacoated tool inserts, core pins, and thermal sheaths, respectively, while they were being tested in the field. The figures show that $\mathrm{C}^{3 \text { 's }}$ zirconia surface treatment can lead to life extensions; for example, in case of tool inserts the useful life $1000 \%$. Results show that this treatment not only increases the life but also increases the performance of the tool insert. The coatings allowed spindle speeds as high as $8500 \mathrm{rpm}$, and production was increased by $10.3 \%$. The increase in the life as well as the performance of the tool could be attributed to the zirconia or zirconia-rich layer present on the surface, which prevents the material being machined from attaching to the cutting edge, thus preventing the resultant tool wear. The fine-grained structure (nano-size crystallites), as observed during the X-ray analysis, may also contribute to the increased wear resistance at the cutting edge of the tool insert.

Conclusion: The test results obtained from the zirconia-coated tool inserts, core pins, and thermal sheaths show that zirconia or similar surface treatments can be potentially used to treat surfaces of materials used in applications where enhanced wear properties and reduced erosion or soldering due to molten metal attack are desired. In addition, using infrared techniques can make these treatment processes much faster and cheaper, thus reducing the costs for many industries. The improved properties in the case of the tool insert were due to the fine-grained cubic zirconia, which prevented the cutting edge from getting worn out during the machining operation. The mechanisms underlying the reduced soldering and erosion for core pins and thermal sheaths were not studied as a part of this project and will be investigated and reported separately. 


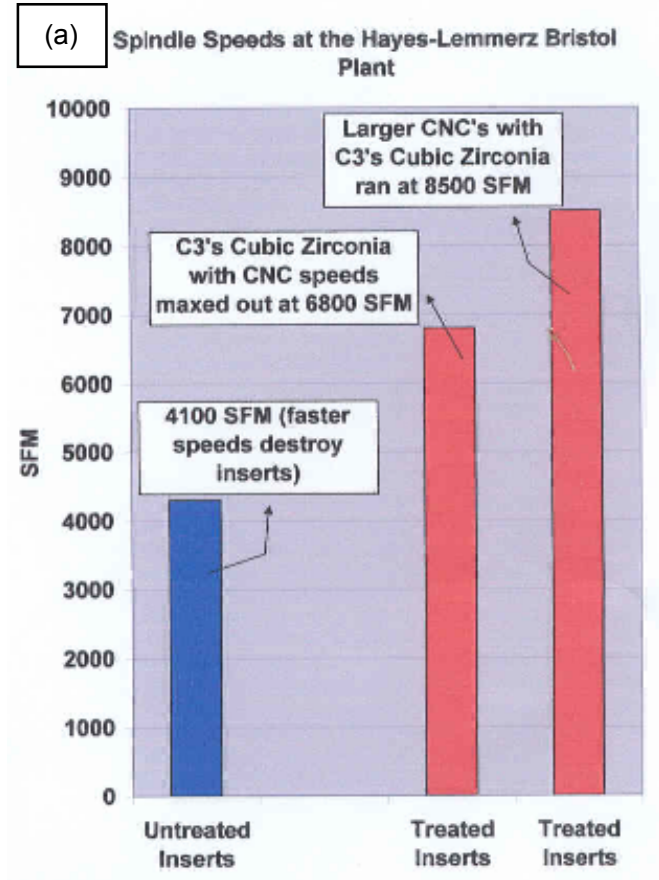

(b) Soldering Reduction of Aluminum Die Cast Core Pins

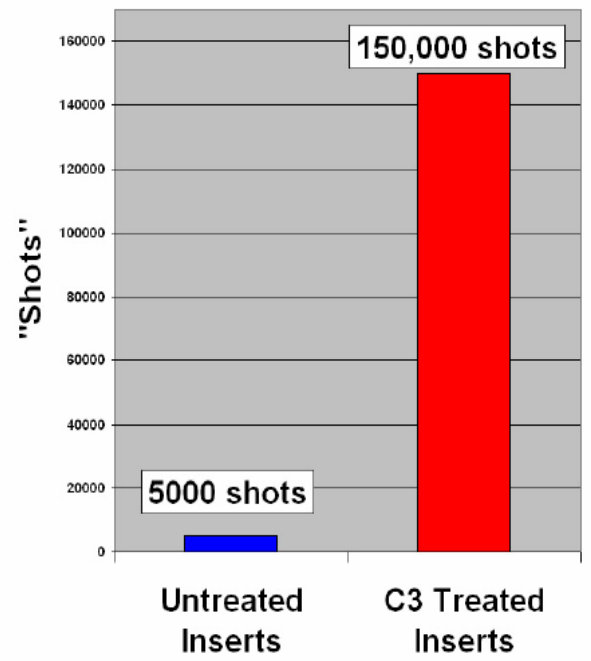

Number of Parts Milled - Client \#-

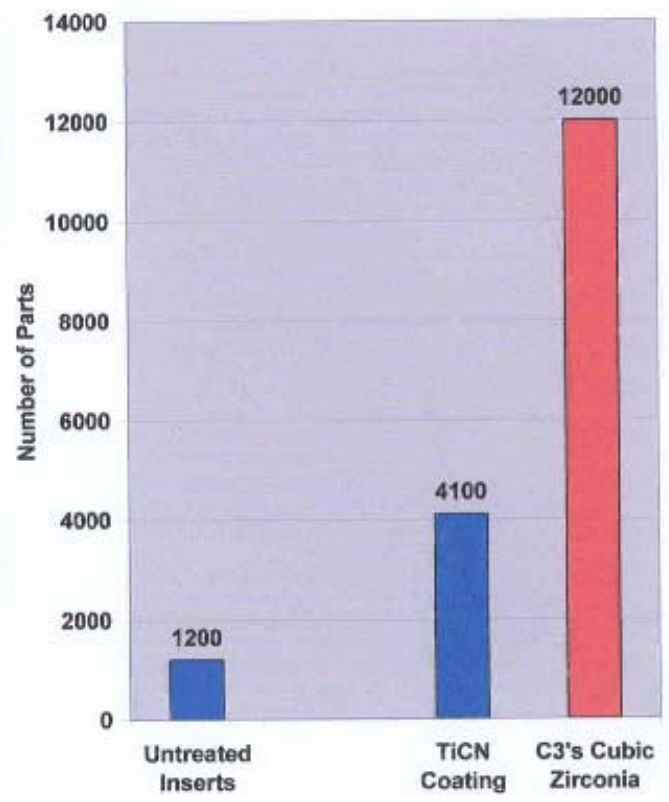

(c) Cycle* Life Extension of $\mathbf{H - 1 3}$ Thermal Couple Sheaths

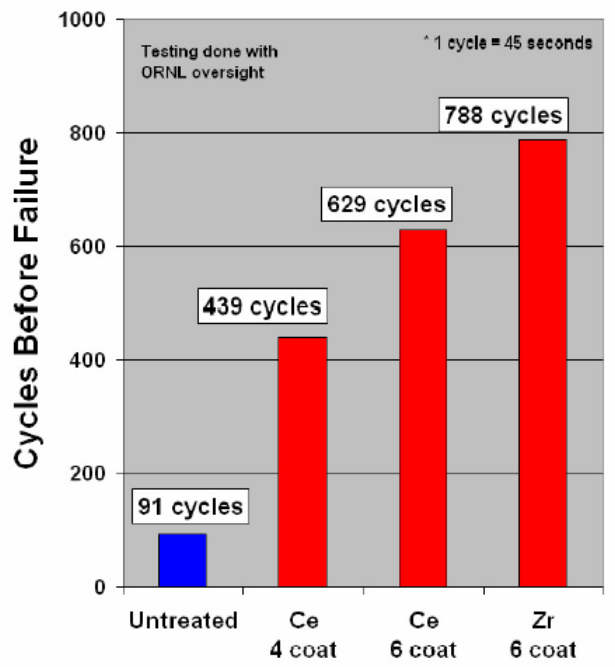

Fig. 3. (a) Zirconia-coated inserts allowed spindle speeds to increase from $4100 \mathrm{rpm}$ to 6500 to $8000 \mathrm{rpm}$ without reducing the life of the insert and achieved $1000 \%$ life extension during milling of Al 356; (b) zirconia surface treatments yielded life extensions up to $3000 \%$ for aluminum die-cast core pins; and (c) unlike bare $\mathrm{H}-13$ thermal sheaths, which lasted for 91 cycles, zirconia-treated $\mathrm{H}-13$ thermal couple sheaths lasted for 788 cycles, thus extending the sheath life by $850 \%$.

\section{Reports/Publications/Awards:}

C. A. Blue, "Rapid Infrared Fusion of $\mathrm{C}^{3}$ Solution-Based Coatings," MPLUS report, 2003. 
MPLUS No.: MC-02-035

Title: Particle Effects on Texture Development during Processing of Aluminum Sheet

User Organization: Alcoa Technical Center Alcoa Center, PA 15069

User Contact: Dr. Hasso Weiland, 724-337-3133 hasso.weiland@alcoa.com

ORNL R\&D Staff: $\quad$ B. Radhakrishnan, 865-241-3861 radhakrishnb@ornl.gov

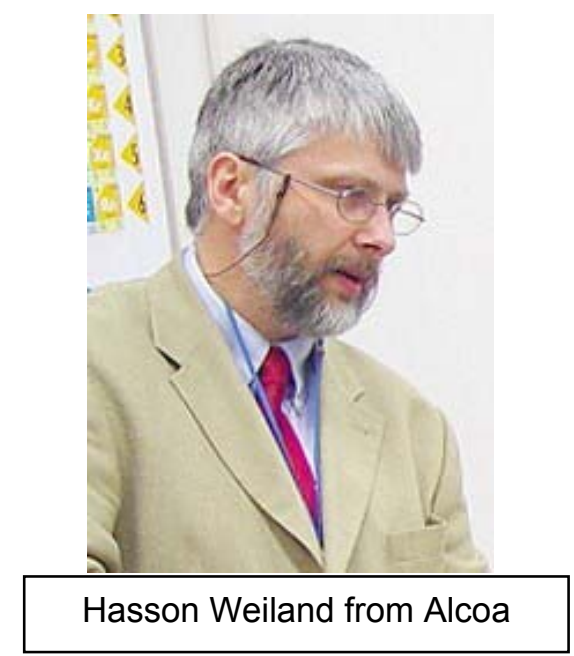

G. B. Sarma, 865-574-5147 sarmag@ornl.gov

Relevance to OIT: The formability or shaping behavior of aluminum alloy sheet is strongly affected by the microstructure of the sheet. The product yield from this process may be improved if one understands the impact of various sheet features like hard particles on the formability of the sheet. The focus of this project was to use a computational model to evaluate the influence of hard particles on the microstructure during hot deformation of aluminum alloys. The results of the model indicate that hard particles may lead to shorter processing times at temperature of aluminum sheet and may promote new grain orientations, which will impact the formability of the sheet.

Objective: To perform meso-scale simulations to understand the influence of coarse, nondeformable particles on the recrystallization kinetics and the development of recrystallization textures in aluminum alloys. The simulations focused on the effect of particle shape and particle location within the microstructure and the initial grain orientation prior to deformation on the final recrystallized texture and recrystallization kinetics

Results: The presence of hard particles is necessary to initiate recrystallization in single crystals. In the case of bi-crystals containing a hard particle in the grain boundary, the recrystallization kinetics is faster than in particle-free systems indicating that the growth rate of particle stimulated nucleation (PSN) is faster than the straininduced boundary migration present in particle-free bicrystals. In the case of a tri-crystal containing a hard particle at the triple point, there is again a significant increase in recrystallization kinetics compared with the particle-free case. The recrystallization kinetics is also sensitive to the particle shape as well as to the individual grain orientations. Although "random" orientations are formed in the localized deformation zone in the vicinity of the hard particles, the orientations of the nuclei that grow seem to have a definite orientation relationship with respect to the matrix grains that result in the formation of special boundaries. This is the first time that the above "micro-growth selection" has been simulated at the microstructural length scale. 
In the future, the microstructure simulation results can be incorporated into an overalll process model that can predict the recrystallization kinetics and texture evolution during thermomechanical processing of commercial aluminum alloys with a significant elimination of empiricism found in existing models (see Figs. 1 and 2).

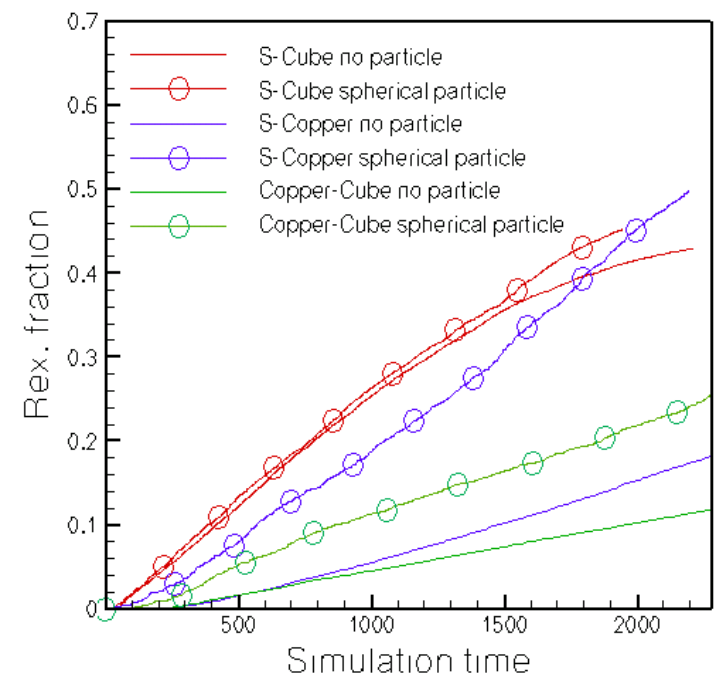

Fig. 1. Simulations quantify the influence of particle on recrystallization kinetics of aluminum bicrystals.

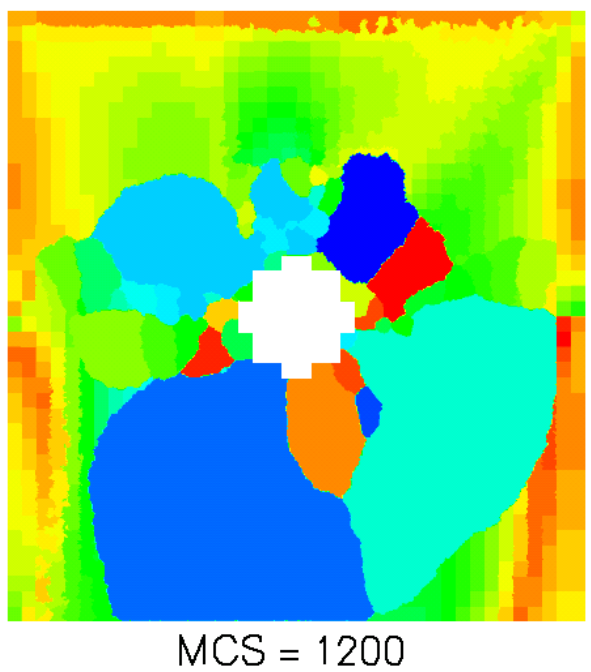

Fig. 12. Simulations capture the formation of recrystallized grains with "random" crystallographic orientations which originate from the particledeformation zone in an aluminum bicrystal.

\section{Reports/Publications/Awards:}

B. Radhakrishnan and G. Sarma, "Simulation of Microstructure and Texture Evolution in Particle-Containing Aluminum Alloys," MPLUS report, 2003.

Results of MPLUS MC-02-035 presented at the Thermec 2003 conference held in Madrid, Spain, July 7-11, 2003.

Journal article to be published in Philosophical Magazine. 
MPLUS No.: MC-02-036

Title: Quantitative Characterization of the Phase Transformation Kinetics and Dilation Strains of a Hyper-Eutectoid SAE 41XX Steel Alloy for Incorporation into a Process Optimization Simulation Tool

User Organization: Caterpillar, Inc.

East Peoria, IL 61630

User Contacts: $\quad$ K.W. Burris, 309-578-6621

Burris_Kenneth_W@cat.com

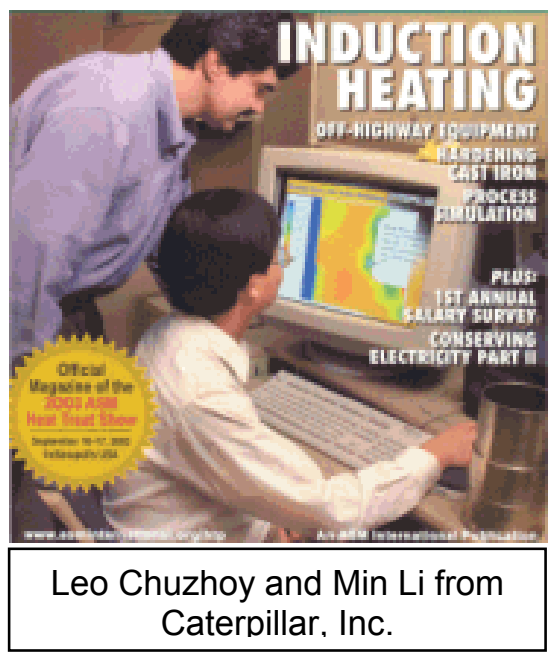

L. Chuzhoy, 309-578-6621

chuzhoy@cat.com

ORNL R\&D Staff: Gerard M. Ludtka, 865-574-5098

ludtkagm1@ornl.gov

Relevance to OIT: Product cost and performance are two major pressures influencing the acceptance of energy-savings technologies by the manufacturers, suppliers, and users in the steel, forging, and heat-treatment industries. Energy cost has become a significant portion of total product cost in these sectors. Major reductions in energy use are potentially achievable for these industries through the development and optimization of cost-effective fabrication processes and enhanced product performance. The key enabling technologies to achieve these benefits are improved materials and realistic microstructure-level simulations to predict manufacturability and life-cycle performance. Success in these key areas is critically dependent on having reliable phase transformation kinetic and dilation data for conducting accurate predictive optimization modeling for the evolution of microstructure, residual stress, and distortion. This MPLUS project utilized the unique high-speed quenching dilatometer facilities at ORNL to provide these critical phase transformation data for Caterpillar's materials and process modeling endeavors to enhance product performance and improve fabrication processing energy efficiency. This project is relevant to the forging, heat-treating, mining, metal casting, and welding industries.

Objective: To perform a high-speed quenching dilatometry investigation of the phase transformation kinetics and dilations of a hypereutectoid SAE 41XX steel at various cooling rates from an austenitization temperature of $1700^{\circ} \mathrm{F}\left(927^{\circ} \mathrm{C}\right)$. The $A_{C 1}, A_{C c m}$, $A_{R 1}$, and $A_{R c m}$ transformation temperatures will be determined for this alloy as part of this investigation for defining these critical transformation temperatures needed for incorporation into the modeling tool and in support of developing a continuous cooling transformation (CCT) diagram. The overall objective is to generate quantitative volumechange information as a function of temperature, time, and microstructure to capture the CCT behavior of this material that can be used in process optimization modeling 
simulations of carburized SAE 41XX steels. Selected metallographic and X-ray diffraction support will augment this information, as required, to define the microstructures that are evolving at the various cooling rates.

Results: A series of dilatometric experiments was conducted on SAE 41XX steel specimens. The cylindrical specimens were $3 \mathrm{~mm}$ in diameter and $8 \mathrm{~mm}$ long. The experiments provided quantitative characterization of volumetric changes and microstructural transformations of the steel during heating and cooling. An austenitization temperature of $927^{\circ} \mathrm{C}$ was used for each test.

The following studies were conducted:

1. Duration of Austenitization: The specimens were soaked at the austenitization temperature for $1 \mathrm{~s}$ and $20 \mathrm{~min}$ and then rapidly cooled. When austenitization time was increased from $1 \mathrm{~s}$ to $20 \mathrm{~min}$, the martensite start (Ms) temperature dropped from 187 to $130^{\circ} \mathrm{C}$ (Fig. 1).

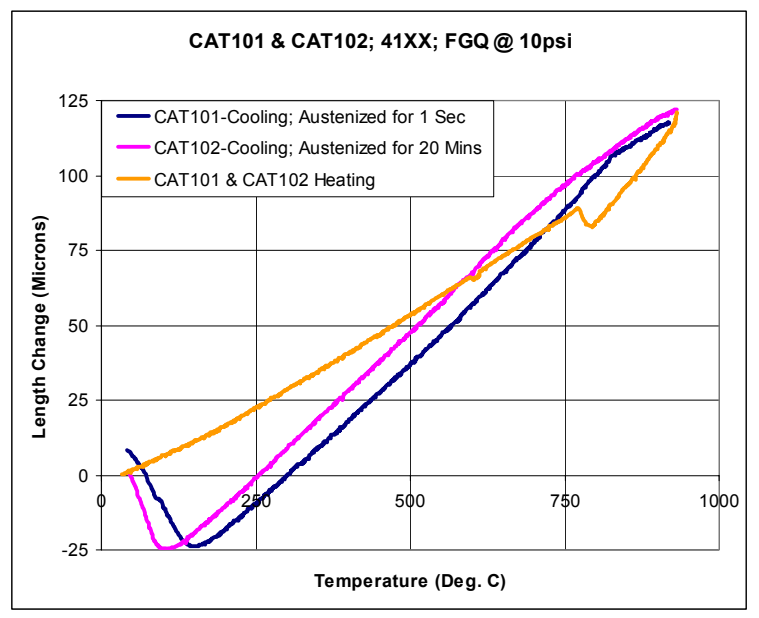

Fig. 1. Effect of austenitization time.

2. Austensite start temperature on heating $\left(A_{C_{X}}\right)$ and austensite start temperature on cooling $\left(A_{R x}\right)$ temperatures: The specimens were slowly heated and then cooled to determine the $A_{C x}$ and $A_{R x}$ transformation temperatures (Fig. 2). The measured $A_{C 1}$ and $A_{C 3}$ temperatures were 739 and $795^{\circ} \mathrm{C}$, respectively. The secondary transformation, which was probably due to carbide dissolution, was identified at $822^{\circ} \mathrm{C}$.

3. Transformation start $\left(T_{s}\right)$ and transformation finish $\left(T_{f}\right)$ temperatures: The specimens were cooled from 950 to $250^{\circ} \mathrm{C}$ in $150 \mathrm{~min}$ (see Fig. 3). The $T_{s}$ and $T_{f}$ temperatures were found to be between 725 and $730^{\circ} \mathrm{C}$ and between 661 and $664^{\circ}$, respectively. 


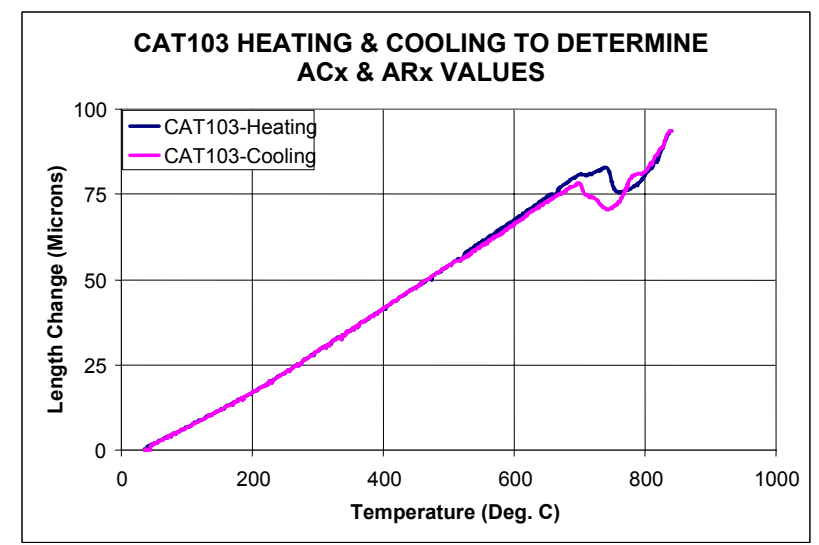

Fig. 2. Transformation temperature.

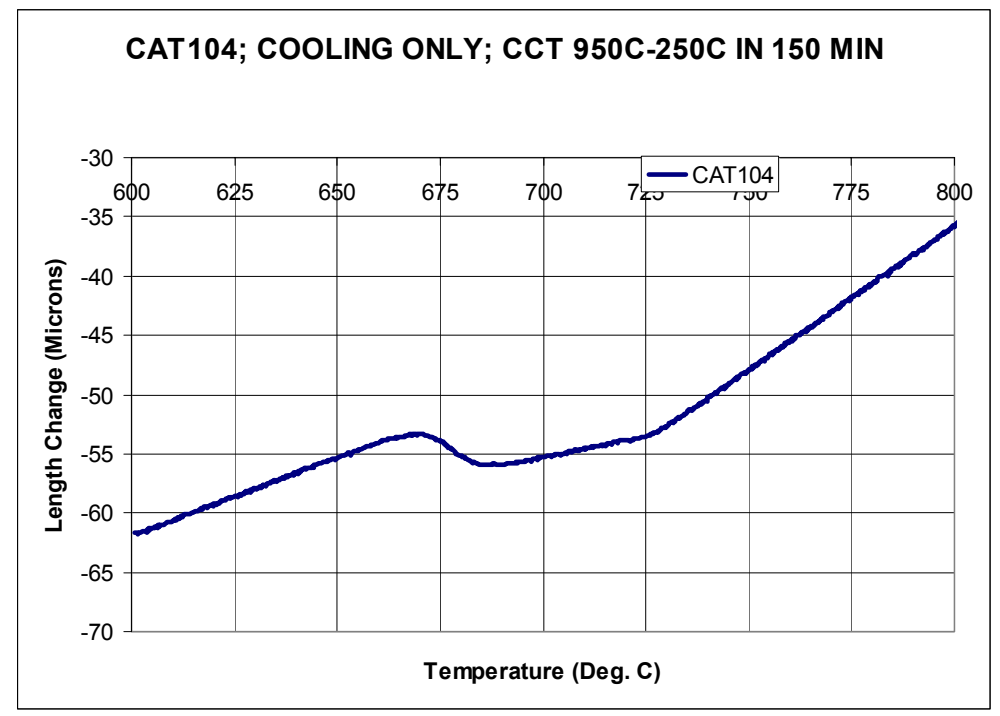

Fig. 3. $T_{s}$ and $T_{f}$ temperatures.

\section{Reports/Publications/Awards:}

G. M. Ludtka, K. W. Burris, and L. Chuzhoy, "Quantitative Characterization of the Phase Transformation Kinetics and Dilation Strains of a Hypereutectoid SAE 41XX Steel Alloy for Incorporation into a Process Optimization Simulation Tool," MPLUS report, May 2003. 
MPLUS No.: MC-02-037

Title: High-Temperature Mechanical Properties Testing For Finite-Element Prediction of Residual Stress In a Spot Weld

User Organization: University of Missouri - Columbia Columbia, MO 65211

User Contacts: Dr. Sanjeev K. Khanna, 573-884-9109 khannas@missouri.edu

Dr. Xing Long, 573-884-7384 longx@missouri.edu

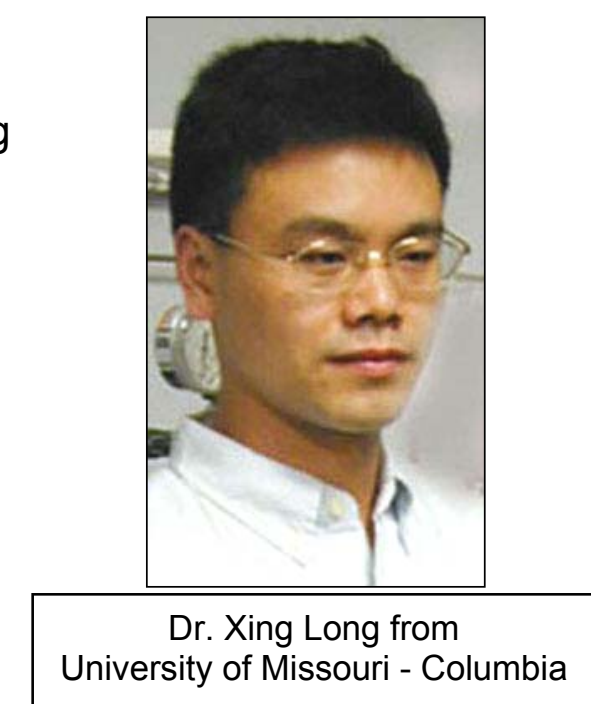

ORNL R\&D Staff: K. C. Liu, 865-574-5116 liukc@ornl.gov

\section{E. Lara-Curzio, 865-574-1749 laracurzioe@ornl.gov}

Relative to OIT: The service life of many industrial components that incorporate weldments is often limited by the reliability and durability of the weldments. At the same time, the reliability and durability of weldments is significantly influenced by the state of residual stresses. The ability to model, predict, and control residual stresses in weldments could impact positively their reliability and durability.

Objective: The purpose of this research is to establish a numerical model to simulate the whole process of spot welding and to obtain the residual-stress distribution in a welded joint. Since the residual stresses are attributed to microstructure evolution and to the changes in the material's physical and mechanical properties, all of the properties must be described as a function of temperature. Thermophysical properties were determined previously; therefore, high temperature mechanical properties were investigated to complete the data base.

Results: Two types of aluminum, types 6111-T4 and 5754-NG, were tested in tension at elevated temperatures ranging from room temperature to $500^{\circ} \mathrm{C}$ in steps of $100^{\circ} \mathrm{C}$.

1. Tensile stress-strain curves (Figs. 1 and 2) for the aluminums at elevated temperatures show that the tensile behavior is highly temperature dependent.

2. On the strain basis, 6111 aluminum yields higher tensile strength than 5754 aluminum by about $30 \%$ at every temperature tested. 


\section{Auminum, Tensile S-S Curves}

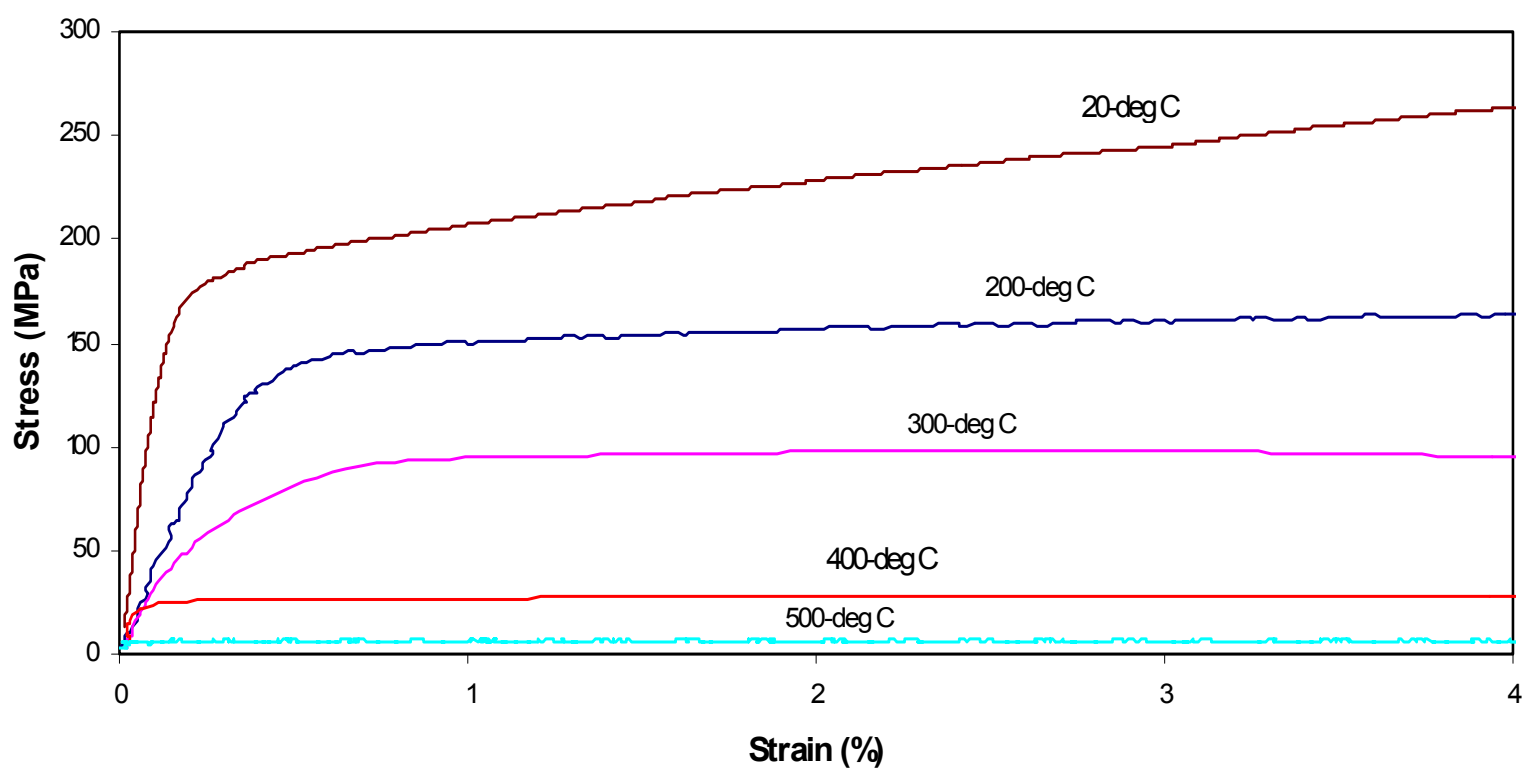

Fig. 1. Tensile behavior of 6111 aluminum alloy tested at elevated temperatures.

\section{Aluminum, Tensile S-S Curves}

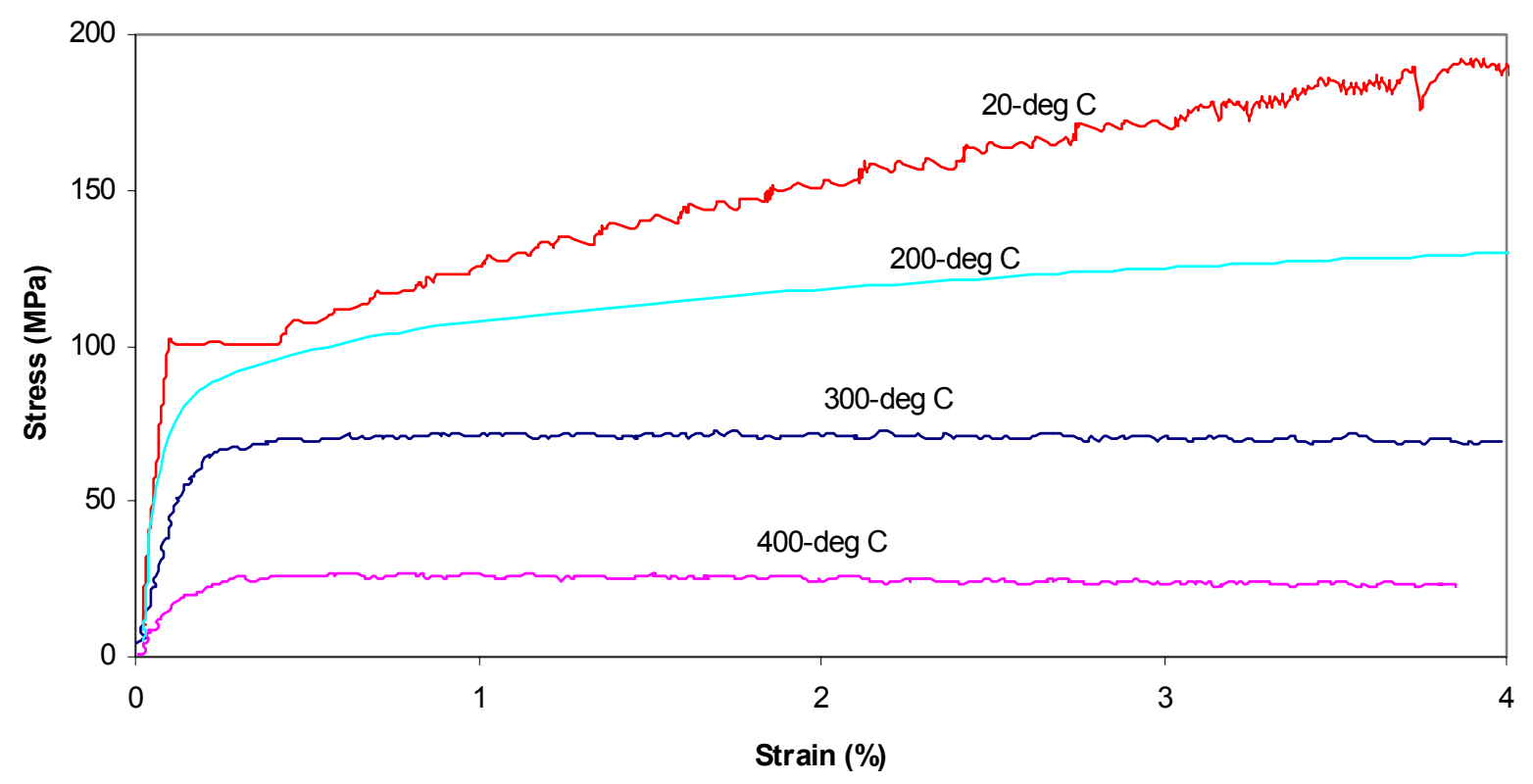

Fig. 2. Tensile behavior of 5754 aluminum alloy tested at elevated temperatures. 
3. Figure 3 shows discrepancies in elastic moduli obtained at 300 and $400^{\circ} \mathrm{C}$ by resonant ultrasound spectroscopy and those determined from tensile stress-strain curves. Both sets of data would have been very comparable if the viscoplastic effects were factored out from the tensile stress-strain curves.

a)

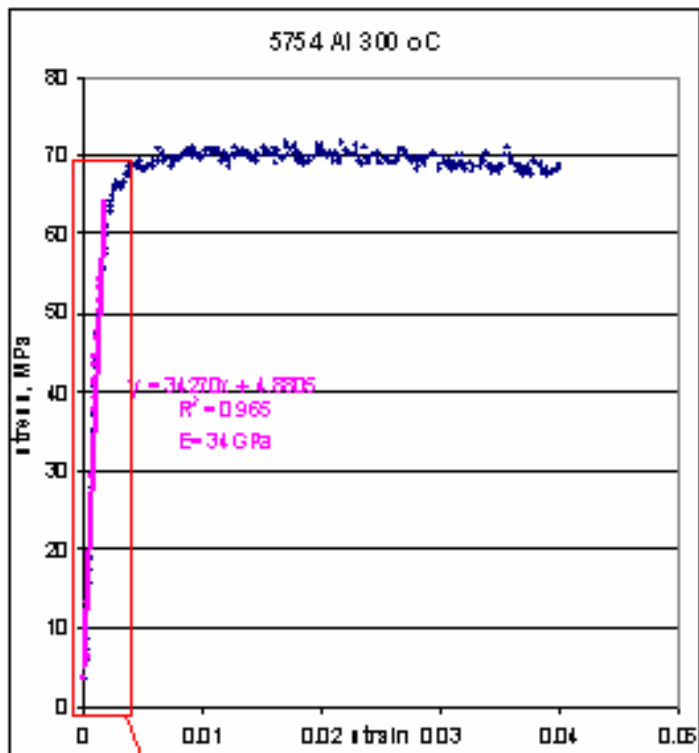

c)

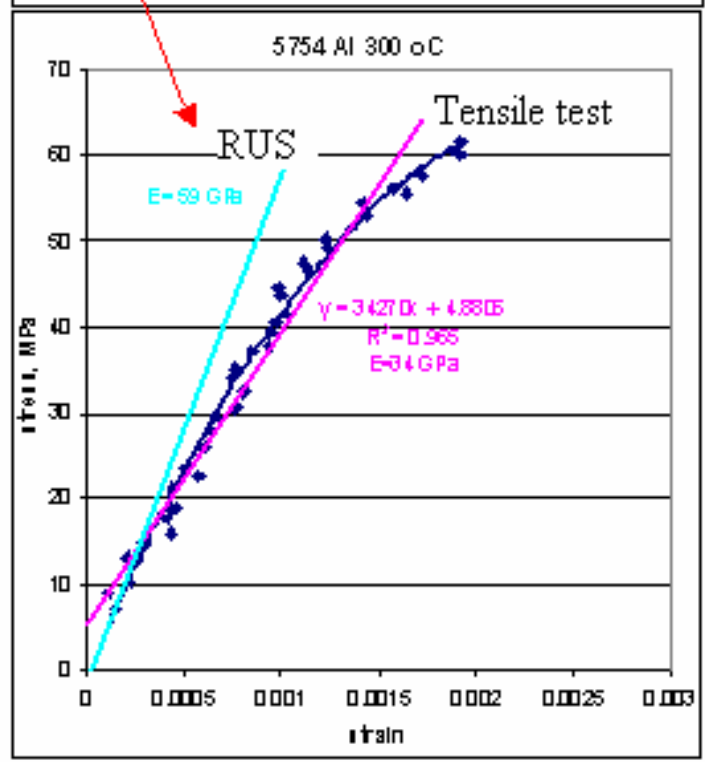

b)

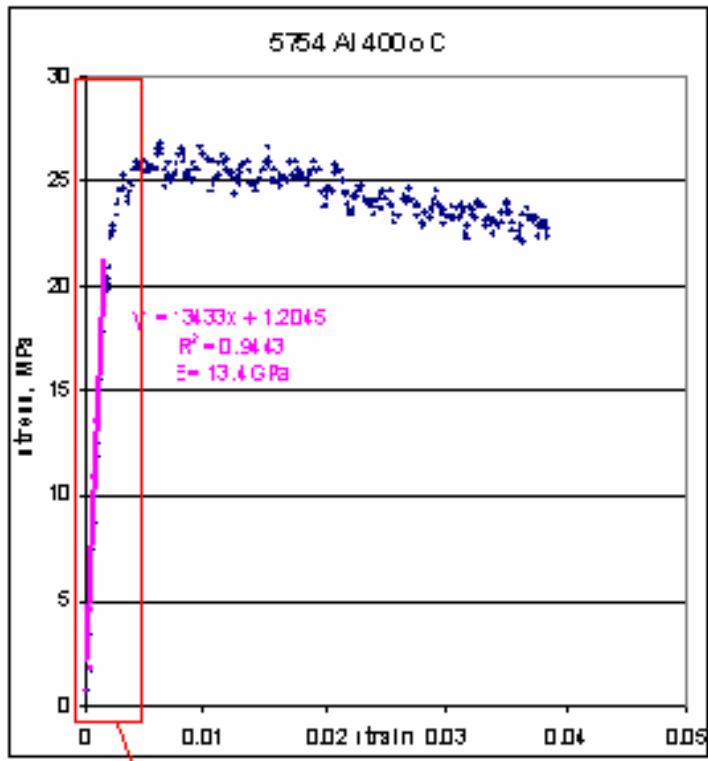

d)

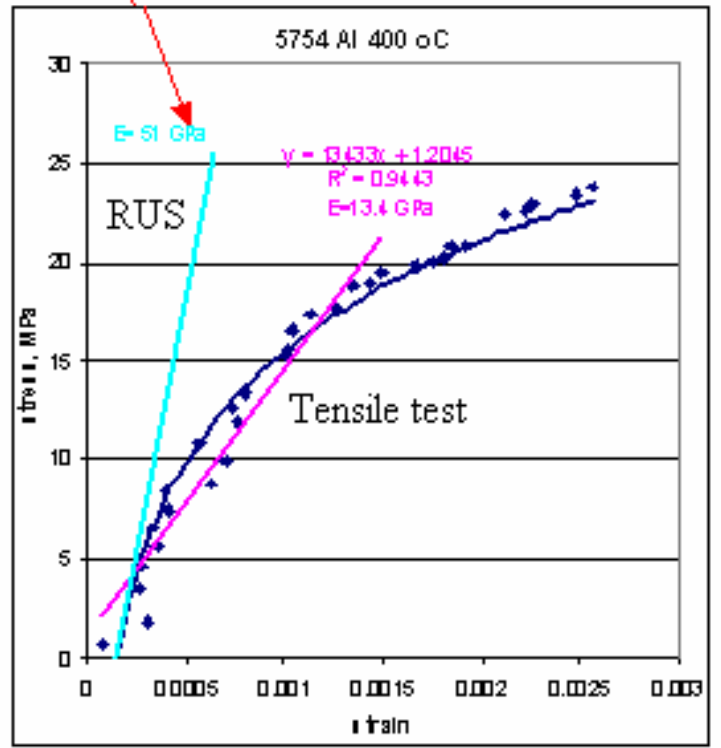

Fig. 3. Comparisons of elastic moduli measured with resonant ultrasound spectroscopy (RUS) and those obtained from tensile tests at 300 and $400^{\circ} \mathrm{C}$.

\section{Reports/Publications/Award:}

S. K. Khanna, X. Long, K. C. Liu, C. Stevens, and E. Lara-Curzio, "Determination of Thermophysical and Thermomechanical Properties of 5754 and $61 \mathrm{~d} 11$ Aluminum Alloys for Spot Welding Simulation Application," MPLUS report, 2003. 
MPLUS No.: MC-02-038

Title: Analysis of Aluminum Sheet Materials

User Organization: Secat, Inc.

Lexington, KY 40511

User Contacts: Subodh Das, 859-514-4989

skdas@engr.uky.edu

Shridas Ningileri, 859-514-4955, ext.114

sningileri@secat.net

ORNL R\&D Staff: H. M. Meyer, III, 865-574-5092

meyerhmiii@ornl.gov

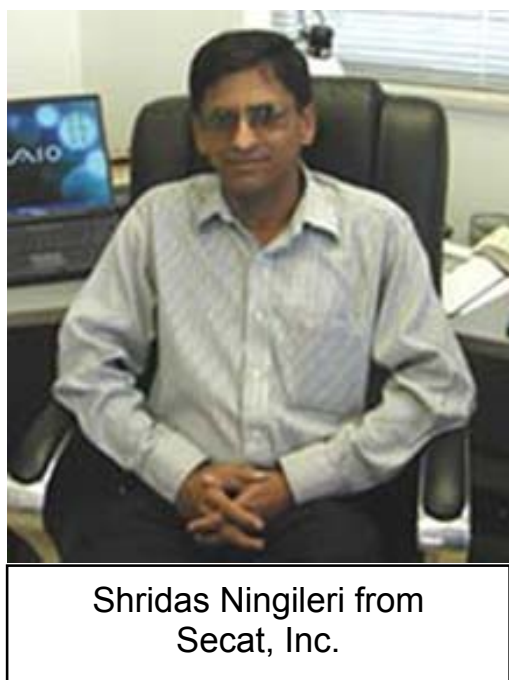

E. A. Kenik, 865-574-5066

kenikea@ornl.gov

Relevance to OIT: Aluminum recycling is extremely important, especially with respect to energy use in aluminum production. Over $40 \%$ of all U.S. aluminum is recycled primarily in aluminum sheet for cans. The sheet production process includes a variety of coatings used to protect both the sheet material and the consumer. Failure of these coatings due to process conditions can lead to substantial scrap and rework of the aluminum sheet. In this project, aluminum sheet specimens were characterized as to coating type and effectiveness. Analysis showed that the coatings were uniform for both chromate-based coatings and vinyl-based coatings.

Objective: Aluminum sheet materials from Secat, Inc. were examined by means of scanning Auger microanalysis (SAM) and secondary electron microscopy (SEM). This work was performed as part of a larger effort to understand the effectiveness of protective coatings for aluminum materials used to make beverage containers. In some cases the samples that were analyzed showed corrosion resulting from a failed protective coating. For those samples analysis was performed to try to understand the cause of the failure. Two separate studies were completed. The first study focused on coated sheet materials used for making beverage cans, while the second study focused on samples taken from manufactured can lids.

Results: The results varied for the samples analyzed. All of the samples were created from either aluminum sheet stock or aluminum can stock materials. The sheet stock samples were examined to understand the general nature of the protective coatings that are applied prior to can manufacturing. Can lids were also examined to try to understand how effectively the coating worked to prevent scratch-induced corrosion. For several samples the analysis was complicated by the thick vinyl layer that is ultimately deposited for protection. Despite these complications, useful data were obtained for each sample. 
Results can be summarized as follows:

1. Some samples were received "as-is," with no specifically applied coating (e.g., A6 in Fig. 1). Since Al is known to form an oxide scale at ambient conditions, these asreceived surfaces showed $\mathrm{Al}, \mathrm{O}$, and $\mathrm{C}$. (The detected $\mathrm{C}$ is typically referred to as "ubiquitous C" and is derived from adsorbed C-containing species such as $\mathrm{CO}, \mathrm{CO}_{2}$, and hydrocarbons.) Sputter profiling confirmed that these native oxides were thin, nominally 20 to 40 angstroms thick.

2. Some samples were specifically coated with a thick oxide (e.g., A4 in Fig. 1) by exposure to a "chromate conversion process." This protective coating showed - in addition to $\mathrm{Al}, \mathrm{O}$, and $\mathrm{C}$ - the presence of $\mathrm{Cr}$ and $\mathrm{P}$. Sputter profiling showed that these coatings were one to several microns thick.
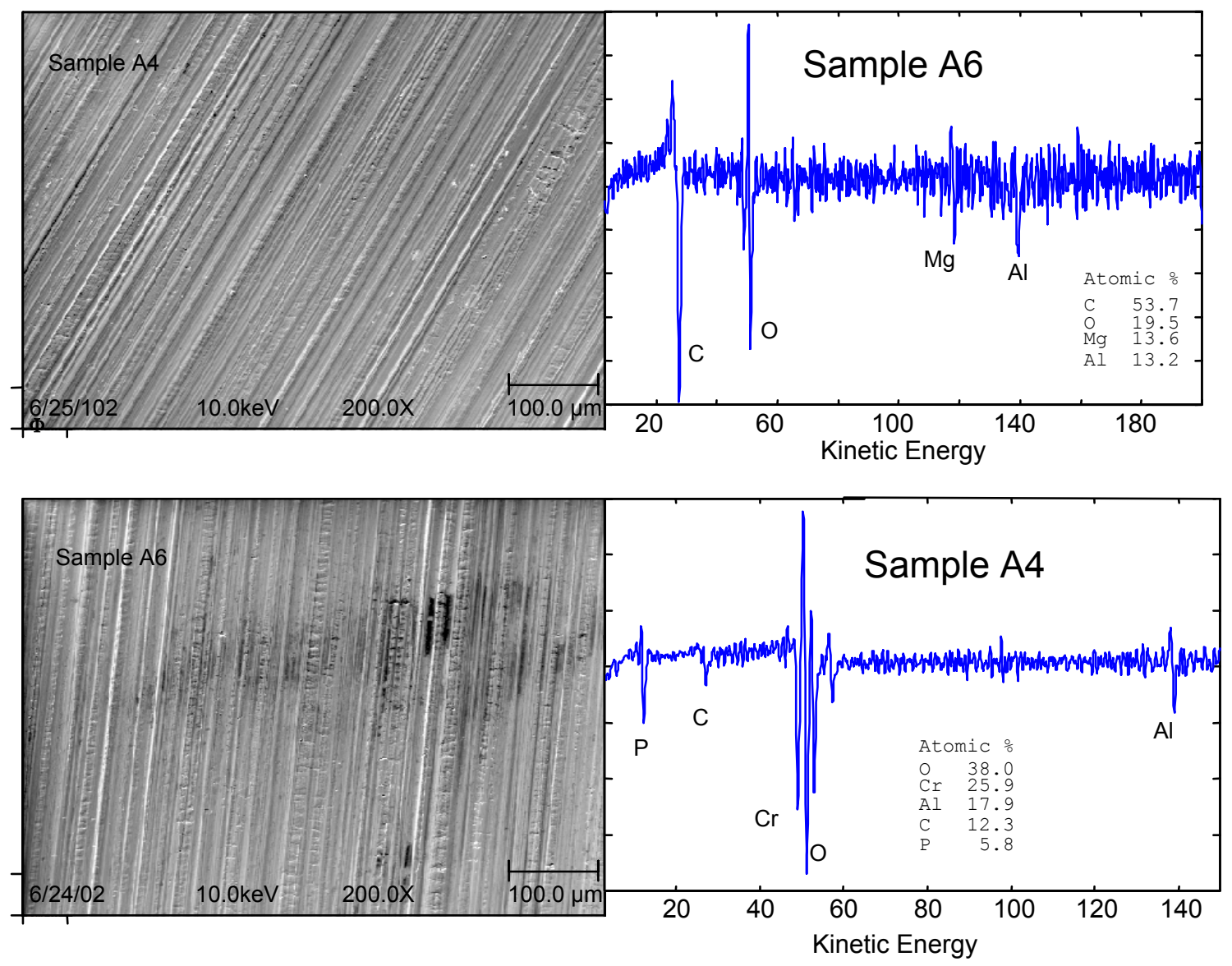

Fig. 1. SEM and SAM spectra for samples A-6 and A-4. Sample A-6 is an example of uncoated aluminum sheet material, and sample A-4 is an example of a chromium-oxide coated sheet. 
3. Five samples showed a thick vinyl coating that prevented complete analysis of the coated aluminum as a result of sample charging. The vinyl primarily showed carbon with varying amounts of chlorine. In one case, the vinyl was thin enough that aggressive sputtering was able to mill through the coating to the aluminum and showed that an oxide layer was present at the vinyl-aluminum interface.

\section{Reports/Publications/Awards}

H. M. Meyer III and E. A. Kenik, Letter report (Final Report on MPLUS Project MC-02038, "Analysis of Aluminum Sheet Materials," dated November 20, 2002), provided to Secat, Inc. Data were supplied in electronic form per Secat's request. 
MPLUS No.: MC-02-039

Title: Modeling to Identify Causes for Gray-Syracuse" Hot Cracking in Cobalt-Based Alloy FSX-414 during Investment Casting

User Organization: Gray-Syracuse, Inc. Chittenango, NY 13037

User Contact: Cezar Cisu, 315-687-0014 ccisu@escocorp.com

ORNL R\&D Staff: Q Qingyou Han, 865-574-4352 hanq@ornl.gov

Relevance to OIT: Cracks in steel or aluminum castings can lead to significant yield reductions and high rework of materials. Cracking usually develops at high temperatures near the melting point. The industrial system that was modeled in this project had a yield rate of approximately $66 \%$ due to cracking during solidification. This project focused on modeling the cracking susceptibility of a specific nickel-based superalloy as a function of alloy composition. A cracking criteria was successfully developed that enabled the industry to increase its yield to the $94 \%$ level. This approach is very general and may be able to be extended to many industrial-based alloy systems. Minimizing crack formation in castings can lead to direct energy, cost, and environmental benefits. The outcome of this MPLUS is directly related to the metal casting, steel, and aluminum industries

Objective: The cobalt-based alloy FSX-414 has been successfully used for making turbine blades for high-temperature applications. However the alloy is prone to hot tearing, and the hot-tearing tendency varies from melt to melt for a given casting. Industrial observation indicates that the hot tear ratio varies from 0 to $65 \%$ for the alloy at its chemical specification. The purpose of this proposal is to explore the use of ThermoCalc ${ }^{\mathrm{TM}}$ modeling for identifying the possible causes for hot cracking observed in a high-strength, cobalt-based alloy (FSX-414) during investment casting. The modeling results will be verified through microstructural analysis. Once verified, modeling results will be used to prepare recommendations for improving the casting process and/or some alloy compositions to eliminate the hot cracking.

Results: Thermodynamic simulations have been carried out to investigate the hotcracking tendency of the cobalt-based alloy FSX-414 as a function of composition. The simulation results reveal that $\mathrm{P}, \mathrm{Nb}, \mathrm{Si}, \mathrm{Fe}, \mathrm{W}$, and $\mathrm{Mo}$ are elements that strongly affect the hot tearing of the alloys. A small increase in the concentration of these elements results in a large increase in the hot tearing of the alloy. It is suggested that the hot tearing tendency of this alloy is closely related to the solidus temperature of the alloy, rather than to the solidification range as the classic hot tearing theory suggests. A 
criterion for hot-tearing formation is proposed based on the solidus temperature of the alloy. The criterion fits well with experimental data obtained in a turbine blade casting.

The simulation results based on the theory of solidification range are shown in Fig. 1. The general trend is that the cracking ratio increases as the solidification range of the alloy increases. The variation in composition leads to the variation in hot tearing formation. However there is a large scatter on the data shown in Fig. 1. When the solidification range is below $105^{\circ} \mathrm{C}$, the cracking ratio is zero. However the cracking ratio can be as high as $65 \%$ when the solidification temperature is $106.5^{\circ} \mathrm{C}$, much higher than the cracking ratios at larger solidification ranges. This indicates that the dependence of hot tearing on the solidification range is rather complicated.

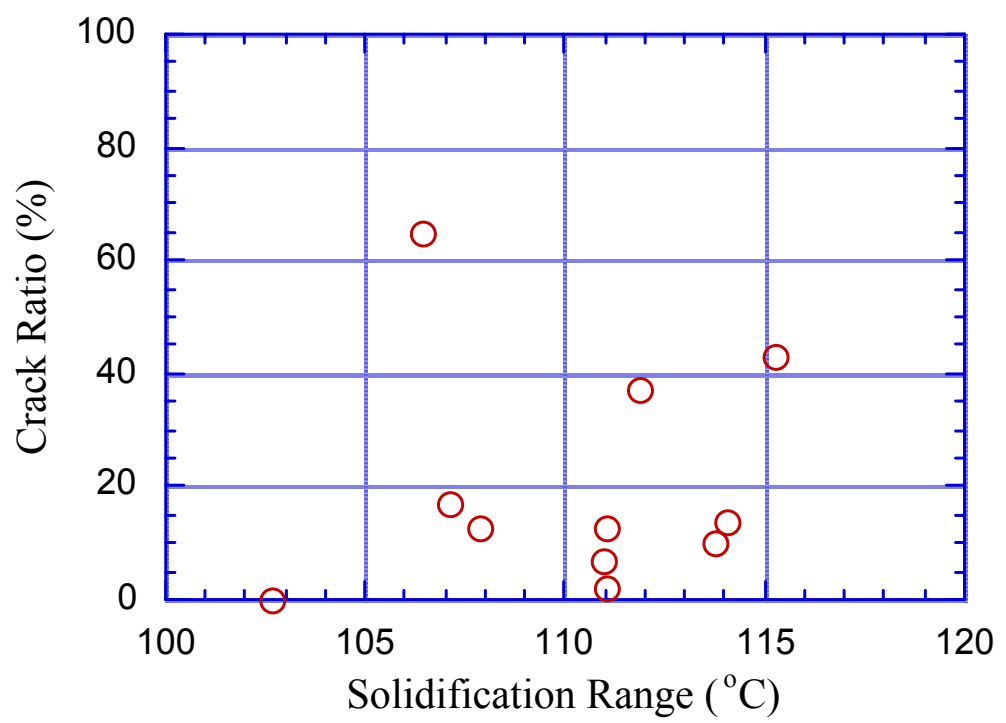

Fig. 1. Results based on the theory of solidification range.

Figure 2 shows the relationship between the hot-tearing ratio and a parameter,

$$
\sum_{i=1}^{N} S_{i} \Delta C_{i}
$$

which is a measure of the solidus temperature of the alloy. The hot-tearing ratio increases linearly with decreasing solidus temperature. It makes more sense to link the cracking ratio to the solidus temperature of the alloy, particularly when discussing the cracking tendency of individual melts with a composition variation within a given specification. The thermal/mechanical stress can be built up when the temperature in a casting reaches the dendrite coherency point (the point at which a dendritic network forms). The coherency point occurs at a temperature corresponding to a solid fraction of about 0.3. Because solute segregation is not substantial at small solid fractions, the 
coherency point is not affected much by the low-melting temperature constituents (segregating elements). However, the solidus temperature is very sensitive to presence of segregating elements. Close to the solidus temperature, substantial stress can be built up in the casting, but a small fraction of liquid is still present. The liquid will embrittle the alloy and thus form hot tearing in the region that is last to freeze.

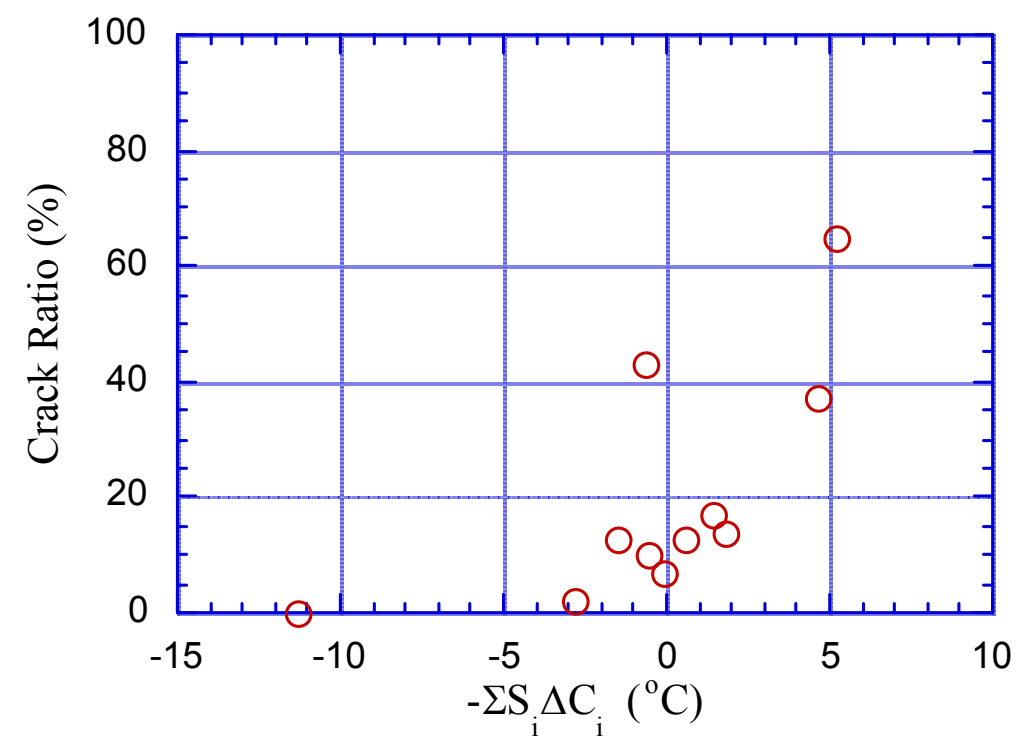

Fig. 2. Results based on the solidus temperature of the alloy.

Table 1 lists the mean composition and the solidus slop value, $S_{i}$, for each element. Elements with a large negative value of $S_{i}$ decrease the solidus temperature more and, as a result promote hot tearing. $\mathrm{P}, \mathrm{Nb}, \mathrm{Si}, \mathrm{Fe}, \mathrm{W}$, and Mo strongly affect the hot-tearing tendency of the alloys. Boron has a large negative value, but it reacts with nitrogen to form nitride. An $\mathrm{H}$ parameter defined in Eq. (2) below is proposed. The hot-tearing ratio increases as the $H$ value increases to prevent hot tearing. It is suggested to make an alloy with a smaller $H$ value or to control the concentrations of niobium and phosphorus to a lower level. Industrial practice based on our suggestions indicates that the hottearing ratio decreases from a previous average of $34 \%$ to less than $5 \%$.

Table 1. The mean composition and the $S_{i}$ values for each element

\begin{tabular}{|c|c|c|c|c|c|c|c|c|c|c|}
\hline & $\mathbf{C}$ & $\mathbf{S i}$ & $\mathbf{N i}$ & $\mathbf{C r}$ & $\mathbf{M o}$ & $\mathbf{N b}$ & $\mathbf{B}$ & $\mathbf{W}$ & $\mathbf{F e}$ & $\mathbf{P}$ \\
\hline$C_{0}(\mathrm{wt} \%)$ & 0.25 & 0.90 & 10.5 & 29.5 & 0.08 & 0.05 & 0.007 & 7.0 & 1.0 & 0.90 \\
\hline$S_{i}\left({ }^{\circ} \mathrm{K} / \mathrm{wt} \%\right)$ & +25.5 & -11.3 & +0.54 & +0.035 & -1.60 & -66.63 & -1772.9 & -3.66 & -3.67 & -1772.9 \\
\hline
\end{tabular}

$$
\begin{aligned}
H= & -25.5\left(C_{C}-0.25\right)+11.3\left(C_{S i}-0.9\right)-0.54\left(C_{N i}-10.5\right) \\
& -0.035\left(C_{C r}-29.5\right)+1.60\left(C_{M o}-0.08\right)+66.63\left(C_{N b}-0.05\right) \\
& +3.66\left(C_{W}-7.0\right)+3.67\left(C_{F e}-1.0\right)+1773\left(C_{P}-0.006\right)
\end{aligned}
$$




\section{Reports/Publications/Awards:}

Q. Han and J. Zeh, "Prediction of Elemental Segregation and Phase Formation in Aluminum 5754 Alloy," MPLUS report, October 2002.

Q. Han, "Influence of Chemical Composition on Hot Tearing Susceptibility in FSX-414 Alloy," accepted for publication in Transactions of American Foundry Association, 2004. 
MPLUS No.: MC-02-040

Title: Effect of Fluidized Bed-Based Heat

Treatment on Microstructure of 431

Stainless Steel

User Organization: Metal-Tech of Tennessee, LLC Newport, TN 37821

User Contact: David L. King, 423-625-2030 mtt@planetc.com

ORNL R\&D Staff: Vinod K. Sikka, 865-574-5112

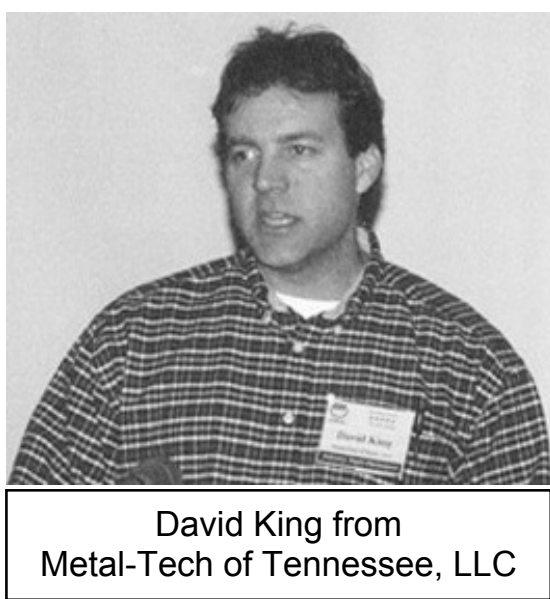
sikkavk@ornl.gov

Relevance to OIT: The $\mathrm{Fe}-18 \% \mathrm{Cr}$ stainless steels are used extensively in many industry sectors including chemical, mining, and pulp and paper. These steels offer several benefits: ease of heat treating to achieve high hardness, exceptional corrosion resistance, and low cost because they contain no nickel. Although simple, the heattreatment variants can result in a variety of microstructure and hardness combinations. This MPLUS project has resulted in significant advancement in the understanding of heat treatment, microstructure, and hardness correlations that can be applied to component heat treating for commercial applications. This project is relevant to steel, chemical, mining, and pulp and paper industries.

Objective: The project's objective was to investigate the effect of fluidized bed-based heat treatment on the microstructure and hardness of type 431 stainless steel. Type 431 is a $\mathrm{Fe}-18 \% \mathrm{Cr}$ steel containing $0.15 \% \mathrm{C}$. It is an air hardening steel and transforms to martensite when cooled from austenitizing temperature.

Results: Ten samples were examined by means of optical metallography and microhardness. Selected specimens were also examined through microprobe analysis. These analyses led to the following conclusions:

1. Raw knuckles, prior to heat treatment, have uniform microstructure from surface to the center and a uniform microhardness of 280 to $300 \mathrm{HV}$, or $R_{C} 28-30$. No banding of different etchants is noted near the surface.

2. Raw knuckle, heat-treated in argon at $1900^{\circ} \mathrm{F}$ for $1 \mathrm{~h}$ followed by cooling in air, retains a very uniform microstructure without any banding. The microhardness of the specimen goes from 500 to $560 \mathrm{HV}$, or $R_{\mathrm{C}} 50-56$. The outside diameter was of low hardness $\left(R_{C} 50\right)$ and a higher inside diameter $\left(R_{C} 56\right)$ as opposed to the specimen's interior of $R_{C} 53-54$. The lower surface hardness is presumably caused by some decarburization of the surface near the outside diameter by the small amount of oxygen that may be present in the argon gas used during heating at $1900^{\circ} \mathrm{F}$ for $1 \mathrm{~h}$. 
3. Microprobe data in Figs. 1 and 2 show that the specimens heat-treated in carburizing gas result in higher carbon content near the surface than at the center. The enriched carbon region extends to approximately 4 mils into the specimen. The region contains second-phase particles that are typically high in chromium; this suggests they are chromium carbide.

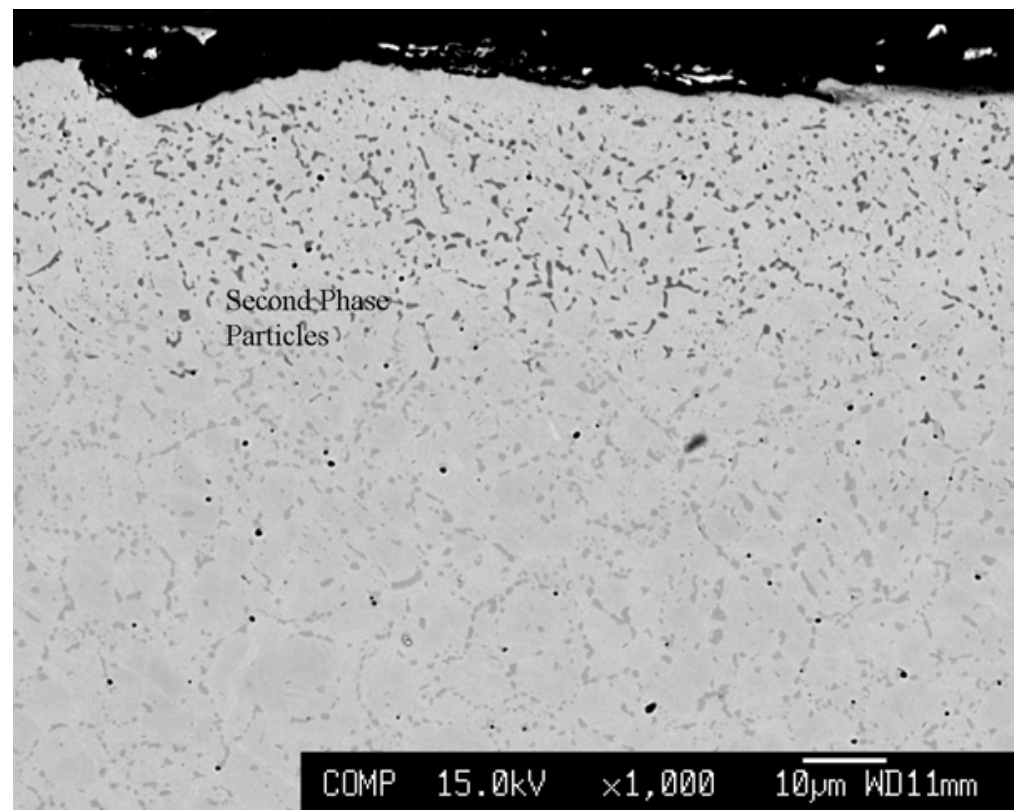

(a)

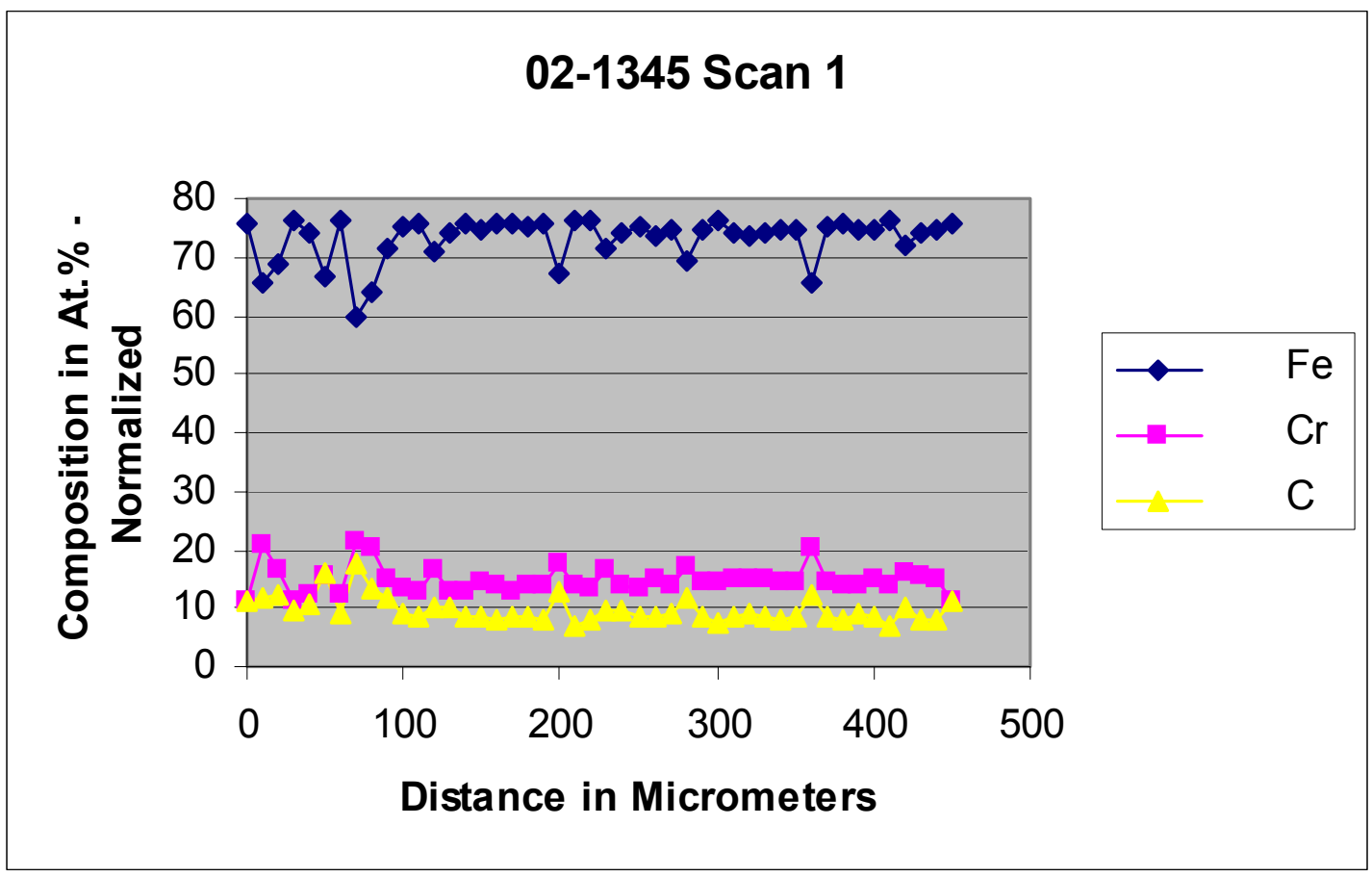

(b)

Fig. 1. Backscattered electron image (a) and microprobe scan (b) for a failed knuckle carbon-enrichment near surface and presence of chromium carbide. 

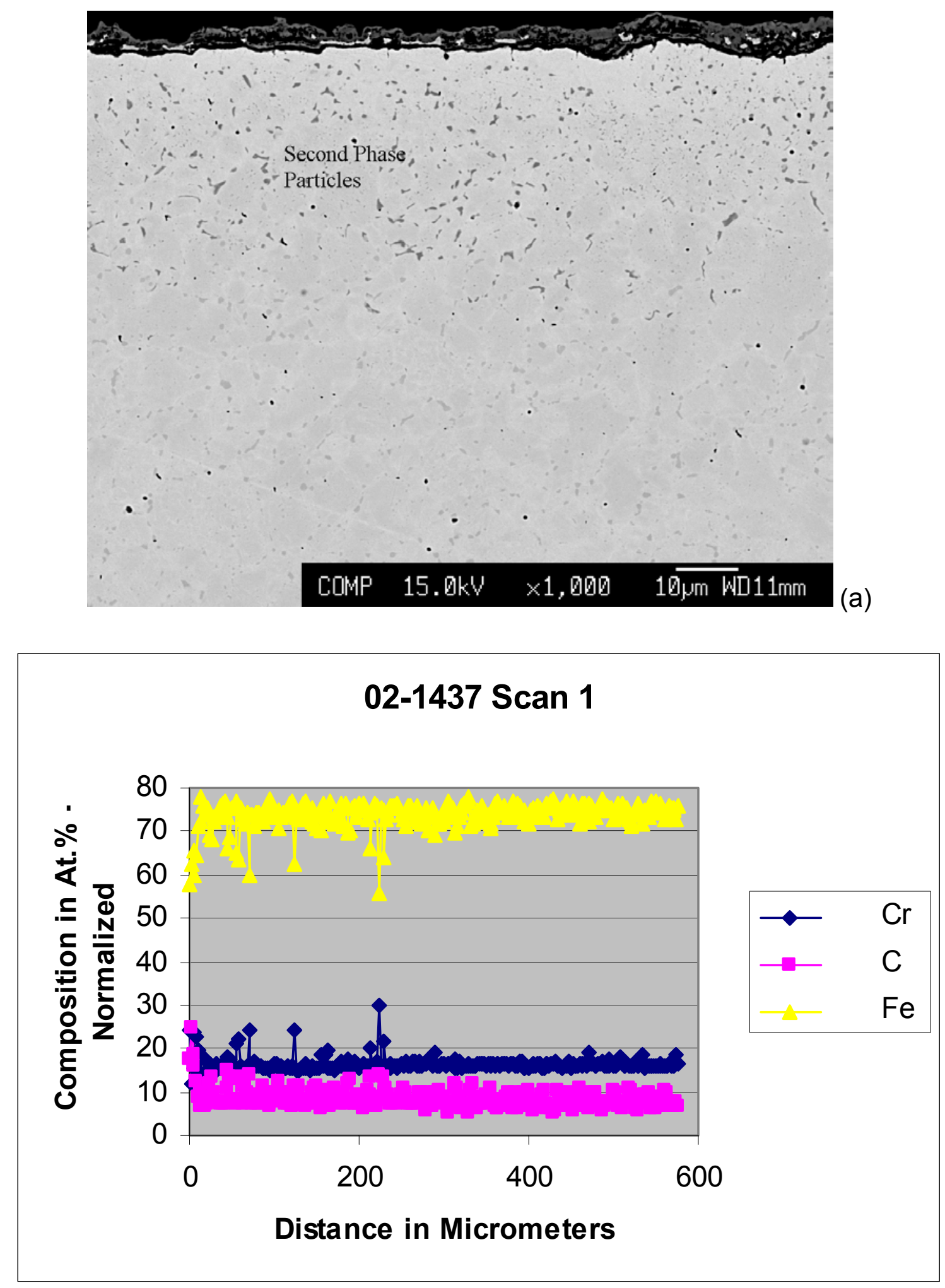

(b)

Fig. 2. Backscattered electron image (a) and microprobe scan (b) for a new knuckle carbon enrichment near surface and presence of chromium carbide. 


\section{Reports/Publications/Awards:}

Vinod K. Sikka, Jackie Mayotte, and David L. King, "Microstructural Analysis of Samples of Type 431 Stainless Steel from Metal-Tech of Tennessee, LLC," MPLUS report, 2002. 
MPLUS No.: MC-02-042

Title: Reducing Dross Formation during Remelting of Aluminum Sows

User Organization: Logan Aluminum Russellville, KY 42276

User Contact: John Zeh, 270-755-6502 john.zeh@logan-aluminum.com

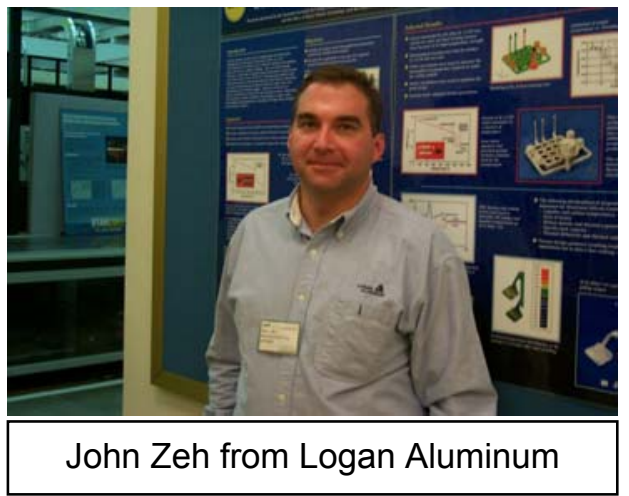

ORNL R\&D Staff: Qingyou Han, 865-574-4352 hanq@ornl.gov

Relevance to OIT: During recycling of aluminum scrap, a large amount of high-quality aluminum is turned into dross leading to substantial equivalent energy losses. Minimizing dross formation in aluminum remelt secondary ingot (RSI) can result in a significant energy savings in the aluminum industry. In this MPLUS project, various aluminum RSI production methods were evaluated for RSI produced at three industrial facilities. The results showed that RSI with the lowest dross formation can be achieved by controlling the solidification cooling rate and the composition of the RSI. This project is directly related to the aluminum industry.

Objective: In a previous MPLUS project, we observed a huge amount of dross formation during remelting of aluminum sows. The dross formation is related to the internal defects such as cracking and porosity that occur during the solidification of aluminum sow. The purpose of this research is to investigate methods that reduce the harmful effects on dross formation. The results can lead to large energy/cost savings for the aluminum industry.

Results: Twelve aluminum 5182 RSIs weighing about $1500 \mathrm{lbs}$ each were made at three industrial locations. These RSIs were made by using one of two types of melting furnaces (i.e., induction versus rotary furnace), cooling rates (air cool versus water spray cool), and mold sizes (9 versus 13 in.). Fluxing was tested. The composition of the RSI was also varied. Dross formation was measured in $1.25-\times 1.25-\times 6$-in. specimens taken from the center of the RSIs. The experimental results indicate the following:

- Dross formation is greater in cracked RSIs.

- Dross formation occurs less in RSIs cooled by water spray than cooled in air.

- Reducing the magnesium concentration reduces dross formation.

- The size of the RSIs and fluxing has little effect on dross formation.

Figure 1 shows dross formation in the RSIs with and the RSIs without cracking formation on their top surface. The amount of dross found in the center of the cracked RSIs was more than 50\%, much higher than in those not cracked. Figure 1 was 
obtained under the condition that the top surface of the RSIs was water spray cooled. Avoiding cracking seems to be the primary issue in reducing dross formation when the top of the RSI is cooled with water spray.

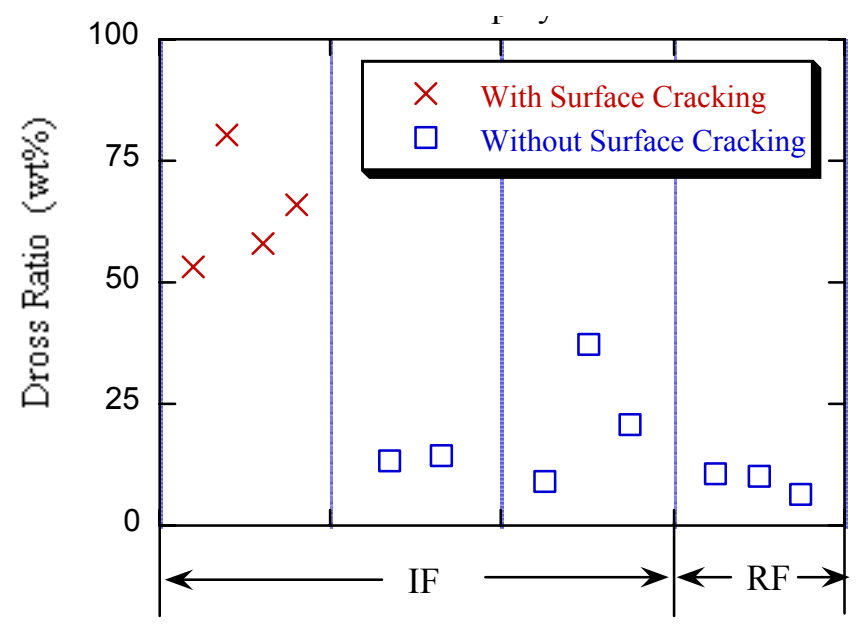

Fig. 1. Surface cracking increases dross formation in the RSI.

Cooling rate has an important effect on dross formation. Figure 2 shows dross formation in 9-in. RSIs [Fig. 2(a)] and 13-in. RSIs [Fig. 2(b)] with either air cooling or water spray cooling. No matter whether the RSIs were made by using an induction furnace or a rotary furnace, dross formation was always much higher when the RSIs were cooled in air than when cooled using water spray. Temperature measurement in the RSIs indicated that the cooling rate with water-spray cooling was higher than with air cooling.

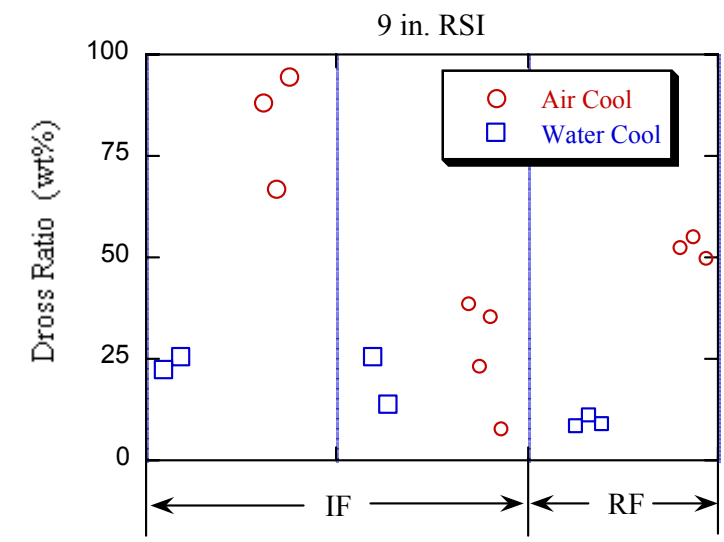

(a)

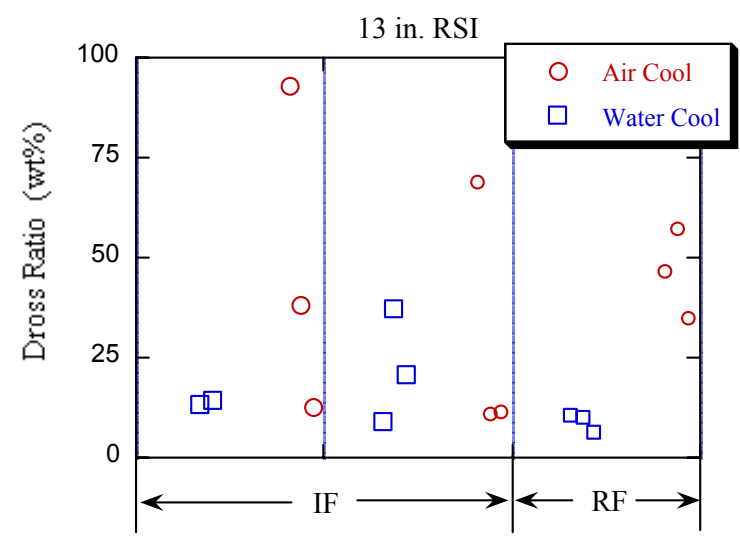

(b)

Fig. 2. Dross formation is much less in specimens with water spray cooling than those with air cooling. 
Magnesium has a major influence on dross formation in aluminum $5182 \mathrm{RSI}$. Figure 3 shows dross formation as a function of bulk magnesium concentration in specimens taken from the center of the RSIs. Dross formation increases substantially as the bulk concentration of magnesium increases. Thermodynamic simulation indicated that the solidification range of an alloy increases as the magnesium concentration increases. Optical microscopy revealed that the morphology of the hydrogen porosity varies from spherical (at low magnesium concentrations) to interdendritic (at high magnesium concentrations). This observation supports our speculation that the high amount of dross formation is related to the oxidation of the interdendritic surfaces during the solidification of the RSI.

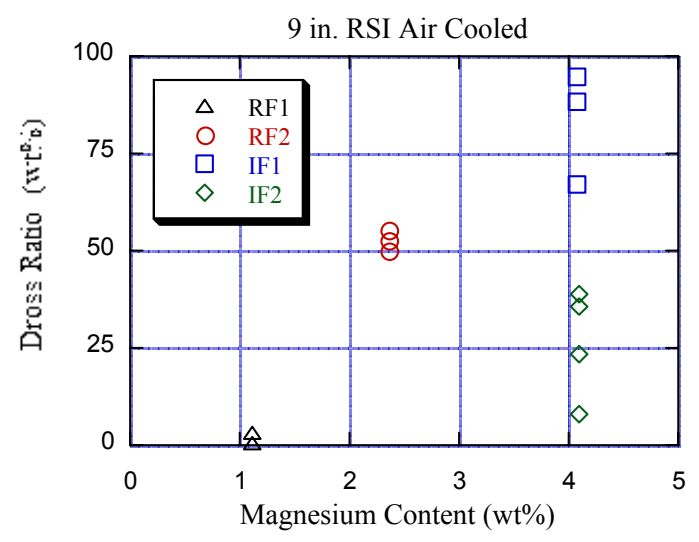

(a)

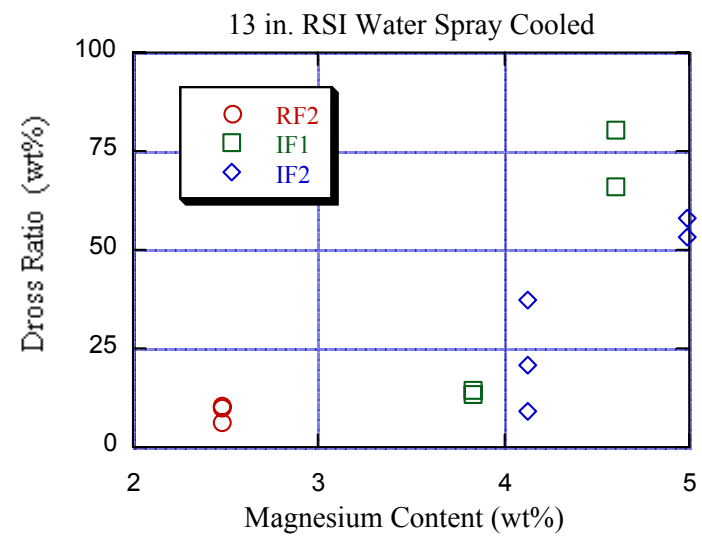

(b)

Fig. 3. Dross formation as a function of the bulk concentration of magnesium in: (a) 9-in. RSIs air cooled and (b) 13-in. RSIs water-spray cooled.

\section{Reports/Publications/Awards:}

Q. Han, and J. Zeh, "Reducing Dross Formation during Remelting of Aluminum Sows," MPLUS report, October 2002.

Q. Han, J. L. Zeh, and R. D. Peterson, "Some of the Factors Affecting Dross Formation in Aluminum 5182 Alloy RSI," Light Metals 2004, accepted for publication. 
MPLUS No.: MC-02-043

Title: The Effect of Boron and Zirconium on the Resistance of HAYNES ${ }^{\circledR} 214^{\mathrm{TM}}$ Alloy to Strain Age Cracking

User Organization: Haynes International Inc. Kokomo, IN 46904-9013

User Contact: $\quad$ Mark D. Rowe, 765-456-6228 mrowe@haynesintl.com

ORNL R\&D Staff: S. Suresh Babu, 865-574-4806

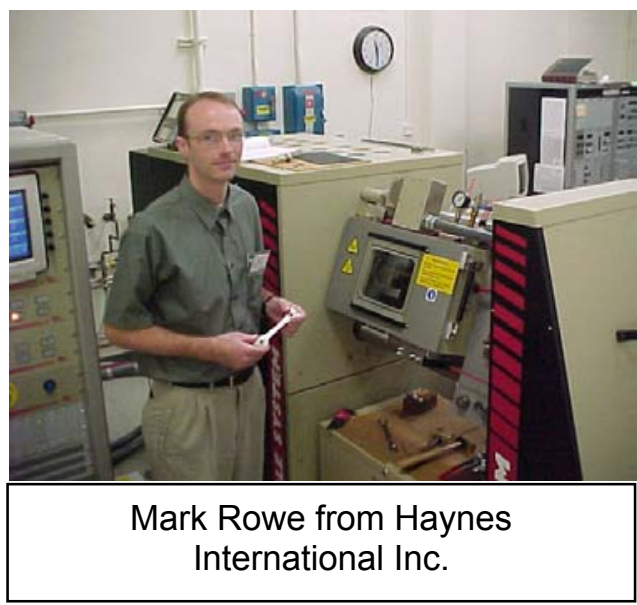
babuss@ornl.gov

Relevance to OIT: Nickel-base alloys of type 214 are being considered for application in chemical industries dealing with both high tempering and acid-corrosion resistance since they can improve the process cycle efficiency. However, these alloys, due to the presence of strengthening precipitates, undergo severe property degradation on welding due to strain-age cracking. The current project pertains to the development of composition modification, welding practices, and heat-treatment methodology for these alloys so that the adverse effects can be minimized. This project is directly related to the chemical industry.

Significance of the Results: Thermomechanical simulation and transmission electron microscopy showed that the addition of certain elements (i.e., boron and zirconium) can mitigate strain-age cracking by improving the grain boundary strength. These results suggest that it is possible to maintain present levels of strengthening as well as reduce the adverse effect of welding by microalloying. This will lead to the increased use of these alloys so that chemical industry infrastructures can be redesigned for better performance.

Objective: The objective of this MPLUS project was to determine the mechanism by which boron zirconium addition increases the resistance of 214 type alloys to intergranular cracking. The ductility of Alloy 214 was measured while it was being heated through the gamma prime precipitation temperature range and then compared with modified Alloy 214 without boron and zirconium additions. This was accomplished under MPLUS MC-01-021, which showed that addition of boron and zirconium significantly improved the resistance of 214 type alloys to intergranular fracture. This was followed up with microstructural characterization by transmission electron microscopy (TEM), under a continuation of the MPLUS program MC-02-043 to determine the mechanism by which boron and zirconium addition improved ductility. A substantial amount of testing was performed at Haynes to complement the MPLUS results, including alloy/specimen preparation, tension testing, metallography, and scanning electron microscopy (SEM) examination. 
Results: Two alloys were studied in this MPLUS research. One alloy (EN1001) was made with intentional additions of boron and zirconium, similar to commercial HAYNES 214 alloy, while the other alloy (EN1101) was made without boron or zirconium. The alloy with boron and zirconium displayed significantly greater ductility in Gleeble testing than the alloy without boron and zirconium. A similar test method was used to measure ductility at Haynes; the results are given in Fig. 1. The test used at Haynes, based on an elevated temperature tensile test, differentiated between the two alloys more precisely than the Gleeble test because of the type of specimen used.

In the follow-up MPLUS program, TEM examination was performed at ORNL on the two alloys after heating them to the test temperature, then cooling them rapidly to preserve the microstructure at test temperature. TEM examination showed a difference in the grain boundary carbide microstructure of the two alloys, as shown in Fig. 2. Energy dispersive X-ray analysis in the TEM revealed a chromium-depleted layer at the grain boundary in the alloy without boron-zirconium addition. Chromium depletion was not detected to the same extent in the alloy with boron-zirconium addition. The solubility of aluminum in 214 alloy increases as the chromium content is reduced; thus a chromiumdepleted layer could potentially lead to the formation of a weak, $\gamma^{\prime}$ denuded layer adjacent to the grain boundary in 214 type alloy. This is a potential explanation for the improvement in ductility with boron-zirconium addition; however, further TEM or atom probe tomography characterization would be needed to confirm this observation. These results were presented at the Annual American Welding Society Convention in Detroit, MI, in April 2003.

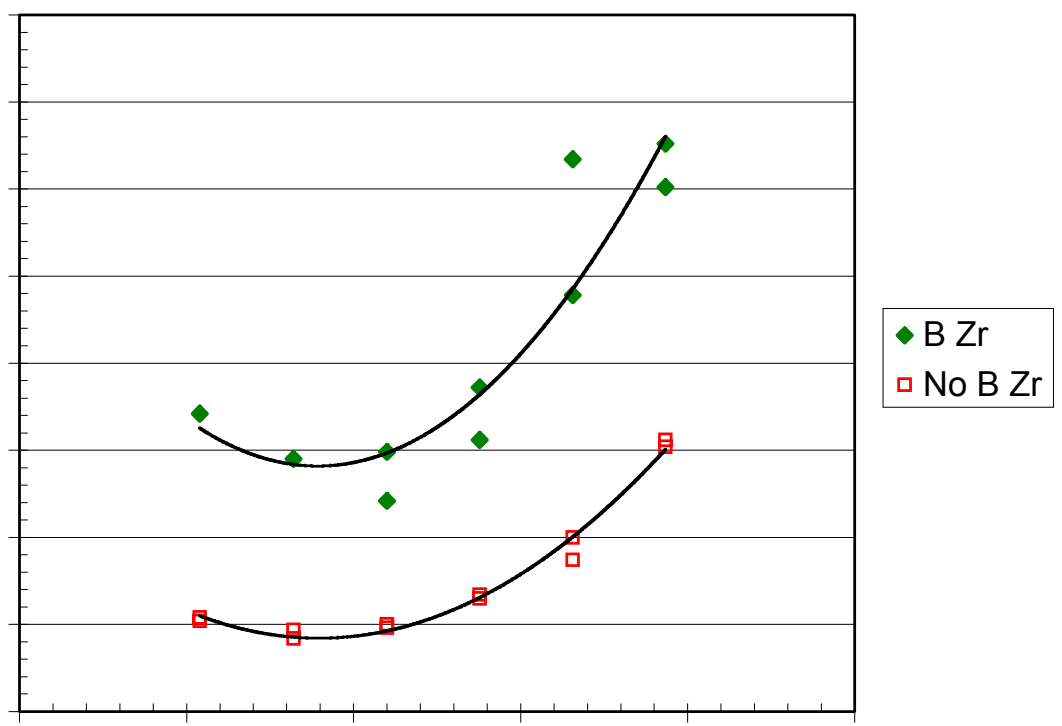

Fig. 1. Effect of boron and zirconium addition on the ductility of 214 type alloys in the strain age cracking temperature range (complementary testing performed at Haynes International). 
Future Work: Addition of boron-zirconium to superalloys to improve creep life by delaying intergranular cracking has been practiced since the 1950s; however, the mechanism by which boron-zirconium addition improve grain boundary strength is still not clear. Thus, elucidation of this mechanism would have relevance to superalloys in general as well as to 214 type alloys specifically. Atom probe tomography has been used at ORNL to show that boron-zirconium addition to molybdenum alloys reduces harmful segregation of oxygen to the grain boundaries. ${ }^{*}$ Atom probe tomography examination of the 214 type alloys could reveal whether a similar mechanism is at work in nickel-base alloys as in molybdenum-base alloys.

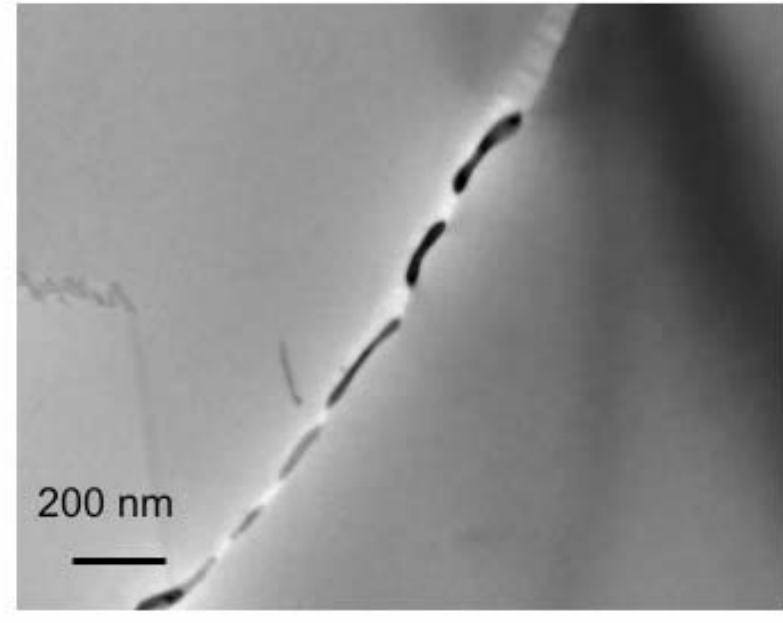

No B Zr

Gleeble, $1400 \mathrm{~F}$ (760 C), quench

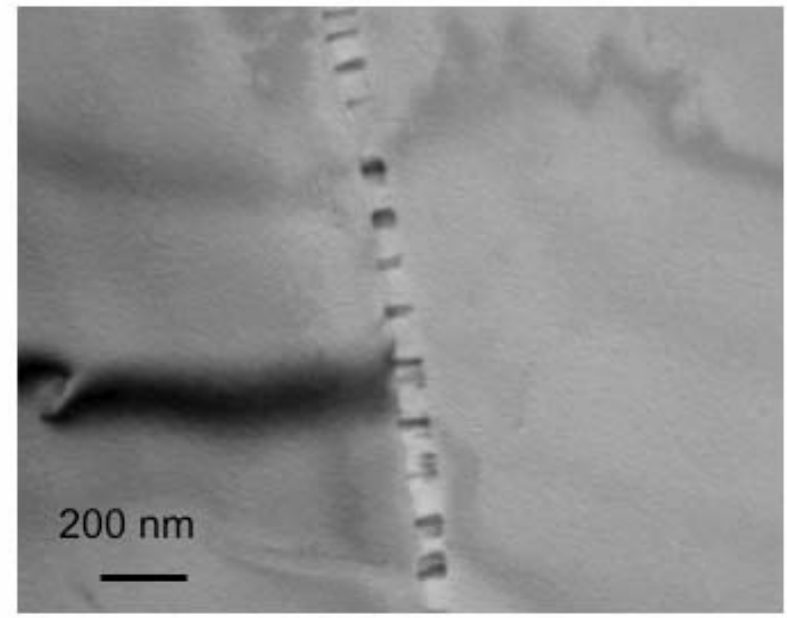

$\mathrm{B} \mathrm{Zr}$

Gleeble, $1400 \mathrm{~F}(760 \mathrm{C})$, quench

Fig. 2. Effect of boron and zirconium addition on grain boundary microstructure of 214 type alloys heated into the strain age cracking temperature range (TEM results from MPLUS program at ORNL).

\section{Reports/Publications/Awards:}

M. D. Rowe, "Gleeble Testing of HAYNES ${ }^{\circledR} 214^{\mathrm{TM}}$ Type Alloys under the MPLUS Program," MPLUS report, January 2001.

M. D. Rowe, "The Effect of Boron and Zirconium on the Resistance of HAYNES ${ }^{\circledR} 214^{\mathrm{TM}}$ Alloy to Strain Age Cracking," presented at the $84^{\text {th }}$ Annual American Welding Society Convention, Detroit, MI, April 7-10, 2003.

${ }^{*}$ M. K. Miller, E. A. Kenik, K. F. Russell, and A. J. Bryhan, "Improvements in the Ductility of Molybdenum Weldments by Alloying Additions of $\mathrm{Zr}, \mathrm{B}$, and $\mathrm{C}$," available on-line: http://www.ms.ornl.gov/programs/fusionmatls/pdf/dec2000/Miller.pdf. 
MPLUS No.: MC-02-044

Title: Detection of Cracks in Green Powder Metallurgy Compacts

User Organization: Caterpillar, Inc.

Rockwood, TN 37854

User Contact: Mike Pershing, 865-576-4294

pershma@cat.com

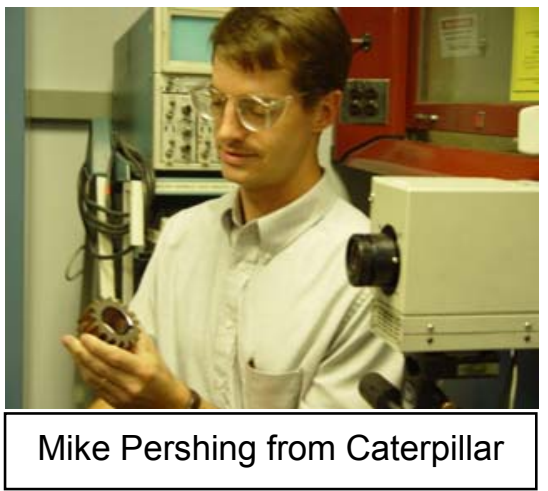

Bill Kovacich, 865-354-5603

kovacichb@cat.com

ORNL R\&D Staff: $\quad$ R. B. Dinwiddie, 865-574-7599

dinwiddierb@ornl.gov

Relevance to OIT: Effective early detection of green cracks in powder metal compacts is a key issue for the powder metal industry. Early detection would dramatically improve costs, efficiencies, and reliability for powder metal components, making the energy efficient powder metal process attractive to more kinds of components. This project is directly relevant to increased reliability for gears and other parts using sinter-harden powders where some green machining is desired before sintering.

Objective: Investigate the possibility of using infrared imaging, with its enhancements available at ORNL, for detecting cracks in green powder compacts. The project will involve (1) feasibility of detecting cracks in green compacts, (2) part size and shape considerations, (3) detectable crack size limit, and (if successful in items 1 through 3 ) (4) develop recommendations for equipment that will be needed for an on-line inspection and feedback.

Results: Several thermographic techniques were attempted in an effort to detect known cracks in green powder compact gears but without success. The techniques included flash thermography, electric pulse thermography, replicant techniques, and thermosonics. We also tried heating the parts to the pressing temperature. In no case were we able to detect the crack. Our conclusion is that thermography is not a viable nondestructive technique for the detection of flaws in green metal compact gears.

\section{Reports/Publications/Awards:}

Ralph Dinwiddie and Mike Pershing, "Detection of Cracks in Green Powder Metallurgy Compacts," MPLUS report, 2003. 
MPLUS No.: MC-02-045

Title: Characterization of Viscoplastic Behavior of Nodular Cast Iron for Life Prediction Modeling

User Organization: NW Numerics and Modeling, Inc. Seattle, WA 98109

User Contact: Ron Foerch, 206-352-8030 foerch@nwnumerics.com

ORNL R\&D Staff: K. C. Liu, 865-574-5116 liukc@ornl.gov

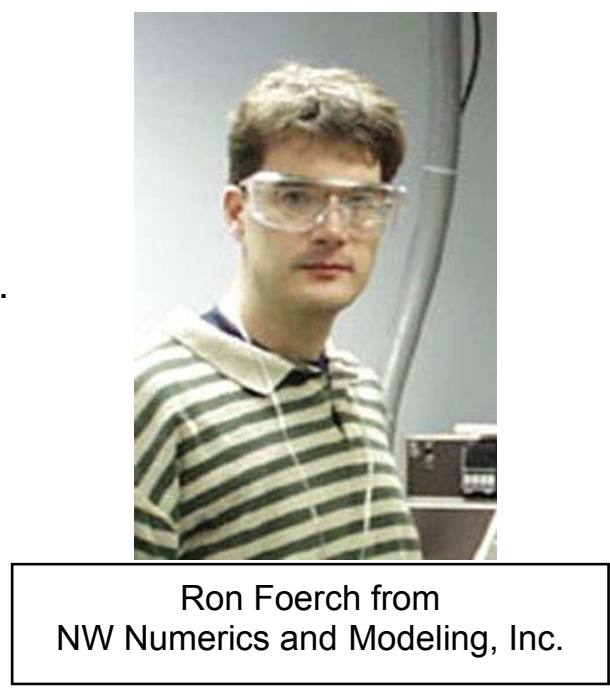

E. Lara-Curzio, 865-574-1749 laracurzioe@ornl.gov

Relevance to OIT: Unexpected failure of industrial components is undesirable because it results in expensive downtime. Therefore, the ability to predict the durability of components that are used in high-temperature applications could have a significant positive impact on operating costs. Viscoplastic models could provide the tools necessary to predict damage evolution and component life. The project is related to the metal casting industry.

Objective: To develop mathematical models of material behavior to predict the deformation, lifetimes, and mechanical performances of automotive engine components and complex assemblies of these components. This project focused on elevated temperature behavior of nodular cast iron as a prime candidate material for automotive exhaust manifolds.

Results: Thermomechanical fatigue behavior and viscoplastic cyclic response of nodular cast iron were characterized for formulating constitutive models for finite element analysis use and to develop life predictive capability. A test matrix with both classical and novel loading and isothermal and temperature variable conditions was used to derive many synergistic mechanisms of deformation. Special effort was made to address fundamental problems in properly characterizing the behavior of metals at elevated temperatures, but separating combined effects of isotropic hardening or softening, kinematic hardening, and viscous overstress at a wide range of stress levels remained difficult. The lack of uniformity in the microstructure of the material evaluated was another problem that appeared to limit the applicability of the experimental results. Nonetheless, the information gained from this study was extremely useful to the material producer for improving the material. Furthermore, the results validate the experimental approach. Using his experience gained at ORNL, Dr. Foerch has acquired an electrohydraulic materials testing system to conduct simple tensile and fatigue tests. 


\section{Reports/Publications/Awards:}

Ronald Foerch, Report No. 02034-1, July 12, 2002, delivered to Joe Bishop of GM Powertrain. 
MPLUS No.: MC-02-046

Title: TEM Investigation into the Mechanism of Composite Membrane Cracking in Kraft Recovery Boilers

User Organization: MeadWestvaco Research Chillicothe, $\mathrm{OH} 45601$

User Contact: J. D. Willis, 740-772-3748 jdw3@meadwestvaco.com

ORNL R\&D Staff: E. A. Kenik, 865-574-5066 kenikea@ornl.gov

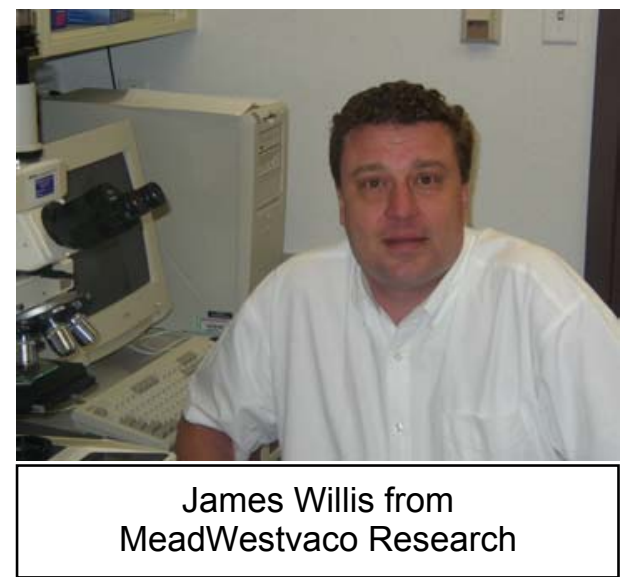

\section{ORNL R\&D Staff: E. A. Kenik, 865-574-5066}

MeadWestvaco Research

Relevance to OIT: Air entry ports in Kraft recovery boilers currently have significant cracking in membranes between boiler tubes. These cracks can result in severe operating and maintenance issues (from steam explosions to extensive downtime for repair). This project evaluated cracked boiler membranes of two different roll clad materials (304L and Inconel 625 on ferritic steel), both of which suffered significant membrane cracking. The results of the microstructural examinations indicate that: (1) temperature cycling and associated thermal fatigue of the components are not the primary source of the cracking, and (2) the presence of sulfur-based corrosion products in the cracks of the 625 clad suggest that in this case environmentally assisted cracking may be resulting from sulfur present in the black liquor.

Objective: Investigate the microstructure of cracked membrane from the Escanaba boiler to determine if thermal fatigue or some other effect is the cause for initiation and/or propagation of the cracks in 304L stainless steel and Inconel 625 cladding.

Results: The microstructure near the external (fireside) surfaces of membrane welds for both a 304L/ferritic steel and a 625/ferritic steel composite tube assembly were examined by transmission electron microscopy (TEM). The dislocation microstructure was examined in order to determine if thermal fatigue was contributing to the cracking. The microstructure of an unexposed 625 weld overlay was also examined to provide the baseline structure of as-welded alloy 625 for comparison with that observed in the inservice component. In addition, the microstructure and corrosion products in cracks in the 625 clad were examined in the SEM. Specific observations included the following:

1. Both the 304L and 625 clads exhibited extensive dislocation structures (Fig. 1); however, there was no evidence of a dislocation cell structure in either material. This absence indicates that pure thermal fatigue is not a likely cause of the observed cracking. The unexposed 625 weld overlay exhibited significant but lower network dislocation density than that in the exposed 625 clad. As such, both clads had experienced some deformation from thermal cycling in the Kraft boiler. 

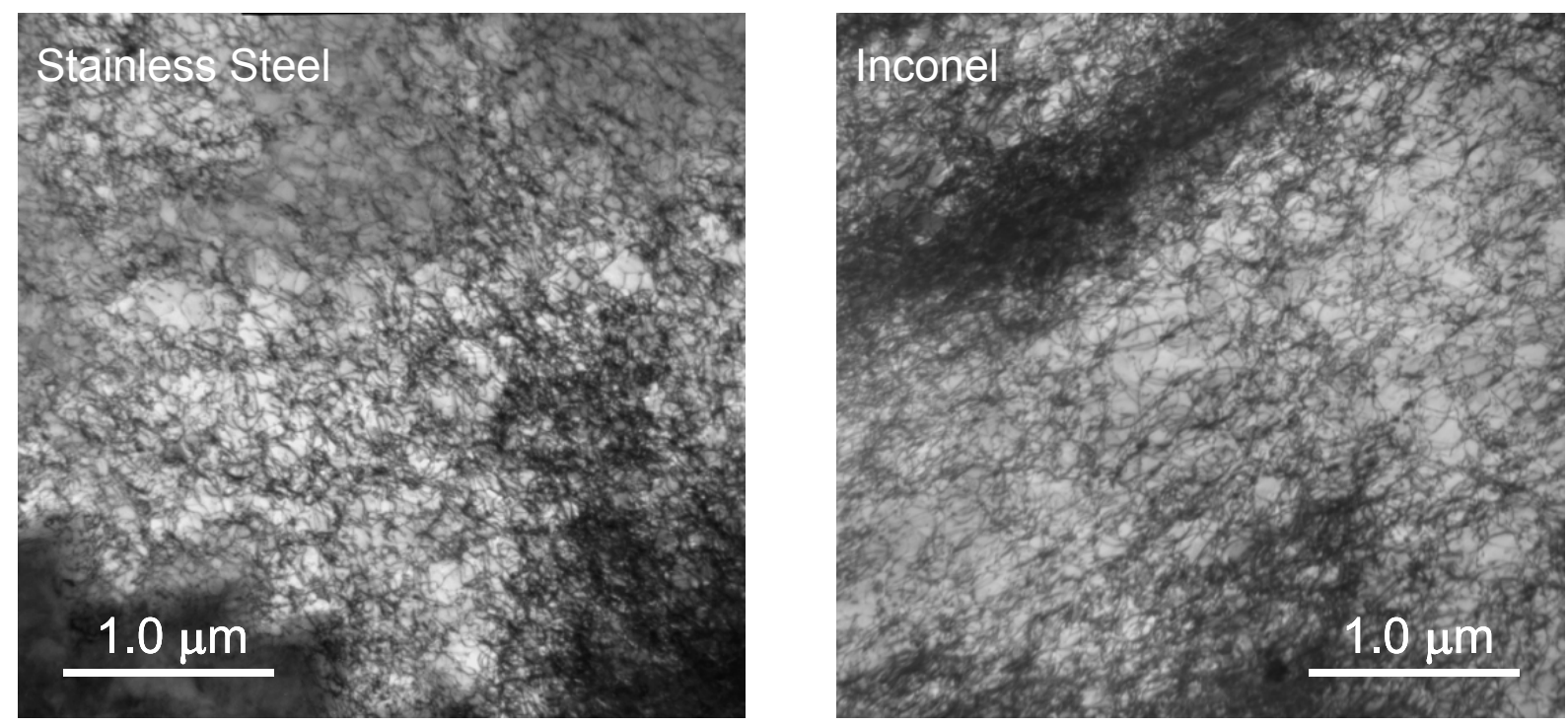

Fig. 1. Near-surface dislocation microstructure of stainless steel and Inconel 625 clads.

2. The 625 clad exhibited several different intergranular and intragranular second phases, including oxides (generally aluminum rich) and grain boundary precipitates enriched in $\mathrm{Mo}, \mathrm{Cr}, \mathrm{Nb}$, and $\mathrm{Si}$. These latter precipitates had large lattice parameters that would be typical of either eta or $G$ phase silicides, which would also be consistent with their observed composition.

3. Because pure thermal fatigue was discounted as the source of the observed cracking, the possibility of environmentally assisted cracking of the 625 clad was investigated. A cross-sectional specimen was prepared for scanning electron microscopy and X-ray microanalysis of the corrosion products in cracks in the clad [Fig. 2(a)]. The thickness of the cladding was nonuniform and the clad interface was offset at the cracks. The origin of this offset is unclear without further work. However, the offset may be a processing defect that induces subsequent cracking due to stress and environment, or it may be the result of cracking and localized deformation under the residual stresses in the composite tube.

4. Several corrosion products are present in the cracks and in the corrosion pockets in the underlying steel [Fig. 2(b)]. A dark phase in and near the crack is iron oxide with varying levels of $\mathrm{S}, \mathrm{K}, \mathrm{Ni}$, and $\mathrm{Cr}$. The lighter phase in the pocket is iron sulfide with varying $\mathrm{O}, \mathrm{K}$, and $\mathrm{Ca}$. There are corrosion products on the sides of the cracks through the Inconel 625. A dark phase that is possibly nickel sulfate with traces of $\mathrm{K}$ and $\mathrm{Cr}$ and a lighter phase that appears to be nickel sulfide with lower levels of $\mathrm{Cr}$ and $O$ are present in secondary cracks. 


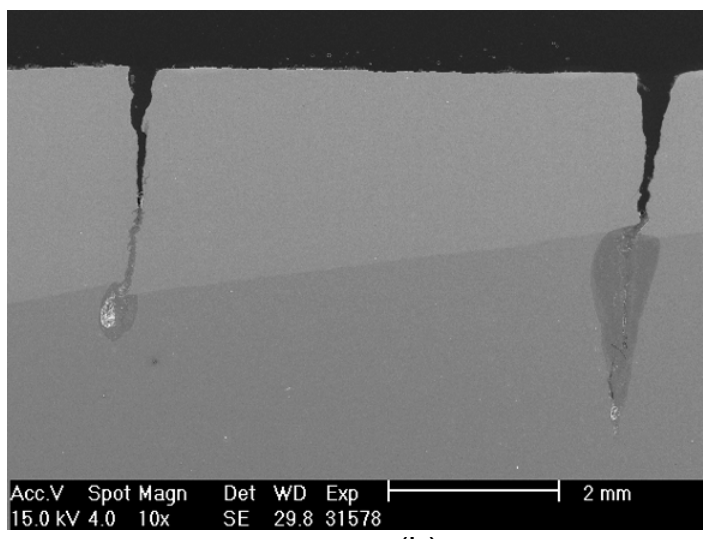

(b)

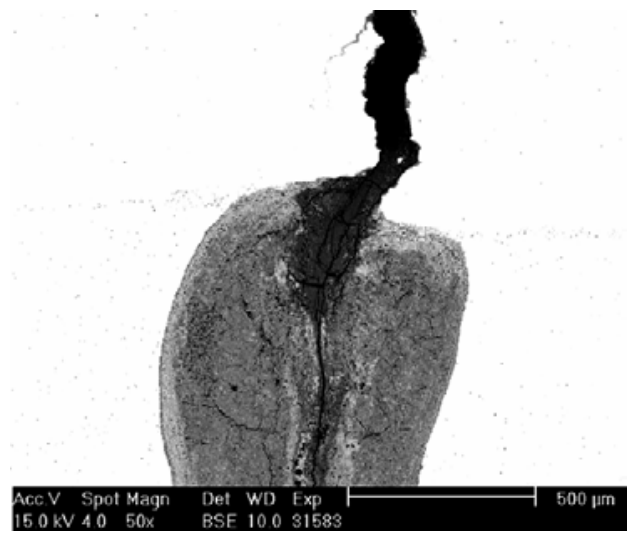

(b)

Fig. 2. Cross section of a specimen of 625 clad on steel: (a) cracks and corrosion pocket and (b) backscattered electron image of corrosion products in crack and pocket magnified from right side of image (a).

\section{Reports/Publications/Awards:}

E. A. Kenik and J. D. Willis, "TEM Investigation into the Mechanism of Composite Membrane Cracking in Kraft Recovery Boilers," MPLUS report, June 2003. 
MPLUS No.: MC-02-047

Title: Prediction of Elemental Segregation and Phase Formation in Aluminum 5754 Alloy

User Organization: Commonwealth Aluminum Uhrichsville, $\mathrm{OH} 44683$

User Contact: Zhong Li, 740-922-8365 liz@mail.cacky.com

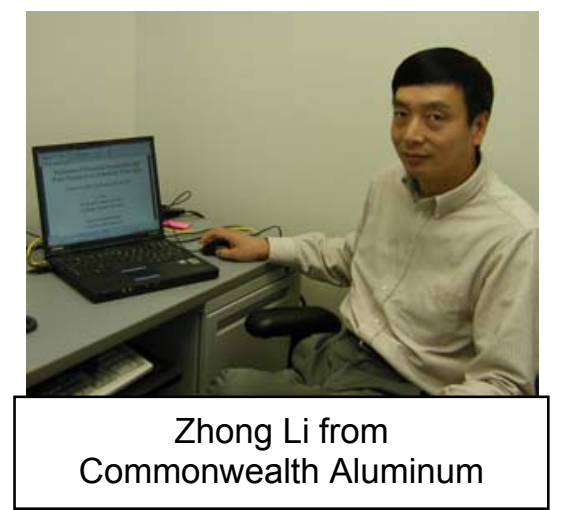

ORNL R\&D Staff: Qingyou Han, 865-574-4352 hanq@ornl.gov

Relevance to OIT: Twin-belt continuous casting of aluminum 5754 alloy is a much more energy- and cost-efficient process than the direct chill method. However, segregation and second phase formation in the aluminum limits the use of twin-belt-produced products. (The particles that are formed during solidification are brittle and thus limit the applications where this type of aluminum material can be used.) This project predicted the trend of the segregation and phase formation behavior in aluminum 5754 alloy to better understand and minimize the formation of the brittle particles. This project is directly related to the aluminum industry.

Objective: One of the issues for twin-belt continuous casting is elemental segregation. It affects the secondary phase formation, homogenization heat-treatment time, and the mechanical properties of the final rolled materials. The purpose of this MPLUS project was to investigate the segregation and the related phase formation in aluminum 5754 alloy. Thermodynamic simulation was carried out to determine the partition coefficient and the segregation ratio of each element in the alloy. Phase evolution during solidification was predicted. Attempts were made to minimize elemental segregation and second phase formation during solidification and to shorten the homogenization time of the alloy. The results will be useful for energy saving and process optimization. This project is directly relevant to the aluminum industry.

Results: The solidification of aluminum 5157 alloys has been simulated to determine the phase fractions of each phase in the alloy as a function of composition. A total of 81 compositions have been calculated. The simulation results indicate the following:

- The phase fractions of the intermetallic phases can be altered significantly by a slight change in composition. This suggests that micro-alloying should be an effective way for controlling the phase fraction of the alloy.

- The distribution coefficient of the solute element changes significantly during solidification. However, a small change in the composition of the major elements ( $\mathrm{Mg}, \mathrm{Mn}, \mathrm{Fe}$, and $\mathrm{Si}$ ) does not alter the distribution coefficient significantly. 
- The segregation ratio of the solute is strongly affected by the precipitation of the intermetallic phases. Under equilibrium conditions, silicon segregation decreases with decreasing magnesium concentration.

Figure 1 shows the mean phase fractions of $\mathrm{Al}_{3} \mathrm{Fe}, \alpha(\mathrm{ALFeSi}), \mathrm{Al}_{6} \mathrm{Mn}$, and $\mathrm{Mg}_{2} \mathrm{Si}$ as a function of composition. The mean phase fraction of $\mathrm{Al}_{3} \mathrm{Fe}$ decreases as $\mathrm{Mn}$ and $\mathrm{Si}$ increase and $\mathrm{Fe}$ decreases. The mean phase fraction of $\alpha(\mathrm{AlFeSi})$ increases as $\mathrm{Mn}$, $\mathrm{Fe}$, and $\mathrm{Si}$ increase. The mean phase fraction of Al6Mn increases as $\mathrm{Mn}$ and $\mathrm{Fe}$ increase and $\mathrm{Si}$ decreases. The mean phase fraction of $\mathrm{Mg}_{2} \mathrm{Si}$ is strongly affected by the silicon concentration. In each of the plots in Fig. 1, the composition variation is in the range of $0.5 \%$, but the mole fractions of some of the phases can be varied by a few times. This indicates that the phase fraction can be controlled easily by changing slightly the bulk concentration of the alloy.

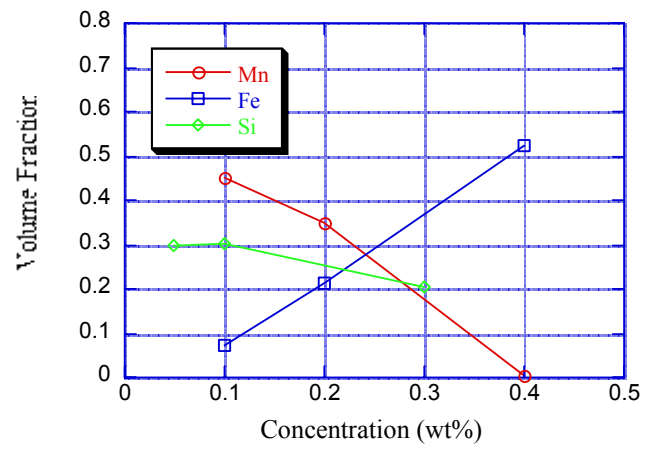

(a) $\mathrm{Al}_{3} \mathrm{Fe}$

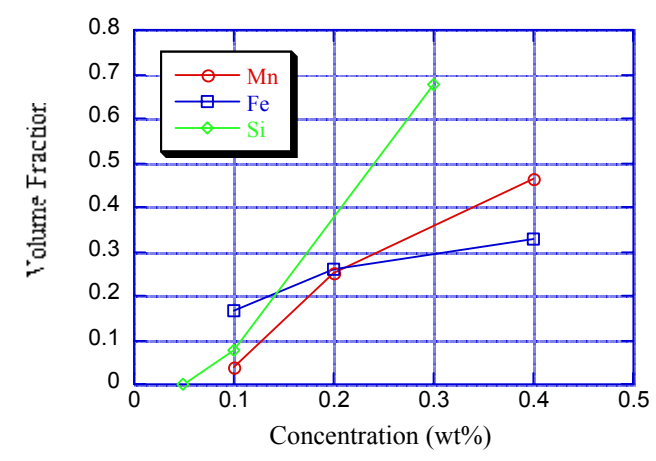

(b) $\alpha($ AlFeSi)

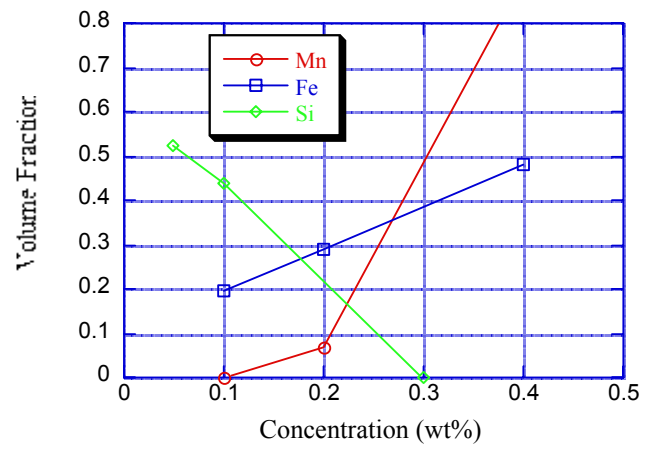

(c) $\mathrm{Al}_{6} \mathrm{Mn}$

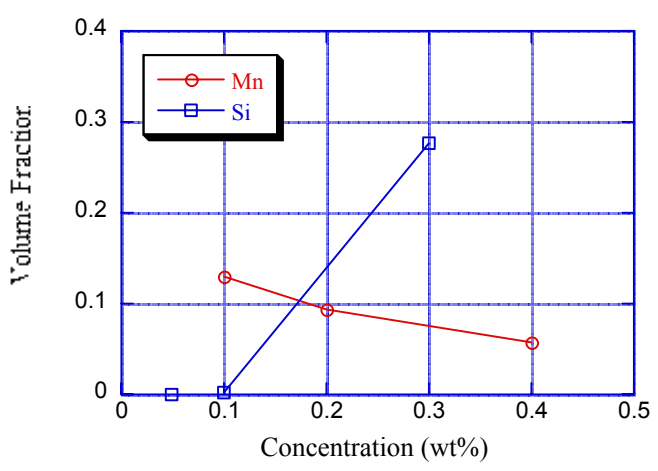

(d) $\mathrm{Mg}_{2} \mathrm{Si}$

Fig. 1. Relationship between phase fractions and the composition of the alloys.

Figure 2 shows the variation of the distribution coefficient (partition coefficient) of the solute element during solidification of the alloy. As the temperature decreases, the partition coefficient of silicon decreases and that of iron increases. The changes in partition coefficients are significant due to high segregation of the solute elements. However, in the composition range of the alloy, a small change in composition does not change the partition coefficient much. 


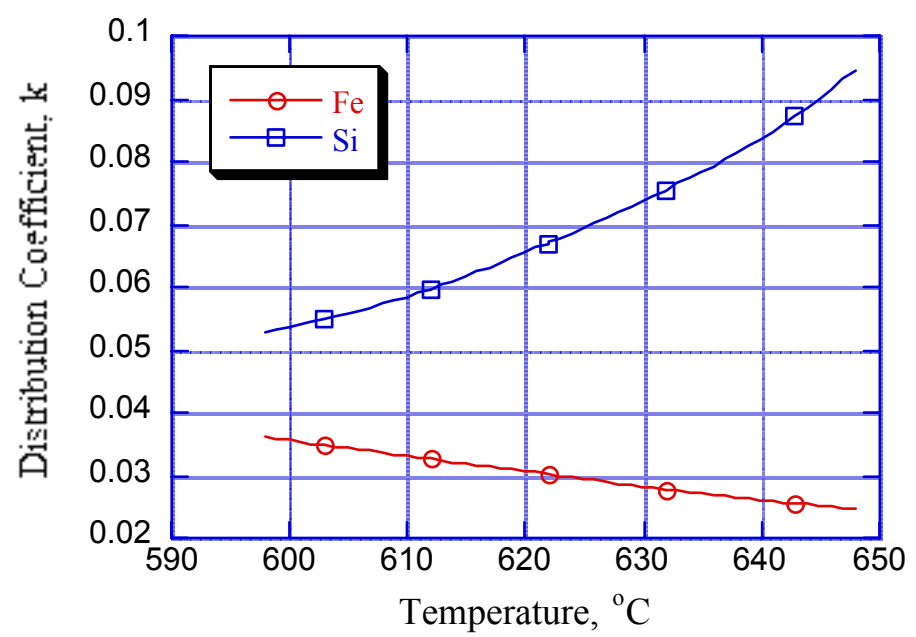

Fig. 2. The changes of partition coefficients of iron and silicon during solidification.

The simulation results also indicate that the segregation ratios of some of the solute elements can be altered by a slight change in composition. Silicon has a major effect on changing the segregation ratios of magnesium and silicon itself.

All of the simulation results are presented in the form of mathematical formulas. The phase fraction of each phase, the partition coefficient, and the segregation ratio of the solute elements can be estimated from the known composition though the use of these simple mathematical equations.

\section{Reports/Publications/Awards:}

Q. Han and J. Zeh, "Prediction of Elemental Segregation and Phase Formation in Aluminum 5754 Alloy," MPLUS report, October 2002. 
MPLUS No.: MC-02-048

Title: Ferrite Prediction in Type 316 Stainless Steel

User Organization: Carpenter Specialty Alloys Reading, PA 19612-4662

User Contact: Y. Murty, 610-208-2646

ymurty@cartech.com

J. Heilmann, 610-208-2000

jheilmann@cartech.com

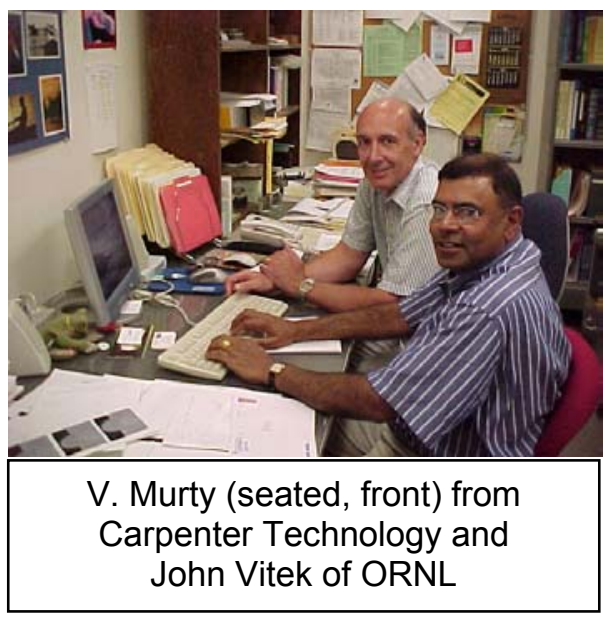

ORNL R\&D Staff: J. Vitek, 865-574-5061

vitekjm@ornl.gov

Relevance to OIT: Continuous chill casting is a common procedure for producing specialty alloys. In the case of stainless steel castings, surface cracks may form during the casting process, resulting in rejection of the casting, energy waste, and increased cost of the final product. This MPLUS project was aimed at identifying the procedures needed to reduce the occurrence of cracks and thereby reducing energy consumption by maximizing the yield of successful crack-free castings. This project is directly relevant to the steel and metal casting industries.

Objective: The mode of solidification in stainless steels (primary ferrite or primary austenite), and the resultant ferrite content in the as-cast material, are associated with the susceptibility of forming cracks during solidification. Experience at Carpenter Specialty Alloys showed the ferrite content varied from heat to heat, and across the cross section of the castings. The objective of this project was to identify the mode of solidification in castings, relate the solidification behavior to the extent of surface crack formation, explain the variation in ferrite content across the as-cast cross section, and suggest alloy modifications that would improve cast yield and energy efficiency by reducing the susceptibility to crack formation during solidification.

Results: Calculations were performed using computational thermodynamics and kinetics models as well as in-house-developed ferrite prediction neural networks to understand the observed differences in ferrite number from casting to casting and across the cross section of individual castings. Two different alloy compositions taken from production heats were studied. Ferrite prediction models were found to be in general agreement with experimental measurements. In addition, the models predicted the observed differences between alloy compositions. However, the empirical models could not predict the variation across the casting cross section that was observed. Instead, computational thermodynamics and kinetics calculations were found to be far more useful. These calculations correctly identified the sensitivity of the solidification mode and resultant ferrite number to alloy composition. Furthermore, when combined 
with kinetics calculations and estimates of the variation of cooling rate from the outside of a billet to the inside, they correctly predicted the observed variation in ferrite number with location.

Specifically, the following was found:

1. The primary solidification mode for the two alloy compositions was different and this led to different ferrite levels in the cooled as-cast structure. Representative results are shown in Fig. 1.

2. Suggestions were made regarding minor composition adjustments that would promote more consistent solidification and lead to more surface-crack-resistant billets while still meeting the overall alloy composition specifications.

3. The variation in cooling rate during solidification and subsequent cooling with position in the billet was used to carry out kinetic calculations, and the results showed the proper positional variation of ferrite number. It was found that the combination of solidification cooling rate and high-temperature solid-state cooling rate was critical in defining the extent of transformation during cooling. Sample results are shown in Fig, 2.
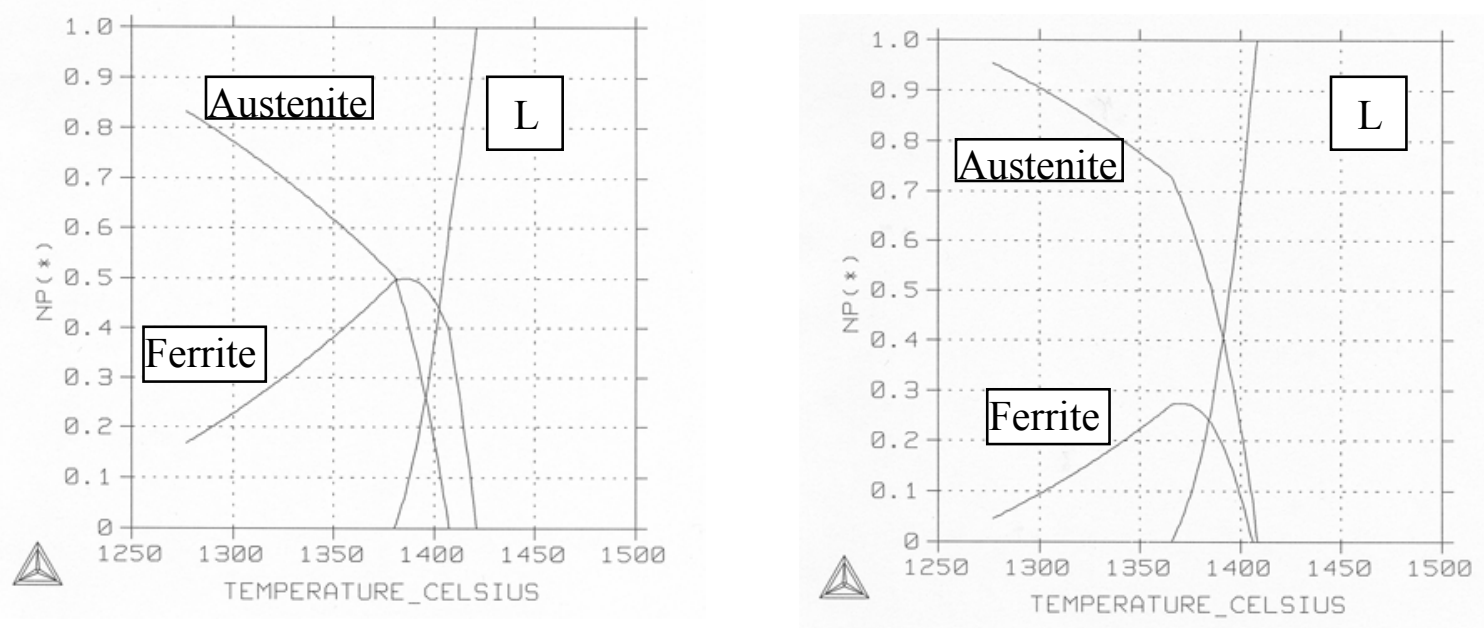

Fig. 1: Calculated phase fraction versus temperature curves for two alloys showing difference in solidification mode (primary ferrite on left, primary austenite on right) and the resultant difference in ferrite content at lower temperatures. 

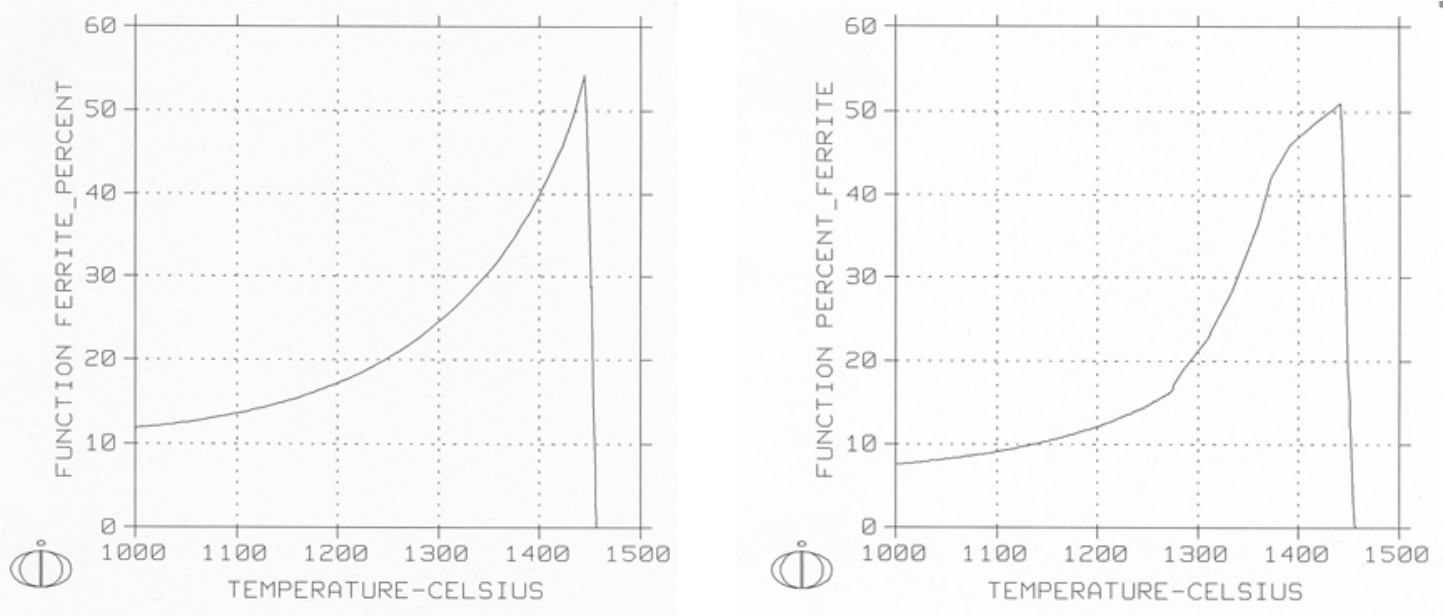

Fig. 2. Calculated percent ferrite versus temperature as a result of using kinetic models and estimated cooling curves for center (left) and edge (right) of billet. The results show that even though the billet edge solidifies faster, the final ferrite level is lower because more ferrite transforms to austenite during solid state cooling.

\section{Reports/Publications/Awards:}

J. Vitek, "Ferrite Predictions in Type 316 Stainless Steel" MPLUS report, 2002. 
MPLUS No.: MC-02-049

Title: Creep Influence on Low-Cycle Fatigue and Fatigue Crack-Propagation Behaviors of Superalloy Haynes ${ }^{\circledR} 230$ in a Vacuum Environment

User Organization: The University of Tennessee Knoxville, TN 37996-2200

User Contacts: Peter K. Liaw, 865-974-6356 pliaw@utk.edu

Dwaine L. Klarstrom, 765-456-6218

dlklarstrom@haynesintl.com

Lijia Chen, 865-974-0245

Ichen@utk.edu

Gongyao Wang, 865-974-0645

gwang@utk.edu

Yulin Lu, 865-974-0645

ylu@utk.edu

ORNL R\&D Staff: Edgar Lara-Curzio, 865-574-1749 laracurzioe@ornl.gov

Kenneth C. Liu, 865-574-5116 liukc@ornl.gov

Relevance to OIT: Increases in the efficiency of industrial processes require materials capable of retaining their strength and corrosion resistance at higher operating temperatures. At high temperatures, creep and mechanical fatigue are often the mechanisms that control the mechanical performance of materials. In applications where water vapor is present, such as in industrial processes that involve combustion gases, alumina-forming alloys are desirable because of their good corrosion resistance. Haynes ${ }^{\circledR} 230$ is a candidate alloy for many high-temperature industrial applications because of its ability to form a protective layer of alumina and its good mechanical properties. Investigations on the long-term mechanical behavior of this alloy are necessary to determine the range of temperatures and mechanical stresses where this alloy can perform reliably, thus enabling an increase in the efficiency of many industrial applications that involve water vapor.

Objective: To separate the effect of creep and oxidation on the low-cycle fatigue and fatigue crack-growth behaviors of Haynes ${ }^{\circledR} 230$ alloy. 
Results: Low-cycle fatigue and crack-growth tests were done in air at elevated temperatures. The results were analyzed and published. High-temperature vacuum testing is in the process of being set up. Induction coils for low-cycle fatigue and fatigue crack-growth tests were designed. Samples, pulling rods, and inserts were machined. The pulling rod, insert, and sample geometries are shown in Figs. 1 through 4.
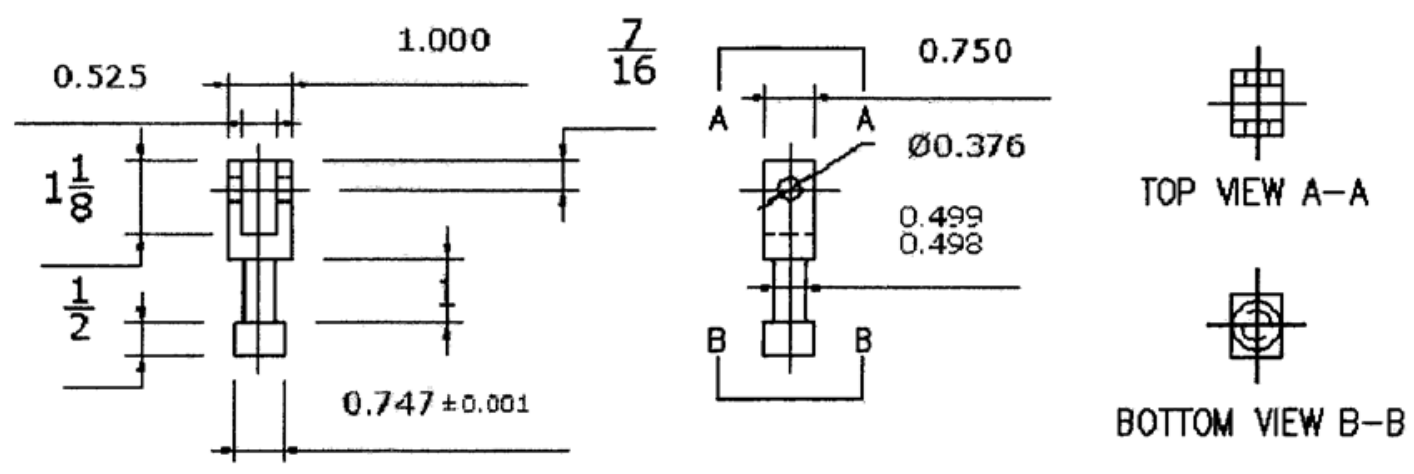

TENSILE PULL ROD

Fig. 1. Pulling rod (in.) for compact-tension crack-growth testing designed by Dr. Kenneth C. Liu at the Oak Ridge National Laboratory, Oak Ridge, TN.

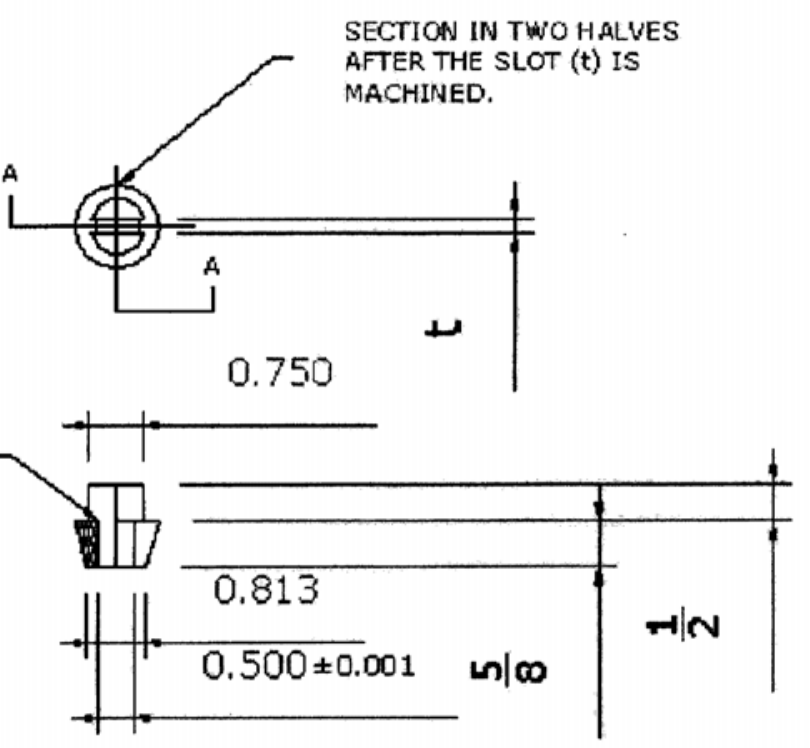

SECTION MEW A-A

SPLIT INSERT

Fig. 2. Split insert (in.) for smooth bar, low-cycle fatigue testing designed by Dr. Kenneth C. Liu at the Oak Ridge National Laboratory, Oak Ridge, TN. 


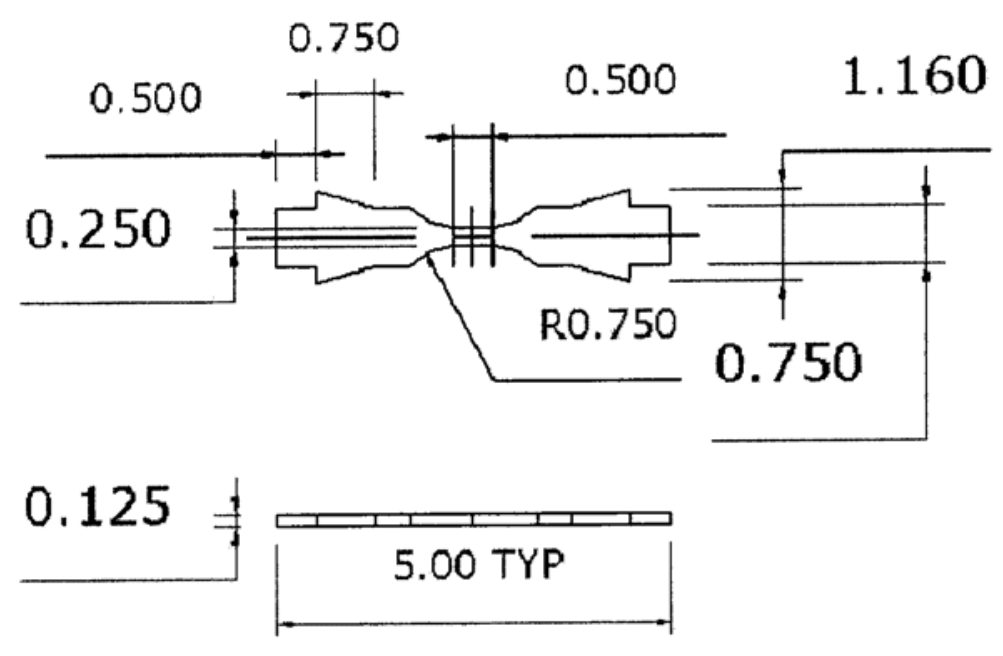

\section{PLATE-TYPE FATIGUE SPECIMEN}

Fig. 3. Geometry of the low-cycle fatigue specimen $(\mathrm{mm})$ designed by Dr. Kenneth C. Liu at the Oak Ridge National Laboratory, Oak Ridge, TN.

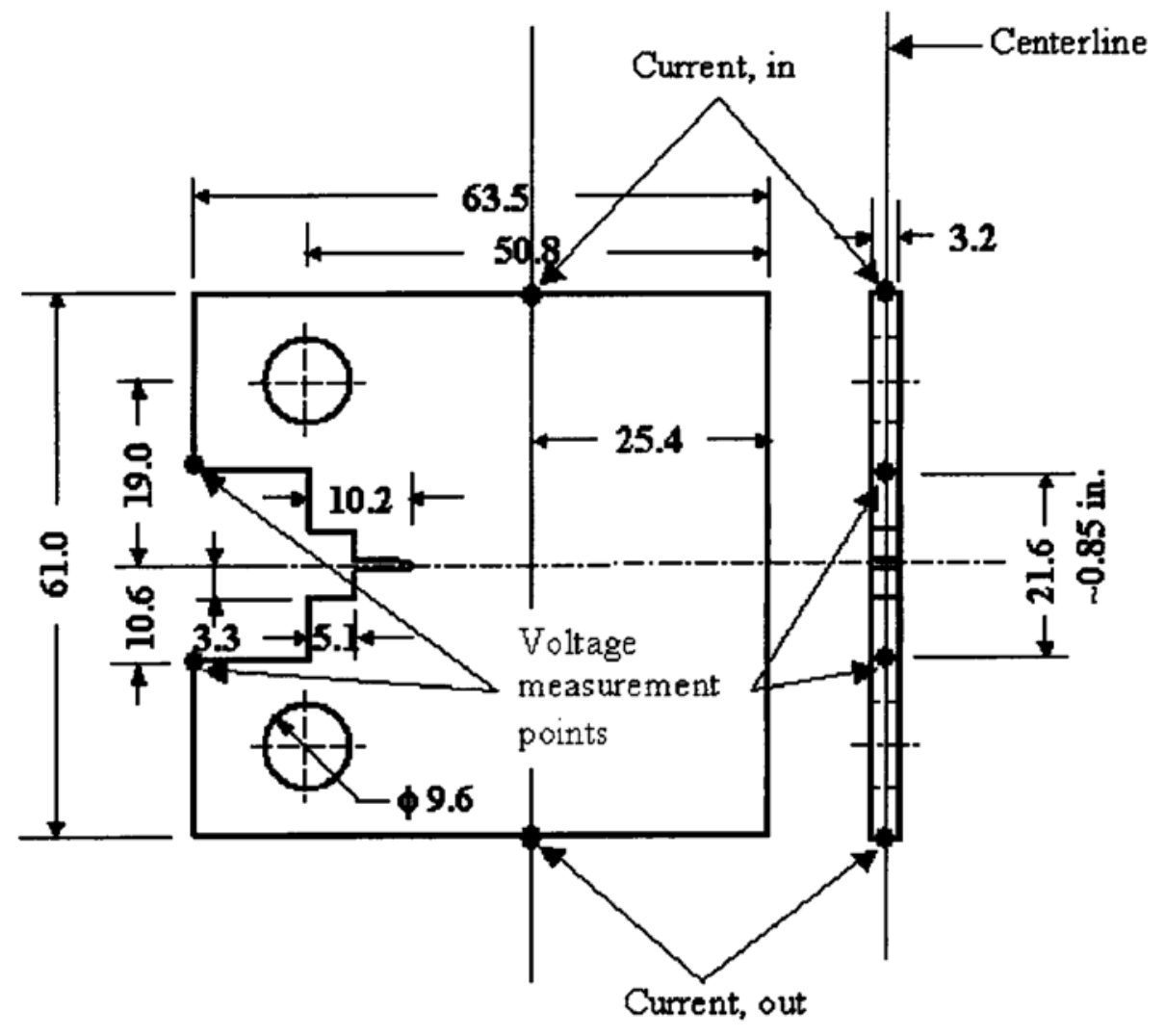

Fig. 4. Geometry of a compact-tension specimen $(\mathrm{mm})$ and electric-potential wire-placement locations. 


\section{Reports/Publications/Awards:}

K.C. Liu, “Final Report of Proposal MC-02-049 for FY 2002," MPLUS report, 2003.

L.J. Chen, Y.H. He, P.K. Liaw, J.W. Blust, P.F. Browning, R.R. Seeley, and D.L. Klarstrom, "High-Temperature Low-Cycle Fatigue Behavior of Haynes ${ }^{\circledR} 230$ Superalloy," Ninth International Symposium on Superalloys, Superalloys 2000, Seven Springs, Pittsburgh, PA, September 17-21, 2000, ed. T.M. Pollock, R.D. Kissinger, R.R. Bowman, K.A. Green, M. McLean, S.L. Olson, and J.J. Schirra, Minerals, Metals, and Materials Society, pp. 573-581 (2000).

Y.L. Lu, L.J. Chen, P.K. Liaw, G.Y. Wang, R.L. McDaniels, S.A. Thompson, J.W. Blust, P.F. Browning, A.K. Bhattacharya, J.M. Aurrecoechea, and D.L. Klarstrom, "ElevatedTemperature Crack-Growth Behavior of Nickel-Base Haynes ${ }^{\circledR} 230$ Alloy at $927^{\circ} \mathrm{C}$," Symposium on Modeling the Performance of Engineering Structural Materials III, TMS/ASM Fall Meeting, Columbus, OH, October 7-10, 2002, ed. T.S. Srivatsan, D.R. Lesuer, and E.M. Taleff, Minerals, Metals, and Materials Society, pp. 123-133 (2002).

Y.L. Lu, L.J. Chen, P.K. Liaw, G.Y. Wang, S.A. Thompson, J.W. Blust, P.F. Browning, A.K. Bhattacharya, J.M. Aurrecoechea, and D.L. Klarstrom, "Elevated-Temperature Crack Growth Behavior of Nickel-Base Hastelloy ${ }^{\circledR}$ X Alloy," Symposium on Materials Lifetime Science and Engineering, TMS Annual Meeting, San Diego, CA, March 2-6, 2003, ed. P.K. Liaw, R.A. Buchanan, D.L. Klarstrom, R.P. Wei, D.G. Harlow, and P.F. Tortorelli, Minerals, Metals, and Materials Society, pp. 33-42 (2003). 
MPLUS No.: MC-02-050

Title: Defining the Instrumental Measurements and Procedures Required to Properly Control the Lost Foam Casting Process

User Organization: Walford Technologies Oak Ridge, TN 37830

User Contact: Graham Walford, 865-482-4995 photonx@vol.com walfordgv@ornl.gov

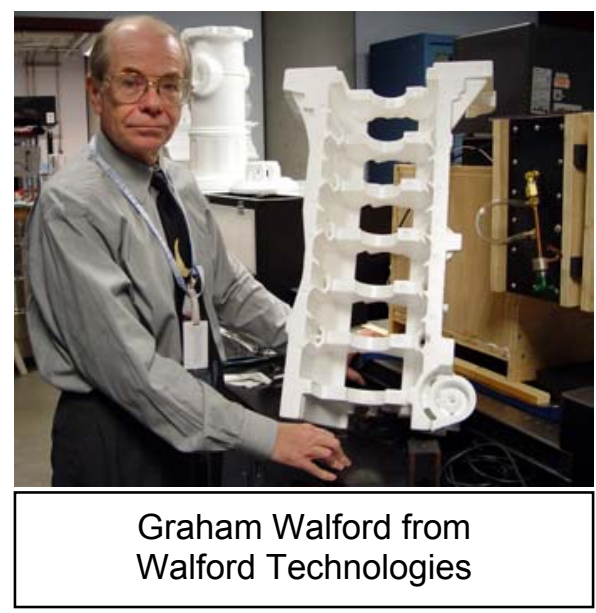

ORNL R\&D Staff: $\quad$ Ralph B. Dinwiddie, 865-574-7599 dinwiddierb@ornl.gov

Relevance to OIT: The Infrared imaging technology has provided a unique insight into the lost foam casting process to understand the behavior of the metal fill and pattern decomposition process. This work has led directly to the need to address issues concerning casting defect, effects of foam and coating properties and opportunities concerning the casting of magnesium and steel. It is anticipated that casting yield, quality, and the opportunity to develop new, more complex and lighter weight castings will result because of this process understanding and optimization. Such developments have attendant energy savings. This project is directly relevant to the metal casting industry.

Objective: To better understand the primary lost foam pattern parameter and develop means to measure those parameters.

Results: Walford Technologies undertook an MPLUS activity to further develop methods to characterize expanded polystyrene patterns.

Methods of primary attention included the following:

1. Study of gas permeability of coating and foam with Infrared imaging methods.

2. Bead fusion utilizing optical imaging (transmitted and backscattered light.

3. Foam void space utilizing optical absorption in absorbed translucent oils (this measurement provides permeability measurement).

4. Bead chaos measurement (identifies primary gas flow channels in the foam) by means of optical imaging.

5. Coating thickness and behavior. 
The above represents aggressive targets to resolve in one project. However, progress was made in all areas by combining these studies with capabilities and measurement activity at Walford Technologies.

Optical imaging methods were successfully utilized to quantify surface fusion level and volume permeability in the one measurement. Permeability measurements were made thermally for both foam and coating.

Coating thickness variations were visualized by means of thermal methods. Bead chaos locations were identified as primary sites of gas flow in the foam.

The above results have been presented at several foundry meetings, and they are the basis of continuing developments in the study of the lost foam casting process.

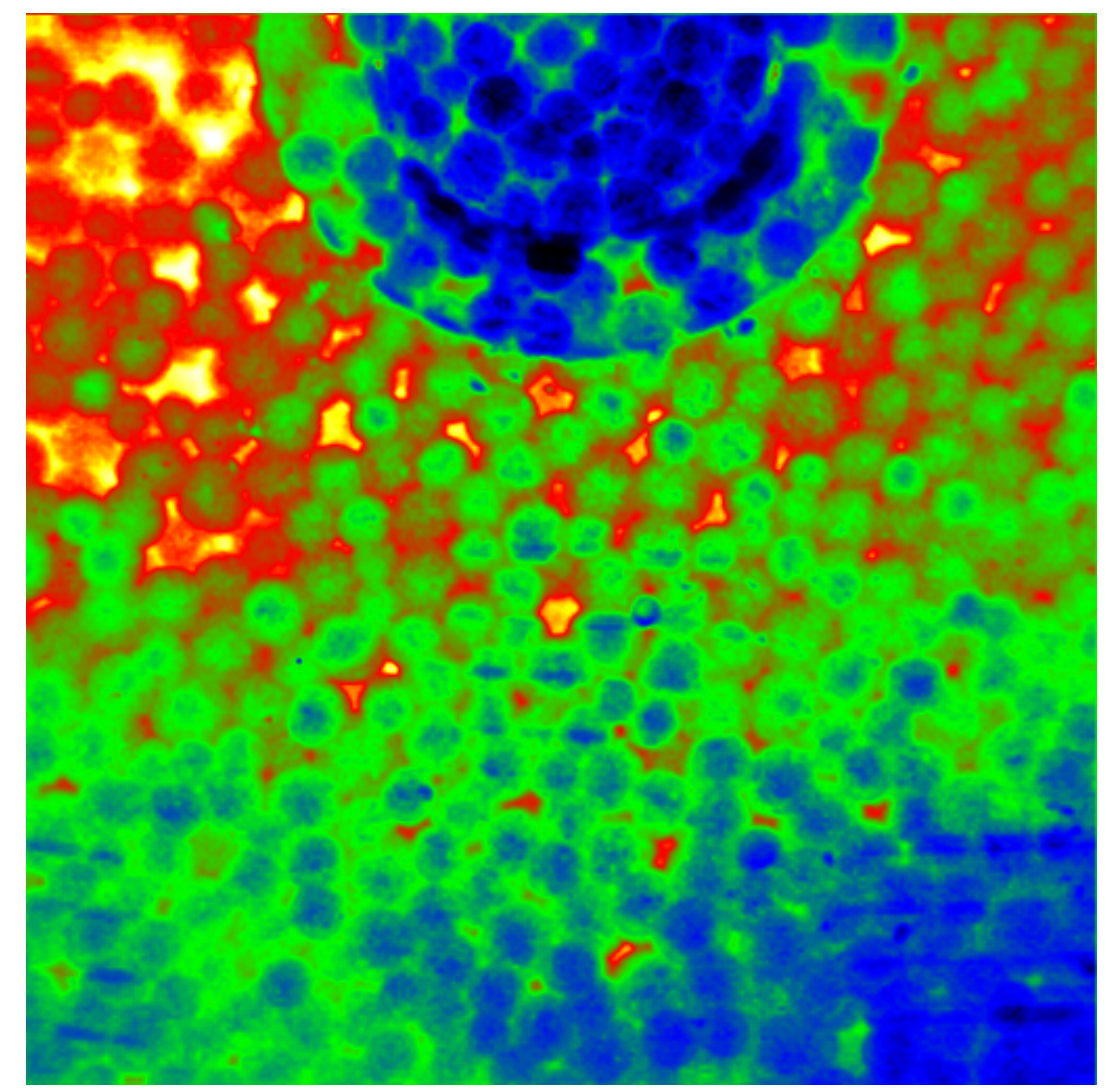

Fig. 1. Thermal image of low-fusion foam pattern showing permeability of hot gas (white, yellow, and red areas) near a filling port.

\section{Reports/Publications/Awards:}

Several presentations have been made at casting meetings and Lost Foam Consortia meetings. Several lost foam-involved corporations now utilize measurement methods developed from this effort. 
MPLUS No.: MC-02-051

Title: Quantifying and Correlating Lost Foam Pattern Properties with Metals Fill Casting Performance: Understanding the Process

User Organization: Foseco-Morval, Inc. Bessemer, AL 35022

User Contact: Dennis Nolan dennis.nolan@fosecoinc.com

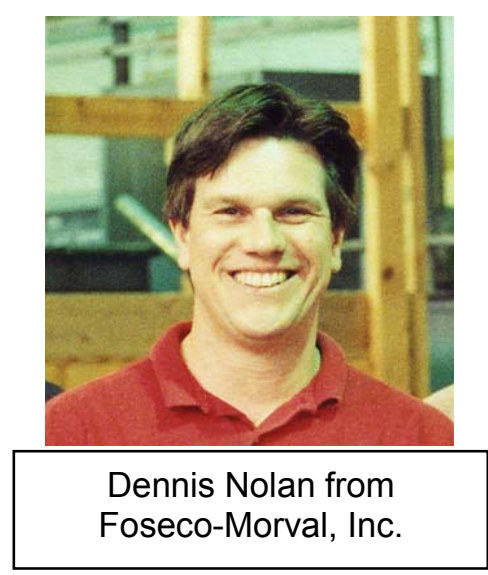

ORNL R\&D Staff: $\quad$ R. B. Dinwiddie, 865-574-7599 dinwiddierb@ornl.gov

Relevance to OIT: Understanding the influence of the foam properties on lost foam casting quality is critical if improvements are to be made in the process and increasing yield (more efficient energy use). The project successfully developed and demonstrated for the first time real time infrared (IR) imaging of the lost foam casting process. Initial results indicate that significant metal flow behavior is very much dependent on foam pattern permeability.

Objective: The objective of the project was to develop a real time IR imaging technique for monitoring the lost foam casting of aluminum. The approach was to visualize the molten metal foam interactions with two types of foams [high fusion (less porosoity) and low fusion (more porosity)].

Results: A casting flask that allows the IR camera to image the molten metal as it burns into the foam was assembled and successfully tested. Three window materials were tested (Quartz, Pyrex). Quartz is the most transparent in the wavelength band of the IR camera and allows imaging of the uncoated foam cells for close-up study of the metal-foam interaction. Pyrex has sufficient transparency in the IR to allow imaging of the metal-foam interaction on a part-wide scale (coated or uncoated). However, the Pyrex is too opaque to allow imaging of the foam cell structure at room temperature. Pyrex is much less expensive than Quartz so the Quartz use is limited to close-up studies. Both Pyrex and Quartz crack due to thermal shock several seconds after the part has been filled.

The real time IR visualization of the interaction of metal flow with the foam pattern was successfully demonstrated. Aluminum casting experiments were performed on both low and high fusion foam patterns. This technique shows significant differences in the metal flow behavior depending on foam pattern permeability. The metal flowed more uniformly in a high fusion low permeability foam pattern. 

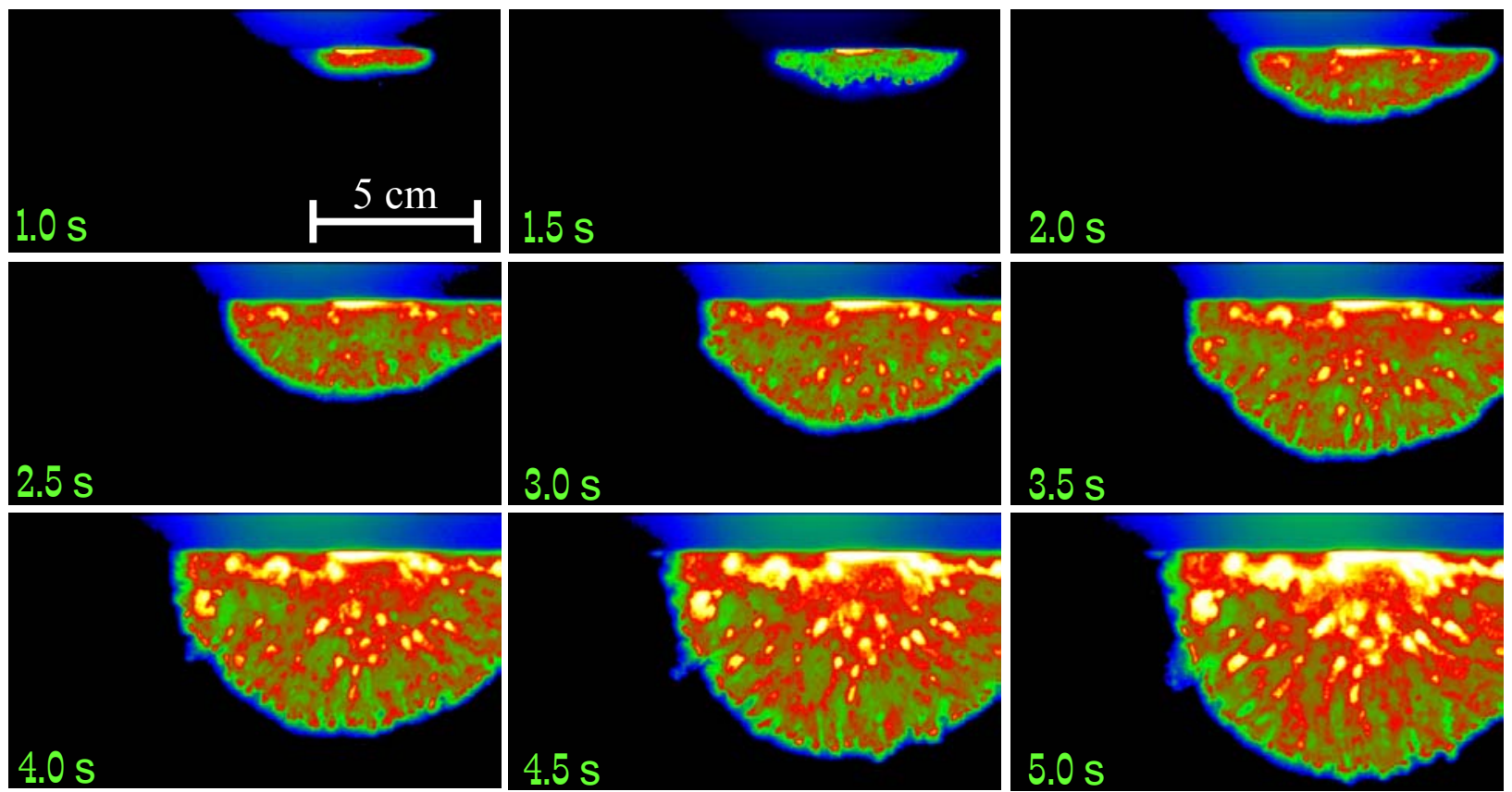

Fig. 1. Thermal image sequence of molten aluminum burning nonuniformly into a lowdensity foam pattern.

\section{Reports/Publications/Awards:}

Ralph Dinwiddie and Dennis Nolan, "Quantifying and Correlating Lost Foam Pattern Properties with Metals Fill Casting Performance: Understanding the Process," MPLUS report, 2003.

The results from this MPLUS will be discussed in presentations given at the 2004 American Foundrymen's Society Casting Congress and the 2004 International Society for Optical Engineering ThermoSense conference. 
MPLUS No.: MC-02-052

Title: Qualifying Production Grade Foam and Coatings with Optical and Infrared Methods for the Lost Foam Casting Process

User Organization: GM Powertrain Saginaw, Ml 48605-5073

User Contact: Jerry A. Barendreght, 989-757-0810 jerry.a.barendreght@gm.com

ORNL R\&D Staff: $\quad$ R. B. Dinwiddie, 865-574-7599 dinwiddierb@ornl.gov

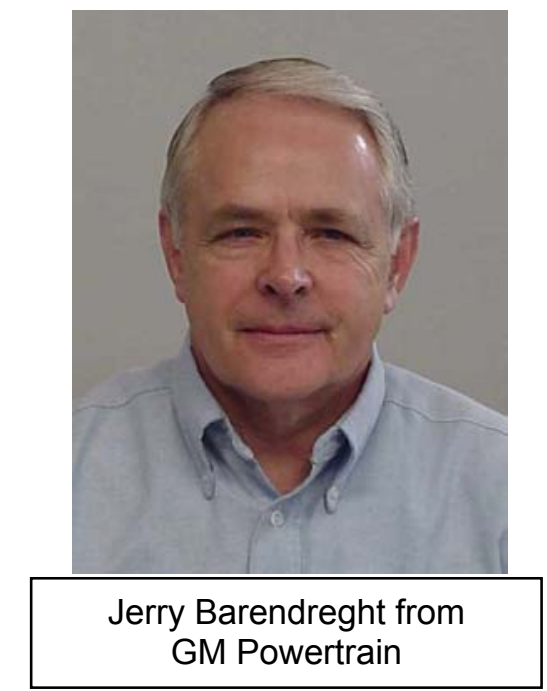

Relevance to OIT: The lost foam casting process is very energy efficient relative to many other casting processes. Improvements can be made in the process in order to make it more efficient. The casting quality is directly related to the permeability of the foam pattern and its interactions with pyrolysis products (both gaseous and liquid). Elimination of these defects can improve yield and is thus directly related to improved energy efficiency of the process. The project successfully developed a method and demonstrated gas permeability mapping of the foam patterns prior to casting in a laboratory environment.

Objective: Observe image foam patterns both optically and by ORNL's infrared gas permeability method and correlate these images with oil uptake, density scans, and optical fusion measurement. Identify the coating/foam fusion relationship.

Results: An optical technique was successfully developed to observe and record the optical density of the foam panels. Line scans from the recorded images clearly show the through-thickness density variations that result from the processing conditions. Preliminary investigations using the infrared gas permeability technique show promise. Low density areas identified by our optical scan technique correlate with areas identified by the infrared gas permeability images as areas with higher gas flow. These results also correlate with oil uptake measurements. However, the optical and infrared imaging techniques offer the advantage of being nondestructive and do not result in the production of hazardous waste as does the oil uptake technique. 


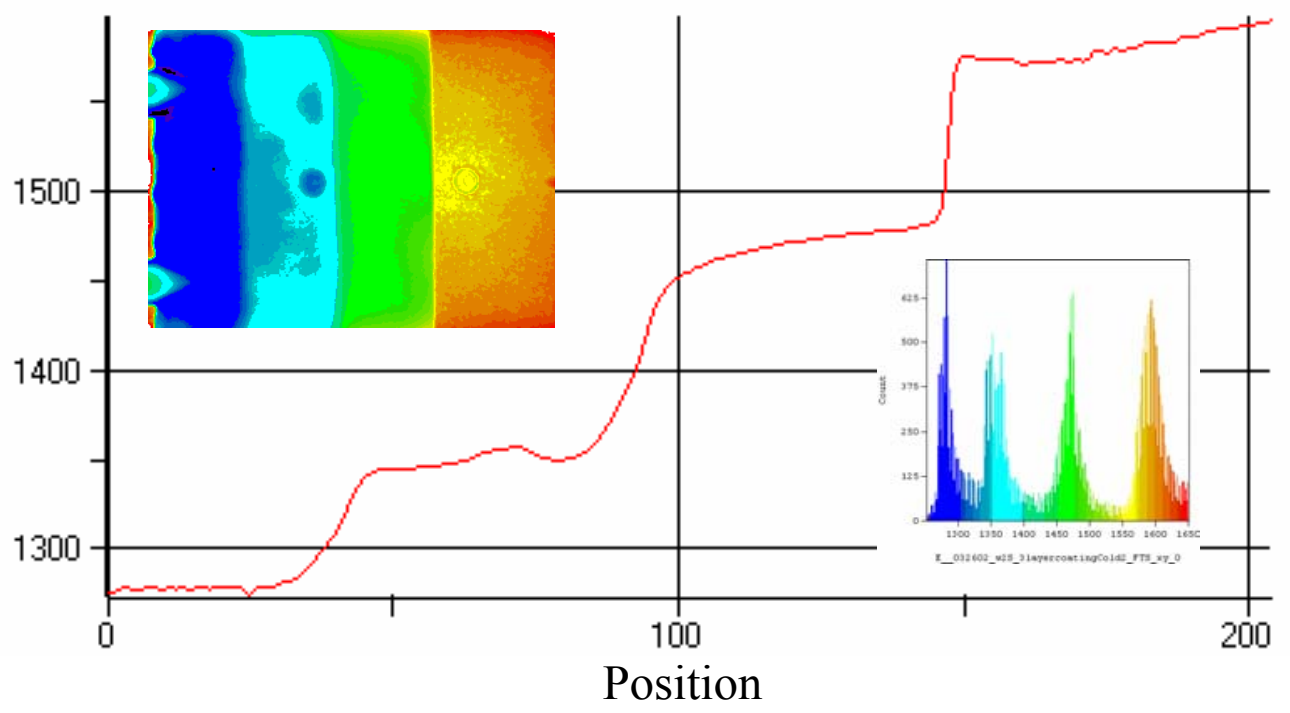

Fig. 1. Graph showing the permeability of a foam pattern with a coating applied with four different thicknesses. The thinnest coating is on the right (red) and is the most permeable to the hot gas.

\section{Reports/Publications/Awards:}

Presented at the Lost Foam Consortium Meeting and will be presented at the 2004 American Foundrymen's Society Casting Congress. These results will also be included in an International Society for Optical Engineering paper that will be presented at the ThermoSense Conference in April 2004. 
MPLUS Proposal List

\begin{tabular}{|c|c|c|c|c|c|}
\hline $\begin{array}{c}\text { Proposal } \\
\text { No. }\end{array}$ & Organization & $\begin{array}{c}\text { Proposal } \\
\text { Title }\end{array}$ & $\begin{array}{c}\text { Organization } \\
\mathrm{PI}\end{array}$ & $\begin{array}{c}\text { ORNL } \\
\text { PI }\end{array}$ & Relevance \\
\hline $\begin{array}{l}\text { MC-02- } \\
001\end{array}$ & $\begin{array}{l}\text { John Deere Co. } \\
\text { Moline, IL }\end{array}$ & $\begin{array}{l}\text { Grader Moldboard } \\
\text { Weld Cracking } \\
\text { Problem }\end{array}$ & $\begin{array}{l}\text { Daniel Hartschuh } \\
563-388-4127 \\
\\
\text { Robert Gaster } \\
309-765-3741\end{array}$ & $\begin{array}{l}\text { Suresh Babu } \\
865-574-4086\end{array}$ & $\begin{array}{l}\text { Mining } \\
\text { Welding }\end{array}$ \\
\hline $\begin{array}{l}\text { MC-02- } \\
002\end{array}$ & $\begin{array}{l}\text { Walford } \\
\text { Technologies } \\
\text { Oak Ridge, TN }\end{array}$ & $\begin{array}{l}\text { Characterization of } \\
\text { Metal Filling and Gas } \\
\text { Permeability in Lost } \\
\text { Foam Casting }\end{array}$ & $\begin{array}{l}\text { Graham Walford } \\
865-482-4995\end{array}$ & $\begin{array}{l}\text { Ralph Dinwiddie } \\
865-574-7599\end{array}$ & $\begin{array}{l}\text { Aluminum } \\
\text { Metal Casting }\end{array}$ \\
\hline $\begin{array}{l}\text { MC-02- } \\
003\end{array}$ & $\begin{array}{l}\text { Edison Welding } \\
\text { Institute } \\
\text { Columbus, } \mathrm{OH}\end{array}$ & $\begin{array}{l}\text { Modeling of } \gamma^{\prime} \text { Phase } \\
\text { Precipitation from } \gamma \\
\text { Phase in Nickel-Base } \\
\text { Superalloy toward } \\
\text { Understanding Strain } \\
\text { Age Cracking }\end{array}$ & $\begin{array}{l}\text { S. P. Khurana } \\
614-688-5250 \\
\\
\text { J. R. Dydo } \\
614-688-5250\end{array}$ & $\begin{array}{l}\text { Suresh Babu } \\
865-574-4806\end{array}$ & Chemical \\
\hline $\begin{array}{l}\text { MC-02- } \\
004\end{array}$ & $\begin{array}{l}\text { E.I. du Pont de } \\
\text { Nemours and Co. } \\
\text { Wilmington, DE }\end{array}$ & $\begin{array}{l}\text { Report on Validation } \\
\text { of the Low- } \\
\text { Temperature } \\
\text { Extrapolation of } \\
\text { Thermodynamic } \\
\text { Parameters }\end{array}$ & $\begin{array}{l}\text { Steve Grise } \\
302-774-4653\end{array}$ & $\begin{array}{l}\text { Suresh Babu } \\
865-574-4806 \\
\text { Mike Miller } \\
865-574-4719\end{array}$ & Chemical \\
\hline $\begin{array}{l}\text { MC-02- } \\
005\end{array}$ & $\begin{array}{l}\text { Alvord Polk, Inc. } \\
\text { Millersburg, PA }\end{array}$ & $\begin{array}{l}\text { Characterization of } \\
\text { Laser Clads Made on } \\
\text { Steel Substrates }\end{array}$ & $\begin{array}{l}\text { Henry Peng } \\
717-362-6962\end{array}$ & $\begin{array}{l}\text { Suresh Babu } \\
865-574-4806 \\
\\
\text { Ed Kenik } \\
865-574-5066 \\
\text { Andy Payzant } \\
\text { 865-574-6538 }\end{array}$ & Mining \\
\hline $\begin{array}{l}\text { MC-02- } \\
006\end{array}$ & $\begin{array}{l}\text { Duraloy } \\
\text { Technologies, Inc. } \\
\text { Scottdale, PA }\end{array}$ & $\begin{array}{l}\text { Improved Alloys for } \\
\text { Coiler Drums for } \\
\text { Plate Reversing Mills }\end{array}$ & $\begin{array}{l}\text { Roman Pankiw } \\
\text { 724-887-5000 X188 } \\
\text { Don Voke } \\
\text { 724-887-5100 X155 } \\
\text { Kevin Marsden } \\
\text { 412-464-4400 X281 }\end{array}$ & $\begin{array}{l}\text { Mike Santella } \\
865-574-4805\end{array}$ & $\begin{array}{l}\text { Steel, } \\
\text { Chemical, } \\
\text { Petrochemical, } \\
\text { Forest } \\
\text { Products, and } \\
\text { Metal Casting }\end{array}$ \\
\hline $\begin{array}{l}\text { MC-02- } \\
007\end{array}$ & $\begin{array}{l}\text { HY-Tech } \\
\text { Research Corp. } \\
\text { Radford, VA }\end{array}$ & $\begin{array}{l}\text { Die Casting } \\
\text { Performance Testing } \\
\text { of H13 Samples } \\
\text { Processed with } \\
\text { HYBron }^{\mathrm{TM}} \text { Boron- } \\
\text { Based Coating } \\
\text { Technology }\end{array}$ & $\begin{array}{l}\text { Christopher Klepper } \\
540-639-4019 \\
\text { Jim Williams } \\
\text { 205-222-7419 }\end{array}$ & $\begin{array}{l}\text { Gail Ludtka } \\
865-576-4652\end{array}$ & Chemical \\
\hline $\begin{array}{l}\text { MC-02- } \\
008\end{array}$ & Cancelled & & & & \\
\hline $\begin{array}{l}\text { MC-02- } \\
009\end{array}$ & Cancelled & & & & \\
\hline $\begin{array}{l}\text { MC-02- } \\
010\end{array}$ & $\begin{array}{l}\text { Inductoheat } \\
\text { Madison Heights, } \\
\text { MI }\end{array}$ & $\begin{array}{l}\text { A Noncontact, Very } \\
\text { Rapid Surface Temp- } \\
\text { erature Measurement } \\
\text { using Advanced } \\
\text { Infrared Imaging }\end{array}$ & $\begin{array}{l}\text { Madhu Chatterjee } \\
248-585-9393 \text { X213 }\end{array}$ & $\begin{array}{l}\text { Ralph Dinwiddie } \\
865-574-7599\end{array}$ & $\begin{array}{l}\text { Metal } \\
\text { Processing }\end{array}$ \\
\hline
\end{tabular}


MPLUS Proposal List (continued)

\begin{tabular}{|c|c|c|c|c|c|}
\hline $\begin{array}{c}\text { Proposal } \\
\text { No. }\end{array}$ & Organization & $\begin{array}{c}\text { Proposal } \\
\text { Title }\end{array}$ & $\begin{array}{c}\text { Organization } \\
\mathrm{PI}\end{array}$ & $\begin{array}{c}\text { ORNL } \\
\text { PI }\end{array}$ & Relevance \\
\hline $\begin{array}{l}\text { MC-02- } \\
011\end{array}$ & $\begin{array}{l}\text { Inductoheat } \\
\text { Madison Heights, } \\
\text { MI }\end{array}$ & $\begin{array}{l}\text { Comparison of } \\
\text { Tempering Response } \\
\text { of Steels to Induction } \\
\text { Heating vs. } \\
\text { Conventional Heating }\end{array}$ & $\begin{array}{l}\text { Madhu Chatterjee } \\
\text { 248-585-9393 X213 }\end{array}$ & $\begin{array}{l}\text { Vinod Sikka } \\
\text { (865) 574-5112 }\end{array}$ & $\begin{array}{l}\text { Steel } \\
\text { Heat Treating }\end{array}$ \\
\hline $\begin{array}{l}\text { MC-02- } \\
012\end{array}$ & Cancelled & & & & \\
\hline $\begin{array}{l}\text { MC-02- } \\
013\end{array}$ & $\begin{array}{l}\text { ITW - Hobart Bros } \\
\text { Company } \\
\text { Troy, OH }\end{array}$ & $\begin{array}{l}\text { Stress-Rupture } \\
\text { Testing of } 9 \mathrm{Cr} \text { Steel } \\
\text { Weldment }\end{array}$ & $\begin{array}{l}\text { Fuhu Chen } \\
937-332-5233\end{array}$ & $\begin{array}{l}\text { Mike Santella } \\
865-574-4805\end{array}$ & Steel \\
\hline $\begin{array}{l}\text { MC-02- } \\
014\end{array}$ & $\begin{array}{l}\text { Matrix Solar } \\
\text { Technologies, Inc. } \\
\text { Albuquerque, NM }\end{array}$ & $\begin{array}{l}\text { Silicon Powder Melt } \\
\text { Process and } \\
\text { Equipment } \\
\text { Development Project }\end{array}$ & $\begin{array}{l}\text { Gary Stevens } \\
205-222-7419\end{array}$ & $\begin{array}{l}\text { Gail Ludtka } \\
865-576-4652\end{array}$ & Crosscutting \\
\hline $\begin{array}{l}\text { MC-02- } \\
015\end{array}$ & $\begin{array}{l}\text { Chand } \\
\text { Metallurgical } \\
\text { Worchester, MA }\end{array}$ & $\begin{array}{l}\text { Forming Porous } \\
\text { Metal Filters }\end{array}$ & $\begin{array}{l}\text { Ronald Chand } \\
508-791-9549\end{array}$ & $\begin{array}{l}\text { Claudia Walls } \\
865-574-3177\end{array}$ & Chemical \\
\hline $\begin{array}{l}\text { MC-02- } \\
016\end{array}$ & $\begin{array}{l}\text { Ford Motor } \\
\text { Company } \\
\text { Dearborn, MI }\end{array}$ & $\begin{array}{l}\text { Infrared Processing } \\
\text { for Conditioning and } \\
\text { Repair of Forming } \\
\text { Dies }\end{array}$ & $\begin{array}{l}\text { Armando Joaquin } \\
313-845-9497 \\
\\
\text { Allen Roche } \\
313-390-8889\end{array}$ & $\begin{array}{l}\text { Mike Santella } \\
865-574-4805\end{array}$ & Forging \\
\hline $\begin{array}{l}\text { MC-02- } \\
017 \\
\end{array}$ & Cancelled & & & & \\
\hline $\begin{array}{l}\text { MC-02- } \\
018\end{array}$ & $\begin{array}{l}\text { Visteon Glass } \\
\text { Systems } \\
\text { Allen Park, MI }\end{array}$ & $\begin{array}{l}\text { Thermochemical } \\
\text { Optimization of Float } \\
\text { Glass Composition: } \\
\text { Low-Alumina Glass } \\
\text { Development }\end{array}$ & $\begin{array}{l}\text { Ed Boulos } \\
313-755-1539 \\
\\
\text { Pavel Hrma } \\
309-376-5092\end{array}$ & $\begin{array}{l}\text { Ted Besmann } \\
865-574-6852\end{array}$ & Glass \\
\hline $\begin{array}{l}\text { MC-02- } \\
019\end{array}$ & $\begin{array}{l}\text { The University of } \\
\text { Tennessee } \\
\text { Knoxville, TN }\end{array}$ & $\begin{array}{l}\text { The Effect of } \\
\text { Austenitizing } \\
\text { Temperature and } \\
\text { Time on the } \\
\text { Formation of } \\
\text { Martensite in Steels }\end{array}$ & $\begin{array}{l}\text { Charlie Brooks } \\
865-974-5336\end{array}$ & $\begin{array}{l}\text { Gerry Ludtka } \\
865-574-5098\end{array}$ & Steel \\
\hline $\begin{array}{l}\text { MC-02- } \\
020\end{array}$ & $\begin{array}{l}\text { Ford Research } \\
\text { Laboratory } \\
\text { Dearborn, MI }\end{array}$ & $\begin{array}{l}\text { Physical, Mechanical, } \\
\text { and Microstructural } \\
\text { Characterization of } \\
\text { Ultrasonic Welding of } \\
\text { Aluminum Alloys }\end{array}$ & $\begin{array}{l}\text { Ray Jahn } \\
313-323-8930\end{array}$ & $\begin{array}{l}\text { Ed Kenik } \\
865-574-5066\end{array}$ & $\begin{array}{l}\text { Welding and } \\
\text { Joining }\end{array}$ \\
\hline $\begin{array}{l}\text { MC-02- } \\
021\end{array}$ & $\begin{array}{l}\text { Spirax Sarco Inc. } \\
\text { Blythewood, SC }\end{array}$ & $\begin{array}{l}\text { Heat Treatment } \\
\text { Optimization for } \\
\text { Steam Trap Seat of } \\
\text { AISI } 420^{\circ} \text { F Stainless } \\
\text { Steel }\end{array}$ & $\begin{array}{l}\text { Robert Jacenko } \\
803-714-2051 \\
\\
\text { Malcolm Gordge } \\
803-714-2000\end{array}$ & $\begin{array}{l}\text { Vinod Sikka } \\
865-574-5112\end{array}$ & Steel \\
\hline $\begin{array}{l}\text { MC-02- } \\
022\end{array}$ & Cancelled & & & & \\
\hline $\begin{array}{l}\text { MC-02- } \\
023\end{array}$ & $\begin{array}{l}\text { Deloro Stellite } \\
\text { Group, Ltd. } \\
\text { St. Louis, MO }\end{array}$ & $\begin{array}{l}\text { Hot-Hardness Data } \\
\text { on Wear- and } \\
\text { Corrosion-Resistant } \\
\text { Alloy }\end{array}$ & $\begin{array}{l}\text { James Wu } \\
\text { 314-514-7665 X15 }\end{array}$ & $\begin{array}{l}\text { Vinod Sikka } \\
865-574-5112\end{array}$ & $\begin{array}{l}\text { Steel, } \\
\text { Mining, and } \\
\text { Chemical }\end{array}$ \\
\hline $\begin{array}{l}\text { MC-02- } \\
024\end{array}$ & $\begin{array}{l}\text { Scot Forge } \\
\text { Spring Grove, IL }\end{array}$ & $\begin{array}{l}\text { Effect of Forging and } \\
\text { Heat Treating on } \\
\text { Residual Stress in } \\
\text { Aluminum Forgings }\end{array}$ & $\begin{array}{l}\text { Bob Krysiak } \\
847-587-1000\end{array}$ & $\begin{array}{l}\text { Tom Watkins } \\
865-574-2046\end{array}$ & $\begin{array}{l}\text { Aluminum } \\
\text { and } \\
\text { Forging }\end{array}$ \\
\hline
\end{tabular}


MPLUS Proposal List (continued)

\begin{tabular}{|c|c|c|c|c|c|}
\hline $\begin{array}{c}\text { Proposal } \\
\text { No. }\end{array}$ & Organization & $\begin{array}{c}\text { Proposal } \\
\text { Title }\end{array}$ & $\begin{array}{c}\text { Organization } \\
\text { PI }\end{array}$ & $\begin{array}{c}\text { ORNL } \\
\text { PI }\end{array}$ & Relevance \\
\hline $\begin{array}{l}\text { MC-02- } \\
025\end{array}$ & $\begin{array}{l}\text { CC Metals and } \\
\text { Alloys, Inc. } \\
\text { Calvert City, KY }\end{array}$ & $\begin{array}{l}\text { Effects of Process } \\
\text { Variables on Shaped } \\
\text { Castings of Fe-Si Alloys }\end{array}$ & $\begin{array}{l}\text { Ed Bredniak } \\
270-395-2121\end{array}$ & $\begin{array}{l}\text { Qingyou Han } \\
865-574-4352\end{array}$ & Metal Casting \\
\hline $\begin{array}{l}\text { MC-02- } \\
026\end{array}$ & $\begin{array}{l}\text { Stoody Company } \\
\text { Bowling Green, } \\
\text { KY }\end{array}$ & $\begin{array}{l}\text { Creep Rupture Behavior } \\
\text { of Modified 9Cr-1Mo Flux- } \\
\text { Cored Arc Weldments }\end{array}$ & $\begin{array}{l}\text { Ravi Menon } \\
270-781-9777 \\
\\
\text { Jack Wallin } \\
270-781-9777\end{array}$ & $\begin{array}{l}\text { Ken Liu } \\
865-574-5116 \\
\text { Edgar Lara-Curzio } \\
865-574-1749\end{array}$ & $\begin{array}{l}\text { Mechanical } \\
\text { Properties }\end{array}$ \\
\hline $\begin{array}{l}\text { MC-02- } \\
027\end{array}$ & $\begin{array}{l}\text { ALLVAC } \\
\text { Monroe, NC }\end{array}$ & $\begin{array}{l}\text { Effect of Processing and } \\
\text { Microstructure on the } \\
\text { Corrosion Polarization } \\
\text { Response of a Corrosion- } \\
\text { Resistant Alloy }\end{array}$ & $\begin{array}{l}\text { John Pridgeon } \\
704-289-4511 \text { X1273 }\end{array}$ & $\begin{array}{l}\text { Vinod Sikka } \\
865-574-5112 \\
\text { Steve Pawel } \\
865-574-5138 \\
\text { Dane Wilson } \\
865-576-4810\end{array}$ & $\begin{array}{l}\text { Forest } \\
\text { Products, } \\
\text { Chemical, } \\
\text { and } \\
\text { Petrochemical }\end{array}$ \\
\hline $\begin{array}{l}\mathrm{MC}-02- \\
028\end{array}$ & $\begin{array}{l}\text { Scot Forge } \\
\text { Spring Grove, IL }\end{array}$ & $\begin{array}{l}\text { Modeling of Elemental } \\
\text { Segregation in Alloy } \\
\text { Ingots and Thermal } \\
\text { Treatments for } \\
\text { Homogenization }\end{array}$ & $\begin{array}{l}\text { Tony Biell } \\
800-435-6621\end{array}$ & $\begin{array}{l}\text { Qingyou Han } \\
\text { 865-574-4352 }\end{array}$ & $\begin{array}{l}\text { Steel } \\
\text { and } \\
\text { Metal Casting }\end{array}$ \\
\hline $\begin{array}{l}\text { MC-02- } \\
029\end{array}$ & $\begin{array}{l}\text { West Virginia } \\
\text { University } \\
\text { Morgantown, WV }\end{array}$ & $\begin{array}{l}\text { Sanitization Wood } \\
\text { Treatment }\end{array}$ & $\begin{array}{l}\text { Joe McNeel } \\
\text { 304-293-2941 X2169 } \\
\text { Jeffrey Slahor } \\
\text { Ed Cesa } \\
\text { Ben Dawson-Andoh } \\
\text { Elmer Lang } \\
\text { 304-293-7550 }\end{array}$ & $\begin{array}{l}\text { Craig Blue } \\
865-574-4351\end{array}$ & $\begin{array}{l}\text { Pulp and } \\
\text { Paper }\end{array}$ \\
\hline $\begin{array}{l}\text { MC-02- } \\
030\end{array}$ & $\begin{array}{l}\text { Spirax Sarco, } \\
\text { Inc. } \\
\text { Blythewood, SC }\end{array}$ & $\begin{array}{l}\text { Evaluation of Ceramic } \\
\text { Seal Disks for } \\
\text { Thermodynamic Steam } \\
\text { Traps }\end{array}$ & $\begin{array}{l}\text { Malcolm Gordge } \\
803-714-2172\end{array}$ & $\begin{array}{l}\text { Steve Nunn } \\
865-576-1668\end{array}$ & Crosscutting \\
\hline $\begin{array}{l}\text { MC-02- } \\
031\end{array}$ & $\begin{array}{l}\text { H.B. Fuller Co. } \\
\text { Saint Paul, MN }\end{array}$ & $\begin{array}{l}\text { Infrared Heating of } \\
\text { Polymers }\end{array}$ & $\begin{array}{l}\text { Charles Graves } \\
651-236-5051 \\
\text { Shelley Kueppers }\end{array}$ & $\begin{array}{l}\text { Craig Blue } \\
865-574-4351\end{array}$ & $\begin{array}{l}\text { Metal } \\
\text { Working, } \\
\text { Forging, } \\
\text { Casting, } \\
\text { Internal } \\
\text { Combustion, } \\
\text { and } \\
\text { Turbine } \\
\text { Engines } \\
\end{array}$ \\
\hline $\begin{array}{l}\mathrm{MC}-02- \\
032\end{array}$ & $\begin{array}{l}\text { Ametek } \\
\text { Eighty-Four, PA }\end{array}$ & $\begin{array}{l}\text { Identification of Process } \\
\text { Parameters for Ease of } \\
\text { Compaction and Sintering } \\
\text { of Tool Steel (M2) } \\
\text { Powders }\end{array}$ & $\begin{array}{l}\text { George Jucha } \\
724-225-8400 \\
\text { Dick Mason } \\
724-250-5182\end{array}$ & $\begin{array}{l}\text { Vinod Sikka } \\
865-574-5112 \\
\text { Terry Tiegs } \\
865-574-5173 \\
\text { G. Muralidharan } \\
\text { 865-574-4281 }\end{array}$ & $\begin{array}{l}\text { Steel, } \\
\text { Heat Treating, } \\
\text { and } \\
\text { Powder } \\
\text { Metallurgy }\end{array}$ \\
\hline $\begin{array}{l}\text { MC-02- } \\
033\end{array}$ & $\begin{array}{l}\text { Weirton Steel } \\
\text { Corporation } \\
\text { Weirton, WV }\end{array}$ & $\begin{array}{l}\text { Characterization of Iron } \\
\text { Oxide Powder from Steel } \\
\text { Acid Pickling Process at } \\
\text { Weirton Steel }\end{array}$ & $\begin{array}{l}\text { Howard Snyder } \\
304-797-4999 \\
\text { Phil Elbaz } \\
304-797-2738\end{array}$ & $\begin{array}{l}\text { Vinod Sikka } \\
865-574-5112 \\
\\
\text { G. Muralidharan } \\
865-574-4281 \\
\end{array}$ & Steel \\
\hline
\end{tabular}


MPLUS Proposal List (continued)

\begin{tabular}{|c|c|c|c|c|c|}
\hline $\begin{array}{c}\text { Proposal } \\
\text { No. }\end{array}$ & Organization & Proposal Title & Org. PI & ORNL PI & Relevance \\
\hline $\begin{array}{l}\text { MC-02- } \\
034\end{array}$ & $\begin{array}{l}\text { Component } \\
\text { Composite } \\
\text { Coatings } \\
\text { International, LLC } \\
\text { Roswell, GA }\end{array}$ & $\begin{array}{l}\text { Rapid Infrared Fusing } \\
\text { of } \mathrm{C}^{3} \text { Coatings }\end{array}$ & $\begin{array}{l}\text { Mann Shoffner } \\
\text { 404-876-4351 } \\
\text { Mark Deininger } \\
770-998-6392\end{array}$ & $\begin{array}{l}\text { Craig Blue } \\
865-574-5112\end{array}$ & $\begin{array}{l}\text { Metal Working, } \\
\text { Forging, } \\
\text { Casting, } \\
\text { Internal } \\
\text { Combustion, } \\
\text { and Turbine } \\
\text { Engines }\end{array}$ \\
\hline $\begin{array}{l}\text { MC-02- } \\
035\end{array}$ & $\begin{array}{l}\text { Alcoa Technical } \\
\text { Center } \\
\text { Alcoa Center, PA }\end{array}$ & $\begin{array}{l}\text { Particle Effects on } \\
\text { Texture Development } \\
\text { during Processing of } \\
\text { Al Sheet }\end{array}$ & $\begin{array}{l}\text { Hasso Weiland } \\
724-337-3133\end{array}$ & $\begin{array}{l}\text { B. Radhakrishnan } \\
865-241-3861 \\
\\
\text { Gorti Sarma } \\
865-574-5147\end{array}$ & Aluminum \\
\hline $\begin{array}{l}\text { MC-02- } \\
036\end{array}$ & $\begin{array}{l}\text { Caterpillar, Inc. } \\
\text { East Peoria, IL }\end{array}$ & $\begin{array}{l}\text { Quantitative Charac- } \\
\text { terization of the } \\
\text { Phase Transforma- } \\
\text { tion Kinetics and } \\
\text { Dilation Strains of a } \\
\text { Hyper-Eutectoid SAE } \\
41 X X \text { Steel Alloy for } \\
\text { Incorporation into a } \\
\text { Process Optimization } \\
\text { Simulation Tool }\end{array}$ & $\begin{array}{l}\text { K. W. Burris } \\
\text { 309-578-6621 } \\
\text { L. Chuzhoy } \\
\text { 309-578-6621 }\end{array}$ & $\begin{array}{l}\text { Gerry Ludtka } \\
865-576-5098\end{array}$ & $\begin{array}{l}\text { Steel, } \\
\text { Forging, } \\
\text { Heat Treating, } \\
\text { Welding, and } \\
\text { Casting }\end{array}$ \\
\hline $\begin{array}{l}\text { MC-02- } \\
037\end{array}$ & $\begin{array}{l}\text { Univ. of Missouri - } \\
\text { Columbia } \\
\text { Columbia, MO }\end{array}$ & $\begin{array}{l}\text { High-Temperature } \\
\text { Mechanical } \\
\text { Properties Testing for } \\
\text { Finite-Element } \\
\text { Prediction of Residual } \\
\text { Stress in a Spot Weld }\end{array}$ & $\begin{array}{l}\text { Sanjeev Khanna } \\
573-884-9109 \\
\text { Xing Long } \\
\text { 573-884-7384 }\end{array}$ & $\begin{array}{l}\text { Ken Liu } \\
\text { 865-574-5116 } \\
\\
\text { E. Lara-Curzio } \\
865-574-1749\end{array}$ & $\begin{array}{l}\text { Mechanical } \\
\text { Properties }\end{array}$ \\
\hline $\begin{array}{l}\text { MC-02- } \\
038\end{array}$ & $\begin{array}{l}\text { Secat, Inc. } \\
\text { Lexington, KY }\end{array}$ & $\begin{array}{l}\text { Analysis of Aluminum } \\
\text { Sheet Materials }\end{array}$ & $\begin{array}{l}\text { Shridas Ningileri } \\
\text { 859-514-4955 X114 }\end{array}$ & $\begin{array}{l}\text { Ed Kenik } \\
865-574-5066 \\
\\
\text { Henry Meyer, III } \\
\text { 865-574-5092 }\end{array}$ & Aluminum \\
\hline $\begin{array}{l}\text { MC-02- } \\
039\end{array}$ & $\begin{array}{l}\text { Gray-Syracuse, } \\
\text { Inc. } \\
\text { Chittenango, NY }\end{array}$ & $\begin{array}{l}\text { Modeling to Identify } \\
\text { Causes for Hot } \\
\text { Cracking in Cobalt- } \\
\text { Based Alloy FSx-414 } \\
\text { during Investment } \\
\text { Casting }\end{array}$ & $\begin{array}{l}\text { Cezar Cisu } \\
315-687-0014\end{array}$ & $\begin{array}{l}\text { Qingyou Han } \\
865-574-4352\end{array}$ & Metal Casting \\
\hline $\begin{array}{l}\text { MC-02- } \\
040\end{array}$ & $\begin{array}{l}\text { Metal-Tech of } \\
\text { Tennessee, LLC } \\
\text { Newport, TN }\end{array}$ & $\begin{array}{l}\text { Effect of Fluidized } \\
\text { Bed-based Heat } \\
\text { Treatment on } \\
\text { Microstructure of } 431 \\
\text { Stainless Steel }\end{array}$ & $\begin{array}{l}\text { David King } \\
423-625-2030\end{array}$ & $\begin{array}{l}\text { Vinod Sikka } \\
865-574-5112\end{array}$ & Steel \\
\hline $\begin{array}{l}\text { MC-02- } \\
041\end{array}$ & Cancelled & & & & \\
\hline $\begin{array}{l}\text { MC-02- } \\
042\end{array}$ & $\begin{array}{l}\text { Logan Aluminum } \\
\text { Russellville, } \mathrm{KY}\end{array}$ & $\begin{array}{l}\text { Reducing Dross } \\
\text { Formation during } \\
\text { Remelting of } \\
\text { Aluminum Sows }\end{array}$ & $\begin{array}{l}\text { John Zeh } \\
270-755-6502\end{array}$ & $\begin{array}{l}\text { Qingyou Han } \\
865-574-4352\end{array}$ & Aluminum \\
\hline $\begin{array}{l}\text { MC-02- } \\
043\end{array}$ & $\begin{array}{l}\text { Haynes } \\
\text { International, Inc. } \\
\text { Kokomo, IN }\end{array}$ & $\begin{array}{l}\text { The Effect Boron and } \\
\text { Zirconium on the Re- } \\
\text { sistance of HAYNES } \\
214^{\mathrm{TM}} \text { Alloy to Strain } \\
\text { Age Cracking }\end{array}$ & $\begin{array}{l}\text { Mark Rowe } \\
765-456-6228\end{array}$ & $\begin{array}{l}\text { Suresh Babu } \\
865-574-4806\end{array}$ & Metal Casting \\
\hline
\end{tabular}


MPLUS Proposal List (continued)

\begin{tabular}{|c|c|c|c|c|c|}
\hline $\begin{array}{c}\text { Proposal } \\
\text { No. }\end{array}$ & Organization & $\begin{array}{c}\text { Proposal } \\
\text { Title }\end{array}$ & $\begin{array}{c}\text { Organization } \\
\text { PI }\end{array}$ & $\begin{array}{c}\text { ORNL } \\
\text { PI }\end{array}$ & Relevance \\
\hline $\begin{array}{l}\text { MC-02- } \\
044\end{array}$ & $\begin{array}{l}\text { Caterpillar, Inc. } \\
\text { Rockwood, TN }\end{array}$ & $\begin{array}{l}\text { Detection of Cracks in } \\
\text { Green Powder } \\
\text { Metallurgy Compacts }\end{array}$ & $\begin{array}{l}\text { Mike Pershing } \\
\text { 865-354-5617 } \\
\\
\text { Bill Kovacich } \\
865-354-5603\end{array}$ & $\begin{array}{l}\text { Ralph Dinwiddie } \\
865-574-7599\end{array}$ & Metal Casting \\
\hline $\begin{array}{l}\text { MC-02- } \\
045\end{array}$ & $\begin{array}{l}\text { NW Numerics and } \\
\text { Modeling, Inc. } \\
\text { Seattle, WA }\end{array}$ & $\begin{array}{l}\text { Characterization of } \\
\text { Viscoplastic Behavior } \\
\text { of Nodular Cast Iron } \\
\text { for Life Prediction } \\
\text { Modeling }\end{array}$ & $\begin{array}{l}\text { Ron Foerch } \\
206-352-8030\end{array}$ & $\begin{array}{l}\text { K. C. Liu } \\
865-574-5116 \\
\\
\text { E. Lara-Curzio } \\
865-574-1749\end{array}$ & $\begin{array}{l}\text { Material } \\
\text { Behavior }\end{array}$ \\
\hline $\begin{array}{l}\text { MC-02- } \\
046\end{array}$ & $\begin{array}{l}\text { MeadWestvaco } \\
\text { Research } \\
\text { Chillicothe, } \mathrm{OH}\end{array}$ & $\begin{array}{l}\text { TEM Investigation } \\
\text { into the Mechanism of } \\
\text { Composite Mem- } \\
\text { brane Cracking in } \\
\text { Kraft Recovery } \\
\text { Boilers }\end{array}$ & $\begin{array}{l}\text { James Willis } \\
740-772-3748\end{array}$ & $\begin{array}{l}\text { Ed Kenik } \\
\text { 865-574-5066 }\end{array}$ & $\begin{array}{l}\text { Pulp and } \\
\text { Paper }\end{array}$ \\
\hline $\begin{array}{l}\text { MC-02- } \\
047\end{array}$ & $\begin{array}{l}\text { Commonwealth } \\
\text { Aluminum } \\
\text { Uhrichsville, } \mathrm{OH}\end{array}$ & $\begin{array}{l}\text { Prediction of Elemen- } \\
\text { tal Segregation and } \\
\text { Phase Formation in } \\
\text { Al } 5754 \text { Alloy }\end{array}$ & $\begin{array}{l}\text { Zhong Li } \\
740-922-8365\end{array}$ & $\begin{array}{l}\text { Qingyou Han } \\
\text { 865-574-4352 }\end{array}$ & Aluminum \\
\hline $\begin{array}{l}\text { MC-02- } \\
048\end{array}$ & $\begin{array}{l}\text { Carpenter } \\
\text { Specialty Alloys } \\
\text { Reading, PA }\end{array}$ & $\begin{array}{l}\text { Ferrite Prediction in } \\
\text { Type } 316 \text { Stainless } \\
\text { Steel }\end{array}$ & $\begin{array}{l}\text { J. Heilmann } \\
610-208-2000 \\
\text { Y. V. Murty } \\
610-208-2646\end{array}$ & $\begin{array}{l}\text { John Vitek } \\
865-574-5061\end{array}$ & Metal Casting \\
\hline $\begin{array}{l}\text { MC-02- } \\
049\end{array}$ & $\begin{array}{l}\text { University of } \\
\text { Tennessee } \\
\text { Knoxville, TN }\end{array}$ & $\begin{array}{l}\text { Creep Influence on } \\
\text { Low-Cycle Fatigue } \\
\text { and Fatigue Crack - } \\
\text { Propagation Behav- } \\
\text { iors of Superalloy } \\
\text { Haynes }{ }^{\circledR} 230 \text { in a } \\
\text { Vacuum Environment }\end{array}$ & $\begin{array}{l}\text { Peter Liaw } \\
\text { Lijia Chen } \\
\text { Gongyao Wang } \\
\text { Yulin Lu } \\
865-974-6356 \\
\\
\text { D. Klarstrom } \\
765-456-6218\end{array}$ & $\begin{array}{l}\text { E. Lara-Curzio } \\
865-574-1749 \\
\text { K. C. Liu } \\
865-574-5116\end{array}$ & Metal Casting \\
\hline $\begin{array}{l}\text { MC-02- } \\
050\end{array}$ & $\begin{array}{l}\text { Walford } \\
\text { Technologies } \\
\text { Oak Ridge, TN }\end{array}$ & $\begin{array}{l}\text { Defining the } \\
\text { Instrumental } \\
\text { Measurements and } \\
\text { Procedures Required } \\
\text { to Properly Control } \\
\text { the Lost Foam } \\
\text { Casting Process }\end{array}$ & $\begin{array}{l}\text { Graham Walford } \\
865-482-4995\end{array}$ & $\begin{array}{l}\text { Ralph Dinwiddie } \\
865-574-7599\end{array}$ & Metal Casting \\
\hline $\begin{array}{l}\text { MC-02- } \\
051\end{array}$ & $\begin{array}{l}\text { Foseco-Morval } \\
\text { Bessemer, AL }\end{array}$ & $\begin{array}{l}\text { Qualifying and } \\
\text { Correlating Lost } \\
\text { Foam Pattern } \\
\text { Properties with } \\
\text { Metals Fill Casting } \\
\text { Performance: } \\
\text { Understanding the } \\
\text { Process }\end{array}$ & $\begin{array}{l}\text { Dennis Nolan } \\
519-763-7177 \text { X518 }\end{array}$ & $\begin{array}{l}\text { Ralph Dinwiddie } \\
865-574-7599\end{array}$ & Metal Casting \\
\hline $\begin{array}{l}\text { MC-02- } \\
052\end{array}$ & $\begin{array}{l}\text { GM Powertrain } \\
\text { Saginaw, MI }\end{array}$ & $\begin{array}{l}\text { Qualifying Production } \\
\text { Grade Foam and } \\
\text { Coatings with Optical } \\
\text { and Infrared Methods } \\
\text { for the Lost Foam } \\
\text { Casting Process }\end{array}$ & $\begin{array}{l}\text { Jerry Barendreght } \\
989-757-0810\end{array}$ & $\begin{array}{l}\text { Ralph Dinwiddie } \\
865-574-7599\end{array}$ & Metal Casting \\
\hline $\begin{array}{l}\text { MC-02- } \\
053\end{array}$ & Cancelled & & & & \\
\hline
\end{tabular}




\section{STAFF CONTACTS AND GENERAL INFORMATION}

Staff contacts and sources for general information are listed below.

Program:

Dr. Peter Angelini, Program Manager

Oak Ridge National Laboratory

1 Bethel Valley Rd.

Oak Ridge, TN 37831-6065

Phone: (865) 574-4565, Fax: (865) 576-4963, Email: angelinip@ornl.gov

General information and submittals:

Ms. Millie Atchley

MPLUS Administrative Specialist

Metals Processing Laboratory User (MPLUS) Facility

Oak Ridge National Laboratory

1 Bethel Valley Rd.

Oak Ridge, TN 37831-6083

(865) 574-4358, Fax: (865) 574-4357, Email: atchleyml@ornl.gov

User Center Leaders:

Processing:

Dr. Vinod Sikka, (865) 574-5112, Email: sikkavk@ornl.gov Joining:

Dr. Stan David, (865)574-4804, Email: davidsa1@ornl.gov Characterization:

Corrosion: Dr. Peter Tortorelli, (865) 574-5199, Email: tortorellipf@ornl.gov

Mechanical: Dr. Edgar Lara-Curzio, (865) 574-1749, Email: laracurzioe@ornl.gov Materials/Processing Modeling:

Dr. B. Radhakrishnan, (865) 241-3861, Email: radhakrishnan@ornl.gov

Additional information and proposal applications are available at http://www.ms.ornl.gov/emfacility/mplus/mplus.htm 


\section{ACKNOWLEDGMENTS}

Research sponsored by the U.S. Department of Energy, Office of Energy Efficiency and Renewable Energy, Industrial Technologies Program, Industrial Materials for the Future and Aluminum Industry of the Future under contract DE-AC05-000R22725 with UT-Battelle, LLC. 
